\title{
Changes in immune cell populations and the antibody response to Streptococcus pneumoniae after exposure to a mixture of herbicides
}

\author{
Patricia de la Rosa \\ West Virginia University
}

Follow this and additional works at: https://researchrepository.wvu.edu/etd

\footnotetext{
Recommended Citation

de la Rosa, Patricia, "Changes in immune cell populations and the antibody response to Streptococcus pneumoniae after exposure to a mixture of herbicides" (2003). Graduate Theses, Dissertations, and Problem Reports. 1952.

https://researchrepository.wvu.edu/etd/1952

This Dissertation is protected by copyright and/or related rights. It has been brought to you by the The Research Repository @ WVU with permission from the rights-holder(s). You are free to use this Dissertation in any way that is permitted by the copyright and related rights legislation that applies to your use. For other uses you must obtain permission from the rights-holder(s) directly, unless additional rights are indicated by a Creative Commons license in the record and/ or on the work itself. This Dissertation has been accepted for inclusion in WVU Graduate Theses, Dissertations, and Problem Reports collection by an authorized administrator of The Research Repository @ WVU. For more information, please contact researchrepository@mail.wvu.edu.
} 


\title{
Changes in immune cell populations and the antibody response to Streptococcus pneumoniae after exposure to a mixture of herbicides
}

\author{
Patricia de la Rosa \\ Dissertation submitted to the School of Medicine at West \\ Virginia University in partial fulfillment of the \\ requirements for the degree of \\ Doctor of Philosophy \\ in \\ Microbiology, Immunology and Cell Biology \\ John B. Barnett Ph.D. \\ Christopher Cuff, Ph.D. \\ Dan Lewis, Ph.D. \\ Jean Meade, D.V.M., Ph. D. \\ Mark Reasor, Ph.D. \\ Rosana Schafer, Ph.D., Chair \\ Department of Microbiology, Immunology and Cell \\ Biology \\ Morgantown, West Virginia \\ 2003
}




\section{ABSTRACT \\ Changes in immune cell populations and the antibody response to Streptococcus pneumoniae after exposure to a mixture of herbicides}

\section{Patricia de la Rosa}

The environment that we live in is composed of many different chemicals, Because of this, all chemical exposures, whether environmental or industrial, are exposures to mixtures. These mixtures have the potential to affect the immune system in a manner that is qualitatively or quantitatively different from the response to the individual components of the mixture. My experiments examine the effects of in vivo exposure to a mixture of herbicides on immune cell populations and on the humoral immune response to immunization with heat killed, whole-cell, Streptococcus pneumoniae (HKSP). The herbicide propanil (3,4-dichloropropionanilide) is sold as a mixture with the herbicide 2,4-D (2,4-dichlorophenoxyacetic acid). In vivo exposure to the mixture of propanil and 2,4-D increases cell loss in the thymus and bone marrow to a greater extent than would be predicted from the cell loss caused by exposure to the individual herbicides. To determine whether the lymphocyte cell number decreases depress the functional immune response, I examined the T-independent (phosphorylcholine, PC) and T-dependent (pneumococcal surface protein A, PspA) antibody response to Streptococcus pneumoniae (SP) immunization after single-herbicide and herbicide-mixture exposure. Mice were exposed to propanil, 2,4-D or a mixture of propanil and 2,4-D and immunized i.p. with HKSP. Exposure to the mixture, in contrast to the individual herbicides, increased the number of IgM and all isotypes of IgG spot forming cells (SFC) responding to PC and PspA antigen as determined by ELISPOT following immunization with HKSP. Exposure to HKSP on day 4 after herbicide treatment resulted in smaller fold antibody increases suggesting that events that occur within the first 4 days after exposure are critical in the response. These results highlight the importance of studying the effects of mixtures on the immune system and contribute to the understanding of the potential connection between exposure to chemicals and disease. 


\section{DEDICATION}

I would like to dedicate this dissertation to my family: to my parents, John and Mary Kosco who encouraged me and imparted in me the discipline to persevere in the face of adversity, to my children, Charlie and Lizzy de la Rosa, who believed in me and never complained, and to my sister and brother-in-law, Ellen Kosco and Ron Balvers, for their unfailing generosity and support. This work is a testimony to your love. 


\section{ACKNOWLEDGEMENTS}

I would most like to thank my advisor, Rosana Schafer, who, like all great mentors, provided just the right amount of support, encouragement and unrelenting drive for perfection necessary to instill in me a love for science and professionalism. I would also like to thank Rosana for her interest in both my personal and professional growth. Her friendship made the Schafer lab a fun place to work.

I am also in debt to John Barnett who opened his lab and its resources to me. Thank you for your support at the start of my graduate career, as well as every day since.

I would also like to recognize my committee, Rosana Schafer, John Barnett, Chris Cuff, Dan Lewis, Jean Meade and Mark Reasor for their time, dedication, interest, insight and understanding.

I would like to thank the people in my lab: Kathy Brundage for her keen insight, interesting science discussions and untiring explanations; and Cheryl Walton, who assisted me in too many ways to mention. I would also like to thank them for their friendship that carried me through many difficult times.

Finally, I would like to thank David Weissman for his understanding and for providing me with the peace of mind necessary to write.

This work was supported by the National Institutes of Health grant ES07460 and ESO10953. 


\section{TABLE OF CONTENTS}

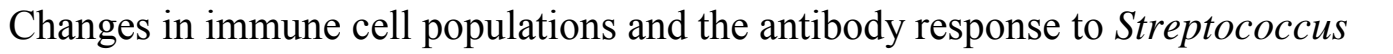

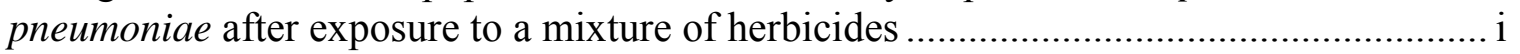

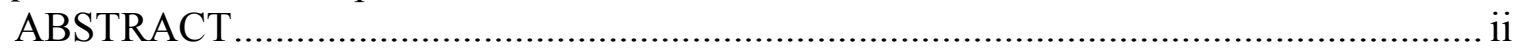

I DEDJCATIQN

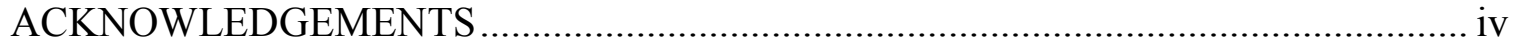

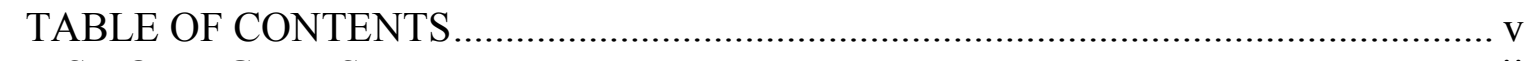

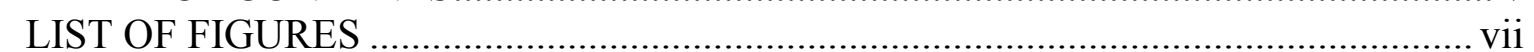
LIST OF TABLES ……………………………………................................... vii

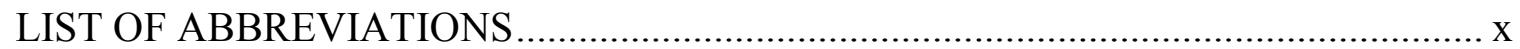

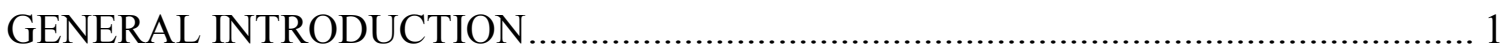

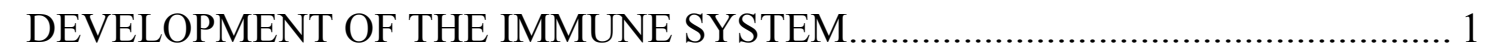
HHE PRIMARY ANTIBODY RESPONSE................................................... 4 PROPANIL__

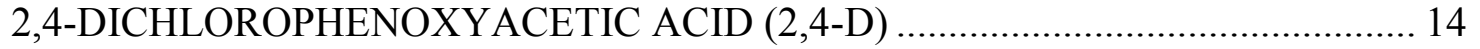
MIXTURES

STREESS

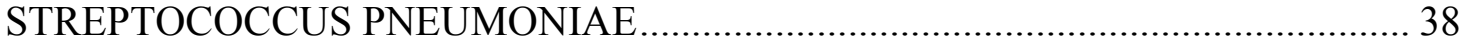
SLMMARY.

Chapter 1 Characterization of Thymic Atrophy and the Mechanism of Thymocyte Depletion after Exposure to a Mixture of Herbicides

A BSTRTACT

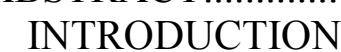

MATERTATS ANA TEETHODS

RESULTS

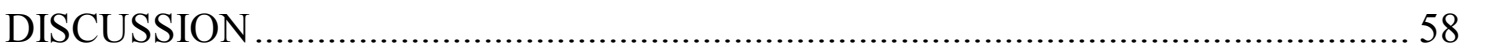
ACKNOTWLEDGEMENTS Chapter 2. Loss of Pre B and_IgM+ B.Cells in the Bope_Marrowafter Exposureto a

Mixture of Herbicides .............................................................................. 81

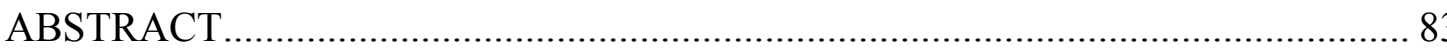

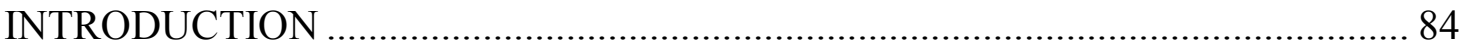

METHODS … …

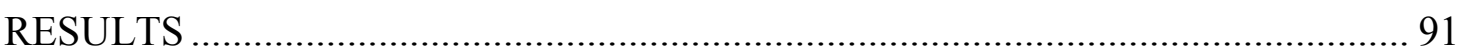

DISCUSSTION

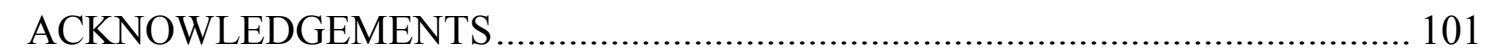

Cihapter 3 . CChanges in Spieen Celi Populations after Exposure to a Mixture of Propanil and $2,4-1 \ldots \ldots$

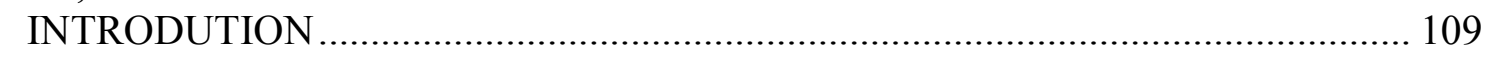

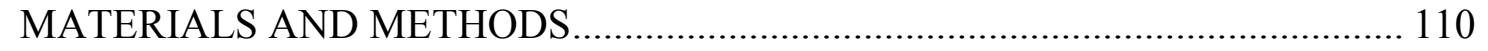

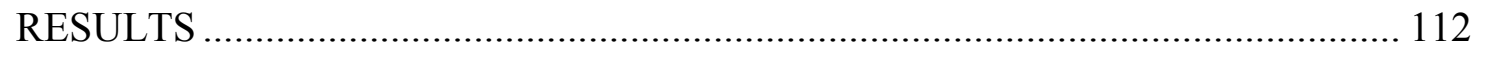
LRISCUSSIQN Chapter 4. Evaluation of the Antibody Response to Streptococcus pneumoniae after Exposure to a Mixture of Herbicides LINTRODUCTION 


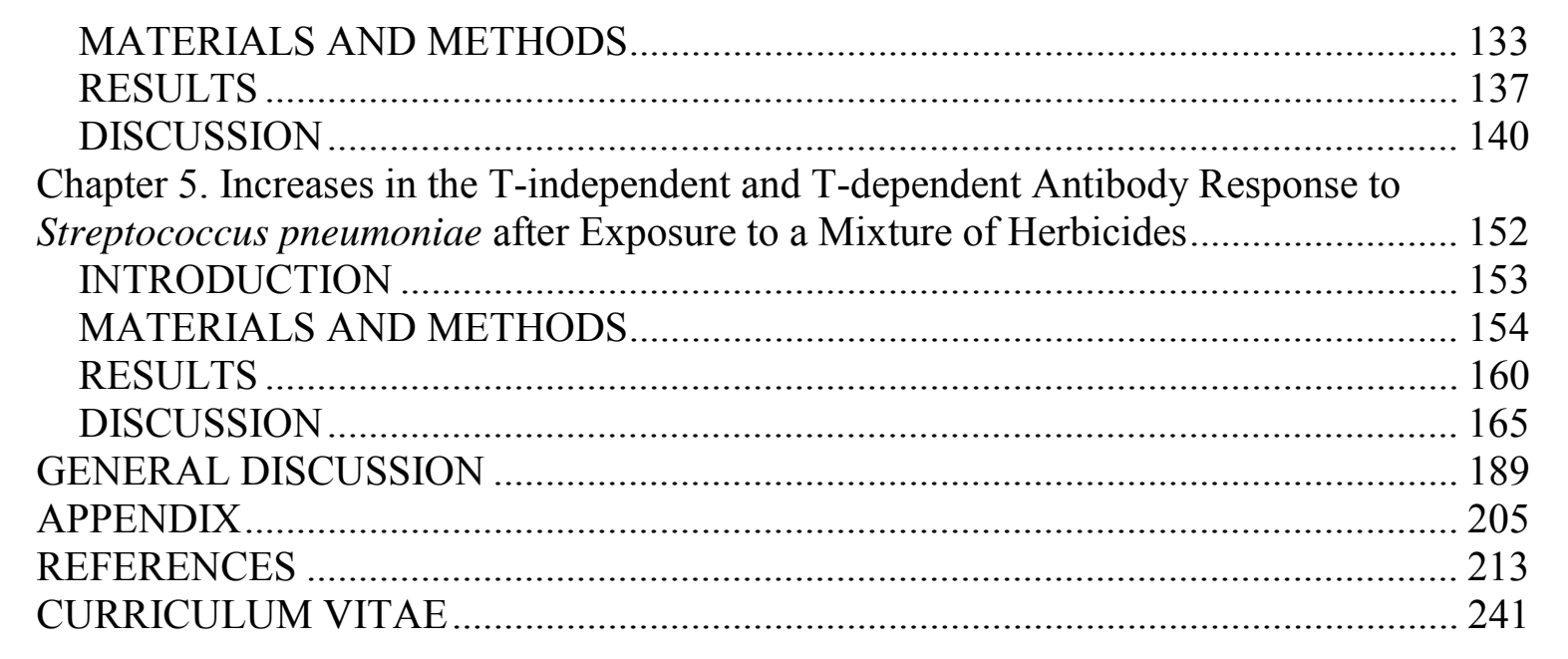




\section{LIST OF FIGURES}

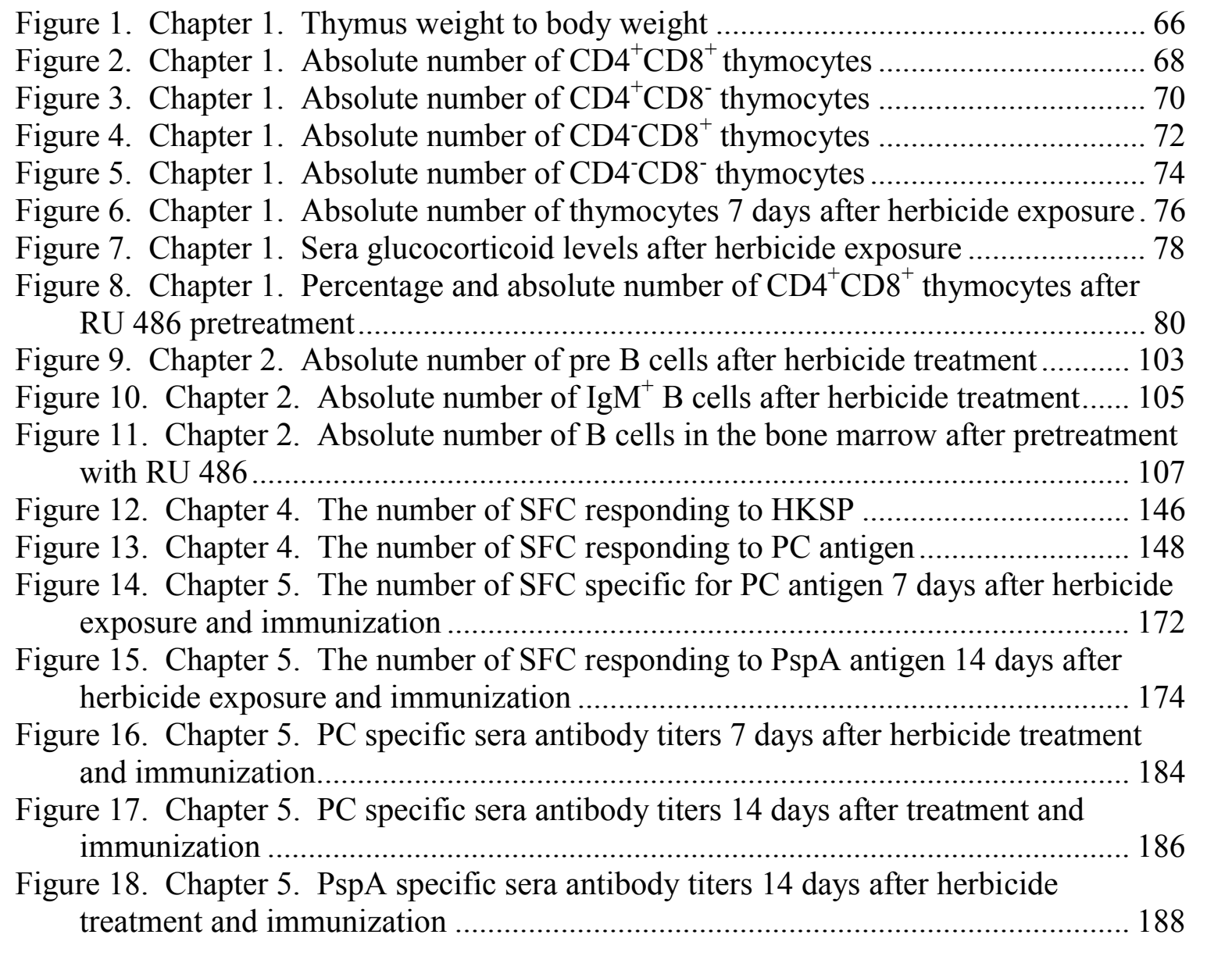




\section{LIST OF TABLES}

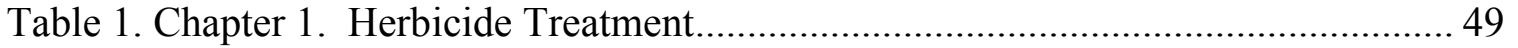

Täble 2. Chapter 2. Herbicide Treatment 88

Table 3. Chapter 3. Spleen weight to body weight and spleen total cell count at 7 and 14

days after treatment 122

Table 4. Chapter 3. Spleen population percentages 7 days after treatment _................... 123

Table 5. Chapter 3. Absolute cell numbers in the spleen at 7 days after herbicide treatment

Table 6. Chapter 3. Absolute number of cells of unknown phenotype in the spleen at 7 days after treatment.

Tāble 7. Chapter 3. Spleen population percentages 14 days after herbicide treatment . 126

Table 8. Chapter 3. Absolute cell numbers in the spleen at 14 days after herbicide

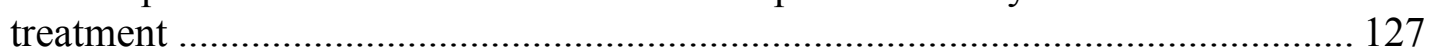

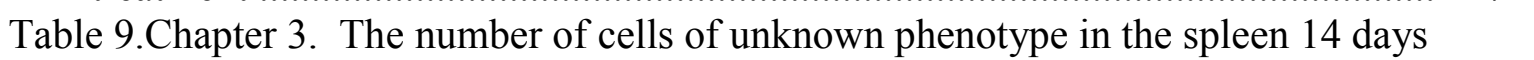

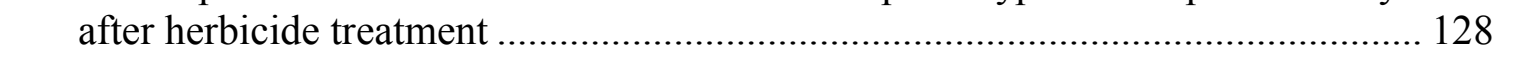

Table 10. Chapter 3._._Differential percentages_z_days after herbicide treatment

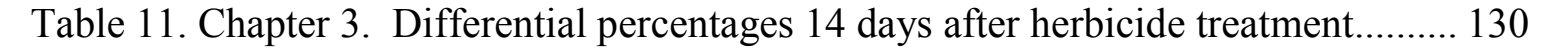

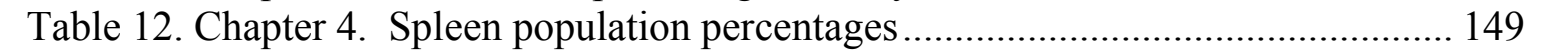

Table 13.Chapter 4. Absolute cell number in the spleen ..................................................150

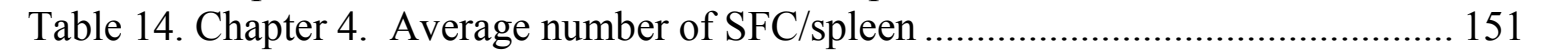

Table 15 . Chapter 5. Spleen population percentages 7 days after herbicide treatment and immunization ...................................................................................... 175

Täb̄e 16. Chapter 5 . Ábsolute cell numbers in the spleen 7 days after herbicide treatment

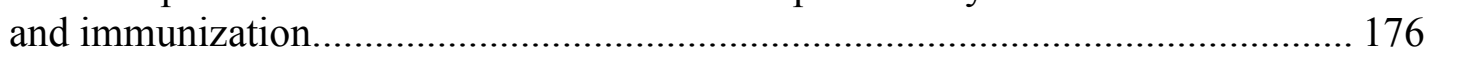

Täble 17. Chapter 5. Spleen population percentages 14 days after herbicide treatment

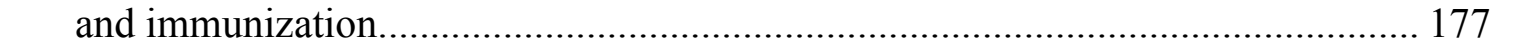

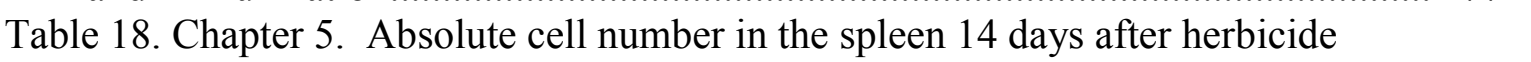
treatment and immunization

178

Table 19. Chapter 5. Average number of SFC/spleen 7 days after herbicide treatment and immunization

Table 20. Chapter 5. Average number of SFC/spleen 14 days after herbicide treatment and immunization........................................................................................ 180

Table 21. Chapter 5. Differential percentages of lymphocytes, monocytes and neutrophils 7 days after herbicide treatment and immunization ........................ $18 \overline{1}^{-}$

Table 22 . Chapter 5 . Differential percentages of lymphocytes, monocytes and neutrophils 14 days after herbicide treatment and immunization ........................ $18 \overline{2}^{-}$

Table 23 . Appendix Changes in absolute cell number in the thymus at 2 and 7 days post ---- treatment_ and changes_in corticosterone hormones at_ 1 hr post_treatment ........... $2066_{-1}$

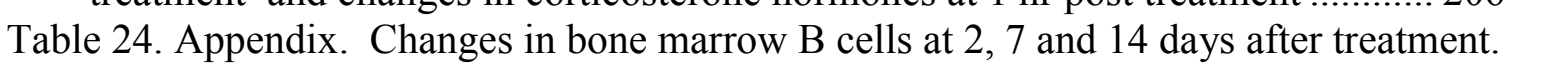

Table 25.Appendix. Changes in the absolute cell number with RU 486pretreatment 2 hrs prior to herbicide exposure.

Table 26. Appendix. Changes in absolute cell number in non-immunized spleens at 7 and

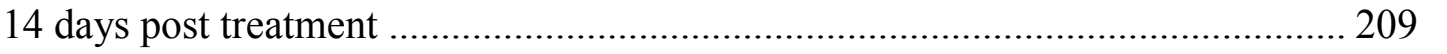


Table 27 . Appendix. Changes in absolute cell number in the spleens of $\mathrm{D} 4$ immunized animals.

Tăble 28 . A ppendix. Changes in absolute cell number in spleens of D 0 immunized

animals at 7 and 14 days post treatment. ..................................................... 210

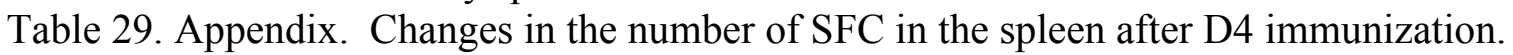
.

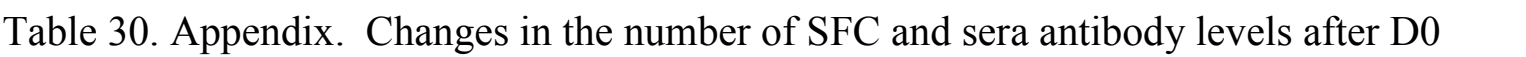
immunization. 


\title{
LIST OF ABBREVIATIONS
}

\author{
2,4-D \\ 2,4-Dichlorophenoxyacetic acid \\ Adrenocorticotropin hormone \\ Adrenalectomized \\ ADX \\ G lipid kinase, $\mathrm{PI} 3-\mathrm{K}$ signal transduction pathway component \\ AKT \\ Activation protein-1 \\ AP1 \\ Professional antigen presenting cell \\ APC \\ Area under the curve \\ AUC \\ CD80 and CD86 \\ B7 \\ $B$ cell activating factor of the TNF-alpha family \\ BAFF \\ B cell receptor \\ BCR \\ Burst forming unit - erythrocyte \\ BFU-E \\ Bone marrow-derived dendritic cell \\ CD3 \\ CD28 \\ $T$ cell receptor associated molecule involved in signal transduction \\ $T$ cell costimulatory molecule expressed on APC \\ CD40 \\ $B$ cell costimulatory molecule expressed on T cells \\ CFU-E \\ Erythrocyte progenitor cell. Colony forming unit - erythrocyte \\ CFU-GM \\ Myeloid progenitor cell. Colony forming unit - myelocyte \\ CFU-M \\ CFU-S \\ C-JUN \\ $\mathrm{CMI}$ \\ Con A \\ Monocyte progenitor cell. Colony forming unit - monocyte \\ Myeloid stem cell. Colony forming unit - myeloid stem cell \\ proto-oncogene, component of AP-1 \\ Cell mediated immunity \\ Concanavalin A \\ CNS \\ Central nervous system \\ $\mathrm{CRH}$ \\ Corticotropin releasing hormone \\ D0.01, \\ $0.01 \mathrm{mg} \mathrm{2,4-D/kg}$ body weight, $0.1 \mathrm{mg} \mathrm{2,4-D/kg} \mathrm{body} \mathrm{weight,} 36 \mathrm{mg} 2,4-\mathrm{D} / \mathrm{kg}$ \\ D0.1, D36, \\ body weight, $50 \mathrm{mg} \mathrm{2,4-D/kg} \mathrm{body} \mathrm{weight,} 100 \mathrm{mg} \mathrm{2,4-D/kg} \mathrm{body} \mathrm{weight,} 150 \mathrm{mg}$ \\ D50, D100, \\ 2,4-D/kg body weight, $200 \mathrm{mg}$ 2,4-D/kg body weight \\ D150, D200 \\ Day 0 \\ Herbicide treatment and immunization on day 0 \\ Day 4 \\ DC \\ Herbicide treatment on day 0 and immunization on day 4 \\ Dendritic cell \\ DCA \\ Dichloroanaline \\ DEX \\ Dexamethasone \\ DTH \\ Delayed-type hypersensitivity \\ ELISA \\ Enzyme Linked Immunosorbent Assay \\ ELISPOT \\ ERK \\ ETOH \\ Enzyme Linked Immun \\ Extra-cellular-signal-regulated kinase, signal transduction \\ FDC \\ Ethyl alcohol \\ FTOC \\ Follicular dendritic cell \\ GaAs \\ Fetal thymic organ culture \\ $\mathrm{GH}$ \\ Gallium Arsenide \\ GM-CFS Granulocyte/macrophage colony stimulating factor
}




\begin{tabular}{|c|c|}
\hline GR & Glucocorticoid receptor \\
\hline $\mathrm{GR}^{-} /$ & Glucocorticoid receptor knockout mouse \\
\hline HKSP & Heat-killed Streptococcus pneumoniae \\
\hline hPBL & human peripheral blood lymphocytes \\
\hline HPA & hypothalamic pituitary axis \\
\hline IFN- $\gamma$ & Interferon-gamma \\
\hline $\mathrm{IgH}$ & Immunoglobulin heavy chain gene \\
\hline IL-2 & Interleukin-2 \\
\hline IL-2R $\alpha$ & Interleukin-2 receptor $\alpha$ \\
\hline IL-7 & Interleukin-7 \\
\hline IL-10 & Interleukin-10 \\
\hline IL-12 & Interleukin-12 \\
\hline IL-13 & Interleukin-13 \\
\hline IL-1 $\beta$ & Interleukin-1-beta \\
\hline $\mathrm{IP}_{3}$ & Inositol 1,4,5-triphosphate \\
\hline IL-6 & Interleukin-6 \\
\hline KLH & Keyhole limpet hemocyanin \\
\hline LD50 & Lethal dose sufficient to cause death in $50 \%$ of exposed animals \\
\hline LPS & Lipopolysaccharide \\
\hline MCSF & Monocyte colony stimulating factor \\
\hline MHC & Major histocompability molecule \\
\hline MIP-1 $\alpha$ & CXC Neutrophil derived chemokine. Macrophage inflammatory protein - $1 \alpha$ \\
\hline MIP-3 $\alpha$ & CXC Neutrophil derived chemokine. Macrophage inflammatory protein - $3 \alpha$ \\
\hline $\mathrm{M} \varphi$ & Macrophage \\
\hline $\mathrm{NF}-\kappa \mathrm{B}$ & Nuclear factor-kappa-B \\
\hline NK & Natural killer cells \\
\hline NP & (4-hydroxy-3-nitrophenyl) acetyl \\
\hline NTP & National Toxicology Program \\
\hline $\begin{array}{l}\text { P5, P10, } \\
\text { P50, P100, } \\
\text { P150, P200 }\end{array}$ & $\begin{array}{l}5 \mathrm{mg} \text { Propanil/kg body weight, } 10 \mathrm{mg} \text { Propanil/kg body weight, } 50 \mathrm{mg} \text { Propanil/kg } \\
\text { body weight, } 100 \mathrm{mg} \text { Propanil/kg body weight, } 150 \mathrm{mg} \text { Propanil/kg body weight, } \\
200 \mathrm{mg} \text { Propanil/kg body weight }\end{array}$ \\
\hline PALS & Periarterial lymphoid sheath \\
\hline PBL & Peripheral blood lymphocyte \\
\hline $\mathrm{PC}$ & Phosphorylcholine \\
\hline PDC & Plasmacytoid dendritic cell \\
\hline PI3K & Phosphoinositide 3-kinase \\
\hline PMA & Phytohaemagglutinin, T cell mitogen \\
\hline PspA & Pneumococcal surface protein A \\
\hline RAF & G protein S/T kinase of the Ras/Raf/MEK/ERK signal transduction pathway \\
\hline RAG-1/-2 & Recombination activation genes 1 and 2 \\
\hline RAS & G-protein of the Ras/Raf/MEK/ERK signal transduction pathway \\
\hline $\mathrm{RBC}$ & Red Blood Cell \\
\hline RU 486 & Mifepristone, Glucocorticoid receptor blocker \\
\hline $\mathrm{SFC}$ & Spot forming cell \\
\hline SLRL & Sex linked recessive lethal test for Mutagenesis \\
\hline $\mathrm{SP}$ & Streptococcus pneumoniae \\
\hline
\end{tabular}




$\begin{array}{ll}\text { SRBC } & \text { Sheep red blood cell } \\ \text { SW:BW } & \text { Spleen weight to body weight ratio } \\ \mathrm{t}_{1 / 2} & \text { Half life } \\ \text { TCR } & \text { T cell receptor } \\ \text { TCR } \beta & \text { T cell receptor beta chain } \\ \text { TCR } \alpha & \text { T cell receptor alpha chain } \\ \text { TD } & \text { T-dependent } \\ \text { TEC } & \text { Thymic epithelial cell } \\ \text { TGF } & \text { Transforming growth factor-beta } \\ \text { Th1 } & \text { T-helper cell type 1 } \\ \text { Th2 } & \text { T-helper cell type 2 } \\ \text { TI-2 } & \text { T-independent type 2 } \\ \text { TNC } & \text { Thymic nurse cell } \\ \text { TNF } \alpha & \text { Tumor necrosis factor-alpha } \\ \text { TW:BW } & \text { Thymus weight to body weight ratio } \\ \text { US EPA } & \text { US Environmental Protection Agency } \\ \text { USGS } & \text { US Geographic Survey } \\ \text { USGS- } & \text { US Geographic Survey National Water Quality Assessment } \\ \text { NAWQA } & \end{array}$




\section{GENERAL INTRODUCTION}

\section{DEVELOPMENT OF THE IMMUNE SYSTEM}

\section{T cell development}

The thymus is the primary organ of $\mathrm{T}$ cell development and the selection of the naïve T cell repertoire. Structurally, the thymus is grossly divided into three sections, the subcapsular region, the cortex and the medulla. As thymocytes proceed through development they progress from the outermost area, the subcapsule, through the cortex and into the central medulla area before exiting the thymus to the periphery (reviewed in Picker and Siegelman, 1998). The thymus is composed of two stromal cell types, the cortical epithelium (TEC) and the medullary epithelium (Anderson, et al., 1996; Laufer, et al., 1999). Bone marrow derived $\mathrm{M} \varphi$ that reside in both the cortex and medulla, and dendritic cells (DC) that reside in the cortico-medullary junction and the medulla also participate in thymic T cell development (Anderson, , et al., 1996; Laufer, et al., 1999). A fifth cell type, the thymic nurse cell (TNC), is of unknown function but is known to engulf and release late $\mathrm{CD} 4{ }^{-} \mathrm{CD} 8^{-} /$early $\mathrm{CD} 4^{+} \mathrm{CD} 8^{+}$thymocytes (Wekerle and Ketelson, 1980; Tolosa and Ashwell, 1999). Although the thymus has some endocrine activity (to be discussed in greater detail later) the primary function of the thymus is to promote the development of functional $\mathrm{T}$ cells. This is accomplished through the deletion of nonproductive $\mathrm{T}$ cells, during positive selection, and autoreactive $\mathrm{T}$ cells, during negative selection, from the T cell repertoire (Benoist and Mathis, 1998; Kileen, et al., 1998). Positive selection, or the recognition of antigen presented on self MHC, occurs in the cortex on MHC class II-expressing TEC (Anderson, et al., 1996; Laufer, et al., 1999). 
Negative selection, or the elimination of autoreactive cells, occurs in the corticomedullary junction or in the medula where self-reactive $\mathrm{T}$ cells are deleted by bone marrow-derived antigen presenting cells (APC) (Laufer, et al., 1999).

$\mathrm{T}$ cell precursors enter the thymus from the bone marrow. These cells are classified as triple negative ( $\left.\mathrm{CD}^{-} \mathrm{CD}^{-} \mathrm{CD} 8^{-}\right)$thymocytes because they do not express the T cell markers CD4 and CD8 and do not have a functional T cell receptor (TCR) (Picker and Siegelman, 1998). CD3 ${ }^{-C D} 4{ }^{-C D} 8^{-}$thymocytes have their TCR genes in germline configuration, express IL-2 receptor chain $\alpha(\mathrm{IL}-2 \mathrm{R} \alpha)$ and are dependent on stromal cell attachment and interleukin-7 (IL-7) for survival (Anderson, et al., 1996). TCR $\beta$ gene rearrangement, characterized by an increase in recombination activation genes-1 (RAG 1) and -2 (RAG 2) protein, occurs during the $\mathrm{CD}^{-}{ }^{-} \mathrm{CD} 4^{-} \mathrm{CD} 8^{-}$stage (Picker and Siegelman, 1998). Successful rearrangement of the TCR $\beta$ gene results in expression of membrane bound, pre-TCR/CD3e complex and initiates a clonal expansion of late CD4CD8\%early $\mathrm{CD}^{+} \mathrm{CD}^{+}$cells (Killeen, et al., 1998; DiSanto, 1999). Most of the proliferation in the thymus occurs at this stage in development, pinpointing the $\mathrm{CD} 4^{+} \mathrm{CD} 8^{+}$developmental stage as a critical time for determination of the variability and functionality of the $\mathrm{T}$ cell repertoire (Egerton, 1990). With allelic exclusion of the TCR $\beta$-chain locus, $\mathrm{CD} 4^{+} \mathrm{CD} 8^{+}$ thymocytes become small, slowly cycling cells (Kileen, et al., 1998; Egerton, 1990). Gene rearrangement of the TCR $\alpha$ gene occurs in $\mathrm{CD} 4^{+} \mathrm{CD} 8^{+}$thymocytes (Picker and Siegelman, 1998). Productive rearrangement of the TCR $\alpha$ gene allows for expression of $\alpha \beta T C R$ in conjunction with the CD3 complex (Killeen, et al., 1998).

Stringent selection in the thymus results in mature $\mathrm{T}$ cells that are not autoreactive but that recognize foreign antigen in the context of self MHC (Anderson, et al., 1996). 
There is some controversy on how the same population of $\mathrm{CD} 4^{+} \mathrm{CD} 8^{+}$thymocytes can successfully complete positive selection, or recognition of self in the context of self MHC, and negative selection, or the deletion of self-reactive cells, since both selection processes occur via TCR activation (Anderson, et al., 1996; Tolosa and Ashwell, 1999). The affinity/avidity model suggests that the strength of ligation of the TCR to the MHC determines whether or not a $\mathrm{T}$ cell will complete positive selection (Laufer, et al., 1999). Weak TCR ligation leads to positive selection while strong ligation leads to negative deletion of the autoreactive cell (Anderson, et al., 1996). Only 1-3\% of all CD4 $4^{+} \mathrm{CD} 8^{+}$ thymocytes survive thymic selection to become $\mathrm{CD} 4^{+} \mathrm{CD} 8^{-}$and $\mathrm{CD} 4^{-} \mathrm{CD} 8^{+}$thymocytes (Eagerton, 1990). Cells that survive selection in the thymus exit the thymus as mature functional $\mathrm{T}$ cells.

\section{B Cell Development in the Bone Marrow}

The bone marrow is the source of all adult blood cell lineages and the site of B cell development. All committed B cell progenitors in the bone marrow express CD45R/B220 cell surface protein (Hardy et al., 1991). Development of the B cell population progresses from the pro $\mathrm{B}$ to pre $\mathrm{B}$ to $\operatorname{IgM}^{+} \mathrm{B}$ cells expressing membranebound immunoglobulin heavy chain $\mu(\mathrm{c} \mu)$ (Hardy, et al., 1991; Osmond and Nossal, 1974). Early pro B cell progenitors have their immunoglobulin genes in germline configuration and express high levels of CD43/leukosialin on their surface (Godfrey, 1992). Pro B cells do not express $c \mu$ (Godfrey, 1992). Rearrangement of the immunoglobulin heavy chain gene segments VDJ initiates pro B cell differentiation to the pre B cell stage. This process is dependent on stroma-derived IL-7 stimulation and signaling through the IL-7 receptor (IL-7R) (Carsetti, 2000). Successful heavy chain 
gene rearrangement allows for cell surface expression of $\mathrm{c} \mu$ in the pre-B cell receptor (BCR) complex, stimulating a burst of proliferation and expansion of the pre B cell pool (Carsetti, 2000). At this stage, cells become large blasting cells, called large pre B cells. They begin to detach from the stroma, downregulate the expression of CD43, and undergo immunoglobulin light chain gene rearrangement. Successful light chain gene rearrangement allows for the expression of membrane bound IgM and the cells become small B220 $/ \mathrm{CD}^{-} 3^{-} / \mathrm{IgM}^{\text {low }}$ pre B cells. Pre B cells that do not successfully complete heavy or light chain gene rearrangement are deleted by apoptosis. Only $33 \%$ of B220 ${ }^{+}$ $\operatorname{IgM}^{-}$large pre B cells survive while $43.8 \%$ of small pre B cells are subsequently deleted by negative selection (Lu and Osmond, 1997). The small lymphocyte population of the bone marrow is renewed every $36 \mathrm{hrs}$ due to proliferation in progenitor populations rather than expansion of the more mature B cell populations (Osmond and Nossal, 1974). B cell progenitors that survive selection enter the blood and exit the bone marrow to the periphery.

\section{THE PRIMARY ANTIBODY RESPONSE}

\section{The Spleen}

The spleen is one of the major organs involved in the coordination of $\mathrm{T}$ and $\mathrm{B}$ lymphocytes in the antigen-specific immune response to infection. The antibody response to a protein antigen involves the coordination of three cell types, antigen presenting cells (APC), antigen specific $\mathrm{CD}^{+} \mathrm{T}$ cells and $\mathrm{B}$ cells with surface Ig that is capable of binding to antigen. In a primary antibody response, antigen specific B cells enter the spleen in the periarteriolar lymphoid sheath (PALS) area interspersed around T 
cells (PALS foci) that are abundant in this zone or migrate into the follicular area of the spleen and form germinal centers (Jacob, et al., 1991; McHeyzer-Williams et al., 1993). Both areas are sites of B cell differentiation into antibody-secreting plasma cells. Clonal expansion in the PALS foci allows select B cells to eventually extend past the PALS area into the red pulp area of the spleen (Jacob, et al., 1991). For example, after immunization with the hapten, 4-hydroxy-3nitropnenyl acetyl (NP), foci are apparent at 2 days, clonal expansion peaks at 6 days and begins to decline by 8 days after immunization (Jacob, et al., 1991). By day 12, the foci involute due to apoptosis of the plasma cell population (Smith et al., 1996). Plasma cells in the PALS foci initially produce IgM but are capable of isotype switching and production of specific IgG antibodies (Jacob, et al., 1991). Switching is generalized, rather than selection dependent, and is a response to cytokine stimulation (Jacob, et al., 1991). These cells do not undergo somatic hypermutation and affinity maturation (Jacob, et al., 1991).

Similar to the PALS foci, the germinal centers are also formed by clonal expansion (Jacob, et al., 1991). During the second week of a primary immune response, most of the antigen specific B cell proliferation occurs in the germinal centers (McHeyzer-Williams, 1993). These B cell undergo affinity maturation involving somatic hypermutation and subsequent selection on follicular dendritic cells (FDC) found in the light zone of the germinal center (Tarlington and Smith, 2000). Affinity maturation is a stepwise process. Cells that are initially selected undergo somatic hypermutation of their Ig variable $\left(\mathrm{V}_{\mathrm{H}}\right)$ genes and subsequent re-selection. In this manner, affinity-increasing mutations are selected that increase antigen specificity (McHeyzer-Williams, et al., 1993). In an NP immunization model, the number of antigen specific B cells in the 
germinal center peaks at two weeks after immunization (Jacob et al., 1991). By day 16

post infection, the germinal centers begin to decrease in size (Jacob et al.,1991) and high affinity plasma cells home to the bone marrow (Tarlington and Smith, 2000)

\section{PROPANIL}

\section{Metabolism}

3,4-Dichloropropionanaline (propanil) is a highly selective acylanilide herbicide used on rice crops for weed control (Matsunaka, 1968) Propanil is phytotoxic, affecting the chloroplast membrane, resulting in a loss of energy in the plant (Hofstra and Switzer, 1963). A unique feature of rice plants is that they readily absorb propanil through their roots and shoots but, unlike other plants, are capable of detoxifying the herbicide by hydrolysis. Hydrolysis of propanil in the roots and foliage of the rice plant occurs through the action of an acylamidase enzyme and results in the formation of 3,4dichloroaniline (DCA) and propionic acid (Singleton and Murphy, 1973) A mammalian hepatic-acylamidase enzyme allows for a similar metabolism in man and rodents resulting in the production of DCA as the major metabolite (Williams, et al.,1996; McMillan, et al., 1990). In the soil, the parent compound propanil has a half-life of 72 hrs (Izmerov, 1984). The metabolite DCA is further hydroxylated in a NADPH, P-450 dependent reaction to 6-hydroxy-3,4-dichloroaniline and $N$-hydroxy-3,4-dichloroaniline (McMillan et al.,1990). DCA and its hydroxy metabolites are capable of converting hemoglobin to methemoglobin through the oxidation of the iron molecule in heme (McMillan et al., 1990). Increases in methemoglobin in the blood decreases the amount of oxygen flowing into the tissues resulting in a shift to glycolytic metabolism and increases in lactic acid in the tissues and blood (Bodanski, 1951). 


\section{Human exposure}

There is very little literature available on the effects of human exposure to propanil. Propanil is applied to rice crops by aerial spraying (Barnes, et al., 1987). This technique allows for the exposure of people in the area immediately surrounding the rice field to airborne particles of propanil called drift. Two studies have measured the potential for dermal and mucosal exposure to propanil drift as a function of distance from the rice field (Barnes, et al., 1987; Richards et al., 2001). In one study, $10 \mathrm{~cm} \times 10 \mathrm{~cm}$ denim patches were placed at $-10 \mathrm{~m}$ (within the field) and 10, 50, 100, 500, and $1000 \mathrm{~m}$ in an area predicted to be downwind from the application site (Barnes, et al., 1987). Air sampling pumps and susceptible plants were located next to the denim patches. Data from the denim patches demonstrated a decrease in propanil concentrations with distance from the field up to the $1000 \mathrm{~m}$ sample, however, this data was highly variable and there was a significant difference between the data collected at all five sites. The air pumps were less sensitive and gave very low concentrations even within the spraying field. Susceptible plants demonstrated growth inhibition up to $1000 \mathrm{~m}$ from the spray site. It was concluded from this study that people exposed to aerosolized propanil, resulting from drift from aerial application, are exposed to concentrations 24,000 times below the predicted LD50 for humans, a figure determined by calculating the average exposure (Barnes, et al., 1987).

More recently, propanil drift in and around homes and adjacent rice fields was measured both by collection of drift on polyethylene patches and by active sampling of propanil vapor by air pumps (Richards, et al., 2001). Air pump samples taken near the fields had no detectable propanil vapor and passive collection on polyethylene patches 
was highly variable. From this study it was determined that the factors most important in the drift of aerially applied propanil were wind speed, direction and distance from the field. Wind direction was correlated with deposition levels inside the homes. In conjunction with the drift study, a 2 year study of immune parameters in families living adjacent to rice fields as compared to regional cohorts not exposed to aerial application of propanil was performed (McClure et al., 2001). Blood samples from both children and adults were taken before spraying, 5-7 days after spraying, and after harvest, and analyzed for changes in the percentages of blood leukocytes, leukocyte cell numbers, mitogen-induced proliferation, mitogen-stimulated cytokine production and natural killer cell (NK) activity. No significant differences were found between the control group and the group exposed to propanil in any of the immune parameters measured (Richards, et al., 2001). These two studies highlight the difficulties that arise in the determination of human exposure levels in field situations. From these studies, we can conclude that direct exposure to propanil in rice growing areas is most likely highly variable. Some exposures may occur by inhalation, although the more likely exposure route is through the skin and mouth. Although the population in the vicinity of spraying appears to be unaffected, there may be a high degree of variability in the exposure of this population. Under experimental conditions, propanil has been found to be persistent in pond water and in pond water with sewage sludge inoculum (Lyons et al., 1985) Although there are suggested safety levels for propanil in drinking water, it is not known if propanil or its metabolites are common contaminates of drinking water in the rice growing areas (Kello, 1989). This leaves open the possibility that populations downstream of rice spraying areas may also be exposed to propanil. Further studies are necessary to determine 
whether propanil can affect a population exposed to environmental levels of the herbicide.

Propanil has been demonstrated to be toxic to factory workers exposed to propanil during the production and packaging of the herbicide (Morse et al., 1979). Symptoms associated with propanil exposure included chloracne, small pupils, nausea/vomiting, blurred vision, muscle weakness, fatigue and increased salvation (Morse et al., 1979). Acne occurred in $61 \%$ of the workers working with propanil and was the only symptom definitively connected to propanil exposure in in vivo tests on rabbit ears.

In the laboratory, acute toxic exposure in mice occurs between $200-800 \mathrm{mg}$ propanil/kg body weight (P200 - P800) (Barnett and Gandy, 1989; Singleton and Murphy, 1973). Exposure of mice to non-lethal levels of propanil has also been demonstrated to cause central nervous system depression, loss of righting reflex and immunotoxicity (discussed in detail below) (Singleton and Murphy, 1973). Together, these studies suggest that exposure to propanil in the workplace may cause immunological changes.

\section{Immunotoxicity of Propanil}

In murine models, propanil affects both the innate and acquired immune system. The macrophage $(\mathrm{M} \varphi)$ and natural killer $(\mathrm{NK})$ cell are innate immune cells that have been demonstrated to be highly sensitive to the deleterious affects of propanil. NK cell killing of YAC-1 target cells is significantly decreased by exposure to concentrations of P50 and greater (Barnett et al., 1992). Propanil also affects M $\varphi$ cytokine production. Thioglycollate-elicited, $\mathrm{M} \varphi$ from mice exposed in vivo by oral gavage to $400 \mathrm{mg}$ propanil/kg body weight (P400, $400 \mathrm{mg}$ propanil/kg bw) or i.p to P200, or exposed in 
vitro to $33.3 \mu \mathrm{M}$ propanil had significantly decreased IL-6 and TNF- $\alpha$ production in response to LPS stimulation (Xie et al., 1997). In addition, in vitro phagocytosis of Listeria monocytogenes bacteria by $\mathrm{M} \varphi$ is decreased by propanil exposure (Frost et al., 2003). Furthermore, LPS stimulated respiratory burst in these cells is also decreased resulting in a decrease in the ability of the $\mathrm{M} \varphi$ to kill bacteria that have been phagocytized (Frost et al., 2003).

Propanil differentially affects $\mathrm{T}$ cell function. Cytotoxic T lymphocyte (CTL) function is not affected by propanil exposure. T cells from mice exposed in vivo to propanil were able to kill P815 target cells similar to controls (Barnett, et al., 1992). In vivo, the cell mediated immune response (CMI) to Listeria monocytogenes was also unchanged. Propanil treated mice, challenged with Listeria monocytogenes, were as resistant as control animals to infection by the intracellular pathogen (Watson, et al., 2000). The T helper (Th) cell-mediated mixed lymphocyte response, contact hypersensitivity response and DNA synthesis in response to Con A stimulation were reduced only at the highest P400 exposure dose (Barnett and Gandy, 1989). In contrast, T cell cytokine production of IFN- $\gamma$, GM-CSF, IL-2 and IL-6 were decreased in a dose dependent manner after in vivo or in vitro exposure to propanil and subsequent in vitro stimulation with Con A (Zhao, et al., 1998). IFN- $\gamma$ and GM-CSF were decreased 53\% and $27 \%$ respectively at 2 days after exposure. Production of both cytokines returned to normal levels by 4 days after exposure. Production of IL-2 and IL-6 were decreased $25 \%-40 \%$ at 2 days and remained suppressed until at least 7 days post treatment (Zhao, et al., 1998). Therefore, the decreases in T cell cytokine production after propanil exposure were rapid, and in the case of IL-2 and IL-6, prolonged for at least 7 days after exposure. 
Propanil also affects human T lymphocytes. Human peripheral blood lymphocyte (hPBL) IL-2 secretion in response to $\mathrm{CD} 3 / \mathrm{CD} 28$ stimulation is decreased by in vitro propanil exposure (personal communication, K. Brundage).

The inhibition of M $\varphi$-derived IL- 6 and TNF- $\alpha$ and T cell derived IL-2 cytokine occurs at the level of cytokine message transcription (Xie, et al., 1997; Zhao, et al., 1998). In the M $\varphi$, LPS stimulation, simultaneous with propanil exposure, resulted in decreased $\mathrm{Ca}^{2+}$ flux and increased levels of intracellular $\mathrm{IP}_{3}$, suggesting that propanil targets the LPS signal transduction pathway (Xie et al.,1997b). In vitro exposure of M $\varphi$ to propanil did not affect IL-6 or TNF- $\alpha$ message stability, however, suggesting that the disruption of cytokine production occurs prior to translation (Xie, et al., 1997b). In the T cell, propanil exposure results in both a decrease in IL-2 transcription as well as increased degradation of the IL-2 mRNA (Zhao, et al., 1999). Therefore, the inhibition of IL-2 production associated with propanil exposure in the $\mathrm{T}$ cell occurs at both a transcriptional and at a post-transcriptional level.

Preliminary data indicate that propanil-induced inhibition of TNF- $\alpha$ and IL-2 is at the level of gene regulation. NF- $\mathrm{KB}$ is a transcription factor that is important in TNF- $\alpha$ transcription. In vitro exposure of $\mathrm{M} \varphi$ to propanil resulted in a reduction in nuclear levels of the transcription factor NF- $\mathrm{kB}$ and a decrease in NF- $\mathrm{\kappa B}$ binding to the TNF- $\alpha$ promoter (Frost, et al., 2001). In T cells, AP-1, NF- $\mathrm{KB}$, and NFAT are transcription factors necessary for the transcription of the IL-2 gene. In the Jurkat T cell line, propanil exposure decreases NF-kB, NFAT and AP-1 binding activity. C-jun, a component of the transcription factor AP-1, is also decreased by in vitro propanil exposure at the protein and mRNA levels (personal communication, $\mathrm{K}$. Brundage). Therefore, changes in $\mathrm{M} \varphi$ 
and $\mathrm{T}$ cell function that occur after propanil exposure are due, at least in part, to decreased cell signaling which results in decreases in cytokine gene transcription and production.

One of the most sensitive immune functions affected by propanil exposure is the ability of the immune system to produce antibody. The T dependent (TD) antibody response requires the interaction of antigen-specific $\mathrm{T}$ cells and $\mathrm{B}$ cells and antigen presenting cells (APC) to simulate an antibody response (DeFranco, 2002). The Tindependent type 2 antibody response (TI-2) does not require cognate recognition of antigenic peptide on MHC or activation of the T cell through the TCR (Mond, et al., 1995). However, cytokines, produced both by the APC (IL-10, IL-12, TNF- $\alpha$ and IL-6) and activated T cells (IL-6 and IFN- $\gamma$ ) are important in TI-2 and TD B cell differentiation into plasma cells and antibody switching (Kahn, et al., 2002). Furthermore, ligation of B cell derived B7 and CD40 surface protein and T cell CD28 and CD40L are necessary for the production of TD and some TI IgG specific isotypes (Wu et al., 1999, Wu, et al., 2000, Wu, et al., 2002). Propanil has been demonstrated to decrease both the TD antibody response to sheep red blood cells (SRBC) and the TI response to DNP-Ficoll (Barnett et al., 1992). The sensitivity of the antibody response to propanil-induced suppression may reflect functional deficiencies, including deficiencies in cytokine production, by more than one cell type.

\section{Propanil and Thymic Atrophy}

Intraperitoneal (i.p.) injection, of P200 or greater, results in splenomegaly that is partly attributed to leukocytosis (Barnett and Gandy, 1989). However, propanil exposure does not affect the percentage or number of $\mathrm{CD} 4^{+} \mathrm{CD} 8^{-}$and $\mathrm{CD} 4{ }^{-} \mathrm{CD} 8^{+} \mathrm{T}$ cells in the 
spleen and mesenteric lymph nodes (Zhao, et al., 1995). In contrast, propanil exposure decreases lymphocyte numbers in the developmental organs (bone marrow and thymus) of the immune system. Exposure to P200 results in thymic atrophy (Barnett and Gandy, 1989; Zhao et al., 1995). Thymus weight and thymocyte cell numbers are reduced by propanil treatment as early as 2 days after treatment (Cuff, et al., 1996). Early cell decreases specifically target the $\mathrm{CD} 4^{+} \mathrm{CD} 8^{+}$thymocyte population (Cuff, et al., 1996). T cell populations begin to repopulate the thymus at 4 days after treatment by proliferation of the more mature $\mathrm{CD} 4^{+} \mathrm{CD} 8^{+}$and $\mathrm{CD} 4{ }^{-} \mathrm{CD} 8^{+}$thymocyte populations (Cuff, et al., 1996). However, in spite of $\mathrm{CD} 4^{+} \mathrm{CD} 8^{+}$and $\mathrm{CD} 4{ }^{-} \mathrm{CD} 8^{+}$thymocyte proliferation, 7 days after treatment the thymus cell count and size remained decreased with decreased cell numbers in all thymocyte populations including the very early $\mathrm{CD}^{-} \mathrm{CD} 4^{-} \mathrm{CD} 8^{-}$progenitor cell (Cuff, et al., 1996). This uniform reduction in the number of all subpopulations suggests that population decreases in the $\mathrm{CD} 4^{+} \mathrm{CD} 8^{+}$thymocyte population that occur at 2 days after treatment (Zhao, et al., 1995) may initiate in response to changes in the proliferative capacity of the $\mathrm{CD} 4{ }^{-} \mathrm{CD} 8^{-}$thymocyte population. By 7 days after treatment, subsequent cell loss that occurs in the $\mathrm{CD} 4^{-} \mathrm{CD} 8^{-}$population may also affect downstream thymocyte populations (Cuff, et al., 1996). T cell depletion in the thymus is due, in part, to increases in sera corticosterone levels as adrenalectomized mice do not have thymic atrophy following propanil exposure (Cuff, et al., 1996).

\section{Propanil and Hematopoiesis}

Propanil exposure affects hematopoiesis of myeloid and erythroid cells. At 7 days post treatment P50 is selectively toxic to bone marrow derived early myeloid progenitor cells (CFU-GM) that are responsive to GM-CSF while more differentiated 
myeloid cells (CFU-M and CFU-S), responsive to M-CSF or G-CSF respectively, were unaffected (Blyer, et al., 1994). In contrast, CFU-M and CFU-S in the spleen were increased suggesting that the spleen may compensate for the depletion of bone marrow hematopoietic cells by expansion of leukocyte stem cells and/or more mature cell populations in the spleen. Human cord blood erythrocyte burst- and colony-forming unit (BFU-E and CFU-E) and CFU-GM progenitor cells have also been found to be decreased after in vitro exposure to propanil (Malerba, et al., 2002).

Taken together, these studies demonstrate that propanil affects the immune system after both in vitro and in vivo exposure. The changes it affects in immune function are specific, affecting T cell, B cell and macrophage function. Several mechanisms of immune suppression have been demonstrated including the suppression of both $\mathrm{T}$ cell and $\mathrm{M} \varphi$ signaling and decreased nuclear localization and DNA binding of transcription factors. Further research is necessary in order to determine the effects of human exposure to propanil in the environment.

\section{2,4-DICHLOROPHENOXYACETIC ACID (2,4-D)}

\section{2,4-D Usage}

2,4-D is a chlorinated phenoxy herbicide that was one of the first herbicides registered in the United States. It is reported to be the most widely used herbicide worldwide and the third most used herbicide in the United States (US)

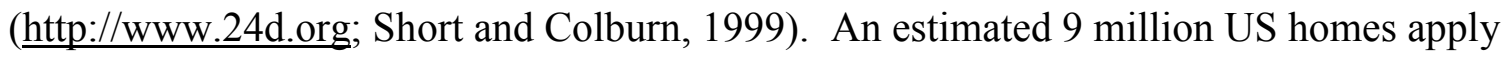
2,4-D annually making it the most used herbicide by home gardeners. It is also the most popular herbicide used in professional lawn care, roadside weed control and waterway treatment (Short and Colburn, 1999). The wide range of applications of this herbicide 
allow for exposure of both rural and metropolitan populations (Short and Colburn, 1999; Environmental Health Criteria 84, 1989; Munro et al., 1992; Haks, M. C., 1999). Based on clinical studies, the no-observed-adverse-effect level (NOAEL) for acute poisoning is $36 \mathrm{mg} \mathrm{2,4-D/kg} \mathrm{body} \mathrm{weight} \mathrm{(D36,} 36 \mathrm{mg} \mathrm{2,4-D/kg} \mathrm{bw)} \mathrm{while} \mathrm{safety} \mathrm{factors} \mathrm{for} \mathrm{chronic}$ exposures have not been established (Environmental Health Criteria 29, 1984).

According to the $\mathrm{WHO}$, human intake of 2,4-D from exposure to environmental levels is negligible (Environmental Health Criteria 29, 1984). However, the use of 2,4-D is so wide spread that the general public may be exposed on a regular basis. Even though 2,4-D is rapidly eliminated from the body, a 1995 study of urinary metabolites of United States adults found $12 \%$ contained 2,4-D, while $20 \%$ of Arkansas children tested had detectable concentrations of 2,4-D in their urine (Hill, et al., 1989; Hill et al., 1995).

\section{Human Exposure}

Upon entry into the body, 2,4-D crosses the epithelium, binds with high affinity to human serum albumen and is transported through the blood to the kidney (Rosso, et al., 1998). It is controversial whether this binding precludes the interaction of the chemical with the cells of the body. In vitro, one study found that 2,4-D did not interact with lipid or protein monolayers (Rosso, et al., 1998) while a second study reported that a $0.01 \mathrm{mM}$ concentration was sufficient to disrupt the lipid bilayer of human red blood cells (RBC) resulting in echinocytic cells (Suwalsky, et al., 1996). At high concentrations, 2,4-D is a known neurotoxicant (Nielson, et al., 1965; Squibb, et al., 1983). Efflux into and out of the brain and excretion through the kidney occurs via the organic acid transport system and requires ATP (Kim, et al., 1981; Villalobos et al., 1996). This is a rate-limiting step, and competition for the renal excretion of 2,4-D through the organic ion transport system 
interferes with the excretion of p-amino-hippurate (Erne, et al., 1974) It has not been determined whether the excretion of 2,4-D can itself be inhibited by other organic acids.

A study with human volunteers who consumed $5 \mathrm{mg} 2,4-\mathrm{D} / \mathrm{kg}$ body weight determined that the half life $\left(\mathrm{t}_{1 / 2}\right)$ of 2,4-D in the blood and urine was 11.5 and $17.7 \mathrm{hrs}$ respectively (Sauerhoff, et al., 1977). 2,4-D is not metabolized by liver enzymes and it does not accumulate in the body. In the study above, $82.3 \%$ of the $2,4-\mathrm{D}$ consumed was eliminated unchanged and $12.8 \%$ was eliminated as a $2,4-\mathrm{D}$ conjugate in the urine (Sauerhoff, et al., 1977). Urinary excretion, however, is dose dependent and higher doses or repetitive exposures may result in prolonged elevation of blood concentrations of 2,4D (Grover, et al., 1986a). In farmers spraying for a single day, the $\mathrm{t}_{1 / 2}$ ranged between 35 and $48 \mathrm{hr}$ (Grover, et al., 1986a). In this study, the amount of herbicide exposure affected the rate of elimination. After a single agricultural exposure the maximum urinary excretion occurred on the $3^{\text {rd }}$ day after exposure. The frequency of exposure to 2,4-D may also affect the elimination rate of the herbicide (Grover, et al., 1986a). Repetitive exposures to even small amounts of herbicide over a 7 day period resulted in detectable concentration of 2,4-D still being present in the urine 4-7 days later (Grover, et al., 1986a). A number of studies have attempted to use urinary excretion levels in order to estimate the amount of 2,4-D intake following exposure. However, this value may be misleading because, following repeated exposures, small amounts of 2,4-D are eliminated through the urine for a long period of time. Following 4-7 agricultural spraying applications, the average dermal exposure to farmers was $1077 \mu \mathrm{g} 2,4-\mathrm{D} / \mathrm{kg}$ sprayed while the average excretion was $21 \mu \mathrm{g}$ 2,4-D/kg sprayed (Grover, et al., 1986a). Factory workers exposed to production plant levels of 2,4-D had urinary excretion rates over 
1000 times below the NOEL for 2,4-D, however, excretion did not return to baseline levels until approximately 3 weeks after cessation of work (Knopp, et al., 1994). In a rat model, excretion rates of 2,4-D were saturated at a single oral dose of $50 \mathrm{mg} 2,4-\mathrm{D} / \mathrm{kg}$ body weight (D50) (Gorzinski, et al., 1987). Therefore, although elimination from the body is rapid and most 2,4-D is recovered in the urine, the time necessary for clearance of 2,4-D from the body is a better indicator of exposure concentrations than the amount of 2,4-D recovered at any time point after exposure. In people acutely exposed to high concentrations of 2,4-D, the time necessary for elimination of the herbicide from the body may allow for a subchronic exposure to 2,4-D in the serum. Repetitive exposures could realistically result in chronic levels of 2,4-D in an animal.

Most 2,4-D exposure occurs to the skin. Farmers involved in the mixing and applying of 2,4-D to wheat receive $80-90 \%$ of the total herbicide exposure in deposits on their hands (Grover, et al., 1986b). The rest of the body (face, eyes, mouth and skin) accounted for $10-20 \%$ while inhalation accounted for less than $2 \%$ of the total herbicide exposure. Following exposure, urinary excretion was less than $2 \%$ of the total potential exposure indicating that only small quantities of the herbicide are actually absorbed through the skin. In confirmation of this study, $\mathrm{C}^{14}$ labeled 2,4-D amine was dissolved in an aqueous solution and given to mice in both oral and dermal treatment regiments (Pelletier, et al., 1989). Approximately 4-10\% of the herbicide was absorbed through the skin while $100 \%$ was absorbed through the stomach. Oral absorption was rapid, with most of the 2,4-D absorbed within $2 \mathrm{hrs}$ of treatment and blood levels of 2,4-D peaking within $1 / 2 \mathrm{hr}$. of treatment. Dermal absorption occurred within $30 \mathrm{~min}$. with a constant supply entering the body from that time until removal by washing. Therefore, 
contamination via multiple routes of exposure are common during field applications of 2,4-D

\section{2,4-D Risk assessment}

2,4-D is classified to be moderately hazardous to relatively non-toxic (Environmental Health Criteria 29, 1984; Munroe, et al., 1992; Garabrant, et al., 2002). Because of the inconsistencies in the experimental data detailed below, these assessments are heavily based on the fact that renal clearance is rapid with 2,4-D exposure and metabolites are not formed.

\section{Carcinogenic effect of 2,4-D}

Although 2,4-D has been reported to be a mutagen, and a carcinogen, laboratory studies on the mutagenic effects of 2,4-D are variable. Garry et al. (1996) found a decrease in the frequency of births and an increase in the number of birth defects for private pesticide applicators with the greatest rates of abnormality occurring in areas with the highest frequency of chlorophenoxy herbicide use. Epidemiological studies have associated 2,4-D exposure with the development of non-Hodgkin's lymphoma, Hodgkin's lymphoma, and soft tissue sarcomas, suggesting that 2,4-D exposure may be correlated to genomic instability (reviewed in Garabrant, 2002; Garry, et al., 2001; Hardell, et al., 1979; Schreinemachers, et al., 2000). However, after in vivo exposure, forestry sprayers using a commercial 2,4-D formula did not show signs of genotoxicity (Mustonen, et al.,1986). In rodents, both chronic and subchronic exposure studies using a wide range of doses did not given clear evidence of carcinogenicity (Charles, et al., 1996a; Charles et al.,1996b). In experimental studies using the Drosophila sex-linked recessive lethal (SLRL) test for mutagenesis, 2,4-D was reported to be non mutagenic in 
adult fruit flies and a potent mutagen in larvae (Lee, et al., 1983, Kale, et al., 1995). One group that investigated the effects of $2,4-\mathrm{D}$ on $\mathrm{hPBL}$, determined that in vitro exposure to purified 2,4-D was not genotoxic while commercial 2,4-D, at the same concentrations, induced significant increases in chromosomal aberrations (Mustonen, et al.,1986). The inconsistency of the laboratory data suggest that 2,4-D is relatively non toxic. However, there is enough contradictory data to indicate that more information is needed before drawing any definitive conclusions.

\section{2,4-D and the Immune System}

The effects of 2,4-D on lymphocyte cell function are also inconclusive. Farmers receiving subchronic exposure during one 2,4-D spraying season had decreased peripheral blood $\mathrm{T}$ cell and natural killer $(\mathrm{NK})$ cell numbers with the recovery of the $\mathrm{T}$ cell proliferative response delayed 50-70 days after exposure (Faustini et al. 1996). However, oral, subacute exposures over a three week period in mice resulted in a slightly increased proliferative response to Con A stimulation suggesting that $\mathrm{T}$ cells were not affected by 2,4-D exposure (Blakley, et al.,1986, Blakley and Schiefer, 1986). Chronic exposure over a 2 year period in rats, chronic exposure over a 1year period in dogs, or subchronic exposure in dogs over a 13 week period, resulted in no change in leukocyte counts or spleen and thymus organ size (Charles, et al., 1996a, Charles, et al., 1996c). In a test of the functional response to immune challenge, mice were chronicly exposed to 50 mg 2,4-D/kg body weight/day (D50/day) over 105 days and subsequently infected with murine lymphocytic leukemia virus (Blakley, et al., 1992). This virus is an endogenous retrovirus that results in overproduction of $\mathrm{CD} 8^{+} \mathrm{T}$ cells, increased thymus size, and changes in spleen, liver and lymph node T cell populations. In this study, all treatment 
groups gave evidence of spontaneous lymphocytic leukemia suggesting that exposure to 2,4-D does not decrease the ability of $\mathrm{T}$ cells to proliferate in response to the virus (Blakley, et al., 1992). Laboratory tests, therefore, do not support the Faustini (1996) study that suggests that 2,4-D effects $\mathrm{T}$ cells.

2,4-D exposure results in variable effects on the humoral immune response. Acute oral 2,4-D exposure in mice was found to enhance primary antibody production against sheep red blood cells while acute topical application, in contrast, decreased B lymphocyte proliferation and suppressed the primary antibody response (Blakley, 1986; Blakley and Schiefer 1986). No attempt was made by the authors to explain a mechanism for the discrepancy in the acute oral vs. acute topical application as subacute topical or oral exposures, considered by the authors to be the type of exposure most comparable to human exposure, found no effect on antibody production (Blakley and Schiefer 1986; Blakley et al., 1998). Using a passive cutaneous anaphylaxis test, mice immunized with 2,4-D conjugated to keyhole limpet hemocyanin (KLH) produced 2,4-D specific IgE, suggesting that 2,4-D may act as hapten (Cushman, et al., 1982). However, topical application of 2,4-D did not result in an immune response indicating that, in vivo, 2,4-D is not an allergen (Cushman, et al., 1982). These results are supported by an epidemiological study of wheezing associated with occupational asthma. Working with 2,4-D did not result in increased wheezing in a large cohort of pesticide applicators again suggesting that 2,4-D is not an allergen (Hoppin, et al., 2002) These studies indicate that 2,4-D does not suppress, and may actually act to stimulate, the antibody response to a protein antigen. 


\section{MIXTURES}

\section{Mixtures}

All US government regulations on chemical usage and exposure levels are extrapolated from the risks calculated for each individual chemical component of the mixture (US EPA Office of Pesticide Programs, 2002a; Environmental Health Criteria 29, 1984, US EPA Office of Pesticide Programs, 2002b). It has been recognized for a long time, however, that all exposures to chemicals are to mixtures of chemicals, due to the presence of many chemical compounds in our environment (Simmons, 1995). A key question in toxicology is whether or not exposure to a mixture of chemicals can increase the chances of deleterious health effects over and above the toxic effects caused by the individual components of the mixture (Yang, 1998). Of special importance within this is area of research is the question whether or not chemicals that are not toxic may increase the toxicity when present in a mixture.

Carcinogenesis is a common endpoint used to determine the toxicity of a chemical. It has been demonstrated that exposure to multiple chemicals during cancer treatment can lead to genetic instability allowing for an increased rate of mutations within a single cell. Therefore, exposure to multiple chemicals may promote the development of cancer (Finett, et al., 2000) The immune system is sensitive to the affects of chemical toxicants (Luster, et al., 1992; Harris, et al., 1997a) and changes in immune function have been linked to the development of cancer (Luster, et al., 1992,). Therefore chemical mixtures may increase the frequency of cancer both by increasing chromosomal damage and decreasing the response of the immune system to cancerous cells.

Pesticides represent an important group of chemicals that are often applied as mixtures and that are found as common contaminates in air and groundwater samples 
(USGS, 1997; USGS NAWQA, 1998). Herbicides are the most widely used class of pesticides (Short and Colburn, 1999). Roloff et al. (1992) correlated chronic exposure to a mixture of atrazine and linuron to additive cytogenic effects in vitro. Chronic, oral treatment of mice with non-toxic concentrations of atrazine and linuron in a mixture resulted in chromosomal damage to spleen cells (Roloff, et al., 1992). Cytogenic effects were also increased in an additive manner in the bone marrow of mice exposed subchronically to a mixture of alachlor and atrazine. Interestingly, chronic exposure to the mixture resulted in a decrease in the number of aberrant cells in the bone marrow due to bone marrow hyperplasia (Meisner, et al., 1992). Together, these studies demonstrate that exposure to a mixture of chemicals can increase toxicity.

\section{Mixtures and the Immune System}

Hong et al. (1991), found that increased proliferation in the bone marrow after exposure to a mixture of chemicals maintained homeostasis of immune cell populations, however, subtle defects existed that were only detectable with further challenge. In their study, chronic exposure to a mixture of 25 common groundwater contaminates resulted in decreased colony formation by myeloid progenitor cells (CFU-GM) in the bone marrow. After cessation of treatment, recuperation of the bone marrow required 10 weeks. If treated mice were subjected to whole body irradiation during the period of bone marrow recovery, however, there was a dose dependent decrease in the number of CFU-GM in the mice that were exposed to the mixture of groundwater chemicals (Hong et al., 1991). Consistent with this finding, multiple irradiations during the exposure period, to even the lowest concentration of groundwater contaminates, resulted in a progressively fewer number of cells capable of colony formation with each successive irradiation (Hong et 
al., 1993). Therefore, exposure of bone marrow stem cells to a mixture of chemicals in contaminated groundwater at low concentrations can result in residual toxicity that only becomes apparent with further challenge.

Germolec et al. (1989) found that proliferating cells of the immune system, including the myeloid multipotent bone marrow stem cells and plasma forming B cells, had increased sensitivity to a mixture of 25 common groundwater contaminates. In this study, none of the groundwater contaminates were present in sufficient quantity alone to affect the immune system so all changes in immune cell function were due to the combined effect of the mixture. The immunosuppressive effects of the mixture were specific to myeloid cell development and B cell function. No significant histological or hematological changes occurred in mice that received groundwater contaminates in their drinking water and no changes were noted in the ability of $\mathrm{NK}, \mathrm{M} \varphi$, and CTL cells to lyse target cells. Furthermore, treatment with the groundwater contaminates did not suppress the ability of mice to resist an immunlogical challenge with Listeria monocytogenes or kill PYB6 tumor cells. There was, however, an increase in red blood cell (RBC) parasitization with Plasmodium yoelii, a malarial parasite that requires a humoral response to resist infection (Germolec, et al., 1989). This study demonstrates that a chemical mixture may cause a combined effect that is greater than the effects caused by the individual components of the mixture. The most profound effects, after exposure to the mixture of groundwater contaminates, occurred to the rapidly dividing and proliferating cells of the immune system.

In contrast to the Germolec et al. study (1989), antibody production to keyhole limpet hemocyanin (KLH) was unchanged after JP8 jet fuel exposure (Ullrich, 1999, 
Ullrich and Lyons, 2000). Dermal exposure to JP8 jet fuel, a hydrocarbon mixture used as fuel in aircraft, suppresses anti-CD3 stimulated T cell proliferation, delayed type hypersensitivity (DTH) to bacterial antigens, and contact hypersensitivity to chemical allergens. Increases in IL-10, an anti-inflammatory cytokine that selectively suppresses T helper-1 (TH1) cell development and promotes T helper-2 cell development, has been found to be one of the mechanisms of JP8-induced immune suppression (Ullrich and Lyons, 2000). Therefore, exposure to JP8 specifically targets T cell function. Together, these studies discussed above demonstrate that the immune system is highly sensitive to the toxic effects of chemicals and that mixtures of chemicals can regulate the immune system through different mechanisms, resulting in very different changes in immune function.

\section{Mixtures containing 2,4-D}

The route of exposure, duration of exposure, developmental stage at the time of exposure, the chemical form of 2,4-D, as well as the composition of the commercial formulation have all been suggested as possible variables that may explain the inconsistent experimental results obtained from 2,4-D exposure (Kale et al., 1995; Blakley, 1986; Blakley and Schiefer, 1986; Garry, et al., 1999). Of particular interest to our study is a possible link suggested between mixture exposure and increased toxicity. All purified formulations of 2,4-D, 2,4-D acid, amine and ester, have been found to have similar toxicity in both rats and dogs (Charles, et al., 1996b; Charles, et al., 1996c). The presence of other chemical compounds, however, may affect the toxic response. In the SLRL mutagenicity study of mature drosophila fruit flies and larvae, a commercial preparation of 2,4-D was found to be a potent mutagen in larvae while the purified form 
of 2,4-D was found to be non-mutagenic in adult flies (Kale, et al., 1995; Lee, et al.,1983). Gary et al., 1999, investigated the genotoxicity of 6 commercial herbicide preparations of 2,4-D, including purified acid, ester and amine in various formulations and 2 chlorophenoxy herbicide mixtures containing 2,4-D. Only one of the mixtures was found to be weakly genotoxic. However, the addition of herbicide adjuvants, including surfactants and oils that alone do not cause chromosomal damage, significantly increased the toxicity of mixture.

The "inert ingredients" in the commercial formula may contribute to or cause reported toxic responses (Kale, et al., 1995). The term "inert ingredients" encompasses all other materials, including oils, solvents, defoamers and surfactants that constitute the proprietary formula of a specific pesticide and that are included in the formulation of the pesticide to facilitate its application and, in some cases, to mechanically increase its potentency (US EPA Office of Pesticide Programs, 2002c). The EPA has recently requested that the label "inert ingredient" be changed to "other ingredient" for all pesticides because, although not pesticidally active, these compounds may not be harmless (US EPA Office of Pesticide Programs, 2002c). This may be true in the case of 2,4-D. Oakes and Pollak, 1999, found that the other ingredients in Tordon 75D, a mixture of 2,4-D and picloram, contributed to the ability of this herbicide to inhibit mitochondrial oxidation using a submitochondrial particle assay. In the absence of the other, non-pesticidal, ingredients in the mixture, a 136 fold higher concentration of Tordon 75D was required to obtain the same eeffect (Oakes et al., 1999). Thus an increase in toxicity was observed when $2,4-\mathrm{D}$ is present in a mixture containing picloram and inert ingredients. 
Tordon 202C, another formulation of the herbicides 2,4-D and picloram has also been found to have increased toxicity over the toxicity caused by the individual components of the mixture. Subchronic, oral exposure to Tordon 202C decreased the Tdependent primary humoral immune response and increased the number of urethaneinduced lung tumors (Blakley, 1997; Adams, et al., 1991). Paternal or maternal murine exposure to Tordon 202C exposure resulted in fetal abnormalities (Blakley, 1989a; Blakley, 1989b). In a separate study on sheep and cattle, picloram was found to be less toxic than 2,4-D (Jackson, 1996), however, the Tordon 202C studies did not address the individual toxicity of the 2,4-D and picloram components of the mixture in this study. These studies suggest that the mixture of the herbicides picloram with 2,4-D increases the toxicity of the individual herbicides.

Therefore, one possible explanation for the variations in the toxicity attributed to 2,4-D is that the toxic response after exposure to 2,4-D is dependent on the presence of other chemicals. These chemicals may not be toxic in and of themselves, however, they are able to interact with 2,4-D in a mixture. More research is necessary on this widely used chemical to assure that it is safe in all applications.

\section{Environmental exposure to 2,4-D in a mixture}

Recent reports suggest that 2,4-D, at non-toxic or environmental doses, when present in a mixture acts to increase the toxicity of the mixture. Cavieres et al., (2002) used a commercially formulated mixture containing 2,4-D (7.59\%), mecoprop (3.66\%), dicamba (0.84\%), and other ingredients (87.91\%), at environmentally-relevant exposure concentrations of 2,4-D, ranging from $0.01 \mathrm{mg} 2,4-\mathrm{D} / \mathrm{kg}$ body weight (D0.01) to D100, to study the effects of the mixture on implantation and embryogenesis. Mice were treated 
with the herbicide mixture from conception until weaning. No effects were observed in mice exposed to the D100 treatment. In contrast, decreases were found in the number of implantation sites and litter size in the very low (D0.01) and low dose (D0.1) treatment groups suggesting an inverted $\mathrm{U}$ shaped dose response model for the effects of 2,4-D on embryo implantation (Cavieres, et al., 2002). Therefore 2,4-D, in a mixture, may be toxic at environmental doses.

\section{Metabolism of a mixture containing 2,4-D}

Other studies have demonstrated that 2,4-D, when added to a mixture of chemicals, can affect the metabolism of the mixture (Chaturvedi, et al., 1991). Addition of 2,4-D to a mixture containing parathion and toxaphene, increased liver enzymes $68 \%$ over that of the levels produced by a mixture containing only parathion and toxaphene even though 2,4-D alone is not metabolized in the liver (Chaturvedi et al., 1991). It is possible that 2,4-D, when present in a mixture, can affect the body's response to toxic chemicals.

\section{STRESS}

\section{Stress Regulation of the Response to a Mixture of Chemicals}

Stress can play a major role in the response of an organism to a mixture of chemicals. Stress, including chemical stress can affect the immune system. The immune system interacts with the neuroendocrine system using chemical messengers including a variety of cytokines, hormones and neurotransmitters (Ader et al., 1990; Blalock et al., 1994). In response to stress, hormonal levels, especially hormones regulated by the hypothalamic-pituitary-adrenal (HPA) axis fluctuate, resulting in a variety of emotional, neural and immune system changes. Porter et al., (1984), found that the response to 
infection after exposure to a mixture of pesticides was exacerbated when animals were stressed by lack of water and malnutrition, highlighting the connection between the immune and endocrine systems. There is also a connection between the central nervous system (CNS) and the endocrine system. In one study, rats exposed to a mixture of pesticides had decreased learning ability, significantly lower concentrations of acetylcholine in the hippocampus, and increased thyroxine and somatotropin levels in blood sera (Boyd et al., 1990; Porter et al., 1993). In the same vein, exposure to two different herbicide/nitrate fertilizer mixes was found to increase behavioral aggression, decrease the antibody response to SRBC and decrease thyroid hormone levels (Porter, et al., 1999). Therefore, chemical stresssors can affect the central nervous system (CNS), endocrine and immune system responses.

Mixtures of chemicals have also been found to affect the CNS. JP-8 jet fuel is a benzene-based mixture used by the Army and the Air Force that changes neural and immune function. Exposure guidelines, set by the Navy Occupational Safety and Health, have been adopted to protect military personnel exposed to the chemical mixture. However, these guidelines are not sufficient protection as reports of emotional dysfunction, decreased attention spans and fatigue occur in personnel working with JP-8. JP-8 also effects the immune system. Short-term exposure to JP-8 causes long term decreases in the number of lymphoid cells in the lymph nodes, bone marrow, peripheral blood, thymus and spleens of C57B1/6 mice (Harris, et al., 1997a). Functional immune changes include decreases in NK tumoricidal and CTL-mediated killing (Harris, et al., 2000). The changes in these immune parameters are linked to increases in the $T_{H} 2$-type cytokine interleukin-10 (IL-10) (Harris, et al., 2000). Neutralization of IL-10 with anti- 
IL-10 antibody blocks the toxic immune response to JP8. Immune suppression can also be blocked by using a cyclooxygenase- 2 inhibitor to inhibit the synthesis of prostaglandin $\mathrm{E}_{2}$, a paracrine-acting tissue hormone involved in the inflammatory response or by aerosolized administration of substance P, a small neuropeptide (Ullrich, et al., 1999; Harris, et al., 1997b). Neural, endocrine and immune system interactions function as a system of checks and balances in the body. However, because of this interconnection, even short-term disruption of this system by a chemical stressor has the potential to cause many varied affects on the organism. Due to the complexity of the interconnections between these systems, changes in the neuroimmune response after mixture exposure may be qualitatively and/or quantitatively different from the response caused by exposure to a single chemical.

\section{The Stress Response}

Exposure to chemical toxicants can activate the HPA axis resulting in increased levels of stress hormones in the blood (Pruett, et al., 1993). These hormones can contribute to the immunotoxic effects of the chemical (Pruett, et al., 1993). In the mouse, the glucocorticoid hormone, corticosterone, is the main hormone produced in a stress response. Stress works to increase the amount of corticotropin-releasing hormone (CRH), a hormone produced in the hypothalamus. $\mathrm{CRH}$ acts in a paracrine fashion in the hypothalamus to upregulate the pituitary hormone, adrenocorticotropic hormone (ACTH). ACTH is released into the blood and acts in an endocrine fashion on the adrenal glands to initiate production of glucocorticoid hormone (GH) (Blalock, et al., 1994; Cohen, 1992). Therefore, the stress response is co-coordinated by a complex mixture of neurological and endocrine mediators. 


\section{Stress-induced immunosuppression}

GHs are generally considered to be immune-suppressing hormones. Increases in systemic GH results in T cell apoptosis in the thymus (Wyllie, et al., 1980). Leukocyte cell numbers and immune cell functions, including the humoral immune response, are decreased by GH exposure (Pruett, et al., 1993). Exposure to chemicals can result in immune suppression. Ethanol (ETOH) consumption in mice increases serum corticosterone levels and is associated with decreases in T cells in the thymus and B and T cell losses in the spleen (Padgett, et al., 2000). ETOH induced cellular losses are due, at least partially, to adrenal hormone increases as adrenalectomy (ADX) alleviates cell number decreases in the spleen and partially alleviates $\mathrm{T}$ cell losses in the thymus (Padgett, et al., 2000). The glucocorticoid receptor blocker RU 486 has also been shown to block ETOH induced depletion of T cells in the thymus (Han, et al., 1993). These results suggest that ETOH-induced immune suppression is a result of increased levels of GH in exposed animals. In a similar manner, propanil exposure results in thymic atrophy in normal, but not adrenalectomized mice (Cuff, et al., 1996). GHs can also decrease the functional response of immune cells. RU 486 partially blocks morphine induced suppression of the in vivo antibody response to SRBC (Pruett, et al., 1993). These studies indicate that GHs can suppress the immune response after exposure to a chemical toxicant.

\section{Stress-induced enhancement of the immune response}

Stress can actually enhance some aspects of the immune system while downregulating other immune functions (Vinson, et al., 1998; Maruyama, et al., 1999; Dhabhar, et al., 1998). Dhabhar et al. (1998), found that acute stress induces changes in 
leukocyte distribution resulting in increases in $\mathrm{T}$ cell numbers in the brachial lymph nodes and T, B, NK and monocyte cell numbers in the bone marrow. In this study, rats subjected to restraint stress prior to antigenic challenge enhanced the delayed-type hypersensitivity (DTH) response while chronic stress resulted in immunosuppression. Therefore, stress can modulate the immune system and the effect of stress on the immune system is dependent on the level and duration of stress hormone elevation.

\section{Predicting the role of stress in the immunotoxic response}

Several difficulties exist in modeling the stress response to a chemical toxicant. Flint et al. (2001), found the timing of exposure to stress was critical to the immune response. Restraint stress prior to hapten challenge resulted in an enhanced DTH response while restraint stress prior to sensitization suppressed the DTH response to a cutaneous allergen (Flint, et al., 2001). In this study, HPA modulation targeted the antigen specific $\mathrm{T}$ cell response, as challenge by an antigen, but not an irritant, enhanced cutaneous edema and lymphocytosis (Flint, et al., 2000). Therefore, stress is an immune modulator, but the immune response to stress is also dependent on the activation state of the immune system.

Predicting the response of the immune system after exposure to chemical stress is also complicated by the fact that the stress response may be only part of the immunotoxic effects exerted by the chemical(s). An example of this is the stress response to gallium arsenide (GaAs). Exposure to GaAS results in increases in serum corticosterone levels, decreases in thymus and spleen lymphocyte populations and decreases in the anti-SRBC IgM response. Pre-treatment with RU 486, a glucocorticoid receptor blocker, before GaAs exposure, abrogates the decreases in cell numbers but does not relieve the 
suppression of the IgM response, suggesting a mechanism other than $\mathrm{GH}$ is acting to suppress the antibody response (Burns, et al., 1994). Therefore, the response to chemical stress may be unique to the particular chemical or mixture.

In vivo, the stress response involves a complex mixture of neurological, endocrine and immune mediators. Both hormonal and non-hormonal compounds can modulate the stress response, further complicating efforts to predict the outcome of exposure to a stressor on the immune system (Keller, et al., 1988). Many other hormones and neurotransmitters may be up-regulated in a stress response including endorphins and catecholamines (Ader, et al., 1990). Receptors for other endocrine modulators are found on immune cells and sympathetic nerves are known to enervate the immune organs (Ader, et al., 1990; Blalock, 1994). Therefore the corticosterone response may only be a part of the stress response and the actions of corticosterone may be dependent on the presence or absence of other hormonal or neuronal regulators.

\section{Modeling the Stress Response}

Pruett and Fan (2001) have attempted to model the immune response to stress by comparing corticosterone levels in the serum after exposure to exogenous corticosterone, to serum levels of corticosterone produced after restraint stress, or exposure to a chemical toxicant (Pruett et al., 1999, Pruett et al., 2000, Pruett et al., 2001). This technique separates corticosterone-induced immune changes from immune system changes that are caused by other stress mediators or by direct chemical toxicity. In order to do this, the degree and duration of serum corticosterone levels are mathematically modeled as the area under the corticosterone vs. time curve (AUC). Comparison of the AUC produced after exposure to exogenous corticosterone to the AUC produced after exposure to 
restraint stress or to a chemical allows for the comparison of the mechanism(s) involved in the changes that result to the immune system. In order to do this, the AUC produced after restraint stress or chemical exposure is normalized by adjusting the time of restraint stress or the concentration of the chemical in order to produce a curve similar to the curve that results from exposure to physiological levels of exogenous corticosterone. The AUC produced after exposure to $18 \mathrm{mg} / \mathrm{kg}$ exogenous corticosterone (administered subcutaneously) was equivalent to the AUC produced after 6-8 $\mathrm{h}$ of restraint stress (Pruett et al., 1999). In this experiment, it was determined that MHC class II expression on spleen cells and NK cell suppression, were decreased to an equivalent amount after restraint stress and exogenous corticosterone treatment, suggesting that these decreases were primarily due to the action of corticosterone (Pruett et al., 1999). In comparison, the IgG1 and IgG2a antibody responses to KLH antigen were suppressed more by restraint stress than by corticosterone alone, suggesting the role of other mediators in the modulation of the IgG specific antibody response to KLH (Pruett et al., 2001).

The corticosterone AUC produced after exposure to propanil was also evaluated to determine the role of corticosterone in propanil-induced immune suppression (Pruett et $a l ., 2000)$. In this study, it was determined that a greater percentage of cells were lost in the thymus after exposure to exogenous corticosterone than after exposure to propanil or restraint stress (Pruett et al., 2000). These results suggest the activation of mediators involved in feedback inhibition of the stress response when animals are exposed to propanil. Propanil-induced decreases in B and $\mathrm{T}$ cell populations in the spleen, decreases in MHC class II expression on spleen cells and peripheral blood lymphocytes (PBL), and changes in NK activity were found to be similar to the decreases caused by exogenous 
corticosterone treatment, suggesting that corticosterone is the main mediator of these effects in the immune response after propanil exposure. Propanil-induced suppression of the IgG1 antibody response resembled the AUC produced after restraint stress rather than the AUC produced by exogenous corticosterone. These results suggest that other mediators, in addition to GH, produced in response to restraint stress or propanil, modulate the IgG1 antibody response to KLH. In contrast, decreases in the IgG2a response were much greater with propanil exposure than with either restraint stress or corticosterone treatment, suggesting that another biological mechanism, in addition to stress, acts to further decrease the IgG2a response. These studies suggest that the immunotoxic response to propanil originates from a complex mix of response mediators, feedback control and possibly even direct immunotoxic action by propanil or its metabolites.

\section{The influence of stress hormones on $T$ cell development and the formation of the $T$ cell repertoire}

Physiological levels of $\mathrm{GH}$ are known to selectively delete $\mathrm{CD} 4^{+} \mathrm{CD} 8^{+}$

thymocytes both in vitro and in vivo through the induction of apoptosis (Cohen, 1992; Wyllie, 1980). However, inhibition of GH in fetal thymic organ culture (FTOC), and thymic expression of GR antisense transcripts in transgenic mice, results in reductions of endogenous GH levels and depletion of the $\mathrm{CD} 4^{+} \mathrm{CD} 8^{+}$thymocyte population (Vacchio, et al., 1999; King, et al.,1995) suggesting that decreases as well as increases in GH can result in thymic atrophy. Several lines of research suggest that the maintanence of normal levels of stress hormones are necessary for thymocyte development. TNC are epithelial cells that express MHC class I and class II and possess a neuroendocrine cell phenotype (Greenen, et al., 1999). These cells are known to synthesize oxytocin, 
vasopressin and insulin-like growth factor 2 (Greenen, et al., 1999). TEC cells have been shown to produce endogenous GHs that have been demonstrated in vitro to be involved in the maintenance of the double positive population (Vacchio, et al., 1994; Pazirandeh, et al.,1999). It has been postulated that GH also participate in T cell development by regulating affinity recognition during positive and negative selection (Vacchio, et al., 1999; Xue, et al., 1996). In support of this theory, signaling through the glucocorticoid receptor (GR) or through the TCR/CD3 complex has been demonstrated to induce apoptosis in a $\mathrm{T}$ cell hybridoma cell line while simultaneous signaling through both receptors rescues these cells from death (Zacharchuk, et al., 1990). This discovery has led to the mutual antagonism theory of $\mathrm{T}$ cell selection that states that $\mathrm{GH}$ set the threshold limits for positive selection thus enhancing the positive selection of thymocytes with low avidity (Vacchio, et al., 1999). Mutual antagonism has been demonstrated both in vivo and in vitro. However, FTOC of thymuses from $\mathrm{GR}^{-/}$mice have been found to develop normally in the absence of GH signaling (Purton, et al., 2000). Therefore, although $\mathrm{CD} 4^{+} \mathrm{CD} 8^{+}$thymocytes are very sensitive to increases and decreases in $\mathrm{GH}$ levels, it is unknown whether GH levels are crucial in the determination of the $\mathrm{T}$ cell repertoire.

\section{The influence of stress hormones on B cells in the bone marrow}

Research suggests that increases in GH may decrease B cell numbers in the bone marrow with in vivo exposure (Sabbele, et al., 1987). Repeated injections of dexamethasone (DEX), a synthetic glucocorticoid analog, in C57Bl/6J mice were found to decrease the total number of B cells in the bone marrow but did not change the capacity of the remaining cells to respond to LPS or to produce antibody in a protein A 
plaque assay (Sabbele, et al., 1987). However, in the same study, single acute exposures of mice to DEX did not result in bone marrow cellular loss or the depletion of the pre B cell population (Sabbele, et al., 1987). Corticosterone implants, demonstrated to produce physiologically-relevant exposure to corticosterone in Balb/c/ J mice resulted in decreases in the pre B cell population that were evident by $12 \mathrm{hrs}$ post treatment (Laakko, et al., 2002). $\operatorname{IgM}^{+} \mathrm{B}$ cells were subsequently depleted at $36 \mathrm{hrs}$ after the initial exposure. The very earliest B cell population, the pre-pro B cells, a phenotype dependent on stromal ligation, were found to be unaffected by corticosterone exposure (Laakko, et al., 2002). These studies demonstrate that pre B cells are targeted by GH's, but also suggest that the response to GH may only occur with extended exposure or that the response may also be mouse strain specific.

Borghesi et al. (1997), demonstrated that the response of bone marrow B cells to GH is dependent on stromal cell factors. Both physical contact with the stroma and stroma-produced cytokines in vitro, were found to protect pro B cells from GH induced apoptosis (Borghesi, et al., 1997). In the study in BALBc/J mice detailed above, it was found that bone marrow B cells needed 1000 fold greater concentration of dexamethasone than splenic B cells in order to induce apoptosis (Sabbele, et al., 1987). This may be due, in part, because of protection afforded to the bone marrow by the bone marrow stromal cells. Therefore, the microenvironment of the bone marrow is critical to the response to acute GH exposure.

\section{Neuroendocrine Modulation of the Immune Response}

The antibody response is controlled by both neurologic and endocrine mediators. In vitro stimulation of murine spleen cells with norepinephrine within $6 \mathrm{hrs}$ of 
immunization resulted in an increase in the antibody response to SRBC (Sanders, et al., 1984a; Sanders, et al., 1984b). In contrast, mice immunized with SRBC before exposure to organophosphate pesticides had a suppressed antibody response that was correlated to an increase in cholinergic stimulation associated with pesticide exposure (Casale, et al., 1983). Therefore, the sympathetic nervous system can modulate the antibody response. The effect of neural modulation on the response is dependent on whether norepinephrine or acetylcholine are the predominant neural modulator produced during the stress response.

Endocrine modulators have also been found to vary the antibody response. Fleshner et al. (1996) demonstrated that corticosterone can increase or decrease the antibody response depending on the time of exposure and the concentration of corticosterone in the sera. In these experiments, rats immunized with keyhole limpet hemocyanin (KLH) and subsequently exposed to inescapable tail shock had a decreased anti-KLH IgM and $\operatorname{IgG}$ response up to 21 days after immunization (Fleshner, et al., 1996). Decreases in the IgG response were specific to the TH-1 anti-KLH IgG2a isotype and were blocked by pre-treatment with RU 486. These results may indicate that corticosterone exposure can skew the antibody response to KLH to a more TH-2 type response at the expense of the TH-1 isotype $\operatorname{IgG} 2 \mathrm{a}$.

There is some evidence that the antibody response requires basal levels of corticosterone for optimal levels of antibody production. Basal levels of corticosterone were found to increase the anti-KLH response above that of adrenalectomized mice (Fleshner, et al., 2001). Furthermore, normal increases in corticosterone, measured 5-7 days after KLH immunization, specifically increased the anti-KLH IgG2a antibody 
response (Fleshner, et al., 2001). Therefore, different immune responses may be generated depending on the concentration of corticosterone that is present during the development of the immune response. These studies demonstrate that the antibody response is controlled by a wide variety of neuroendocrine and immune system modulators. Corticosterone is required for an optimal antibody response but, at high concentrations, it can act to suppress the antibody response. These results suggest that neuroendocrine modulation of the antibody response is a tightly controlled system.

\section{STREPTOCOCCUS PNEUMONIAE}

\section{The Antibody Response to Streptococcus pneumoniae}

Streptococcus pneumoniae is an extracellular, gram-positive bacteria. The use of Streptococcus $s p$. in a host resistance model is recommended for the detection of chemical-induced changes to the humoral immune system, granulocytic cells and phagocytic cells by the National Toxicology's Tier II Panel (Luster, et al., 1988). The outer surface of $S$. pneumoniae is composed of the capsule, the cell wall and the plasma membrane. All three components are immunogenic. The capsule is composed of capsular polysaccharide (C polysaccharide). In a pneumococcal infection, the capsule is necessary for virulence and for the development of type-specific immunity (Bruyn, et al., 1992). The cell wall contains inflammatory components that stimulate $\mathrm{M} \varphi$ production of IL-1 and TNF- $\alpha$ during the course of an infection (Bruyn, et al., 1992). The phosphorylcholine (PC) molecule, composed of choline containing teichoic acid, is the main antigenic component of the cell wall. It elicits a strong $\mathrm{T}$ independent antibody response. The cell membrane is composed of lipoteichoic acid, lipids and proteins. It contains the pneumococcal surface protein A (PspA). PspA is the main antigenic 
component of the T dependent antibody response to S. pneumoniae infection in C57Bl/6 mice (Wu, et al., 1999).

Using the heat killed, nonencapsulated, type II variant, R36A, Wu et al. (1999) have characterized the primary and secondary, TD and TI-2 antibody responses to $S$. pneumoniae in $\mathrm{C} 57 \mathrm{Bl} / 6$ mice. In their research, the primary PC specific antibody response peaked at 7 days after treatment. PC specific IgM was found to be the major component of the early antibody response while $\operatorname{IgG} 3$ and $\operatorname{IgG} 2 b$ were the dominant antiPC IgG specific isotypes (Wu, et al., 1999). PC specific antibodies did not increase with subsequent boosting. The primary PspA specific antibody response peaked by 14 days after immunization. Very little IgM was produced in response to the PspA antigen. Dominant isotypes in the PspA response were IgG1, IgG2b and IgG2a (Wu, et al., 1999). The PspA response was increased 10 fold with boosting (Wu, et al., 1999). The IgG anti$\mathrm{PC}$ and anti-PspA responses were both dependent on $\alpha \beta \mathrm{CD} 4^{+} \mathrm{T}$ cell help (Wu, et al., 2002).

In contrast to the PspA response, the anti-PC IgG response does not require cognate TCR/MHC interaction. However, both the TD and TI-2 response require activation of B7 costimulation and upregulation of CD40L (Wu, et al., 2002). The cytokine response and the kinetics of cytokine stimulation of the antibody response after immunization with HKSP are also well defined. TNF- $\alpha$ is required for optimal anti-PC and anti-PspA antibody production (Khan, et al., 2002). IL-6 and IFN- $\gamma$ also act to stimulate the response while IL-10 was found to suppress the anti-PspA antibody response (Khan, et al., 2002). Initial research has also identified myeloid dendritic cells (DC) as important in antigen presentation of bacterial antigen (Colino, et al., 2002). This research makes $S$. 
pneumoniae an ideal system for application to toxicology because a model antibody response has already been established in C57B1/6 mice. The antibody response to $S$. pneumoniae requires the coordination of T cells, B cells and APC and the complexity of the whole bacteria allows for both TI-2 and TD antibody responses. Changes in the normal antibody response after HKSP immunization may implicate a particular cell population that has been affected by mixture exposure leading to more mechanistic research on the actions of the mixture of propanil and 2,4-D on the immune system.

\section{SUMMARY}

We are constantly exposed to chemicals throughout our lifetime. Our environment contains many man made chemicals and natural toxins. Many chemicals that have been demonstrated to be highly toxic can be stored in our bodies for long periods of time (Maugh, et al., 1982). Chemicals can cross the placenta in the blood and be passed from mothers to infants by exposure across the placenta and through mother's milk (Weisglas-Kuperus, et al., 1995, Maugh, et al., 1982). Therefore, exposure to mixtures of chemicals occurs from the time of conception throughout life. Damage to our bodies may accumulate and damage to the immune system of an individual may reflect an accumulation of toxic events. Furthermore, a single acute exposure to a chemical can simultaneously affect several different bodily systems including the CNS, the endocrine and immune systems.

Our present understanding of the toxic response associated with exposure to a mixture of chemicals is not sufficient to predict the response to chemical mixture exposure. More studies are necessary to determine the mechanisms by which a chemical mixture affects a toxic response. 
Chapter 1. Characterization of Thymic Atrophy and the Mechanism of Thymocyte Depletion after Exposure to a Mixture of Herbicides 
Characterization of thymic atrophy and the mechanism of thymocyte depletion after in vivo exposure to a mixture of herbicides

Patricia de la Rosa, John B. Barnett and Rosana Schafer

Department of Microbiology, Immunology and Cell Biology, School of Medicine, Robert

C. Byrd Health Sciences Center, West Virginia University, Morgantown, West Virginia, 26506-9177.

Running title: Characterization of thymic atrophy after in vivo exposure to a mixture of herbicides

Correspondence to:

Rosana Schafer, Ph.D.

Department of Microbiology, Immunology and Cell Biology

P.O. Box 9177

West Virginia University

Morgantown, WV 26506-9177

rschafer@wvu.edu 


\section{ABSTRACT}

3,4-Dichloropropionanilide (propanil) and 2,4-dichlorophenoxyacetic acid (2,4D) are two commonly used herbicides that are marketed as a chemical mixture. This in vivo study demonstrates that a mixture of propanil and 2,4-D, when compared to single herbicide exposures, exacerbated decreases in all thymic $\mathrm{T}$ cell populations and inhibited the repopulation of $\mathrm{T}$ cells in the thymus. Mixture-related decreases in the ratio of thymus weight to body weight (TW:BW) occurred within 2 days after treatment with 150 $\mathrm{mg}$ propanil / kg body weight $+150 \mathrm{mg}$ 2,4-D /kg body weight (150/150). Thymic atrophy resulted from cellular decreases in the double positive thymocyte population $\left(\mathrm{CD}^{+} \mathrm{CD}^{+}\right)$and was correlated to increases in sera corticosterone levels of between 600 - $1000 \mathrm{pg} / \mathrm{ml}$. However, similar corticosterone increases occurred with exposure to $50-$ $150 \mathrm{mg}$ propanil / $\mathrm{kg}$ body weight (50 propanil - 150 propanil) and 50/50 - 100/100 mixture treatments but did not result in cellular loss. In addition, mifepristone (RU 486), a glucocorticoid receptor blocker, only partially protected $150 / 150$ treated animals from thymic atrophy. This suggests that glucocorticoids may be only one mechanism for herbicide-induced thymic atrophy. Using a partial factorial design, synergistic decreases in $\mathrm{CD}^{-} \mathrm{CD}^{-}$cell number occurred in the $100 / 100$ mixture-treated mice, and all thymocyte populations in $150 / 150$ mixture-treated mice. This study emphasizes the importance of studying mixtures and the biological mechanisms involved in the mixture interaction. 
Keywords: 3,4-Dichloropropionaniline, 2,4-Dichlorphenoxyacetic acid, immunotoxicity, thymus, mifepristone, glucocorticoid hormones, interaction, chemical mixture, factorial analysis, herbicide 


\section{INTRODUCTION}

The environment that we live in is a complex mixture of chemicals including both natural and man-made toxins. Most toxicology research, however, is focused on single chemical exposures and does not account for mixture interactions. We have developed an in vivo exposure model to assess the effects on the immune system of a mixture of two herbicides, propanil and 2,4-D. Propanil and 2,4-D are heavily used by the agricultural industry and are commonly applied as a mixture under the product names of NOX-D and Herbanil 368 (Farm Chemicals Handbook, 1998). One of the major goals of this research was to determine if interactions between the two herbicides in a mixture results in a greater effect on the immune system than the individual components of the mixture.

Propanil is an amide herbicide that has immunotoxic effects (Barnett and Gandy, 1989). Decreases in lymphocyte function, including reductions in T-dependent antibody responses, contact hypersensitivity and mixed lymphocyte responses, occur in a murine model after intraperitoneal (i.p.) exposure to propanil (Barnett and Gandy, 1989).

Production of interleukin (IL)-2, IL-6, granulocyte-macrophage colony-stimulating factor (GM-CSF) and interferon-gamma (IFN- $\gamma$ ) by LPS or Con A-stimulated splenocytes is decreased after exposure to propanil in vitro or in vivo (Zhao, et al., 1998).

Propanil induces thymic atrophy that is correlated with a decrease in the $\mathrm{CD}^{+} \mathrm{CD}^{+}$thymocyte population. Research on the mechanisms of cell loss after propanil exposure has determined that thymic atrophy, evident within 2 days of propanil exposure, is attributed, in part, to increased sera corticosterone levels (Cuff et al., 1996). This cellular loss was partially alleviated by adrenalectomy (Cuff, et al. 1996). 
2,4-D, a chlorinated phenoxy herbicide, is reported to be the most widely used herbicide worldwide $\{\mathrm{http} / / \mathrm{www} .24 \mathrm{~d} . \mathrm{org}\}$. The wide range of applications results in exposure in both rural and metropolitan populations (reviewed in: Environmental Health Criteria 84, 1989; Munro et al., 1992). A 1995 study of urinary metabolites of United States adults found $12 \%$ contained 2,4-D, while, in another study, $20 \%$ of Arkansas children had detectable concentrations of 2,4-D in their urine (Hill et al., 1995; Hill et al.,1989). In 1992, a comprehensive, integrated review of epidemiological and toxicological data on 2,4-D concluded that the herbicide is of low toxicity and poses a negligible risk to the public (Munro et al., 1992). However, at least three epidemiological studies have associated 2,4-D exposure with the development of nonHodgkin's lymphoma and soft tissue sarcomas (Hoar et al., 1986; Hardell et al., 1979 and Schreinemachers, 2000). Farmers receiving repeated, subchronic exposure during one 2,4-D spraying season, had decreased peripheral blood $\mathrm{T}$ cell and natural killer (NK) cell numbers and recovery of the $\mathrm{T}$ cell proliferative response was delayed 50-70 days after exposure (Faustini et al., 1996). Acute oral 2,4-D exposure in mice was found to increase proliferation and primary antibody production against sheep red blood cells while acute topical application, in contrast, decreased B lymphocyte proliferation and suppressed the primary antibody response (Blakley, 1986a and Blakley and Schiefer, 1986b). In a mixture exposure model, subchronic oral exposure to Tordon 202C, a mixture of the herbicides picloram and 2,4-D, caused a dose dependent decrease in the Tdependent primary humoral immune response (Blakley, 1997). This study, however, did not look at the immunotoxicity of the individual components of the Tordon $202 \mathrm{C}$ mixture. The addition of 2,4-D to a mixture of parathion and toxaphene increased liver 
enzymes involved in the metabolism of the other two pesticides even though 2,4-D alone did not affect liver enzyme levels (Chaturvedi et al., 1991). Thus, these reports suggest that 2,4-D may be immunotoxic and that the addition of 2,4-D to a mixture of chemicals may change the immunotoxic response.

In this study the effects on the thymus of an in vivo exposure to the chemical mixture of propanil and 2,4-D and the connection between increased in sera corticosterone levels and thymocyte cell loss will be examined. 


\section{MATERIALS AND METHODS}

Animals. C57BL/6 female mice, 6-8 weeks of age, were purchased from Charles River Farms (Wilmington, DE). Mice were allowed to acclimate for one week after shipment and received food and water ad libitum. National Institute of Health (NIH) and Animal Care and Use Committee (ACUC) guidelines were followed throughout the study.

Source of xenobiotics. Propanil was purchased from Chem Service (West Chester, PA) and has a purity of 99\%. Commercial-grade 2,4-D amine (dimethylamine salt of 2,4-dichlorophenoxyacetic acid, Universal Cooperatives, Inc., Minneapolis, MN) with a purity of $39.2 \%$ was purchased from Southern States Cooperative (Morgantown, WV). The concentration of 2,4-D used for all experiments was calculated based on the amount of active 2,4-D.

Exposure of mice to herbicide mixtures. Mice were treated with either a single herbicide (propanil or 2,4-D) or a 1:1 mixture containing both herbicides. Propanil was dissolved in peanut oil (Planters, Nabisco Inc.) and 2,4-D amine was dissolved in phosphate buffered saline (PBS) to the appropriate concentration. Mice were weighed prior to i.p herbicide injection. Single herbicide doses contained 50, 100, 150 or 200 $\mathrm{mg} / \mathrm{kg}$ body weight of either propanil (P50, P100, P150, P200) or 2,4-D (D50, D100, D150, D200). Mixture treatments were given by two consecutive i.p. injections, in a one to one ratio of propanil and 2,4-D. The following treatment doses were administered: 
Table 1. Chapter 1. Herbicide Treatment

\begin{tabular}{|c|c|c|}
\hline \multicolumn{2}{|c|}{ Single Herbicide Treatment } & Mixture Treatment \\
\hline Propanil (mg/kg) & $\mathbf{2 , 4 - D ~ ( m g / k g ) ~}$ & Propanil (mg/kg)/2,4-D (mg/kg) \\
\hline Peanut oil alone (0) & PBS alone (0) & Peanut oil/PBS (0/0) \\
\hline 50 & 50 & $50 / 50$ \\
\hline 100 & 100 & $100 / 100$ \\
\hline 150 & 150 & $150 / 150$ \\
\hline 200 & 200 & $200 / 200$ \\
\hline
\end{tabular}

Cell isolation. Thymuses were weighed and single cell suspensions prepared by teasing the thymuses apart and passing them sequentially through 18-and 26-gauge needles attached to $3 \mathrm{ml}$ syringes. Red blood cells were lysed with Tris-buffered ammonium chloride. Single cells suspensions were washed and re-suspended in media containing PBS supplemented with 1\% fetal bovine serum (FBS, Hyclone, Logan, UT) and $0.04 \%$ sodium azide (Sigma, St. Louis, MO) (staining media). Thymus to body weight was calculated as the ratio of the individual thymus weight to the total body weight.

Immunofluorescence. Isolated cells were stained with anti-CD4-FITC (GK1.5) and anti-CD8 $\alpha-P E$ (53-6.7) (Pharmingen, San Diego, CA). Briefly, 1 x $10^{6}$ cells were stained in a total volume of $25 \mu \mathrm{l}$ of antibody at the appropriate concentration for $25 \mathrm{~min}$. on ice in the dark. Cells were then washed twice and fixed in $0.04 \%$ paraformaldehyde (Fisher Scientific, Pittsburgh, PA). For analysis, 10,000 cells were analyzed on a BectonDickinson FACScan (Becton Dickinson Immunocytometry Systems, Mansfield, MA). Analysis was performed using WinMDI software (Joseph Trotter, Scripps Institute, San Diego, CA). Population percentages, obtained from the flow cytometric analysis on ungated spleen cell populations, were used to calculate the absolute cell numbers of a 
thymocyte population by multiplying the ratio of cells in a population by the total number of cells harvested per organ.

Serum corticosterone levels. Mice used in serum corticosterone experiments were housed two per cage. Mice were injected i.p. with propanil, 2,4-D or a mixture of the two herbicides between 9:00 am and 10:00 am. Serum was collected at $1 \mathrm{hr}, 4 \mathrm{hrs}, 12 \mathrm{hrs}, 24$ hrs, and 48 hrs after injection using 4 mice in each treatment group per timepoint. All efforts were made to reduce stress on these animals by minimizing noise and movement. Blood was collected within $30 \mathrm{sec}$. of handling. Serum corticosterone levels were measured using an ${ }^{125}$ I-radioimmunoassay kit for rats and mice from ICN Biomedicals, Inc. (Costa Mesa, CA).

$R U 486$ treatment. Mice were given $100 \mathrm{mg}$ mifepristone $/ \mathrm{kg}$ body weight by gavage (RU 486, Sigma-Aldrich) $2 \mathrm{hrs}$ prior to, and $12 \mathrm{hrs}$ after, i.p. administration of 150 propanil +150 2,4-D herbicide mixture treatment or $75 \mathrm{mg}$ corticosterone/kg body weight given by gavage (Sigma-Aldrich). Thymuses were harvested, weighed and stained at $48 \mathrm{hrs}$ after corticosterone or herbicide exposure.

Statistics. Comparison of the dose-response to vehicle control: One way analysis of variance (ANOVA) was done on thymocyte population percentages and total cell numbers using a Dunnett's test to compare the response of treated animals to vehicle control with a significance level of $\mathrm{p} \leq 0.05$.

A Tukey HSD analysis was used to compare the changes in TW:BW of the 100/100 mixture to 200 single herbicide treatment and $\mathrm{CD} 4^{+} \mathrm{CD} 8^{+}$total cell number response of the 50/50 mixture to those of the 100 single herbicide treated groups with a significance level of $\mathrm{p} \leq 0.05$. 
Partial factorial analysis: Interactions between the individual herbicide components of a mixture were determined by ANOVA analysis using a factorial design. The factorial design is specific to the statistical analysis of the combined effects of two or more factors. In our experiments we used a partial two-factor design. The null hypothesis $\left(\mathrm{H}_{\mathrm{o}}\right)$ for this model specifies additivity in that the response to the mixture is equal to the total response of the mixture components. A mixture interaction defines a response that is above or below the line of additivity. A multiple regression analysis was used to correlate total cell numbers across all treatments at 2 and 7 days post treatment with increases in glucocorticoid hormones at all timepoints. Statistical analysis was performed using JMP software, (SAS Institute Inc., Cary, NC ). 


\section{RESULTS}

\section{Thymus to Body Weight Ratio}

Herbicide treatment did not affect the body weight of the mice. The extent of thymic atrophy after herbicide treatment was measured as a ratio of thymus weight to body weight (TW:BW). At two days after treatment, thymus to body weight ratios were not affected by single herbicide treatment of P50 to P150 or D50 to D150 (Figure 1A). Similarly, mixtures of either 50/50 or 100/100 did not affect TW:BW ratios. Treatment with the 150/150 mixture caused a statistically significant decrease in the ratio of $\mathrm{TW}: \mathrm{BW}$ as compared to vehicle control (Figure 1A). In addition, TW:BW ratios of P200 and D200 single herbicide and 200/200 mixture-treated mice, were also significantly decreased in size from vehicle control (Figure 1A). For clarity, only the PBS + peanut oil control is shown. All controls had similar responses. Thymic atrophy remained for at least seven days post-treatment in the 150/150 and 200/200 mixture group (Figure 1B). Single herbicide treatment of D200 also resulted in thymic atrophy by 7 days post treatment (Figure 1B).

A Tukey HSD analysis was done to compare the TW:BW of P200 and D200 with mixtures containing the same total herbicide concentration $(100 / 100)$. TW:BW ratios after single herbicide treatments of P200 and D200 were significantly decreased as compared to the 100/100 mixture (Figure 1A). Furthermore, the 100/100 mixture response was similar to the responses by the single 100 treatments and the vehicle control. 


\section{Analysis of Thymocyte Populations}

Two-color flow cytometric analysis was done on individual thymuses to examine thymocyte populations. Thymocytes were separated into four populations: double negative thymocytes $\left(\mathrm{CD} 4^{-} \mathrm{CD} 8^{-}\right)$, double positive thymocytes $\left(\mathrm{CD} 4^{+} \mathrm{CD} 8^{+}\right)$, and the single positive $\left(\mathrm{CD}^{+} \mathrm{CD} 8^{-}\right.$and $\left.\mathrm{CD} 4^{-} \mathrm{CD} 8^{+}\right) \mathrm{T}$ cell populations. Thymocyte maturation proceeds from double negative to double positive to single positive cells.

Decreases in population percentages in the thymus were specific to the $\mathrm{CD} 4^{+} \mathrm{CD} 8^{+}$thymocyte population and occurred after $150 / 150(60 \% \pm 17 \%)$ and $200 / 200$ mixture treatment $(54 \% \pm 8 \%)$ as compared to vehicle $(81 \% \pm 4 \%)$. Increases in the percentages of the $\mathrm{CD}^{+}{ }^{+} \mathrm{CD} 8^{-}(19 \% \pm 7 \%, 150 / 150$ and $14 \% \pm 2 \%, 200 / 200$ vs. $8 \% \pm$ $1 \%$, vehicle) and $\mathrm{CD}^{-} \mathrm{CD}^{-}(12 \% \pm 5 \%, 150 / 150$ and $22 \% \pm 4 \%, 200 / 200$ vs. $6 \% \pm 3 \%$, vehicle) thymocyte populations are accounted for by the decreases in the $\mathrm{CD} 4^{+} \mathrm{CD} 8^{+}$ thymocyte population. By 7 days post treatment, all thymocyte population percentages had recovered to control values (data not shown).

The P100, P150, P200 and D200 treatments significantly decreased absolute cell number of the $\mathrm{CD} 4^{+} \mathrm{CD} 8^{+}$thymocyte population relative to the vehicle control at 2 days post-treatment (Figure 2). Mixture treatments of 100/100, 150/150 and 200/200 also significantly decreased $\mathrm{CD} 4^{+} \mathrm{CD} 8^{+}$absolute cell number (Figure 2) even though the 100/100 TW:BW was not decreased (Figure 1A). Using a partial factorial analysis, the 150/150 mixture-treated $\mathrm{CD} 4^{+} \mathrm{CD} 8^{+}$population demonstrated mixture interactions ( $\mathrm{p} \leq$ $1.5 \times 10^{-5}$ ) indicating that mixture-specific effects occur with $150 / 150$ and $200 / 200$ mixture treatment (Figure 2, denoted by *). 
We analyzed the $50 / 50$ mixture response in the $\mathrm{CD} 4^{+} \mathrm{CD} 8^{+}$population in comparison to the single, P100 and D100 herbicide treatments to determine if the toxic response to the mixture was determined by the total concentration of herbicide (i.e. both herbicides work through a common pathway) rather than by effects that are specific to each individual component of the mixture. The 50/50 mixture response was similar to vehicle treatment and to the P50 and D50 single herbicide treatments and significantly different from the single P100 treatment (Figure 2). In contrast, the 100/100 mixture response was significantly different from the response to the vehicle and statistically similar to the P200, D200 or 200/200 response.

The $\mathrm{CD}^{+} \mathrm{CD}^{-}$thymocyte population was significantly increased after D150 and significantly decreased by D200 single herbicide exposure reflecting the sensitivity of the $\mathrm{CD}^{+} \mathrm{CD}^{-}$thymocyte population to $2,4-\mathrm{D}$ treatment (Figure 3 ). Treatment with the 150/150 mixture did not cause significant decreases as compared to vehicle control, however, a partial factorial analysis of the $\mathrm{CD} 4^{+} \mathrm{CD} 8^{-}$thymocyte population demonstrates mixture interactions occur 2 days after 150/150 and 200/200 treatment ( $\mathrm{p} \leq 4.9 \times 10^{-6}$ and $p \leq 4.5 \times 10^{-5}$ respectively), indicating that mixture-specific affects occur in the response of the on the the $\mathrm{CD}^{+} \mathrm{CD}^{-}$population (Figure 3; denoted by *).

The $\mathrm{CD}^{-} \mathrm{CD}^{+}$absolute cell number was decreased as compared to vehicle control for mixture groups exposed to 100/100, 150/150 and 200/200 (Figure 4). In the $150 / 150$ and 200/200 mixture-treated groups, there were mixture interactions ( $p \leq 2.25 \times$ $10^{-6}$ and $\mathrm{p} \leq 1.0 \times 10^{-2}$ ) (Figure 4, denoted by *). Absolute cell numbers in the CD4 $\mathrm{CD}^{+}$population after treatment with the 50/50 mixture were similar to vehicle and P50 
or D50 single herbicide treatments and significantly different from P100 or D100 single herbicide treatment (Figure 4).

The $\mathrm{CD}^{-} \mathrm{CD}^{-}$population was not significantly decreased by single herbicide and mixture treatment as compared to vehicle control; however, there were mixture interactions, as determined by the partial factorial analysis, in the response of the

$100 / 100,150 / 150$ and 200/200 mixture-treated populations $\left(\mathrm{p} \leq 1.3 \times 10^{-3}, \mathrm{p} \leq 4.5 \times 10^{-12}\right.$ and $\mathrm{p} \leq 1.7 \times 10^{-2}$ respectively) (Figure 5 , denoted by *).

The thymocyte populations were also examined at 7 days post-treatment to determine if the effects on the thymus were persistent. In mice exposed to $150 / 150$ and 200/200 mixture treatment, the $\mathrm{CD} 4^{+} \mathrm{CD} 8^{+}$and $\mathrm{CD} 4{ }^{-} \mathrm{CD} 8^{+}$absolute cell numbers remained decreased and, at this timepoint, the $\mathrm{CD}^{+} \mathrm{CD} 8^{-}$, and $\mathrm{CD}^{-} \mathrm{CD} 8^{-}$were also decreased (Figure 6 A, 6B, 6C and 6D respectively). Seven days after treatment of mice with P150 and P200 the absolute number of cells were recovered to vehicle control levels in the $\mathrm{CD} 4^{+} \mathrm{CD} 8^{+}$thymocyte population while $\mathrm{CD} 4{ }^{-} \mathrm{CD} 8^{+}$thymocytes were decreased by P200 treatment (Figure 6A, 6C respectively). D200 treatment, at this timepoint, decreased all thymocyte populations (Figure 6A, 6B, 6C and 6D).

\section{The induction of glucocorticoid hormones after herbicide exposure}

Increases in systemic glucocorticoid hormones have been demonstrated to cause apoptosis in the $\mathrm{CD} 4^{+} \mathrm{CD} 8^{+}$thymocyte population (Wyllie, 1980). Therefore, glucocorticoid levels in the serum, from mice exposed to propanil, 2,4-D or a 1:1 mixture of the two, were measured at $1 \mathrm{hr}, 4 \mathrm{hrs}, 12 \mathrm{hrs}$ and $24 \mathrm{hrs}$ post treatment using individual animals at each timepoint. Treatment with P50, P100, P150 and P200 and all mixture treatments $(50 / 50,100 / 100,150 / 150$ and 200/200) increased corticosterone to peak levels 
of $600-1000 \mathrm{ng} / \mathrm{ml}$ at one-hour post treatment (Figure 7A, 7B, 7C and 7D respectively). Single herbicide treatment of D200 also increased corticosterone levels to between 600$800 \mathrm{ng} / \mathrm{ml}$ at $1 \mathrm{hr}$ after treatment (Figure 7D). Corticosterone levels fell sharply during the initial 4 hours after P50, P100, P150 and 50/50, 100/100, 150/150 treatments followed by gradual decreases until $24 \mathrm{hrs}$ post treatment when corticosterone levels had returned to baseline (Figures 7A, 7B, 7C). In contrast, corticosterone levels decreased slowly after P200, D200 and 200/200 treatment and only returned to normal levels after $48 \mathrm{hrs}$ (Figure 7D). Since P50 was found to increase glucocorticoid hormones to a level similar to P100 - P200 and 50/50 - 200/200 treatment, Further experiments were conducted at one hour after propanil exposures of P5 - P25 to determine the dose response. Exposure to P5 did not increase glucocorticoid levels over vehicle control (58.07 \pm 36.13 vs. $67.28 \pm 48.81$ respectively). However, increases were found at onehour post treatment in animals receiving P10 $(218 \mathrm{ng} / \mathrm{ml} \pm 165 \mathrm{ng} / \mathrm{ml})$ or P25 (399 ng/ml $\pm 119 \mathrm{ng} / \mathrm{ml}$ ). These increases were similar to $1 \mathrm{hr}$ mixture treatments of $10 / 10$ and 25/25 where corticosterone levels were $275 \mathrm{ng} / \mathrm{ml} \pm 195 \mathrm{ng} / \mathrm{ml}$ and $427 \mathrm{ng} / \mathrm{ml} \pm 209 \mathrm{ng} / \mathrm{ml}$ respectively.

A multiple regression analysis was done to compare exposure-related total cell loss across all treatment groups with sera corticosterone increases. Decreases in the $\mathrm{CD}^{+} \mathrm{CD}^{+}$thymocyte population after exposure to the $50 / 50-200 / 200$ mixtures were negatively correlated (slope $=-8.1 \times 10^{-4}$ ) to glucocorticoid increases that occurred between 1 and 24 hrs post treatment. These results suggest that the cellular decreases in the thymus at two days post treatment correlate with the sera corticosterone increases that 
occur very early in the stress response. Therefore, glucocorticoid increases are a potential mechanism for thymocyte loss after mixture treatment.

RU 486, a glucocorticoid receptor blocker, was used to determine if increased glucocorticoid levels contribute to cellular losses in the thymuses of mixture-treated animals. The 150/150 dose was chosen because mixture interactions were noted in the $\mathrm{CD}^{+} \mathrm{CD}^{+}$thymocyte population at this treatment level (Figure 2). Mice were first pretreated with RU 486 and then injected with the 150/150 herbicide mixture or $75 \mathrm{mg} / \mathrm{kg}$ of corticosterone as a control. Mice received another treatment of RU 486 twelve hours after exposure to the herbicide mixture or corticosterone to maintain glucocorticoid levels in the blood for the remainder of the time course (Burns et al.,1994; Flint et al., 2000). Both corticosterone and the $150 / 150$ mixture treatment significantly reduced thymus to body weight (data not shown) and the percentage and total number of $\mathrm{CD} 4^{+} \mathrm{CD} 8^{+}$cells (Figures $8 \mathrm{~A}$ and 8B). RU 486 alone had no significant effect on the thymus size (data not shown), the percentage or total cell number of $\mathrm{CD}^{+} \mathrm{CD}^{+}$cells (Figures $8 \mathrm{~A}$ and 8B). Treatment with RU 486 maintained the $\mathrm{CD}^{+} \mathrm{CD} 8^{+}$population from decreases in the percentage of cells but not the absolute cell number after corticosterone exposure (Figures $8 \mathrm{~A}$ and $8 \mathrm{~B}$ ). In animals exposed to the $150 / 150$ mixture treatment, the thymus size (data not shown) and $\mathrm{CD} 4^{+} \mathrm{CD} 8^{+}$absolute cell number were partially maintained by pretreatment with RU 486, however, they were still significantly decreased in comparison to the vehicle treated mice (Figure 8B). 


\section{DISCUSSION}

Mixture specific affects can occur in the thymus after exposure to a mixture of propanil and 2,4-D. At 2 days after treatment, decreases in the $\mathrm{CD} 4^{-} \mathrm{CD} 8^{+}$absolute cell numbers were specific to mixture exposure of 100/100, 150/150 and 200/200 and single herbicide treatment of $\mathrm{P} 200$ and D200. The decrease in the number of the $\mathrm{CD} 4{ }^{-} \mathrm{CD} 8^{+} \mathrm{T}$ cells may be a result of decreases in the number of $\mathrm{CD} 4^{+} \mathrm{CD} 8^{+}$precursor cells as the $\mathrm{CD}^{-} \mathrm{CD}^{+}$thymocyte population was also decreased by $100 / 100-200 / 200$ mixture exposure and single herbicide treatments of P200 and D200. However, P100 and P150 significantly decreased the $\mathrm{CD} 4^{+} \mathrm{CD} 8^{+}$thymocytes but did not affect the $\mathrm{CD} 4^{-} \mathrm{CD} 8^{+}$ population. These results suggest that the combined effects of both herbicides are necessary to initiate decreases in the $\mathrm{CD} 4^{-} \mathrm{CD} 8^{+}$thymocytes. The $\mathrm{CD} 4^{+} \mathrm{CD} 8^{+}$and $\mathrm{CD} 4^{-}$ $\mathrm{CD}^{+}$thymocyte population remains decreased by $150 / 150$ and $200 / 200$ treatment at 7 days after treatment, suggesting that one effect of the mixture is to extend the length of time necessary for recovery of these populations.

We examined the response in all thymocyte populations to the 50/50 mixture treatment in comparison to the response after P100 or D100 in order to determine if cellular decreases were determined by the total concentration of herbicide in the mixture irrespective of the individual components of the mixture. This type of response could occur if both herbicides in the mixture act through a similar pathway such as the upregulation of corticosterone hormones. At the 50/50 dose, an animal receives a total concentration of herbicide equivalent to $100 \mathrm{mg} / \mathrm{kg}$. However, while P100 causes significant decreases in the number of $\mathrm{CD} 4^{+} \mathrm{CD} 8^{+}$thymocytes, the $50 / 50$ mixture does not, suggesting that propanil-induced cellular decreases are distinct from the mechanism 
of cellular decreases caused by exposure to 2,4-D. In contrast, the 100/100 mixture response was significantly different from the response to the vehicle and statistically similar to the P200, D200 or 200/200 response. These results suggest that D100, a dose that does not increase glucocorticoid hormones or cause thymic atrophy, increases the effects of P100 exposure when present in the 100/100 mixture.

In this study, a partial factorial analysis for the mixture interaction was done in order to determine the effects on the thymus that were specific to the mixture. Mixture interactions demonstrating mixture-specific affects on the $\mathrm{CD} 4{ }^{-} \mathrm{CD} 8^{-}$population occurred after 100/100, 150/150 and 200/200 mixture exposure and after exposure of $\mathrm{CD} 4^{+} \mathrm{CD} 8^{+}$, $\mathrm{CD}^{+}{ }^{+} \mathrm{CD} 8^{-}$and $\mathrm{CD} 4^{-} \mathrm{CD} 8^{+}$thymocytes to $150 / 150$ and $200 / 200$ mixture treatment (Figure 2, 3 and 4). However, these interactions did not fit into well defined, statistical models because a linear dose response to 2,4-D was not established. In the thymocyte populations tested, the dose response to 2,4-D may be very steep, with dose dependent decreases occurring between $150 \mathrm{mg} / \mathrm{kg}$ - $200 \mathrm{mg} / \mathrm{kg}$, or it may be bimodal, with increases in the number of thymocytes occurring between $50-150 \mathrm{mg} / \mathrm{kg}$ exposures, followed by cellular decreases with exposures to $150-200 \mathrm{mg} / \mathrm{kg}$. If the absolute number of thymocytes is actually increased by 2,4-D exposure, the interaction is nontraditional and may not reflect an actual biological event. However, with the exception of the $100 / 100 \mathrm{CD}^{-} \mathrm{CD} 8^{-}$population which was not tested, all populations that demonstrated an interaction at 2 days after 150/150 and 200/200 treatment, in contrast to the single herbicide treatment response, remained significantly decreased at 7 days. Therefore, within the range of our experiments, there appear to be biological effects that are specific to the mixture and support the statistical analysis of the interaction. 
Hypocellularity in the thymus has been used as a tool to determine the extent of involvement of glucocorticoid hormones in the stress response (Padgett et al., 2000; Han et al., 1993). Glucocorticoids are immunoregulatory hormones known to cause thymic atrophy by apoptotic depletion of the $\mathrm{CD} 4^{+} \mathrm{CD} 8^{+}$thymocyte population (Wyllie, 1980; Cohen, 1992). Several studies have associated thymic atrophy with increases in glucocorticoid levels caused by chemical exposure (reviewed by Pruett et al., 1993). Propanil exposure is associated with an increase in systemic glucocorticoid levels and adrenalectomy partially relieves thymic atrophy in propanil treated mice (Cuff et al., 1996). An increase in glucocorticoid levels is a potential mechanism for the toxic effects on the thymus after exposure to a mixture of propanil and 2,4-D.

In our experiments, corticosterone increases, associated with exposure to propanil, D200 or the herbicide mixture, were correlated with the atrophy of the thymus and loss of the $\mathrm{CD} 4^{+} \mathrm{CD} 8^{+}$population. However, increases in corticosterone alone were not sufficient to induce cellular loss. Pretreatment of mice with RU 486 two hours prior to herbicide exposure also supports the results obtained by measuring sera corticosterone levels. RU 486 is a glucocorticoid receptor II blocker that has been shown to effectively block apoptosis of thymocytes exposed to dexamethasone in vitro and to block thymic atrophy associated with increased sera levels of glucocorticoids after ethyl alcohol consumption in vivo (Xue, et al., 1996). This block is specific to the stress reaction and does not interfere with the type I mineral corticoid receptor responsible for regulation of homeostasis (Miller et al., 1998). RU 486 pretreatment, did not prevent all of the cell loss that occurs to the $\mathrm{CD} 4^{+} \mathrm{CD} 8^{+}$population after mice were exposed to $150 / 150$ mixture treatment. 
Decreases in cell number in the $\mathrm{CD} 4^{-} \mathrm{CD} 8^{+}$population after exposures to mixtures containing 100/100 -150/150 and interactive decreases in the $\mathrm{CD} 4^{+} \mathrm{CD} 8^{+}$thymocyte population after exposure of mice to 150/150 further suggest that 2,4-D may act on the thymus through another mechanism other than by increasing glucocorticoid hormone levels. Glucocorticoids are known to complement the biological response to cytokines and other hormones (Wiegers et al., 1998; Wu and Pruett, 1996). Although corticosterone is the main hormone produced in the mouse during a stress reaction, additional mediators may contribute to the thymic atrophy associated with the herbicide mixture treatment (Pruett and Fan, 2001). Therefore it is possible that glucocorticoids, together with other paracrine and endocrine factors, can selectively affect specific lymphocyte populations.

There is also some indication that 2,4-D can cause depletion of thymocytes by increasing sera levels of corticosterone. Treatment of mice with D200 caused increases in glucocorticoid hormones and resulted in decreases in all thymocyte populations at 2 days after treatment to the same extent as P200 and the 200/200 mixture. Therefore, the overt toxicity of the P200, D200 and 200/200 treatments is due, in part, to increases in sera glucocorticoid hormones. In contrast to the large increase in cellular loss after 150/150 mixture exposure, treatment with P200, D200 and 200/200 all caused similar cell loss in all thymocyte populations (Figure 2-5). Two possible reasons for the lack of additivity in the mixture effect at the 200/200 treatment dose are that either a finite number of herbicide-senstive thymocytes exist, so that the mixture effects are equivalent to the effects of $\mathrm{P} 200$ or $\mathrm{D} 200$ or the number of $\mathrm{CD} 4^{+} \mathrm{CD} 8^{+}$thymocytes is maintained at a 
baseline level by an unknown mechanism of homeostasis after P200, D200 or 200/200 treatment.

More latent toxicity occurred at 7 days in the $\mathrm{CD}^{+} \mathrm{CD} 8^{+}, \mathrm{CD} 4^{+} \mathrm{CD} 8^{-}, \mathrm{CD} 4^{-} \mathrm{CD} 8^{+}$ and $\mathrm{CD} 4 \mathrm{CD} 8^{-}$populations exposed to $150 / 150$ and $200 / 200$ mixture treatment and D200 single herbicide treatment. Seven day decreases in cell number in mixture-treated populations as well as continued decreases in the $\mathrm{P} 200$ treated $\mathrm{CD} 4^{-} \mathrm{CD} 8^{+}$population may be caused by propanil metabolites. The D200 treated populations were also significantly decreased after 7 days in all thymocyte population groups. 2,4-D is eliminated from the body through the kidneys without metabolite formation (Munro et al., 1992) leaving direct toxicity at 7 days unlikely. It is possible that D200 up regulates several hormones, including glucocorticoid hormones, and that the interaction of these hormones results in decreases in thymocyte populations after the chemical has been eliminated from the body. These studies demonstrate that propanil, 2,4-D and the mixture containing propanil and 2,4-D can cause long-term decreases in thymocyte populations

One of the mechanisms by which propanil and 2,4-D may be acting is by changing the proliferative capacity of the $\mathrm{CD} 4{ }^{-} \mathrm{CD} 88^{-}$thymocyte population. Increases in glucocorticoid hormones have been demonstrated to increase the survival of late CD4$\mathrm{CD}^{-}$/early $\mathrm{CD}^{+} \mathrm{CD}^{+}$thymocytes (Zaldumbide et al., 2002). Significant increases in cell number occur in the $\mathrm{CD} 4{ }^{-} \mathrm{CD} 8^{-}$and $\mathrm{CD} 4^{+} \mathrm{CD} 8^{-}$populations after $\mathrm{D} 150$ exposure. Although preliminary, these results suggest that the changes in the thymocyte population 2 days after mixture and 2,4-D exposure may be partly due to changes in cell cycling in the $\mathrm{CD}^{-}{ }^{-} \mathrm{CD} 88^{-}$population. However, whereas mixture exposure results in apparent decreases in $\mathrm{CD}^{-} \mathrm{CD} 8^{-}$cell numbers, treatment with 2,4-D results in apparent increases 
in this population. Further research is necessary to determine the mechanisms of thymocyte depletion after propanil and mixture exposure.

It is interesting that in spite of increases after D150 exposure, all thymocyte subsets were decreased after 150/150 mixture treatment. These results indicate that 2,4-D in the mixture does not antagonize the effects of propanil through the regeneration of cells but acts to increase the toxicity of the propanil component of the mixture.

The toxic response to a mixture of chemicals may be qualitatively and quantitatively different from the response to the individual chemicals comprising the mixture. Since environmental exposures are to multiple, low doses of chemicals, it is particularly important to understand what interactions occur at the no-effect level. In our system, D150, as a single herbicide exposure dose that did not decrease $\mathrm{T}$ cells in the thymus. However, the interaction of D150 with propanil increased and prolonged the toxic response of all $\mathrm{T}$ cell populations in the thymus to the $150 / 150$ mixture treatment. This study emphasizes the importance of studying mixture interactions, and the possible role of glucocorticoids and other mediators in the effects on the host after mixture exposure. 


\section{ACKNOWLEDGEMENTS}

We thank Gerald R. Hobbs, Ph.D, Department of Statistics and Community Medicine,

Robert C. Byrd Health Sciences Center, West Virginia University, for assistance with statistical analysis and Kathleen Brundage Ph.D, (Department of Microbiology,

Immunology and Cell Biology, WVU) for helpful discussion.

This work was supported by the National Institutes of Health grant ES07460 and ESO10953. 


\section{FIGURE LEGENDS}

Figure 1. Thymus weight to body weight ratio. Mice were treated with vehicle (grey bars), propanil (black bars), 2,4-D (open bars), or a mixture containing both propanil and 2,4-D (striped bars). A. Thymus weight to body weight at 2 days post treatment $(n=12)$. B. Thymus weight to body weight at 7 days post treatment $(n=6)$.

Bars represent the average thymus weight to body weight per treatment group \pm standard deviation. $\Gamma \mathrm{p} \leq 0.05$ vs. indicated group. 


\section{Figure 1. Chapter 1. Thymus weight to body weight}

A. Thymus weight to body weight 2 days post treatment

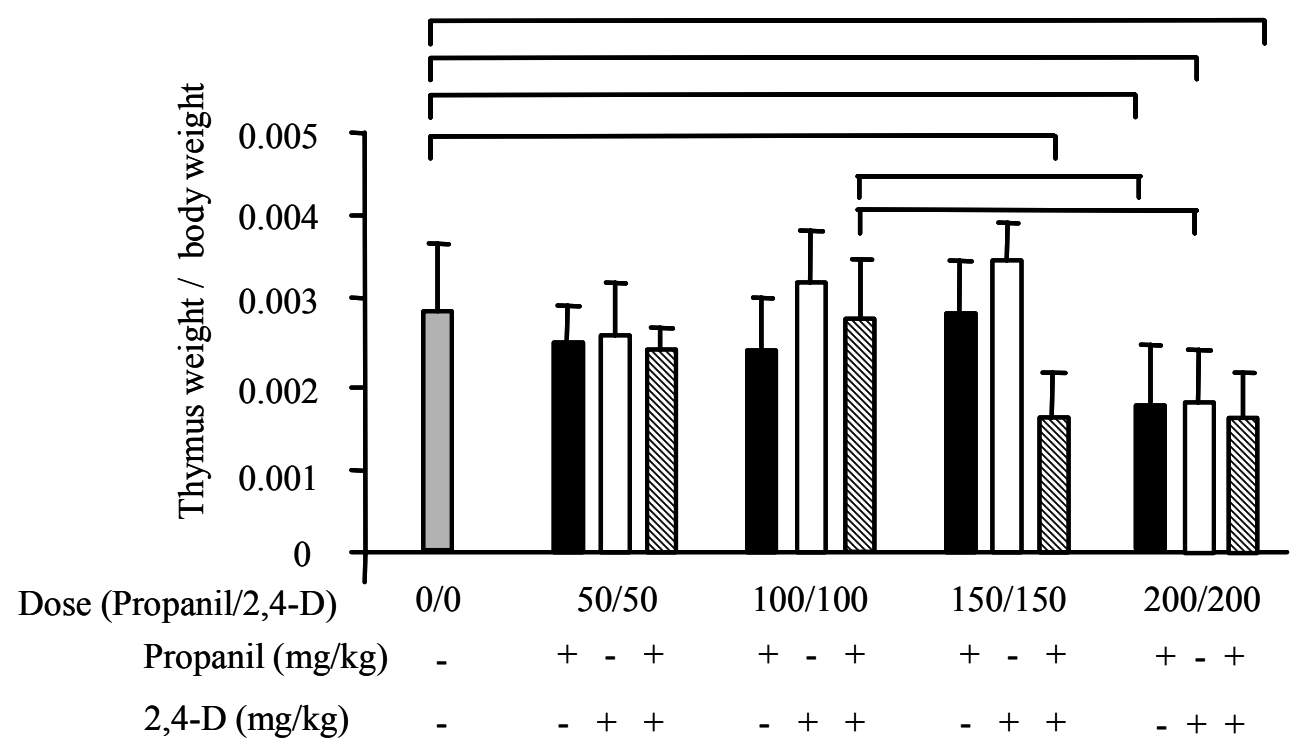

B. Thymus weight to body weight 7 days post treatment

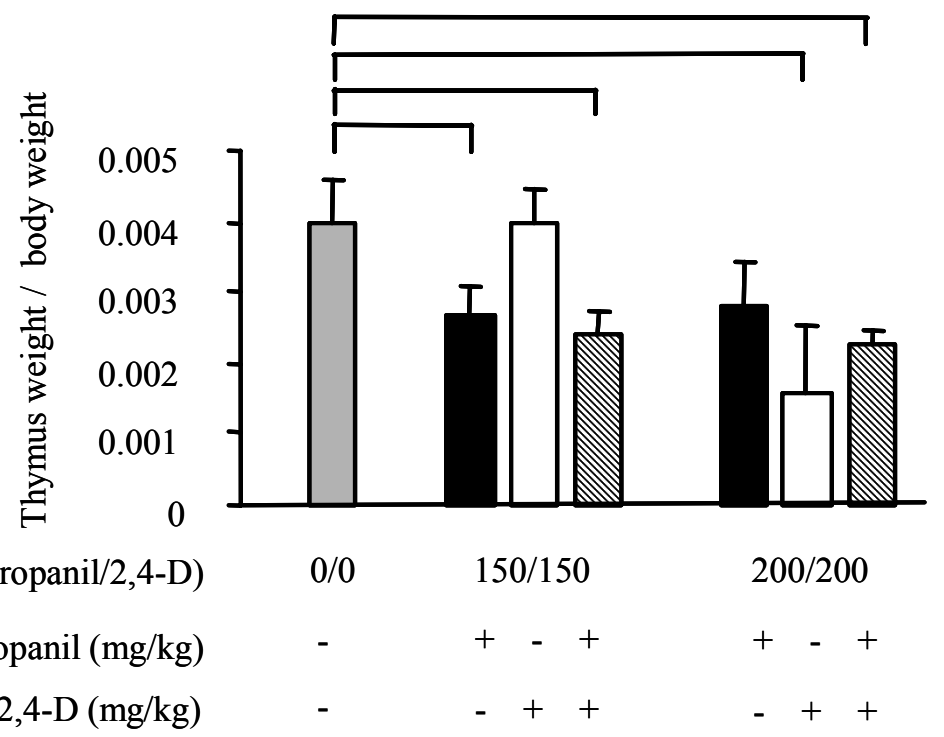


Figure 2. Absolute cell numbers of the $\mathrm{CD} 4^{+} \mathrm{CD} 8^{+}$thymocyte population. Mice were treated with vehicle (grey bars), propanil (black bars), 2,4-D (open bars), or a mixture containing both propanil and 2,4-D (striped bars) and thymuses removed at 2 days post treatment. Thymocytes were stained with anti-CD4 FITC and anti-CD8 PE and total cell numbers calculated as described in Materials and Methods. Bars represent the average of 12 mice \pm standard deviation. $\psi$ mixture interaction. $\square \mathrm{p} \leq 0.05$ vs. indicated group. 
Figure 2. Chapter 1. Absolute number of $\mathrm{CD4}^{+} \mathrm{CD8}^{+}$thymocytes

Figure 2. $\mathrm{CD}^{+} \mathrm{CD}^{+}$

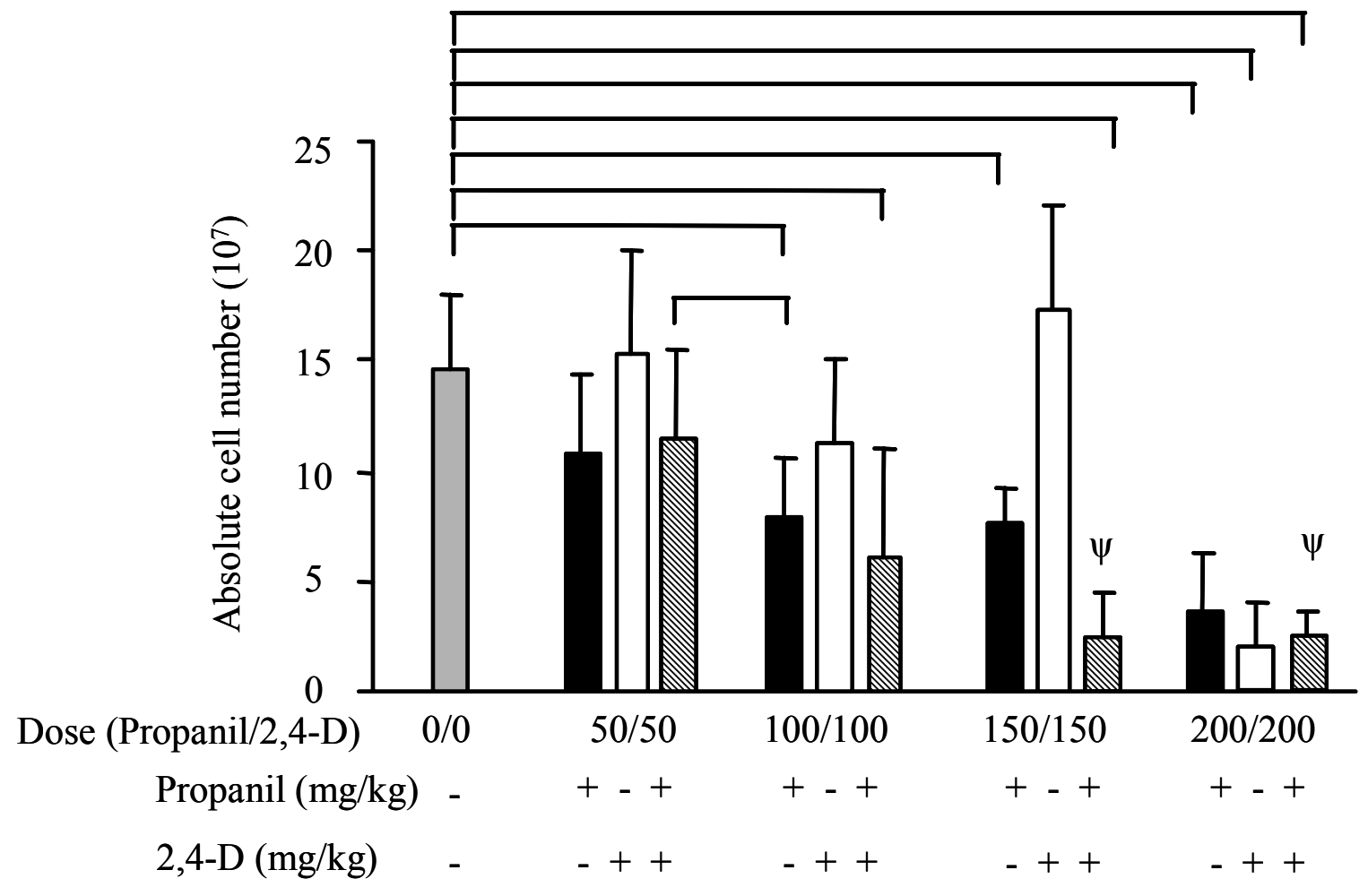


Figure 3. Absolute cell numbers of the $\mathrm{CD} 4^{+} \mathrm{CD} 8^{-}$thymocyte population. Mice were treated with vehicle (grey bars), propanil (black bars), 2,4-D (open bars), or a mixture containing both propanil and 2,4-D (striped bars) and thymuses removed at 2 days post treatment. Thymocytes were stained with anti-CD4 FITC and anti-CD8 PE and total cell numbers calculated as described in Materials and Methods. Bars represent the average of 12 mice \pm standard deviation. $\psi$ mixture interaction. $\square \mathrm{p} \leq 0.05$ vs. indicated group. 
Figure 3. Chapter 1. Absolute number of $\mathrm{CD}^{+} \mathrm{CD8}^{-}$thymocytes

Figure 3. $\mathrm{CD} 4^{+} \mathrm{CD} 8^{-}$

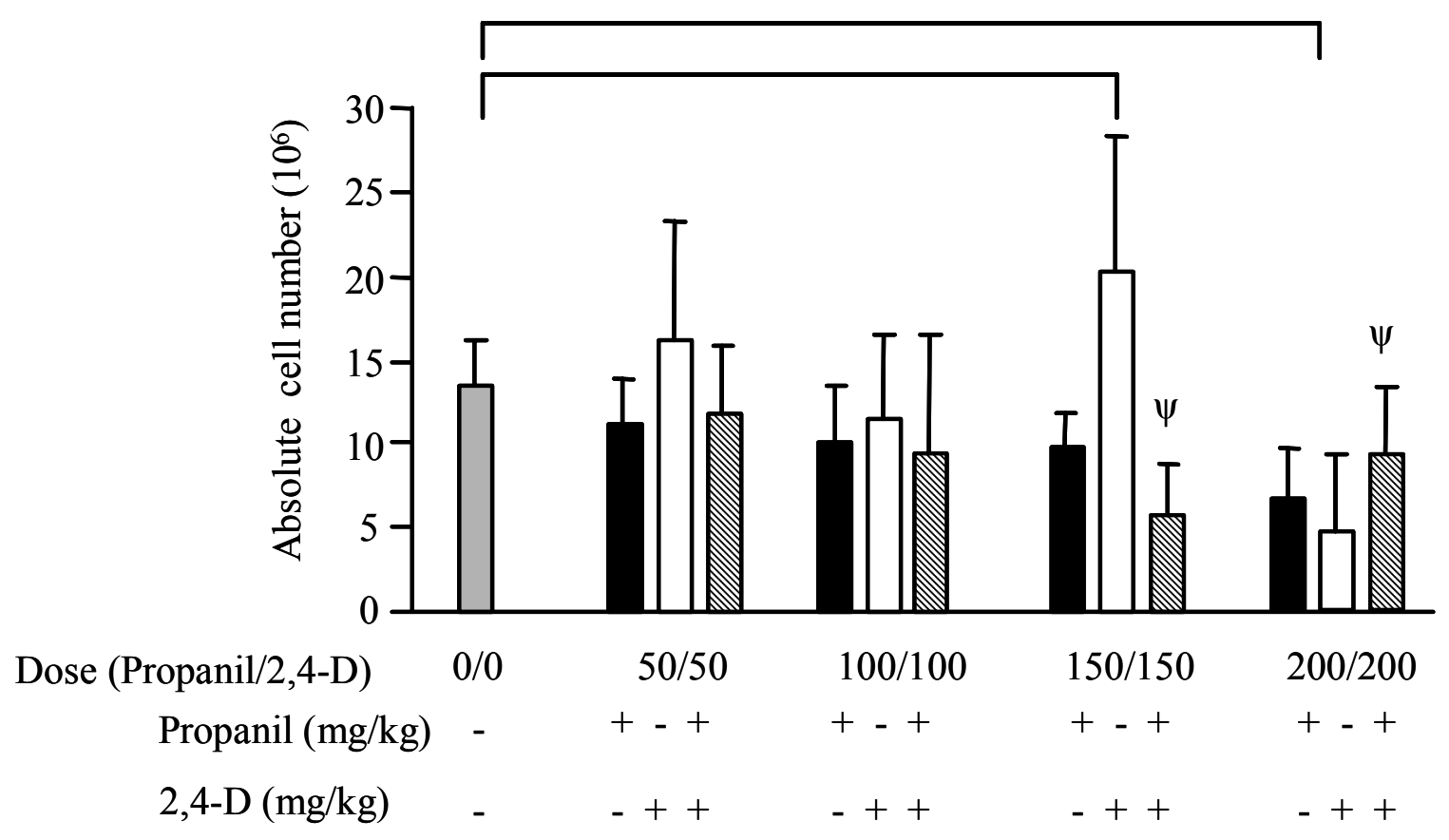


Figure 4. Absolute cell numbers of the $\mathrm{CD} 4^{-} \mathrm{CD} 8^{+}$thymocyte population. Mice were treated with vehicle (grey bars), propanil (black bars), 2,4-D (open bars), or a mixture containing both propanil and 2,4-D (striped bars) and thymuses removed at 2 days post treatment. Thymocytes were stained with anti-CD4 FITC and anti-CD8 PE and total cell numbers calculated as described in Materials and Methods. Bars represent the average of 12 mice \pm standard deviation. $\psi$ mixture interaction. $\square \mathrm{p} \leq 0.05$ vs. indicated group. 
Figure 4. Chapter 1. Absolute number of $\mathrm{CD4} \mathrm{CD8}^{+}$thymocytes

Figure 4. $\mathrm{CD} 4^{-} \mathrm{CD} 8^{+}$

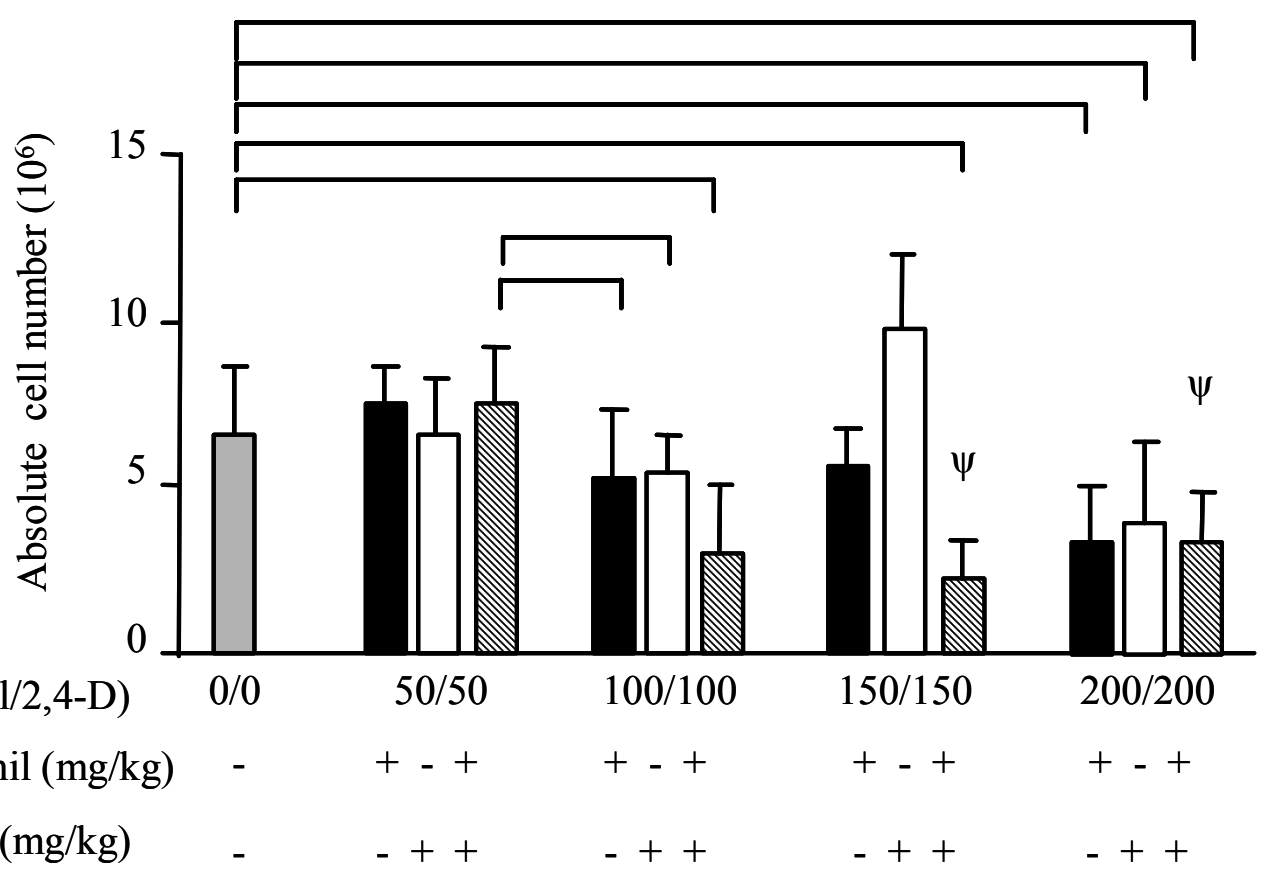


Figure 5. Absolute cell numbers of the $\mathrm{CD} 4{ }^{-} \mathrm{CD} 8^{-}$thymocyte population. Mice were treated with vehicle (grey bars), propanil (black bars), 2,4-D (open bars), or a mixture containing both propanil and 2,4-D (striped bars) and thymuses removed at 2 days post treatment. Thymocytes were stained with anti-CD4 FITC and anti-CD8 PE and total cell numbers calculated as described in Materials and Methods. Bars represent the average of 12 mice \pm standard deviation. $\psi$ mixture interaction. $\longrightarrow p \leq 0.05$ vs. indicated group. 
Figure 5. Chapter 1. Absolute number of $\mathrm{CD}^{-} \mathrm{CD8}^{-}$thymocytes

Figure 5. CD4-CD8-

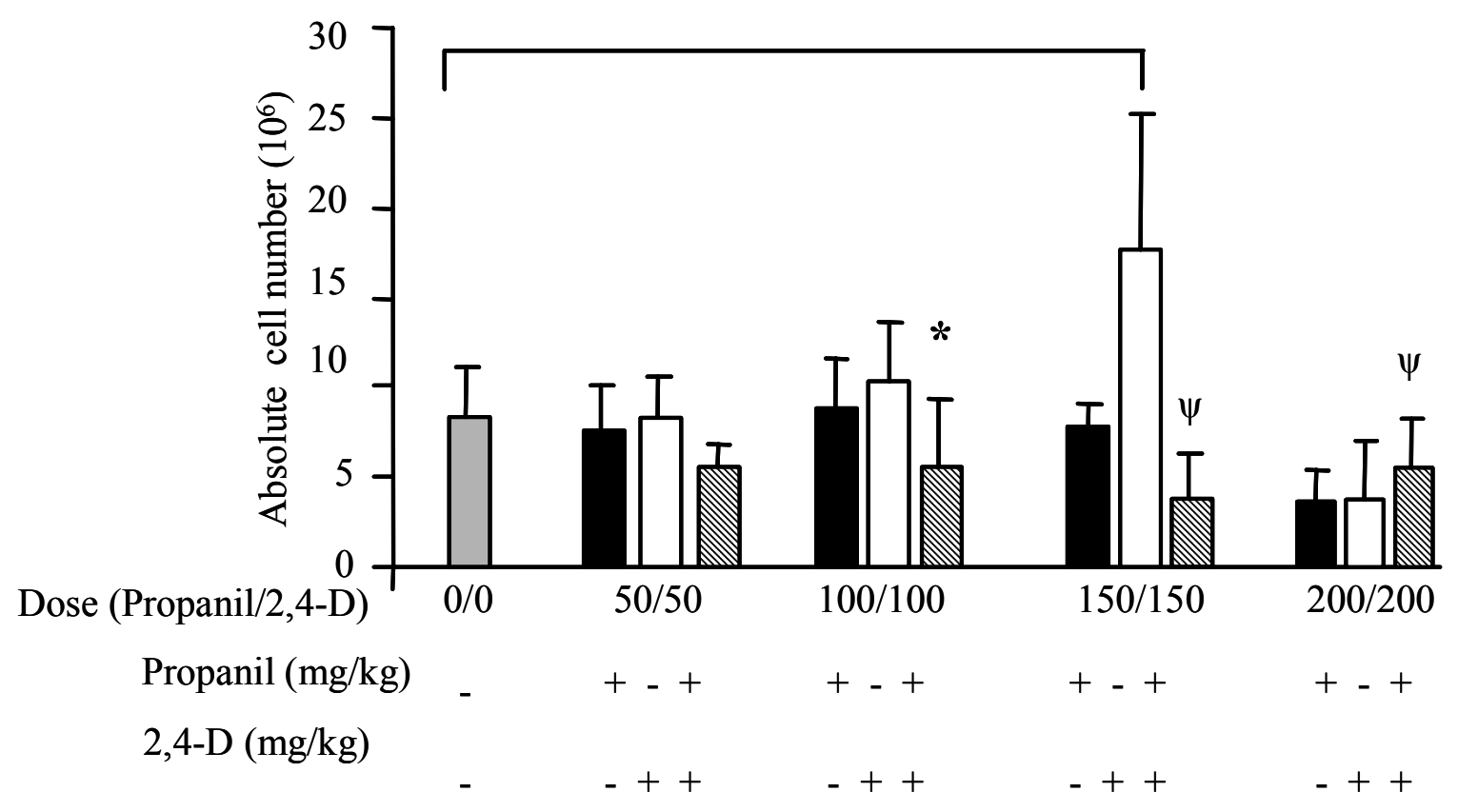


Figure 6. Absolute cell numbers in the thymus 7 days post treatment. Mice were treated with vehicle (grey bars), propanil (black bars), 2,4-D (open bars), or a mixture containing both propanil and 2,4-D (striped bars) and thymuses removed at 7 days post treatment. Thymocytes were stained with anti-CD4 FITC and anti-CD8 PE and total cell numbers calculated as described in Materials and Methods. A. $\mathrm{CD} 4^{+} \mathrm{CD} 8^{+}$thymocyte population. B. $\mathrm{CD}^{+} \mathrm{CD} 8^{-}$thymocyte population. C. $\mathrm{CD} 4^{-} \mathrm{CD} 8^{+}$thymocyte population. D. $\mathrm{CD} 4{ }^{-} \mathrm{CD} 8^{-}$ thymocyte population. Bars represent the average of 6 mice \pm standard deviation.

$\ulcorner\mathrm{p} \leq 0.05$ vs. indicated group. 
Figure 6. Chapter 1. Absolute number of thymocytes 7 days after herbicide exposure

A. $\mathrm{CD} 4^{+} \mathrm{CD} 8^{+}$

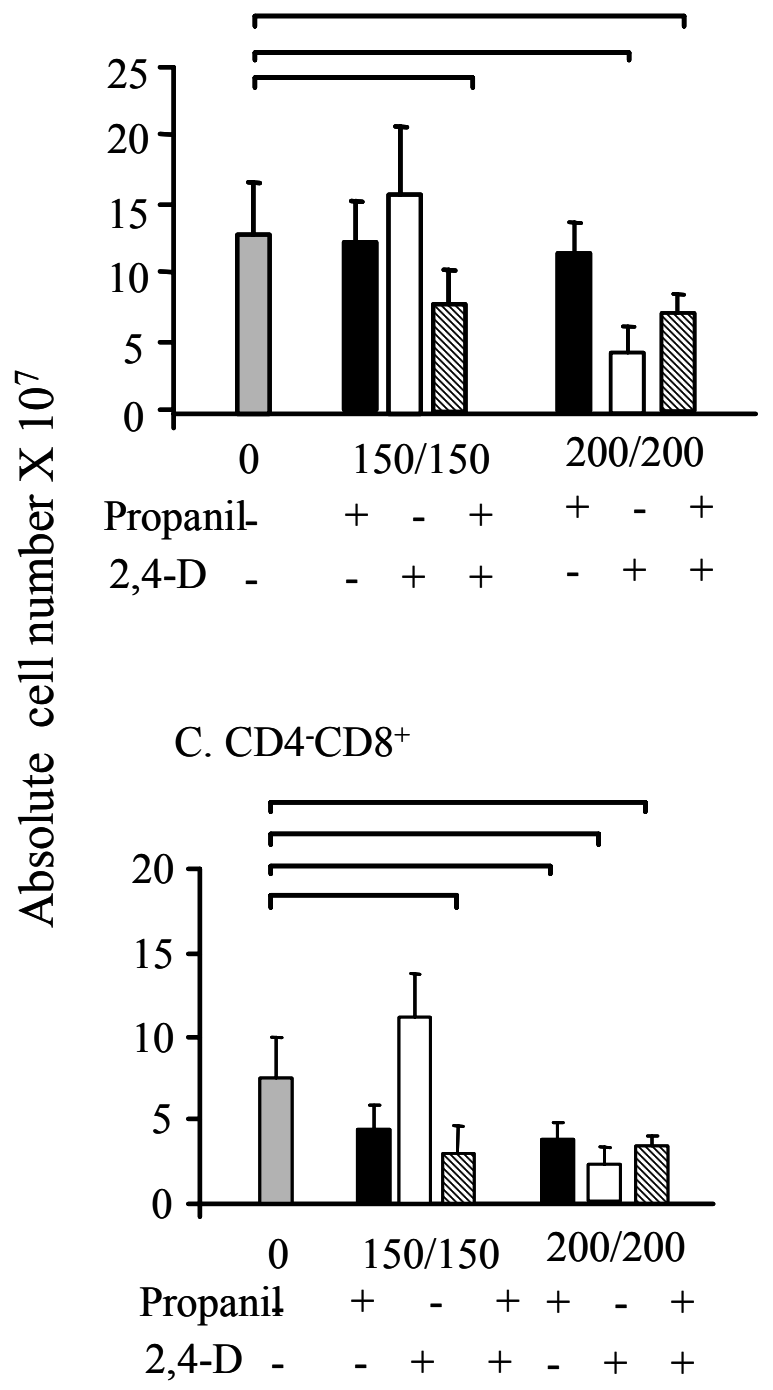

B. $\mathrm{CD}^{+} \mathrm{CD} 8^{-}$
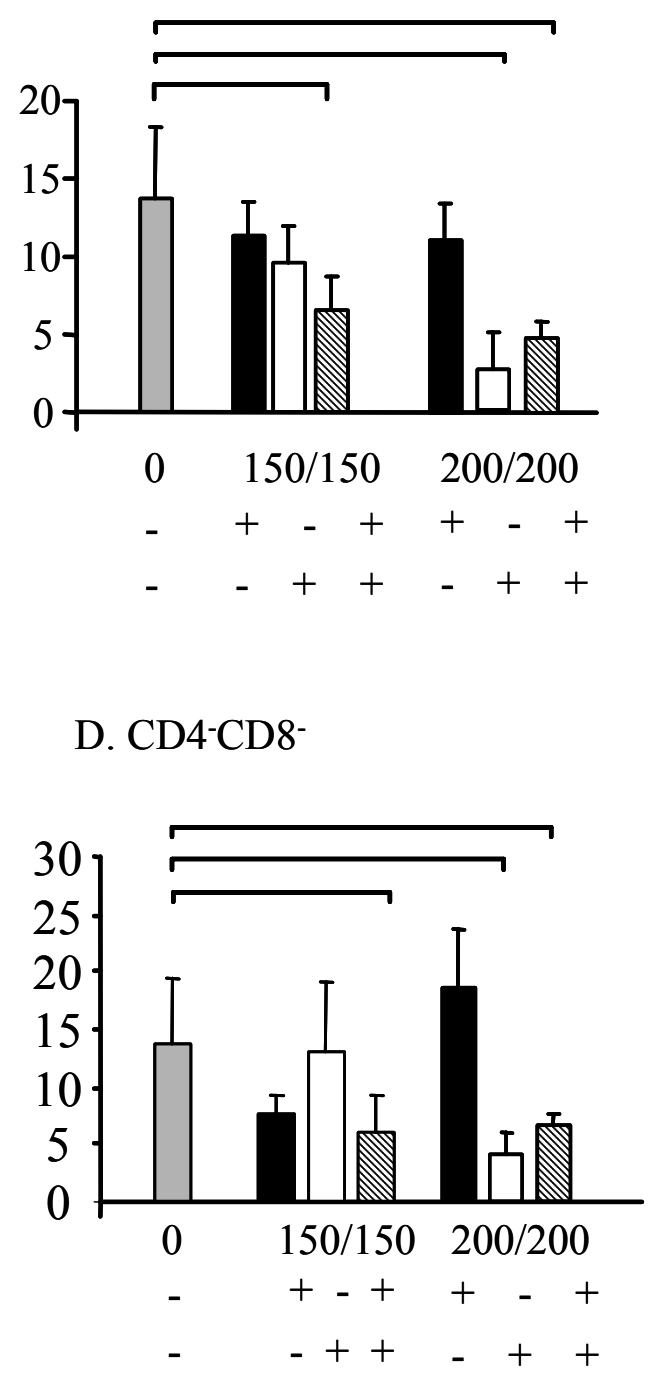

Dose $(\mathrm{mg} / \mathrm{kg})$ 
Figure 7. Serum corticosterone levels. Serum corticosterone levels were measured at 1 , 4, 8, 12 and $24 \mathrm{hrs}$ post treatment with vehicle (diamond), propanil (rectangle), 2,4-D (triangle) and mixture treatment (circle). A. $50 \mathrm{mg} / \mathrm{kg}$ single herbicide mixture and 50/50 mixture treatment. B. $100 \mathrm{mg} / \mathrm{kg}$ single herbicide treatment and 100/100 mixture treatment. C. $150 \mathrm{mg} / \mathrm{kg}$ single herbicide treatment and 150/150 mixture treatment. D. $200 \mathrm{mg} / \mathrm{kg}$ single herbicide treatment and 200/200 mixture treatment. Symbols represent the average of eight mice \pm the standard deviation. ${ }^{*} \mathrm{p} \leq 0.05$ vs. vehicle. 
Figure 7. Chapter 1. Sera glucocorticoid levels after herbicide exposure

A. $\mathbf{5 0 / 5 0}$

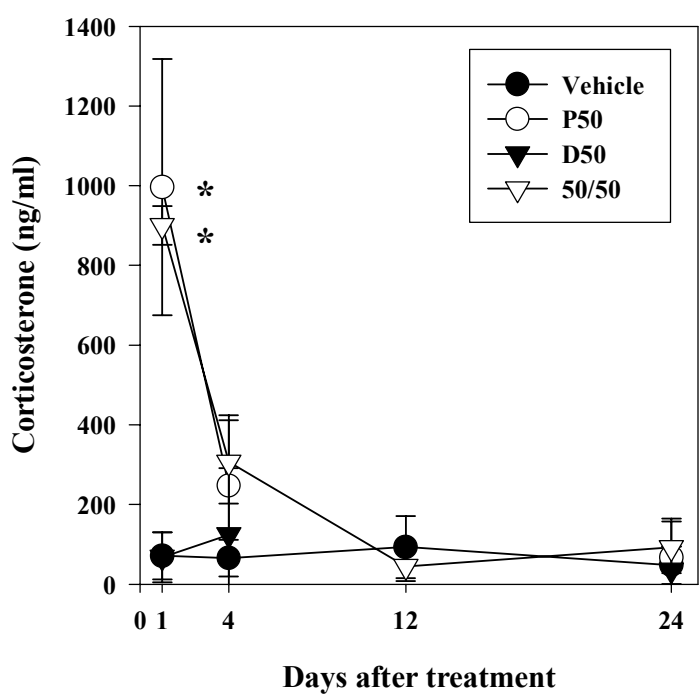

C. $150 / 150$

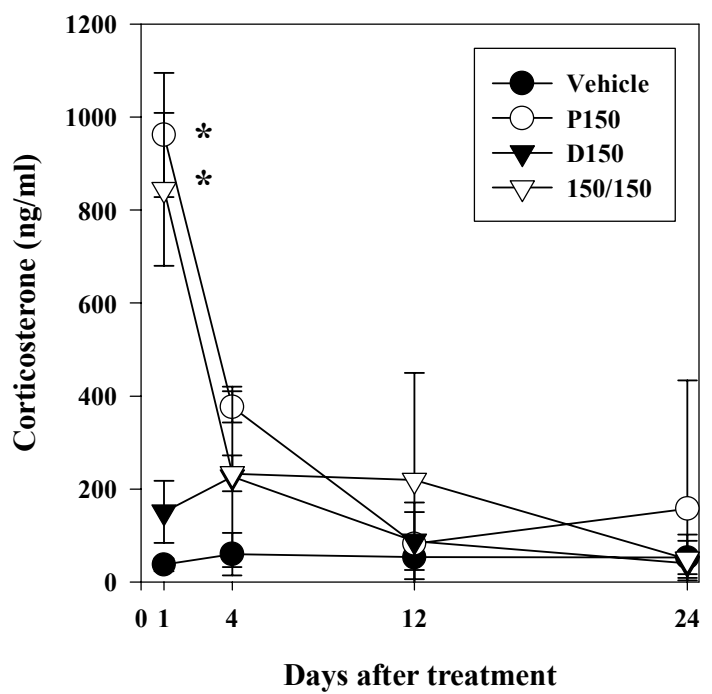

B. $100 / 100$

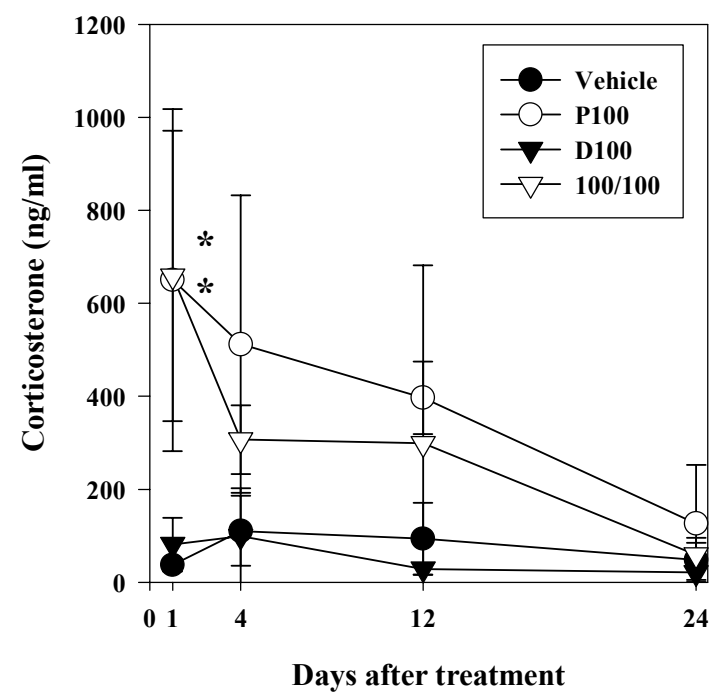

D. $200 / 200$

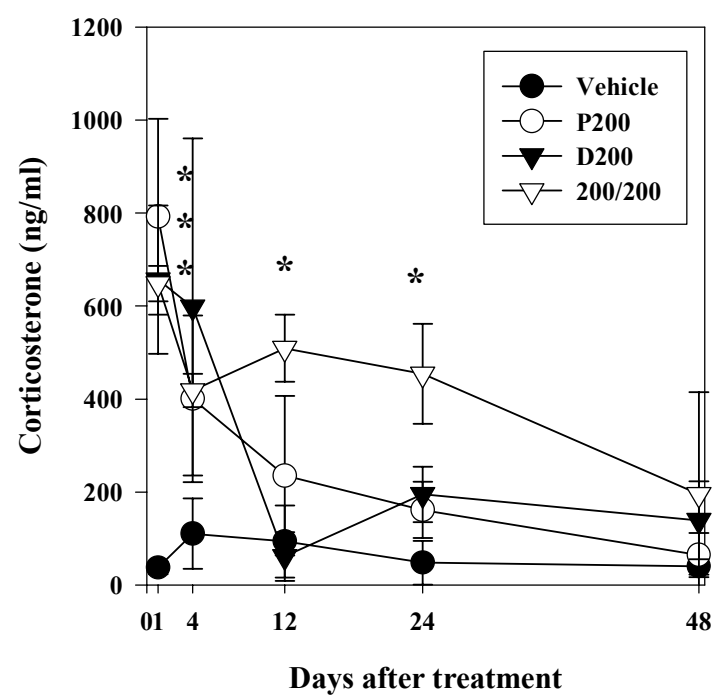


Figure $8 . \mathrm{CD}^{+} \mathrm{CD} 8^{+}$population changes with RU 486 pre-treatment. Mice were treated with RU 4862 hrs prior to and 12 hrs following herbicide mixture treatment. Treatment groups include: Vehicle (open bar), $100 \mathrm{mg} / \mathrm{kg} \mathrm{RU} 486$ (cross hatch), $75 \mathrm{mg} / \mathrm{kg}$ corticosterone (checkered pattern), and 150/50 mixture treatment (diagonal stripe) or RU $486+75 \mathrm{mg} / \mathrm{kg}$ corticosterone (diagonal hatch) and RU $486+150 / 150$ mixture (verticle stripe) treatment. Thymuses were removed at 2 days post treatment and stained with anti-CD4 and anti-CD8 and total cell numbers calculated as described in Materials and Methods. A. The percent of $\mathrm{CD} 4^{+} \mathrm{CD} 8^{+}$thymic T cells. B. $\mathrm{CD} 4^{+} \mathrm{CD} 8^{+}$absolute cell numbers. Numbers represent the average of nine mice \pm the standard deviation. $\mathrm{p} \leq 0.05$ vs. vehicle control. 
Figure 8. Chapter 1. Percentage and absolute number of $\mathrm{CD}^{+} \mathrm{CD8}^{+}$thymocytes after RU 486 pretreatment

A.

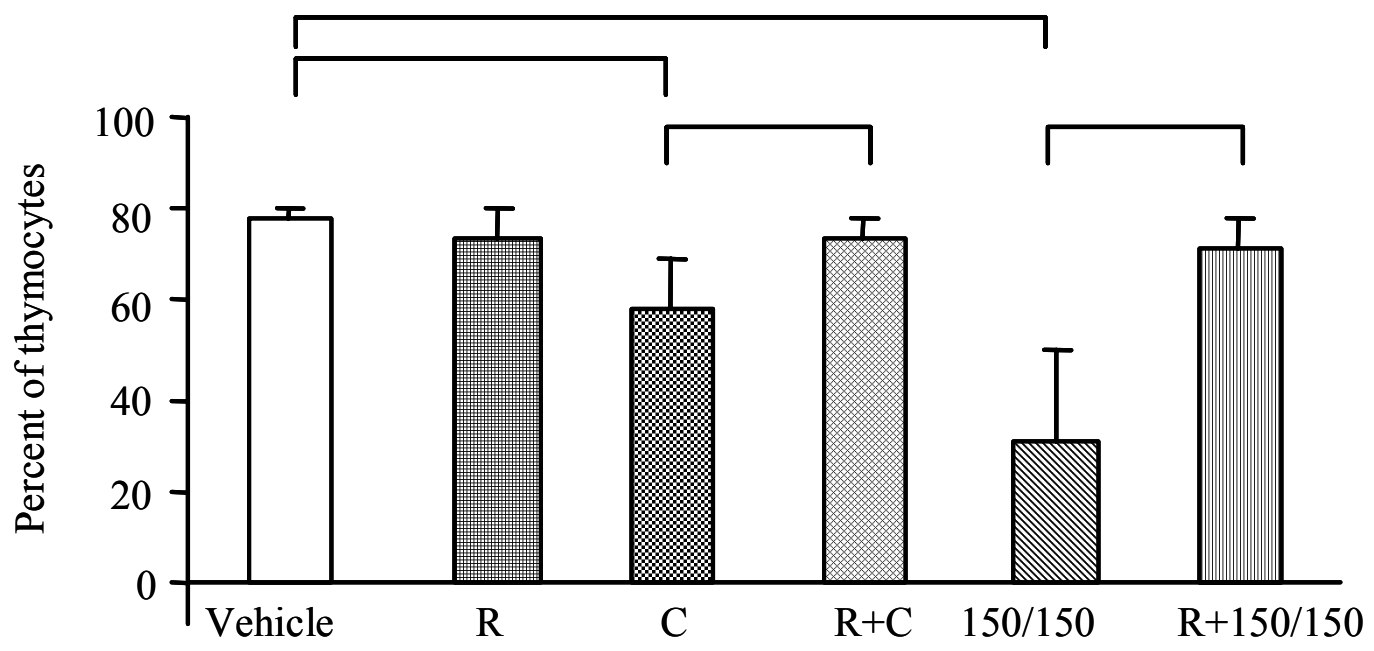

B.

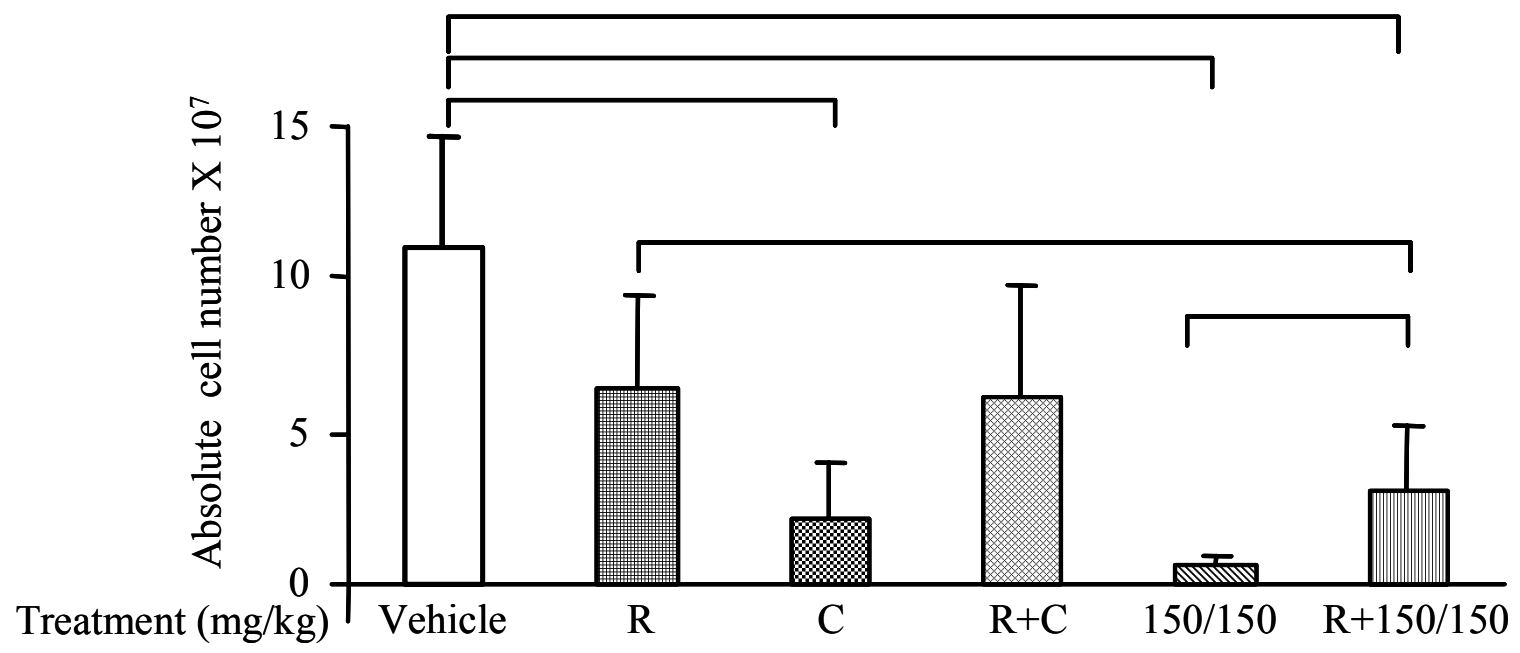


Chapter 2. Loss of Pre B and $\operatorname{lgM}^{+} B$ Cells in the Bone Marrow after Exposure to a Mixture of Herbicides 
Loss of Pre B and $\operatorname{IgM}^{+} \mathrm{B}$ Cells in the Bone Marrow after Exposure to a Mixture of Herbicides

Patricia de la Rosa, John, B. Barnett and Rosana Schafer

Department of Microbiology, Immunology and Cell Biology, School of Medicine, Robert

C. Byrd Health Sciences Center, West Virginia University, Morgantown, West Virginia, 26506-9177.

Running title: Loss of Pre B and $\operatorname{IgM}^{+}$B Cells in the Bone Marrow

Correspondence to:

Rosana Schafer, Ph.D.

Department of Microbiology, Immunology and Cell Biology

P.O. Box 9177

West Virginia University

Morgantown, WV 26506-9177

rschafer@wvu.edu 


\begin{abstract}
This study determined alterations that occur to developing bone marrow B cell populations after in vivo exposure to a binary mixture containing the herbicides 3,4 dichloropropionanilide (propanil) and 2,4-dichlorophenoxyacetic acid (2,4-D) in female C57Bl/6 mice. Propanil is sold commercially as a mixture with 2,4-D. In this study, herbicide mixtures containing propanil and 2,4-D were administered intraperitoneally (i.p.) in a 1:1 ratio ranging from 50 to $200 \mathrm{mg}$ of herbicide/kg body weight. Flow cytometric analysis was used to quantitate bone marrow B cell population changes after mixture and single herbicide treatment. Decreases associated with mixture exposure occurred more rapidly than single herbicide treatment, resulting in an increase in the duration of pre $\mathrm{B}$ and $\mathrm{IgM}^{+} \mathrm{B}$ cell loss after mixture treatment. Previous studies have demonstrated that corticosterone levels are increased by exposure to propanil and the herbicide mixture. Thus, the glucocorticoid hormone, corticosterone, was investigated as a possible mediator of cell loss in the bone marrow. Treatment with RU 486, a glucocorticoid receptor (GR) antagonist, did not abrogate bone marrow cell loss in mice exposed to propanil and/or 2,4-D. These results suggest that increases in corticosterone are not necessary for depletion of the bone marrow B cell population. This study indicates that pre $\mathrm{B}$ and $\operatorname{IgM}^{+} \mathrm{B}$ cell populations are decreased by exposure to propanil, 2,4-D or the mixture containing both propanil and 2,4-D. Exposure to the mixture increased the toxic effect of the individual herbicides on bone marrow pre $\mathrm{B}$ and $\operatorname{IgM}^{+} \mathrm{B}$ cell populations
\end{abstract}




\section{INTRODUCTION}

Bone marrow hematopoiesis can be altered by exposure to drugs and chemicals resulting in immune suppression (Blyler et al., 1994; Thurmond and Gasiewicz, 2000). The rapidly dividing stem cells of the bone marrow in particular are highly sensitive to chemical mixture exposure (Germolec et al.,1989). A series of murine studies demonstrated that residual, subclinical damage to hematopoietic bone marrow cells, associated with exposure to groundwater contaminated with a mixture of chemicals, resulted in decreased bone marrow recovery after subsequent radiation. (Hong et al.,1991; Hong et al.,1993). Meisner et al. (1992) found cytogenic damage to bone marrow cells was significantly increased after chronic oral exposure of mice to a mixture of alachlor and atrazine but was not increased by exposure to either herbicide alone (Meisner et al.,1992). These studies indicate that exposure to mixtures of chemicals may increase the toxic response of the cells of the bone marrow.

In the present study, we examined the effects of in vivo exposure to a mixture of chemicals on the developing B cell populations in the murine bone marrow. The mixture in this study is composed of two commonly used herbicides, propanil and 2,4-D. These herbicides are sold internationally as commercially prepared mixtures under the product names of NOX-D and Herbanil 368 (Farm Chemicals Handbook, 1998).

2,4-D is a chlorinated phenoxy herbicide that was one of the first herbicides registered in the United States. It is reported to be the most widely used herbicide worldwide (http://www.24d.org). 2,4-D is used in a wide range of applications that result in the exposure of both rural and metropolitan populations (Environmental Health 
Criteria 84, 1989; Munro et al., 1992). Studies investigating the immunotoxic effects of 2,4-D have been inconclusive. Acute oral 2,4-D exposure in mice was found to enhance primary antibody production against sheep red blood cells while acute topical application, in contrast, decreased B lymphocyte proliferation and suppressed the primary antibody response (Blakley, 1986; Blakley and Schiefer 1986). On the other hand, subacute topical and oral exposures did not affect antibody production (Blakley and Schiefer 1986; Blakley et al., 1998). In a mixture exposure model, subchronic oral exposure to Tordon 202C, a mixture of the herbicides picloram and 2,4-D, caused a dose-dependent decrease in the T-dependent primary humoral immune response; however, this study did not address the individual toxicity of the 2,4-D component of the mixture (Blakley, 1997). In another mixture study, however, when 2,4-D was added to a mixture containing parathion and toxaphene, liver enzymes were increased $68 \%$ even though $2,4-\mathrm{D}$ alone is not metabolized in the liver (Chaturvedi et al., 1991). Therefore, although toxicological studies have not definitively associated 2,4-D with immunological changes, 2,4-D may have a toxic effect, especially when combined in a mixture.

Propanil is an amide herbicide that is used in rice and wheat production in the United States. Exposure is toxic to developing immune cells, suppressing myeloid stem cell colony formation in the bone marrow and selectively decreasing the number of progenitor T cells in the thymus (Blyler et al., 1994; Zhao et al., 1995). In addition, propanil suppresses macrophage $(\mathrm{M} \varphi), \mathrm{T}$ cell and $\mathrm{B}$ cell function. $\mathrm{M} \varphi$ and $\mathrm{T}$ cell production of cytokines after lipopolysaccharide (LPS) or concanavalin A (Con A) stimulation, respectively, is reduced (Xie et al., 1997; Zhao et al., 1998). T-independent antibody responses are reduced by propanil exposure (Barnett and Gandy 1989). 
Bone marrow B lymphocyte development proceeds from the pro B to pre B to the $\operatorname{IgM}^{+} \mathrm{B}$ cell population. $\operatorname{IgM}^{+} \mathrm{B}$ cells are exported from the bone marrow to the periphery where they comprise part of the mature B cell population of the immune system. The results presented here demonstrate that in vivo exposure to the mixture of propanil and 2,4-D specifically decreases pre $\mathrm{B}$ and $\operatorname{IgM}^{+} \mathrm{B}$ cell populations at 2 days, and they remain decreased up to 7 days post treatment. Exposure to the mixture was more immunotoxic than exposure to the individual herbicides resulting in increased cell loss of pre $\mathrm{B}$ and $\operatorname{IgM}^{+} \mathrm{B}$ cell populations. These data demonstrate that exposure to a mixture of propanil and 2,4-D is toxic to the bone marrow. 


\section{METHODS}

Animals. C57BL/6 female mice, $6-8$ weeks of age, were purchased from Charles River Farms (Wilmington, DE). Mice were allowed to acclimate for one week after shipment and received food and water ad libitum.

Propanil and 2,4-D. Propanil (3',4' -dichloropropionanilide) was purchased from Chem Service (West Chester, PA) and has a purity of 99\%. Commercial-grade 2,4-D amine (39.2\% dimethylamine salt of 2,4-dichlorophenoxyacetic acid, Universal Cooperatives, Inc., Minneapolis, MN) was purchased from Southern States Cooperative (Morgantown, WV). The concentration of 2,4-D used for all experiments was calculated based on the amount of active 2,4-D.

Exposure of mice to herbicides. Mice were treated with either a single herbicide (propanil or 2,4-D) or a 1:1 mixture of both herbicides. Propanil was dissolved in peanut oil (Planters, Nabisco Inc.) and 2,4-D was dissolved in phosphate buffered saline (PBS) to the appropriate concentration. Mice were weighed prior to intraperitoneal (i.p) injection of the herbicides. Single herbicide doses of 50, 100, 150 or $200 \mathrm{mg} / \mathrm{kg}$ body weight were given using either propanil (P50, P100, P150, P200 respectively) or 2,4-D (D50, D100, D150, D200 respectively). Mixture treatments were given by two consecutive i.p. injections, in a one to one ratio of propanil to 2,4-D and were denoted 50/50, 100/100, 150/150 and 200/200. Control animals for mixture treatment also received two injections; one injection of the propanil vehicle (peanut oil) followed by one injection of the 2,4-D vehicle (PBS). Treatment doses were administered as in Table 1: 
Table 2. Chapter 2. Herbicide Treatment

\begin{tabular}{|c|c|c|}
\hline \multicolumn{2}{|c|}{ Single Herbicide Treatment } & Mixture Treatment \\
\hline Propanil (mg/kg) & $\mathbf{2 , 4 - D ~ ( m g / k g ) ~}$ & Propanil (mg/kg)/2,4-D (mg/kg) \\
\hline Peanut oil alone (0) & PBS alone $(0)$ & Peanut oil/PBS $(0 / 0)$ \\
\hline 50 & 50 & $50 / 50$ \\
\hline 100 & 100 & $100 / 100$ \\
\hline 150 & 150 & $150 / 150$ \\
\hline 200 & 200 & $200 / 200$ \\
\hline
\end{tabular}

Cell isolation. Mice were euthanized by cervical dislocation and a left femur and tibia were removed from each mouse at one, two, seven, or fourteen days after exposure to the herbicides. Single cell suspensions were prepared by repeated flushing of the bones with RP-10 media containing RPMI-1640 (BioWhitaker, Walkersville, MD), with $10 \%$ heat inactivated fetal bovine serum (FBS, Hyclone Laboratories, Inc, Logan, UT), 10 mM HEPES (Sigma, St. Louis, MO), 1 mM L-glutamine (Gibco, Rockville, MD), 5 x $10^{-5}$ 2-mercaptoethanol (Sigma), $100 \mathrm{U} / \mathrm{ml}$ penicillin (Gibco), and $100 \mu \mathrm{g} / \mathrm{ml}$ streptomycin (Gibco). Red blood cells were lysed with Tris-buffered ammonium chloride. Single cells were washed, counted and resuspended in media (staining media) containing PBS supplemented with $1 \%$ FBS and $0.04 \%$ sodium azide (Sigma).

Flow cytometric analysis of bone marrow cell populations. Three-color flow cytometric analysis was performed to quantitate the B cell subpopulations. Isolated cells were stained with goat anti-mouse IgM-Biotin (Southern Biotechnology Associates, Inc., Birmingham, AL), rat anti-mouse CD45R/B220-PE (clone RA3-6B2) (BD PharMingen, San Diego, CA) and rat anti-mouse CD43-FITC (clone S7) (BD PharMingen). All steps were performed in staining media. Briefly, $1 \times 10^{6}$ cells were stained with goat antimouse IgM-Biotin and rat anti-mouse CD45R/B220-PE in a total volume of $25 \mu$ of 
antibodies at the appropriate concentrations for $25 \mathrm{~min}$. on ice in the dark. Cells were washed twice and stained with rat anti-mouse CD43-FITC and Streptavidin-Cy-Chrome (BD PharMingen) and incubated for $25 \mathrm{~min}$. on ice in the dark. After incubation, cells were washed twice and fixed in $0.04 \%$ paraformaldehyde (Fisher Scientific, Pittsburgh, PA). For each sample, 10,000 cells were collected for analysis on a Becton-Dickinson FACScan (Becton Dickinson Immunocytometry Systems, Mansfield, MA). For analysis, a lymphoid gate was drawn using forward vs. side scatter and a B cell gate was drawn around $\mathrm{B} 220^{+}$expressing cells. Bone marrow $\mathrm{B}$ cells were separated into three populations: pro B $\left(\mathrm{B} 220^{+} \mathrm{CD} 43^{+} \mathrm{IgM}^{-}\right)$; pre B $\left(\mathrm{B} 220^{+} \mathrm{CD}^{-} 3^{-} \mathrm{IgM}^{\mathrm{lo}}\right)$ and $\mathrm{IgM}^{+} \mathrm{B}$ $\left(\mathrm{B} 220^{+} \mathrm{CD}^{-} 3^{-} \mathrm{IgM}^{\mathrm{hi}}\right)$ cell populations. Analysis was performed using WinMDI software (Joseph Trotter, Scripps Institute, San Diego, CA). Population percentages, obtained from flow cytometric analysis, were used to calculate the absolute cell number by multiplying the percentage of cells in a population by the total number of cells harvested per organ.

$R U 486$ treatment. Mice were given $100 \mathrm{mg}$ RU 486 per kg body weight (mifepristone, Sigma-Aldrich) by gavage $2 \mathrm{hrs}$ prior to, and $12 \mathrm{hrs}$ after, administration of 150/150 (i.p.) or $75 \mathrm{mg} / \mathrm{kg}$ corticosterone (gavage) (Sigma-Aldrich). Bone marrow was harvested and stained $48 \mathrm{hrs}$ after corticosterone or herbicide exposure. The 75 $\mathrm{mg} / \mathrm{kg}$ oral dose was chosen since it has been shown to functionally mimic the action of endogenous glucocorticoid increases (Burns et al., 1994).

Statistics. One way analysis of variance (ANOVA) was done on population percentages and the log of total cell numbers using a Dunnett's test to compare B cell changes in treated bone marrow to vehicle control with a significance level of $\mathrm{p} \leq 0.05$. 
A Tukey HSD analysis was used to compare the absolute cell number of the 50/50 mixture to $100 \mathrm{mg} / \mathrm{kg}$ single herbicide treatment or the $100 / 100$ mixture to $200 \mathrm{mg} / \mathrm{kg}$ single herbicide treatment. In addition, we used a partial factorial design to examine the mixture interaction. The factorial design is specific to the determination of the combined effects of two types of treatments (Schoen, 1996). This model assumes that the response to the mixture will be equal to the addition of the responses given by the individual mixture components. Responses that are greater or lesser than what is predicted by concentration addition are called a mixture interaction.

Interactions between mixtures and the individual components comprising the mixture were determined by ANOVA using the absolute cell number for each treatment group. A mixture interaction defines a response that is above or below the line of additivity. Statistical analysis was performed using JMP software, SAS Institute Inc. (Cary, NC). Cell population analysis after single herbicide or mixture treatment was done using 8 animals in each treatment group. Glucocorticoid experiments were repeated three times using 3 animals per group. 


\section{RESULTS}

\section{Decreases in the pre $B$ population in the bone marrow following exposure to propanil and 2,4-D.}

Herbicide treatment did not affect the body weight of the mice. The effects of herbicide treatment on the B cell populations in the bone marrow were assessed by flow cytometric analysis at one, two, seven, and fourteen days post-exposure. The pro B cell population was not affected by any of the herbicide treatments at any timepoint (data not shown). Two days after exposure to either propanil or 2,4-D, no decreases occurred in the pre B cell population. In contrast, at two days after treatment with the mixture of propanil and 2,4-D, at all doses examined (50/50, 100/100, 150/150, 200/200), the absolute pre B cell number was significantly decreased in comparison to vehicle controls. (Figure 9-D, denoted by asterisk). For clarity, only the PBS + peanut oil control is shown. All controls had similar responses. In addition, there was a statistically significant mixture interaction $(\mathrm{p} \leq 0.05)$ that resulted in greater than additive decreases at the 100/100 dose (denoted by $\psi$ in Figure 9B). This decrease was not a typical interaction in that 2,4-D exposure apparently increased the number of pre B cells at 2 days after treatment.

The pre B cell population remained significantly decreased out to seven days after exposure in all of the mixture-treated groups (Figure 9A-D). In addition, at 7 days after exposure, decreases in pre B cell numbers occurred after exposure to P50, P150 and P200 and D200 (Figure 9A, 9C and 9D).

The decreases caused by exposure to the 50/50-200/200 mixture at 7 days after treatment were similar to the decreases caused by single herbicide P150, P200 and D200 
treatment ( Figure 9A-D). At the 150/150 dose, the factorial analysis, results in a lessthan-additive mixture interaction ( $\mathrm{p} \leq 0.0055$, Figure $9 \mathrm{C}$, denoted by black bar).

To determine if the effects of the mixture on the pre B cell population were the result of exposure to the total herbicide concentration of the mixture, rather than due to effects that are specific to the individual herbicides. We compared the responses 2 days after treatment to either P100 or D100 to a mixture containing an equivalent concentration of herbicide (50/50). The decreases in pre B cell numbers after exposure to the 50/50 mixture (Figure 9A, black bar) were significantly greater than the cell number decreases that occurred in groups receiving P100 (Figure 9B, open bar) or D100 (Figure $9 \mathrm{~B}$, hatched bar), suggesting that, at 2 days after treatment, the bone marrow is particularly susceptible to the effects of mixture exposure. In contrast, the response 2 days after treatment with the 100/100 mixture (Figure 9B, black bar) was similar to the response to the P200 (Figure 9D, open bar) or D200 treatments (Figure 9D,hatched bar), suggesting that the mixture and the single herbicide treatment are equally toxic to the bone marrow at this exposure concentration.

Lower mixture doses of 25/25 and 10/10 did not affect the pre B cell population at any time point (data not shown). Fourteen days after exposure, pre B cell numbers had recovered to control levels in all treatment groups (data not shown).

\section{Decreases in the IgM+ B cell population in the bone marrow following exposure to propanil and 2,4-D.}

The $\operatorname{IgM}^{+} \mathrm{B}$ cell population was also affected by herbicide exposure. Mixture treatment at all doses significantly decreased the $\operatorname{IgM}^{+} \mathrm{B}$ cell population at two and seven days after exposure (50/50, 100/100, 150/150, 200/200, Figure 10A-D). IgM $^{+}$B cell 
decreases also occurred at 7 days occurred after exposure to the single P150 and D200 (Figure 10C and D).

There was a significant mixture interaction 2 days after 100/100 exposure resulting in a greater-than-additive decrease in the $\operatorname{IgM}^{+} \mathrm{B}$ cell response $(\mathrm{p} \leq 0.05$, denoted by a black bar in Figure 10B). Mixture interactions occurred in the $\operatorname{IgM}^{+} \mathrm{B}$ cell population 7 days after 150/150 and 200/200 exposure, indicating a less-than-additive mixture response $\mathrm{p} \leq 0.00013$ and $\mathrm{p} \leq 0.0040$ respectively (Figures 10C and D, denoted by $\psi$ ). Therefore, 7 days after treatment, the response of the $\operatorname{IgM}^{+} \mathrm{B}$ cell population to the 150/150 and 200/200 mixture treatment was less-than the addition of the responses given by the individual components of the mixture.

Lower mixture doses of 25/25 and 10/10 did not affect the number of $\operatorname{IgM}^{+} \mathrm{B}$ cells at any time point (data not shown). By fourteen days after exposure, the $\operatorname{IgM}^{+} \mathrm{B}$ cell populations had returned to control levels in all groups (data not shown).

A Tukey HSD ANOVA was done to compare single herbicide treatment doses with mixtures containing the same total herbicide concentration. At 2 and 7 days after treatment, $\operatorname{IgM}^{+} \mathrm{B}$ cells from the animals receiving the 50/50 mixture treatment (Figure $10 \mathrm{~A}$, black bar) were significantly decreased in comparison to mice receiving a single herbicide treatment of P100 (Figure 10B, open bar) or D100 (Figure 10B, hatched bar). The 100/100 mixture response (Figure 10B, black bar), however, was equivalent to either P200 or D200 treatments (Figure 10D, black bar and hatched bar, respectively). These results suggest that the mixture response at the 50/50 mixture treatment level was not due solely to the total herbicide concentration but was a combined response to the treatment with the mixture of propanil and 2,4-D. In contrast, the $\operatorname{IgM}^{+} \mathrm{B}$ cell response after 
100/100 mixture treatment was similar to single herbicide treatment with P200 and D200, suggesting that maximal decreases occur with all three treatments.

\section{Analysis of the effects of glucocorticoid stress hormones on bone marrow $B$ cell populations after herbicide exposure.}

Previous reports in the literature have demonstrated that in vitro exposure of bone marrow cultures to physiologically significant concentrations of glucocorticoid hormone analogs can decrease pre $\mathrm{B}$ and $\operatorname{IgM}^{+} \mathrm{B}$ cell populations (Andréau. et al., 1998). In addition, glucocorticoids have been demonstrated to be induced by in vivo herbicide treatment and to be partially responsible for thymic atrophy and loss of thymocyte populations in the thymus after propanil exposure (Cuff, et al., 1996). Therefore, we wanted to determine if glucocorticoids were a mechanism for the loss of B cell populations in the bone marrow after exposure to propanil and 2,4-D. RU 486, a type II glucocorticoid receptor antagonist that blocks the effects of glucocorticoids in vivo (Weiss et al., 1996; Freier et al., 1994), was used to investigate the possible contribution that corticosterone may have in the loss of B cell populations in the bone marrow. In contrast to what has been reported for in vitro exposure to glucocorticoids, treatment with corticosterone in vivo did not decrease the pro $\mathrm{B}$, pre $\mathrm{B}$, or $\operatorname{IgM}^{+} \mathrm{B}$ cell populations in the bone marrow as compared to vehicle control (Figure 11A-C). In fact, treatment with 75 $\mathrm{mg} / \mathrm{kg}$ of corticosterone significantly increased the number of $\operatorname{IgM}^{+} \mathrm{B}$ cells (Figure 11C). Treatment of mice with RU 486 alone did not change the B cell populations in the bone marrow (Figure 11A-C). Pre-treatment of mice with RU 486, prior to corticosterone treatment, also did not change the absolute cell numbers in the pro B, pre $\mathrm{B}$, or $\operatorname{IgM}^{+} \mathrm{B}$ cell populations (Figure 11A-C respectively). As demonstrated above, treatment of mice with the $150 / 150$ mixture did not affect the pro B cells and decreased the pre B and $\operatorname{IgM}^{+}$ 
B cell populations (Figure 11A, 11B and 11C). Under these experimental conditions, pre-treatment with RU 486, however, did not prevent significant decreases associated with chemical mixture exposure in the pre $\mathrm{B}$ and $\operatorname{IgM}^{+} \mathrm{B}$ cell population (Figure $11 \mathrm{~B}$ and 11C). Overall, these results suggest that corticosterone does not affect the B cell populations in the bone marrow and is not the mechanism responsible for the loss of bone marrow populations after herbicide exposure. 


\section{DISCUSSION}

The mixture of propanil and 2,4-D selectively decreased both pre-B and $\operatorname{IgM}^{+} \mathrm{B}$ cell populations over the range of doses tested. Significant decreases from vehicle control occurred in mixture-treated groups by two days post treatment and persisted until 7 days after the initial exposure. Decreases associated with mixture exposure occurred more rapidly than single herbicide treatment, resulting in an increase in the duration of pre-B and $\mathrm{IgM}^{+} \mathrm{B}$ cell loss after mixture treatment. Cell number losses after mixture treatment were always equal to or greater than the losses that occurred after single herbicide treatment. Two days after treatment, using a factorial analysis, single herbicide treatment did not affect pre-B or $\operatorname{IgM}^{+} \mathrm{B}$ cells; however, the mixture treatment significantly decreased both populations. Therefore, exposure to the mixture increases the toxic effect of these herbicides on the bone marrow.

Propanil has been previously demonstrated to cause thymic atrophy that is primarily due to a selective depletion of the $\mathrm{CD} 4^{+} \mathrm{CD} 8^{+}$thymocyte population and was correlated with an increase in glucocorticoid hormones (Cuff et al., 1996). Exposure of adrenalectomized mice to propanil did not result in thymic atrophy, further supporting a role for glucocorticoids in thymic loss (Cuff et al., 1996). We have determined that exposure to the mixture containing propanil and 2,4-D (50/50-200/200), propanil alone (P50-P200) or 2,4-D alone (D200) results in equivalent increases in glucocorticoid hormones (ranging between 600-1000 $\mathrm{ng} / \mathrm{ml}$ ) at $1 \mathrm{hr}$ after exposure (manuscript in preparation). The levels returned to normal by 24 to $48 \mathrm{hrs}$ after treatment. The pre-B cell stage may be compared to the $\mathrm{CD} 4^{+} \mathrm{CD} 8^{+}$thymocyte population in that both 
lymphocyte precursor populations undergo clonal expansion and negative selection. However, treatment of mice with 75 and $100 \mathrm{mg} / \mathrm{kg}$ of corticosterone did not affect pro-B or pre-B cell numbers and increased the $\operatorname{IgM}^{+} \mathrm{B}$ cell population (Figure 11 and data not shown). In addition, pre-treatment of mice with RU 486 before 150/150 mixture exposure did not prevent bone marrow B cell populations from cellular loss after chemical mixture exposure. In vitro studies on bone marrow cultures have demonstrated that glucocorticoid hormone analogs can decrease pre- $\mathrm{B}$ and $\operatorname{IgM}^{+} \mathrm{B}$ cell populations (Andréau et al., 1998). However, our results do not support a role for glucocorticoid hormones in the in vivo loss of B cell populations of the bone marrow after chemical mixture exposure. Glucocorticoid hormones, however, interact with other hormones and neurological mediators. It is possible that glucocorticoid hormones, in conjunction with other neuroendocrine mediators, act in the cell loss in the bone marrow. If 2,4-D induces additional hormones, the combination of 2,4-D and propanil, a compound known to increase glucocorticoid hormones, could result in a mixture response that is greater than the response to the individual herbicides.

There are several other potential mechanisms for the loss of bone marrow cell populations after exposure to herbicides. A mechanism for the decrease in pre-B cell numbers two days after mixture exposure may be a selective decrease in the proliferation that occurs as the cell progress developmentally from the pro-B to the pre-B stage. A defect in proliferation at this stage in development would result in a developmental blockade characterized by normal numbers of pro-B cells and decreased pre-B cell numbers similar to our results. 
Data collected one day after mixture exposure suggest that decreases in the $\operatorname{IgM}^{+}$ B cell population may be a downstream effect caused by cell losses in the pre-B cell population. Mice exposed to $150 / 150$ and 200/200 mixture treatment consistently demonstrated initial, although not significant, in pre-B cells decreases from vehicle control within $24 \mathrm{hrs}$ of exposure (data not shown). These decreases occur one day prior to $\operatorname{IgM}^{+} \mathrm{B}$ cell decreases; a time interval that is consistent with the kinetics of pre-B maturation in the bone marrow (Osmond and Nossal, 1974).

Development, survival, and proliferation of B cells at all stages are critically dependent on signaling through the B cell receptor complex (BCR). Signaling through the BCR is complex and induces the activation of several signal transduction pathways that effect B cell maturation (reviewed in Niiro and Clark, 2002). Signaling through the $\mathrm{BCR}$ promotes pre-B cell survival through at least three separate signaling pathways including phosphatidylinositol 3-kinase (PI3-kinase), RAS-RAF-ERK and NF-KB (Niiro et al., 2002; Suzuki et al., 1999). We have demonstrated an effect on several of these pathways in non-B cells leading us to speculate that propanil, 2,4-D, or the mixture, may also affect signaling pathways in B cells. First, propanil decreases nuclear levels of NF$\kappa \mathrm{B}$ in macrophages (Frost et al, 2001) and in a human T cell line, Jurkat (Brundage et al., unpublished data). Additionally, propanil abrogates LPS-induced $\mathrm{Ca}^{2+}$ release, a signal required for NF- $\mathrm{kB}$ activation, in macrophages (Xie et al., 1997). The effect of 2,4-D on LPS-induced $\mathrm{Ca}^{2+}$ release or NF- $\mathrm{kB}$ is not yet known. Thus, there is evidence to support the hypothesis that these herbicides could alter B cell maturation via the NF- $\mathrm{KB}$ activation pathways. Second, we have demonstrated that exposure of two human prostate cancer cell lines to propanil inhibited the expression of hypoxia-inducible factor $1 \alpha$ (HIF- 
$1 \alpha)$ (Jiang et al., 2003, submitted). HIF-1 is a transcription factor that requires PI3kinase and AKT for its synthesis (Laughner et al., 2001), therefore, indirectly suggesting that propanil may inhibit PI3-kinase and AKT, two critical signaling components in B cell survival and proliferation. Thus, there is evidence that propanil can affect at least two critical signaling pathways involved in B cell maturation.

DNA microarray analysis on Jurkat cells has demonstrated at least two additional effects that, if they affect B cells in a similar manner, could lead to reduced survival and proliferation. First, there is a decrease in the expression of cyclin D message levels in propanil-treated cells (Brundage et al., 2003). Cyclin D, a molecule phosphorylated by $\mathrm{AKT}$, is required for cell cycle progression. Second, there is a decrease in the mRNA expression levels of pre-B cell colony-enhancing factor (Brundage et al., 2003). Pre-B cell colony enhancing factor is a cytokine-like molecule that acts in conjunction with stem cell factor and IL-7 in the development of human pre-B cells (Samal et al., 1994). Therefore, evidence from non-B cells would support the hypothesis that at least one of these herbicides, propanil, is capable of affecting the transcription of critical growth factors required for B cell maturation.

The developing cells of the bone marrow can be particularly vulnerable to exposure to mixtures of chemicals. Germolec et al. (1989) and Hong et al. (1991; 1993) reported that in vivo exposure of mice to a mixture of 25 groundwater contaminants was selectively toxic to the rapidly dividing cells of the immune system, including bone marrow stem cell populations. Further studies demonstrated that exposure to a mixture of 25 groundwater contaminants did not result in detectable changes using standard hematological parameters (Hong et al., 1993). However, there were functional changes 
as demonstrated by a dose dependent suppression of the number of colony forming unitsgranulocyte macrophage (CFU-GM) progenitor cells (Hong et al., 1993). Furthermore, it was determined that recovery of bone marrow progenitor cells was delayed after exposure to the mixture and subsequent irradiation (Hong et al., 1991).

In our study, we have demonstrated that exposure to a mixture of propanil and 2,4-D caused a greater loss of bone marrow B cells when compared to the losses that occur after single herbicide exposure. This study underscores the importance of studying the effects of chemical mixtures and chemical mixture interactions on the developing immune system. More research is necessary to determine the exact mechanism(s) of cell loss and recovery in the bone marrow after mixture exposure. However, the studies from our laboratory suggest that propanil, and the mixture containing propanil and 2,4-D, may act to decrease survival, proliferation, and maturation of developing B cell populations by effects on signal transduction pathways, cytokine levels, and/or neuroendocrine mediators. 


\section{ACKNOWLEDGEMENTS}

We thank Gerald R. Hobbs, Ph.D, Department of Statistics and Community Medicine,

Robert C. Byrd Health Sciences Center, West Virginia University, for assistance with statistical analysis and Kathleen Brundage Ph.D, (Department of Microbiology,

Immunology and Cell Biology, WVU) for helpful discussion.

This work was supported by the National Institutes of Health grant ES07460 and ESO10953. 
Figure 9. Bone marrow $\mathrm{B} 220^{+} \mathrm{CD} 43^{-} \operatorname{IgM}^{\text {lo }}$ pre $\mathrm{B}$ cell population changes after exposure to propanil, 2,4-D and the herbicide mixture. Flow cytometric analysis of pre B cell numbers at 1, 2 and 7 days post treatment. Bone marrow B cells were separated as described in Materials and Methods. A. $50 \mathrm{mg} / \mathrm{kg}$ body wgt or 50/50 mixture treatment B. $100 \mathrm{mg} / \mathrm{kg}$ body wgt or $100 / 100$ mixture treatment. C. $150 \mathrm{mg} / \mathrm{kg}$ body wgt or $150 / 150$ mixture treatment. D. $200 \mathrm{mg} / \mathrm{kg}$ body wgt or $200 / 200$ mixture treatment. Vehicle (grey bar), 2,4-D (hatched bar), propanil (open bar) and mixture treatment (black bar). $\mathrm{n}=8$ mice/group. Error bars represent the standard deviation from the mean. ${ }^{*} \mathrm{p}$ $\leq 0.05$ vs. vehicle control. $\psi \mathrm{p} \leq 0.05$ mixture interaction. 
Figure 9. Chapter 2. Absolute number of pre B cells after herbicide treatment Vehicle $\square \quad$ 2,4-D $\square \square$ Propanil $\square \quad$ 2,4-D + Propanil $\square$

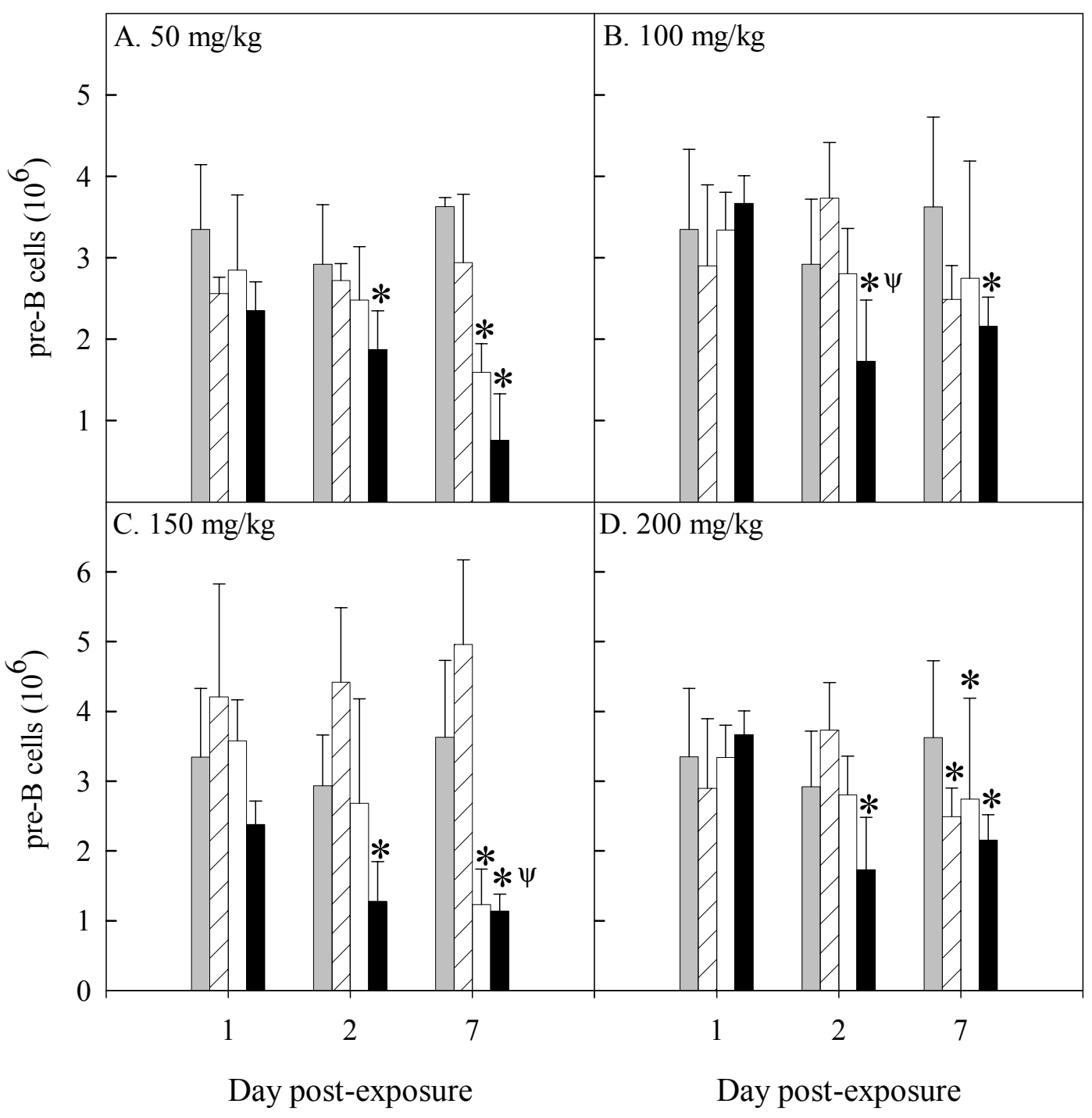


Figure 10. Bone marrow $B 220^{+} \mathrm{CD}^{4} 3^{-} \operatorname{IgM}^{\text {hi }} \operatorname{IgM}^{+} \mathrm{B}$ cell population after exposure to propanil, 2,4-D and the herbicide mixture. Flow cytometric analysis of $\operatorname{IgM}^{+} \mathrm{B}$ total cell numbers at 1,2 and 7 days post treatment. Bone marrow B cells were separated as described in Materials and Methods. A. $50 \mathrm{mg} / \mathrm{kg}$ body wgt or $50 / 50$ mixture treatment B. $100 \mathrm{mg} / \mathrm{kg}$ body wgt or 100/100 mixture treatment. C. $150 \mathrm{mg} / \mathrm{kg}$ body wgt or $150 / 150$ mixture treatment. D. $200 \mathrm{mg} / \mathrm{kg}$ body wgt or $200 / 200$ mixture treatment. Vehicle (grey bar), 2,4-D (hatched bar), propanil (open bar) and mixture treatment (black bar). $\mathrm{n}=8$ mice/group. Error bars represent the standard deviation from the mean. ${ }^{*} \mathrm{p} \leq$ 0.05 vs. vehicle control. $\quad \psi \mathrm{p} \leq 0.05$ mixture interaction. 
Figure 10. Chapter 2. Absolute number of $\operatorname{IgM}^{+} B$ cells after herbicide treatment

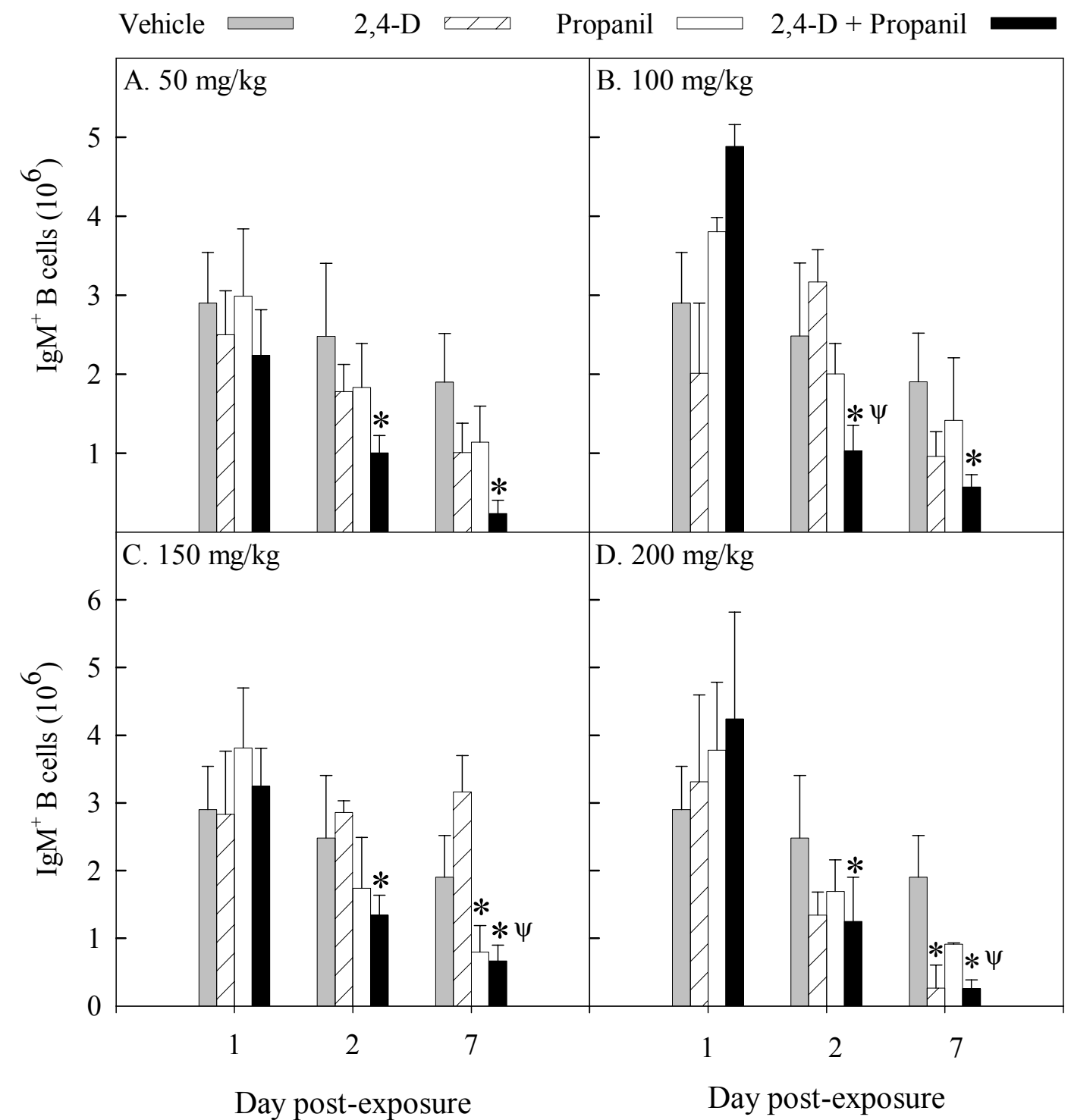


Figure 11. Bone marrow B cell population changes with and without RU 486 treatment. Glucocorticoid receptors were blocked or left unblocked by oral gavage of mice with RU 486 or Ringer's solution $2 \mathrm{hr}$ prior to and $12 \mathrm{hrs}$ after i.p. injection of either vehicle or a 150/150 propanil + 2,4-D mixture or oral gavage of corticosterone $(75 \mathrm{mg} / \mathrm{kg})$. Bone marrow B cell populations were separated by flow cytometric analysis as described in Materials and Methods. A. Pro B total cell number. B. Pre B total cell number. C. $\operatorname{IgM}^{+} \mathrm{B}$ total cell number. $\mathrm{n}=9$ mice/group. Error bars represent the standard deviation from the mean. ${ }^{*} \mathrm{p} \leq 0.05$ vs. vehicle control. 
Figure 11. Chapter 2. Absolute number of $B$ cells in the bone marrow after pretreatment with RU 486

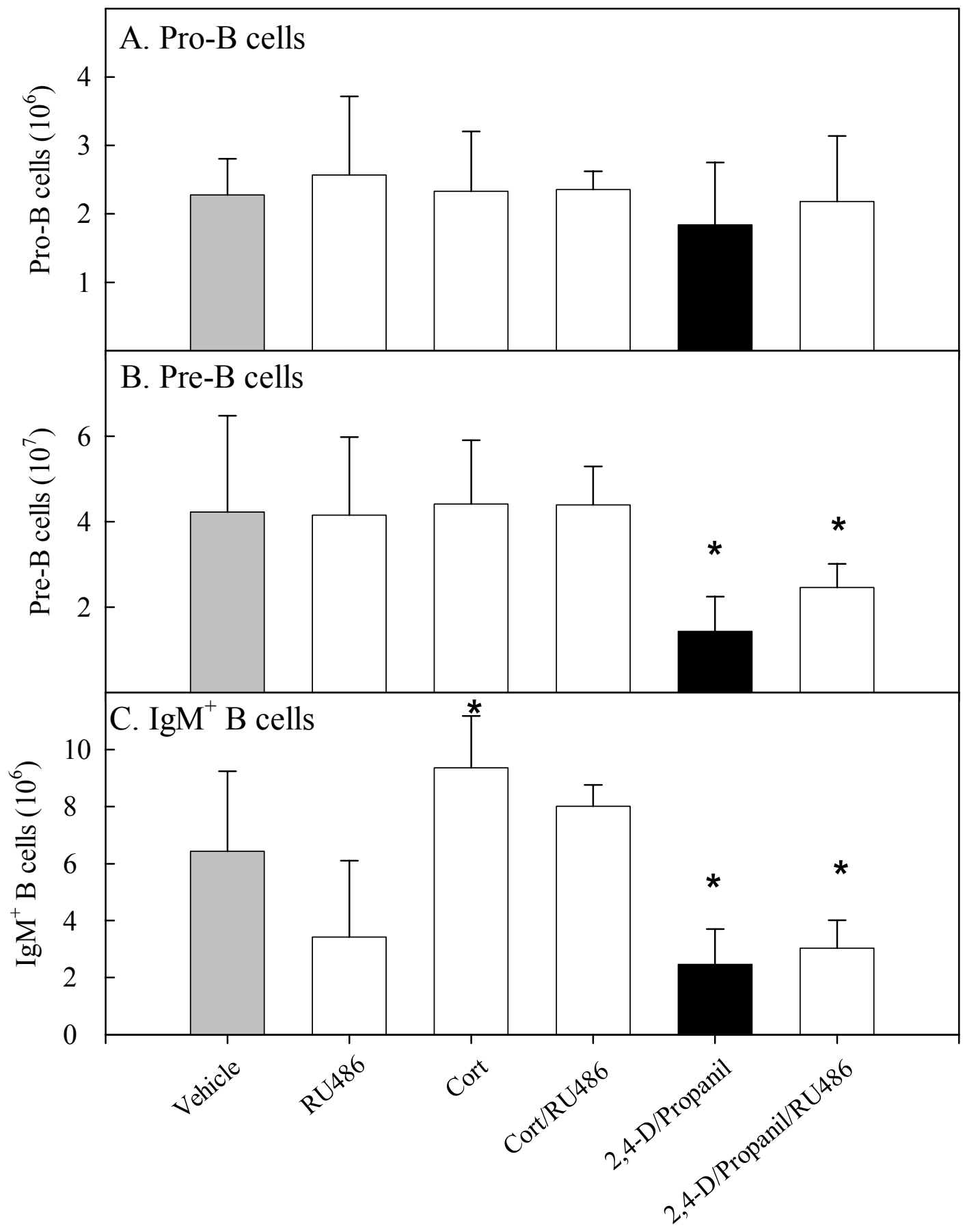


Chapter 3. Changes in Spleen Cell Populations after Exposure to a Mixture of Propanil and 2,4-D 


\section{INTRODUTION}

The capacity of the cells of the immune system to regenerate after chemical exposure make these populations more resilient to chemical-induced changes when assayed by normal toxicological endpoints (Germolec, et al., 1989; Hong, et al., 1992). Data is accumulating, however, to suggest that subtle changes may occur within these populations that are only apparent after subsequent challenge (Hong, et al., 1991; Hong, et al.,1993). This study examines the changes to leukocyte populations in the spleen after exposure to a chemical mixture containing the herbicides 3,4-dichloropropionanaline (propanil) and 2,4-dichlorophenoxyacetic acid (2,4-D). Propanil and 2,4-D are heavily used by the agricultural industry and are commonly applied as a mixture under the product names of NOX-D ${ }^{\circledR}$ and Herbanil $368^{\circledR}$ (Farm Chemicals Handbook, 1998).

We have found that exposure to propanil or 2,4-D specifically decreases the $\mathrm{CD}^{+} \mathrm{CD}^{+} \mathrm{T}$ cell population in the thymus and the pre $\mathrm{B}$ cell population in the bone marrow (Figure 2 and Figure 9A-D). Exposure to the mixture containing both propanil and 2,4-D affected the same populations of cells, however, these affects were more profound and persistent with mixture exposure (Figure 2 and Figure 9A-D and Figure 10A-D).

We have examined the effects of exposure to propanil, 2,4-D or a mixture containing propanil and 2,4-D on the leukocyte populations of the spleen and the mechanism for recovery of the spleen after herbicide exposure. Exposure to propanil results in increases in neutrophils while exposure to 2,4-D decreased the B cell and CD4 ${ }^{+}$ $\mathrm{T}$ cell populations. Mixture treatment resulted in a combined response that was the addition of the changes that occur after exposure to the individual components of the 
mixture. The results suggest that recovery in the spleen may be initiated by maturation of precursor leukocyte populations found in the spleen.

\section{MATERIALS AND METHODS}

Animals. C57BL/6 female mice, 6-8 weeks of age, were purchased from Charles River Farms (Wilmington, DE). Mice were allowed to acclimate for one week after shipment and received food and water ad libitum.

Source of xenobiotics. Propanil was purchased from Chem Service (West Chester, PA) and has a purity of 99\%. Commercial-grade 2,4-D amine (dimethylamine salt of 2,4-dichlorophenoxyacetic acid, Universal Cooperatives, Inc., Minneapolis, MN) with a purity of $39.2 \%$ was purchased from Southern States Cooperative (Morgantown, WV). The concentration of 2,4-D used for all experiments was calculated based on the amount of active 2,4-D.

Exposure of mice to herbicide mixtures. Mice were treated with vehicle, single herbicide treatments of propanil or 2,4-D of 100,150 or $200 \mathrm{mg} / \mathrm{kg}$ body weight ( $\mathrm{kg} \mathrm{bw}$ ) (P100, P150, P200 or D100, D150, D200) or a mixture containing a 1:1 ratio of propanil and 2,4-D (100/100, 150/150, 200/200). Propanil was dissolved in peanut oil (Planters, Nabisco Inc.) and 2,4-D amine was dissolved in phosphate buffered saline (PBS) to the appropriate concentration.

Cell isolation. Spleens were weighed and single cell suspensions prepared by suspending individual spleens in $3 \mathrm{ml}$ of RPMI containing 10\% FBS, 50 mM HEPES, 2 $\mathrm{mM}$ L-glutamine, 100 units $/ \mathrm{ml}$ penicillin, $100 \mathrm{mg} / \mathrm{ml}$ streptomycin and $0.049 \mathrm{mM} \beta$ mercaptoethanol and pressing them through a $70 \mu \mathrm{M}$ nylon screen bag (Fisher Scientific, Pittsburgh, PA). Cells were then passed through a 26 gauge needle. Red blood cells 
were lysed with Tris-buffered ammonium chloride. Single cells were washed and resuspended in media containing PBS supplemented with $2 \%$ FBS and $0.04 \%$ sodium azide (Sigma, St. Louis, MO) (staining media). Spleen weight to body weight (SW:BW) was calculated as the ratio of the individual spleen weight to the total body weight. Total cell counts were done using trypan blue dye exclusion.

Immunofluorescence. For flow cytometric analysis, spleen cells were washed and re-suspended in media containing PBS supplemented with $2 \%$ FBS and $0.02 \%$ sodium azide (Sigma) (staining media). Fc $\gamma$ III/II receptors were blocked with purified mAb anti CD16/CD32. Cells were stained with anti-CD4-FITC (GK1.5), anti-CD8a-PE (53-6.7), anti-CD45R/B220-PE (RA3-6B2), anti-Ly-6G(Gr-1) and anti Ly6C-Fitc (RB6-8C5) antiCD11b-PE (M1-70) and anti-I-A ${ }^{\mathrm{b}}\left(\mathrm{A}_{\beta}^{\mathrm{b}}\right)$ (AF6-120.1) (Pharmingen, San Diego, CA). Staining media (PBS containing 2\% FBS and $0.02 \% \mathrm{NaNa}_{3}$ ) was used for all washes. Individual spleens were analyzed by flow cytometric analysis. Fc $\gamma$ III/II receptors were blocked prior to staining using $1 \mu \mathrm{g}$ antibody/million cells. Cells were then washed twice and $1 \times 10^{6}$ cells were stained in a total volume of $25 \mu 1$ of antibody at the appropriate concentration for $25 \mathrm{~min}$. on ice in the dark. Streptavidin Cy-chrome was used as a second-step reagent for biotinylated antibodies (Pharmingen). Cells were fixed in $0.04 \%$ paraformaldehyde (Fisher Scientific). For analysis, 10,000 cells were analyzed on a Becton-Dickinson FACScan (Becton Dickinson Immunocytometry Systems). Analysis was performed using WinMDI software (Joseph Trotter, Scripps Institute, San Diego, CA). The following populations were stained and analyzed without gates: $\mathrm{CD} 4^{+} \mathrm{T}$ cells, $\mathrm{CD} 8^{+} \mathrm{T}$ cells, $\mathrm{B} 200^{+} \mathrm{B}$ cells, CD11b $\mathrm{b}^{+}-1^{+}$(neutrophils), and $\mathrm{CD} 11 \mathrm{~b}^{+} \mathrm{I}-\mathrm{A}^{\mathrm{b}+}$ (monocytes/dendritic cells). Population percentages, obtained from flow cytometric 
analysis, were used to calculate the absolute cell numbers by multiplying the ratio of cells in a population by the total number of cells harvested per organ.

Differential Cell Count. Individual spleens were processed into single cell suspensions. $5 \mu \mathrm{l}$ of cells suspended in RPMI were spotted on a microscope slide and smeared in a single cell layer by passing over the bead of liquid containing the spleen cells with another microscope slide. Cells were allowed to air dry and then were stained by dipping the slide in a buffered differential Wright-Giemsa stain (Camco Quik Stain II) (Cambridge Diagnostic Products, Inc., Fort Lauderdale, FL) for 10 seconds. Slides were then washed in deionized water twice for 20 seconds each wash and allowed to air dry. 100 cells per slide were counted. White blood cells, including lymphocytes, monocytes, neutrophils, eosinophils and basophils were counted. Red blood cells were excluded from the counts.

Statistics. Comparison of herbicide treatment groups: One way analysis of variance (ANOVA) with a significance level of $p \leq 0.05$ was done on all parameters assayed using a Dunnett's t-test to compare the response of treated animals to vehicle control and a Tukey-Kramer test was used to compare all treatment pairs. Mixture interactions were analyzed using a partial factorial analysis.

\section{RESULTS}

\section{Cell changes in the spleen after herbicide treatment}

Herbicide treatment did not affect the body weight of the mice and, in contrast to the response to mixture exposure in the bone marrow and thymus, no mixture interactions were found in the spleen. Splenomegaly and cell population changes in the spleen were measured at 7 and 14 days after herbicide treatment. Seven days after treatment, propanil 
and mixture treatment resulted in an increase in $\mathrm{SW}: \mathrm{BW}$ at all doses tested (Table 3). P200, 150/150 and 200/200 treatments also resulted in increases in the total number of cells in the spleen at 7 days after exposure (Table 3). Interestingly, at 7 days after treatment, although the P100, P150 and 100/100 treatment caused an increase in the $\mathrm{SW}: \mathrm{BW}$, the total number of cells in the spleen were not increased (Table 3). Therefore, increases in the total number of leukocytes may partially contribute to splenomegaly but is not necessary for an increase in spleen size.

By 14 days after P200 treatment, SW:BW and the total number of cells were still increased to the same amount as the increases seen at 7 days after treatment (Table 3). Fourteen days after treatment with the 200/200 mixture the spleens of mixture-treated animals were still enlarged (Table 3). The total cell count in 200/200 mixture-treated spleens was also still increased at 14 days after treatment (Table 3). Treatment of animals with 2,4-D did not result in increases at 7 or 14 days after treatment in the size of the spleen or in the total cell count of the spleen (Table 3).

Lymphocyte and granulocyte populations after single herbicide and mixture treatment were quantitated using flow cytometric analysis. The populations enumerated were $\mathrm{B} 220^{+}$(B cells), $\mathrm{CD} 4^{+} \mathrm{T}$ cells, $\mathrm{CD} 8^{+} \mathrm{T}$ cells, $\mathrm{CD} 11 \mathrm{~b}^{+} / \mathrm{Gr}-1^{+}$(neutrophils), and $\mathrm{CD}_{11} \mathrm{~b}^{+} / \mathrm{I}-\mathrm{A}^{\mathrm{b}+}$ (macrophage/dendritic cells). No changes were noted in lymphocyte or granulocyte populations at 7 days after treatment with P100, P150, D100 and D150, 100/100 and 150/150 (data not shown). At 7 days post treatment, there were no significant differences in the percentage of cells between vehicle and D200 treated spleens (Table 4). P200 treatment decreased the percentage of B cells, $\mathrm{CD}^{+}{ }^{\mathrm{T}}$ cells and $\mathrm{CD}^{+} \mathrm{T}$ cells (Table 4). Decreases in the mixture-treated lymphocyte populations were 
slightly greater than treatment with P200 single herbicide. 200/200 treatment decreased $\mathrm{B}$ cells $\mathrm{CD} 4^{+} \mathrm{T}$ cells and $\mathrm{CD} 8^{+} \mathrm{T}$ cells (Table 4 ). Phagocytic cell populations, including neutrophils and macrophages were unchanged by herbicide treatment at 7 days postexposure (Table 4).

Eighty-two percent and $80.6 \%$ of all spleen cell populations were stained in vehicle control animals and 2,4-D treated animals respectively (Table 4). In contrast, only $67 \%$ of all cells in the P200 treated and $47 \%$ of all cells in $200 / 200$ treated spleens were stained by the antibodies commonly used to separate the mature lymphocyte and granulocyte populations in the spleen (Table 4).

Although there was a decrease in the percent of some populations in the spleen, due to the increase in total cell numbers in the spleens of P200 treated animals (Table 3), the absolute cell numbers of P200 treated lymphocyte populations were similar to the number of lymphocytes in vehicle and D200 treated spleens after treatment (Table 5). Mixture treatment did result in a decrease in the absolute number of B cells, (Table 5). $\mathrm{CD}^{+} \mathrm{T}$ cells were also decreased after mixture treatment (Table 5).

We added the absolute number of all cells in the spleen that stained positive with the common phenotypic surface markers that we analyzed and subtracted it from the average total number of cells counted for each treatment group to estimate the number of cells in each treatment group that do not have common cell surface markers for mature leukocytes and therefore are cells of unknown phenotype (Table 6). Increases in the number of cells of unknown phenotype over vehicle occurred in P200 and 200/200 treated mice (Table 6). Although these cells were not identifiable by flow cytometric analysis using antibodies to the markers listed above, it is possible that many of these 
cells are leukocytes as red blood cells are lysed prior to cell count and phenotypic analysis.

Fourteen days after treatment, all herbicide treated spleens had decreases in the percent of $\mathrm{B}$ cells and $\mathrm{CD} 8^{+} \mathrm{T}$ cells (Table 7). The percent of $\mathrm{CD} 4^{+} \mathrm{T}$ cells were decreased by P200 and 200/200 treatment but not by D200 treatment (Table 7). In contrast to the lymphocyte populations, the percentage of neutrophils was increased at 14 days after P200 and 200/200 treatment (Table 7). Neutrophil percentages at 14 days after D200 treatment remained similar to vehicle treated control (Table 7).

The percent of the spleen cells stained by antibodies for the phenotypic markers listed above at 14 days after propanil and mixture treatment was only slightly less than the percent of cells in the spleen stained after vehicle treatment (Table 7). The percent of cells stained after D200 treatment was decreased from vehicle and the percent of cells of unknown phenotype after D200 treatment was increased (Table 7).

At 14 days after treatment, the absolute number of lymphocytes (B cells and $\mathrm{T}$ cells) in the spleens of P200 treated animals was similar to the absolute number of lymphocytes in vehicle control animals (Table 8). D200 treatment resulted in decreased numbers of B cells and $\mathrm{CD}^{+} \mathrm{T}$ cells (Table 8). Mixture treatment resulted in a decreased number of $\mathrm{CD}^{+} \mathrm{T}$ cells (Table 8 ). In contrast, to the affects at 14 days after D200 treatment, mixture treatment increased the absolute number of B cells in the spleen at 14 days after treatment (Table 8). The number of neutrophils was also increased by P200 and 200/200 treatment (Table 8).

The number of cells of unknown phenotype in the spleen was calculated at 14 days after treatment to give an estimate of the number of cells that do not stain with the 
common phenotypic markers listed. P200 and 200/200 treated spleens still containd a large number of cells of unknown phenotype as compared to vehicle control, however, the difference in number between the treated groups and vehicle at 14 days post treatment is smaller than the difference at 7 days after exposure (Table 6 vs. Table 9). In contrast, the number of cells of unknown phenotype was increased over vehicle 14 days after D200 treatment, suggesting that recovery of the leukocyte population in the spleen after D200 treatment may occur in a manner similar to to propanil and the mixture (Table 9). In the differential cell count seven days after treatment, lymphocyte cell population percentages were unchanged (Table 10). Monocytes were slightly increased by mixture treatment at 7 days after 200/200 treatment (Table 10). Neutrophil percentages were increased at 7 days after treatment in all herbicide treated groups with the largest increases occurring in the 200/200 treated group (Table 10). The number of banded, immature neutrophils was increased after P200 and 200/200 treatment but not after D200 treatment (Table 10).

Fourteen days after treatment, lymphocytes composed $97 \%$ of the cells in the spleen after vehicle and D200 treatment (Table 11). After P200 treatment, 93\% of the cells in the spleen were lymphocytes while lymphocytes composed $80 \%$ of the spleen after 200/200 treatment (Table 11). Monocytes composed 0.2\% of the spleen after vehicle treatment as compared to $0.6 \%$ after P200, $0.2 \%$ after D200 and $1.6 \%$ after 200/200 treatment (Table 9). Neutrophils composed 3\% of the spleen after vehicle treatment compared to $6 \%$ after P200, 2\% after D200 and 18\% after 200/200 treatment (Table 11). In contrast to the $7 \mathrm{~d}$ differential, at 14 days after treatment, no banded, immature neutrophils were found in the P200 treated group (Table 10 vs. Table 11). A 
much larger number of banded, immature neutrophils were found at 14 days in comparison to the 7 day differential cell count of $200 / 200$ treated spleens $(0 \%$ after vehicle treatment vs. $8 \%$ after $200 / 200$ treatment) (Table 10 vs. Table 11 ).

\section{DISCUSSION}

Exposure to all three herbicide treatments, propanil, 2,4-D or the mixture containing propanil and 2,4-D, resulted in changes in the phenotype of the spleen. In contrast to the thymus and the bone marrow, mixture interactions did not occur in the spleen. The effects of exposure to the mixture on spleen cell populations were similar to the effects caused by exposure to either propanil or 2,4-D. In the spleen, propanil was found to alter granulocyte populations while 2,4-D affected lymphocyte populations. The mixture of propanil and 2,4-D affected both the granulocyte and lymphocyte populations to the same degree as caused by exposure to the individual herbicide.

This research suggests that the mechanism by which homeostasis and/or recovery of splenic immune cell populations occurs, following exposure to propanil, 2,4-D or the mixture, may be through the action of splenic extramedullary hematopoiesis. We were unable to determine the phenotype of all of the cells in the spleens of propanil and mixture-treated animals using the panel of antibodies specific for B cells, T cells, $\mathrm{M} \varphi / \mathrm{DC}$, and neutrophils by flow cytometric analysis. In the differential cell count, it was determined that increases in the percent of neutrophils and increases in banded neutrophils, a neutrophil precursor, after propanil and 200/200 treatment coincide with increases in the total cell count of the spleen as compared to vehicle treated animals (Table 6) . The percentage of banded neutrophils, increased 7 days after propanil and 
200/200 mixture treatment (Table 10). In a normal mouse spleen, the Gr-1 protein is specifically expressed by mature neutrophils (Hestdal, et al., 1991). Increases in the number of banded neutrophils precede the increases in the number of mature neutrophils, as measured by flow cytometric analysis, by one week (Table 8). In the differential cell count at 14 days after treatment, the percentage of banded neutrophils is decreased from the percentage that were counted at 7 days after P200 treatment (Table 11) and a corresponding decrease occurs in total cell count of spleen (Table 9). In contrast, the percentage of banded neutrophils in the differential cell count at 14 days after 200/200 mixture treatment remains increased (Table 11) and the total cell numbers remained increased (Table 9). The simplest explanation for these results is that precursor cells that do not yet express the phenotypic markers of mature cells are present in the spleen. When these cells mature, they are detectable by flow cytometric analysis. Cells in the P200 treated spleen are beginning to mature at 14 days after treatment resulting in an increase in the number of neutrophils at 14 days after treatment (Table 8 and 9). Increases in the number of neutrophils and B cells at 14 days after 200/200 treatment is associated with decreases in the number of cell of unknown phenotype (Table 8 and 9). However, the total cell count of the spleen at 14 days after treatment is still increased (Table 9) and precursor, banded neutrophils, are still present in the spleen (Table 9). These results suggest that the increase in spleen size and total cell count after propanil and mixture treatment are the result of hematopoiesis in the spleen.

Apparent increases in the percentage of splenic monocytes occur in the differential cell count with 200/200 exposure at 14 days after treatment (Table 11). Although we did not measure this population by flow cytometric analysis (Table 7), these 
data suggest that there may be a general increase in the granulocyte population in the spleens of 200/200 treated animals. It is possible that M $\varphi$ or DC precursors represent a portion of the unknown cells at 7 days after treatment. Further study of these important groups is necessary in order to determine their role in the response of the spleen after propanil and mixture treatment.

There are indications that B cell precursors may also participate in the maintenance of homeostasis of the B cell population after 200/200 treatment. At 7 and 14 days after P200 treatment, the absolute numbers of B cells and T cells remain similar to $\mathrm{B}$ and $\mathrm{T}$ cell numbers in vehicle treated mice (Table 5 and 8 ). In contrast, the absolute number of B cells and CD4 $4^{+} \mathrm{T}$ cells were decreased with 200/200 exposure at 7 days after treatment (Table 5). Interestingly, the B cell population, but not the $\mathrm{CD}^{+} \mathrm{T}$ cell population, recovers rapidly from 7 day decreases associated with 200/200 treatment to become significantly increased over vehicle control at 14 days after treatment (Table 5 and 8). The absolute numbers of $\mathrm{B}$ cells and $\mathrm{CD} 4^{+} \mathrm{T}$ cells were also decreased at 14 days after D200 treatment (Table 8). These decreases correspond to an increase in the number of cells in the D200 treated spleen that do not stain with common phenotypic markers of mature leukocytes (from $18 \times 10^{6}$ cells for vehicle to $30 \times 10^{6}$ cells after D200 treatment). These results suggest that although spleen size and cell count do not change with D200 treatment (Table 3), splenic hematopoiesis may also occur after D200 exposure (Table 9). These results also suggest that decreases in the B cell and $\mathrm{CD}^{+} \mathrm{T}$ cell populations after mixture treatment are caused by exposure to the D200 component of the mixture. If so, then the mixture-associated decreases occur earlier than the decreases caused by the single herbicide treatment of 2,4-D. 
It is interesting that the mechanism that allows for B cell recovery after mixture treatment does not maintain the B cell population 14 days after 2,4-D treatment. These results suggest that the mechanism of recovery in the mixture-treated population is associated with exposure to the propanil component of the mixture or is a mixturespecific affect. It is possible that lymphocyte decreases also occur in P200 treated animals but that the cells that are lost are rapidly replaced so that we do not detect any net change by flow cytometric analysis. Thymus $\mathrm{T}$ cell and bone marrow pre $\mathrm{B}$ and $\operatorname{IgM}^{+} \mathrm{B}$ cell populations are depleted 7 days after P200, D200 and 200/200 treatment (Figure 6AD and Figure 9A-D and 10A-D). These cell losses are profound enough to cause temporary decreases in the number of naive $\mathrm{T}$ and $\mathrm{B}$ cells exiting the primary immune organs to the spleen. Lymphocyte populations are decreased by 2,4-D and mixture treatment. In contrast, lymphocyte numbers are not changed in the spleens of propanil treated animals. Therefore, it is possible that homeostasis of lymphocyte populations in the spleen after propanil treatment also depends on the maturation of lymphocyte precursors in the spleen.

Taken together, these results suggest that recovery of leukocyte populations in the spleen after exposure to P200, D200 or the 200/200 mixture is initiated either by an influx of precursor cells into the spleen or the generation of multipotent cells from splenic stem cells. Propanil is known to cause a decrease in the number of myeloid multipotent stem cells in the bone marrow (Blyler, et al., 1994). Preliminary data indicate that propanil exposure increases the number of splenic multipotent myeloid stem cells (Barnett et al., 1992). Further analysis of colony forming units in the spleen is necessary 
in order to determine the origin and phenotype of the cells responsible for recovery of the spleen after herbicide exposure.

A few of the reported immunological consequences of extramedullary hematopoiesis in both humans and mice are myelofibrosis and hematopoietic malignancies (Chagraoui, et al., 2002; Fiegl, et al., 2002). In our system, the loss of lymphocytes leaves open the possibility that temporary immunosuppression may also occur. Conversely, the increase in neutrophil numbers may promote inflammatory disease (Tani, et al., 2001). Therefore, although lymphocyte cell populations were maintained or quickly recovered after herbicide and herbicide mixture treatment, there are important differences between the herbicide and vehicle-treated spleens that could lead to very different responses to immune challenge or to long-term immunological problems. Furthermore, although splenic hematopoiesis appears to be the mechanism of recovery after all treatments, the phenotype of the cells involved are unknown and may differ between treatments. The possibility also exists that functional responses could be substantially different between herbicide treatments due to changes in the mature lymphocyte populations that are not detectable by flow cytometric analysis. Future studies are planned to assess these differences. 
Table 3. Chapter 3. Spleen weight to body weight and spleen total cell count at 7 and 14 days after treatment

\begin{tabular}{|l|cc|cc|}
\hline \multirow{2}{*}{ Treatment $^{\mathrm{a}}$} & \multicolumn{2}{|c|}{ SW:BW $\left(10^{-4}\right)$} & \multicolumn{2}{c|}{ Cell Count $\left(10^{6}\right)$} \\
\cline { 2 - 5 } & \multicolumn{2}{|c|}{ Days post exposure } & \multicolumn{2}{c|}{ Days post exposure } \\
\cline { 2 - 5 } & 7 & 14 & 7 & 14 \\
\hline Vehicle & $35 \pm 4^{\mathrm{b}}$ & $45 \pm 6$ & $68 \pm 20^{\mathrm{c}}$ & $89 \pm 16$ \\
\hline D100 & $37 \pm 3$ & $\mathrm{ND}$ & $66 \pm 51$ & $\mathrm{ND}$ \\
D150 & $39 \pm 10$ & $\mathrm{ND}$ & $68 \pm 25$ & $\mathrm{ND}$ \\
D200 & $31 \pm 4$ & $46 \pm 6$ & $62 \pm 10$ & $83 \pm 27$ \\
\hline P100 & $58 \pm 8^{*}$ & $\mathrm{ND}$ & $63 \pm 31$ & $\mathrm{ND}$ \\
P150 & $52 \pm 5^{*}$ & $\mathrm{ND}$ & $93 \pm 27$ & $\mathrm{ND}$ \\
P200 & $67 \pm 9 *$ & $75 \pm 20 *$ & $130 \pm 23 *$ & $112 \pm 27 *$ \\
\hline $100 / 100$ & $55 \pm 6^{*}$ & $\mathrm{ND}$ & $71 \pm 17$ & $\mathrm{ND}$ \\
$150 / 150$ & $80 \pm 12^{*}$ & $\mathrm{ND}$ & $111 \pm 23 *$ & $\mathrm{ND}$ \\
$200 / 200$ & $88 \pm 2 *$ & $106 \pm 42^{*}$ & $130 \pm 45^{*}$ & $141 \pm 34 *$ \\
\hline
\end{tabular}

a Mice were treated with vehicle, 100-200 mg 2,4-D/kg body weight (D100, D150,

D200), 100-200 mg propanil/kg body weight (P100, P150, P200) or a mixture containing

100-200 mg propanil + 100-200 mg 2,4-D/kg body weight (100/100, 150/150, 200/200).

Spleens were removed at 7 and 14 days after treatment as detailed in Materials and

Methods. 4-8 animals were used per group.

${ }^{\mathrm{b}}$ Data represent the average spleen weight : body weight $\left(10^{-4}\right) \pm$ standard deviation $\times$ $\left(10^{-4}\right)$

c Data represent the average spleen total cell count $\times 10^{6} \pm$ standard deviation $\times 10^{6}$.

$\mathrm{ND}=$ Not determined

- $\mathrm{p} \leq 0.05$ vs. vehicle control. 
Table 4. Chapter 3. Spleen population percentages 7 days after treatment

\begin{tabular}{|c|c|c|c|c|}
\hline Population $^{\mathrm{d}}$ & Vehicle $^{\mathrm{a}}$ & P200 & D200 & $200 / 200$ \\
\hline $\mathrm{B} 220^{+}$ & $43 \pm 7^{b}$ & $33 \pm 8 *$ & $42 \pm 7$ & $23 \pm 6 *$ \\
\hline $\mathrm{CD}^{+}$ & $17 \pm 4$ & $12 \pm 2 *$ & $14 \pm 3$ & $8 \pm 2 *$ \\
\hline $\mathrm{CD}^{+}$ & $12 \pm 2$ & $9 \pm 2 *$ & $14 \pm 3$ & $8 \pm 2 *$ \\
\hline $\mathrm{CD} 11 \mathrm{~b}^{+} / \mathrm{Gr}-1^{+}$ & $8 \pm 3$ & $8 \pm 1$ & $10 \pm 2$ & $7 \pm 2$ \\
\hline $\mathrm{CD}_{11 \mathrm{~b}}{ }^{+} / \mathrm{I}-\mathrm{A}^{\mathrm{b}+}$ & $2 \pm 0.9$ & $5 \pm 4$ & $0.6 \pm 0.1$ & $1 \pm 0.1$ \\
\hline$\%$ Total Spleen & 82 & 67 & 80.6 & 47 \\
\hline
\end{tabular}

a Mice were treated with vehicle, $200 \mathrm{mg}$ propanil/kg body weight (P200), $200 \mathrm{mg}$ 2,4-

$\mathrm{D} / \mathrm{kg}$ body weight (D200) or a mixture containing $200 \mathrm{mg}$ propanil $+200 \mathrm{mg}$ 2,4-D/kg body weight (200/200). Spleens were extracted at 7 days after treatment as detailed in Materials and Methods.

b Data represent the average percent of positive staining cells per spleen \pm standard deviation. 4-8 animals were used per group.

${ }^{\mathrm{c}}$ Data represents the addition of the percentage of $\mathrm{B} 220^{+}, \mathrm{CD} 4^{+}, \mathrm{CD} 8^{+}, \mathrm{CD} 11 \mathrm{~b}^{+} / \mathrm{Gr}-1^{+}$ and $\mathrm{CD} 11 \mathrm{~b}^{+} / \mathrm{I}-\mathrm{A}^{\mathrm{b}+}$ cells per treatment group.

${ }^{\mathrm{d}} \mathrm{B}^{2} 20^{+} \mathrm{B}$ cells, $\mathrm{CD} 4^{+} \mathrm{T}$ cells, $\mathrm{CD} 8^{+} \mathrm{T}$ cells, $\mathrm{CD} 11 \mathrm{~b}^{+} / \mathrm{Gr}-1^{+}$Neutrophils, $\mathrm{CD}_{11 \mathrm{~b}}{ }^{+} / \mathrm{I}-\mathrm{A}^{\mathrm{b}+}$ Macrophage/Dendritic cells p $\leq \mathbf{0 . 0 5}$ vs. vehicle control. 
Table 5. Chapter 3. Absolute cell numbers in the spleen at 7 days after herbicide treatment

\begin{tabular}{|c|c|c|c|c|}
\hline Population $^{\mathrm{c}}$ & Vehicle $^{a}$ & P200 & D200 & $200 / 200$ \\
\hline$\overline{\mathrm{B} 220^{+}}$ & $31 \pm 9^{b}$ & $39 \pm 5$ & $26 \pm 10$ & $19 \pm 6 *$ \\
\hline $\mathrm{CD}^{+}$ & $12 \pm 3$ & $15 \pm 2$ & $10 \pm 3$ & $6 \pm 2 *$ \\
\hline$\overline{\mathrm{CD} 8^{+}}$ & $8 \pm 2$ & $11 \pm 1$ & $8 \pm 2$ & $6 \pm 1$ \\
\hline $\mathrm{CD} 11 \mathrm{~b}^{+} / \mathrm{Gr}-1^{+}$ & $6 \pm 3$ & $7 \pm 5$ & $6 \pm 0.8$ & $9 \pm 3$ \\
\hline $\mathrm{CD} 11 \mathrm{~b}^{+} / \mathrm{I}-\mathrm{A}^{\mathrm{b}+}$ & $1 \pm 1$ & $0.4 \pm 0.2$ & $0.4 \pm 0.2$ & $1 \pm 1$ \\
\hline
\end{tabular}

${ }^{\mathrm{a}}$ Mice were treated with vehicle, $200 \mathrm{mg}$ propanil/kg body weight (P200), $200 \mathrm{mg}$ 2,4-

$\mathrm{D} / \mathrm{kg}$ body weight (D200) or a mixture containing $200 \mathrm{mg}$ propanil $+200 \mathrm{mg}$ 2,4-D/kg body weight (200/200). Spleens were extracted at 7 days after treatment as detailed in Materials and Methods.

${ }^{b}$ Data represent the mean absolute number of positive staining cells per spleen $\left(10^{6}\right) \pm$ standard deviation $\left(10^{6}\right)$. 4-8 animals were used per group.

c $\mathrm{B} 220^{+} \mathrm{B}$ cells, $\mathrm{CD}^{+} \mathrm{T}$ cells, $\mathrm{CD}^{+} \mathrm{T}$ cells, $\mathrm{CD} 11 \mathrm{~b}^{+} / \mathrm{Gr}-1^{+}$Neutrophils, $\mathrm{CD}_{11 \mathrm{~b}}{ }^{+} / \mathrm{I}_{-} \mathrm{A}^{\mathrm{b}+}$ Macrophage/Dendritic cells

$* \mathrm{p} \leq 0.05$ vs. vehicle control. 
Table 6. Chapter 3. Absolute number of cells of unknown phenotype in the spleen at 7 days after treatment

\begin{tabular}{|c|c|c|c|c|}
\hline Cell count $\left(10^{6}\right)$ & Vehicle $^{a}$ & P200 & D200 & $200 / 200$ \\
\hline Spleen cell count & $67 \pm 19^{b}$ & $130 \pm 23 *$ & $62 \pm 10$ & $130 \pm 45 *$ \\
\hline Total cells stained & $58^{\mathrm{c}}$ & 73 & 50 & 37 \\
\hline Remaining cells & $9^{d}$ & 57 & 12 & 93 \\
\hline
\end{tabular}

${ }^{a}$ Mice were treated with $200 \mathrm{mg}$ propanil/kg body weight (P200), $200 \mathrm{mg}$ 2,4-D/kg body weight (D200) or a mixture containing $200 \mathrm{mg}$ propanil $+200 \mathrm{mg}$ 2,4-D/kg body weight (200/200). Spleens were extracted at 7 days after treatment as detailed in Materials and Methods.

${ }^{\mathrm{b}}$ Data represent the mean cell count $\times\left(10^{6}\right) \pm$ standard deviation $\left(10^{6}\right) . \quad 6-12$ animals were used per group.

${ }^{\mathrm{c}}$ Data is derived from Table 5 and represents the addition of the absolute number of $\mathrm{B} 220^{+}, \mathrm{CD} 4^{+}, \mathrm{CD}^{+}, \mathrm{CD} 11 \mathrm{~b}^{+} / \mathrm{Gr}-1^{+}$and $\mathrm{CD} 11 \mathrm{~b}^{+} / \mathrm{I}-\mathrm{A}^{\mathrm{b}+}$ cells per treatment group.

${ }^{d}$ Data represent the difference between the spleen cell count and the total number of cells stained.

$* \mathrm{p} \leq 0.05$ vs. vehicle control. 
Table 7. Chapter 3. Spleen population percentages 14 days after herbicide treatment

\begin{tabular}{|c|c|c|c|c|}
\hline Population $^{\mathrm{d}}$ & Vehicle $^{a}$ & P200 & D200 & $200 / 200$ \\
\hline$\overline{\mathrm{B} 220^{+}}$ & $47 \pm 3^{b}$ & $38 \pm 4 *$ & $35 \pm 10 *$ & $37 \pm 4 *$ \\
\hline $\mathrm{CD}^{+}$ & $15 \pm 3$ & $10 \pm 2 *$ & $10 \pm 7$ & $9 \pm 2 *$ \\
\hline $\mathrm{CD}^{+}$ & $13 \pm 3$ & $9 \pm 3 *$ & $6 \pm 6 *$ & $8 \pm 2 *$ \\
\hline $\mathrm{CD} 11 \mathrm{~b}^{+} / \mathrm{Gr}-1^{+}$ & $2 \pm 0.1$ & $5 \pm 2 *$ & $3 \pm 0.2$ & $7 \pm 2 *$ \\
\hline $\mathrm{CD} 11 \mathrm{~b}^{+} / \mathrm{I}-\mathrm{A}^{\mathrm{b}+}$ & ND & ND & ND & ND \\
\hline$\%$ Total Spleen ${ }^{c}$ & 77 & 62 & 54 & 61 \\
\hline
\end{tabular}

${ }^{\mathrm{a}}$ Mice were treated with vehicle, $200 \mathrm{mg}$ propanil/kg body weight (P200), $200 \mathrm{mg}$ 2,4-

D/kg body weight (D200) or a mixture containing $200 \mathrm{mg}$ propanil $+200 \mathrm{mg}$ 2,4-D/kg body weight (200/200). Spleens were extracted at 14 days after treatment as detailed in Materials and Methods.

${ }^{b}$ Data represent the average percent of positive staining cells per spleen \pm standard deviation. 4-8 animals were used per group.

${ }^{\mathrm{c}}$ Data represents the addition of the percentage of $\mathrm{B} 220^{+}, \mathrm{CD} 4^{+}, \mathrm{CD} 8^{+}$and $\mathrm{CD} 11 \mathrm{~b}^{+} / \mathrm{Gr}-$

$1^{+}$cells per treatment group.

${ }^{\mathrm{d}} \mathrm{B} 220^{+} \mathrm{B}$ cells, $\mathrm{CD} 4^{+} \mathrm{T}$ cells, $\mathrm{CD}^{+} \mathrm{T}$ cells, $\mathrm{CD} 11 \mathrm{~b}^{+} / \mathrm{Gr}-1^{+}$Neutrophils,

$\mathrm{CD}_{11 \mathrm{~b}}{ }^{+} / \mathrm{I}_{-} \mathrm{A}^{\mathrm{b}+}$ Macrophage/Dendritic cells

$\mathrm{ND}=$ not determined

$* \mathrm{p} \leq 0.05$ vs. vehicle control. 
Table 8. Chapter 3. Absolute cell numbers in the spleen at 14 days after herbicide treatment

\begin{tabular}{|c|c|c|c|c|}
\hline Population $^{\mathrm{e}}$ & Vehicle $^{a}$ & P200 & D200 & $200 / 200$ \\
\hline $\mathrm{B} 220^{+}$ & $38 \pm 10^{b}$ & $42 \pm 9$ & $24 \pm 7 *$ cd & $45 \pm 12 *$ \\
\hline $\mathrm{CD}^{+}$ & $13 \pm 4$ & $12 \pm 2$ & $7 \pm 4 *^{\mathrm{c}}$ & $10 \pm 3 *$ \\
\hline $\mathrm{CD}^{+}$ & $10 \pm 3$ & $8 \pm 3$ & $9 \pm 3$ & $9 \pm 3$ \\
\hline $\mathrm{CD} 11 \mathrm{~b}^{+} / \mathrm{Gr}-1^{+}$ & $2 \pm 1$ & $11 \pm 4^{*}$ & $2 \pm 1^{\mathrm{cd}}$ & $15 \pm 7^{*}$ \\
\hline $\mathrm{CD} 11 \mathrm{~b}^{+} / \mathrm{I}-\mathrm{A}^{\mathrm{b}+}$ & ND & ND & ND & ND \\
\hline
\end{tabular}

${ }^{a}$ Mice were treated with $200 \mathrm{mg}$ propanil/kg body weight (P200), $200 \mathrm{mg}$ 2,4-D/kg body weight (D200) or a mixture containing $200 \mathrm{mg}$ propanil $+200 \mathrm{mg}$ 2,4-D/kg body weight (200/200). Spleens were extracted at 14 days after treatment as detailed in Materials and Methods.

${ }^{b}$ Data represent the mean absolute number of positive staining cells/spleen $\left(10^{6}\right) \pm$ standard deviation $\left(10^{6}\right)$. 4-8 animals were used per group.

${ }^{\mathrm{c}} \mathrm{p} \leq 0.05$ vs. P200.

${ }^{d} \leq 0.05$ vs. $200 / 200$.

e $\mathrm{B}^{2} 20^{+} \mathrm{B}$ cells, $\mathrm{CD} 4^{+} \mathrm{T}$ cells, $\mathrm{CD}^{+} \mathrm{T}$ cells, $\mathrm{CD} 11 \mathrm{~b}^{+} / \mathrm{Gr}-1^{+}$Neutrophils, $\mathrm{CD}_{11 \mathrm{~b}}{ }^{+} / \mathrm{I}-\mathrm{A}^{\mathrm{b}+}$ Macrophage/Dendritic cells $* \mathrm{p} \leq 0.05$ vs. vehicle control. 
Table 9.Chapter 3. The number of cells of unknown phenotype in the spleen 14 days after herbicide treatment

\begin{tabular}{|c|c|c|c|c|}
\hline Cell count & Vehicle $^{\mathrm{a}}$ & P200 & D200 & $200 / 200$ \\
\hline Spleen cell count & $81 \pm 20^{b}$ & $104 \pm 24 *$ & $72 \pm 26$ & $125 \pm 40 *$ \\
\hline Total cells stained & $63^{c}$ & 73 & 42 & 79 \\
\hline Remaining cells & $18^{\mathrm{d}}$ & 31 & 30 & 46 \\
\hline
\end{tabular}

a Mice were treated with $200 \mathrm{mg}$ propanil/kg body weight (P200), $200 \mathrm{mg}$ 2,4-D/kg body weight (D200) or a mixture containing $200 \mathrm{mg}$ propanil $+200 \mathrm{mg}$ 2,4-D/kg body weight (200/200). Spleens were extracted at 14 days after treatment as detailed in Materials and Methods.

${ }^{b}$ Data represent the mean cell count $\times 10^{6} \pm$ standard deviation $\times 10^{6}$. 6-12 animals were used per group.

${ }^{\mathrm{c}}$ Data is derived from Table 8 and represents the addition of the absolute number of $\mathrm{B} 220^{+}, \mathrm{CD}^{+}, \mathrm{CD}^{+}$and $\mathrm{CD} 11 \mathrm{~b}^{+} / \mathrm{Gr}-1^{+}$cells per treatment group.

${ }^{d}$ Data represent the difference between the spleen cell count and the total number of cells stained.

$* \mathrm{p} \leq 0.05$ vs. vehicle control. 
Table 10. Chapter 3. Differential percentages 7 days after herbicide treatment

\begin{tabular}{|c|c|c|c|c|}
\hline Population & Lymphocytes $^{a}$ & Monocytes & Neutrophils & $\begin{array}{c}\text { Banded } \\
\text { Neutrophils } \\
\text { c }\end{array}$ \\
\hline Vehicle & $98 \pm 1^{b}$ & 0 & $2 \pm 1$ & 0 \\
\hline $\mathrm{P} 200$ & $94 \pm 4$ & $1 \pm 0.7$ & $5 \pm 3$ & $2 \pm 1$ \\
\hline D200 & $94 \pm 3$ & $1 \pm 1$ & $5 \pm 3$ & 0 \\
\hline $200 / 200$ & $87 \pm 3$ & $2 \pm 1 *$ & $10 \pm 4^{*}$ & $0.2 \pm 0.4$ \\
\hline
\end{tabular}

${ }^{\mathrm{a}}$ Mice were treated with vehicle, $200 \mathrm{mg}$ propanil/kg body weight (P200), $200 \mathrm{mg}$ 2,4D/kg body weight (D200) or a mixture containing $200 \mathrm{mg}$ propanil $+200 \mathrm{mg}$ 2,4-D/kg body weight (200/200). Spleens were extracted at 7 days after treatment as detailed in Materials and Methods. 100 cells were counted/spleen.

${ }^{\mathrm{b}}$ Data represent the average of 12 animals/group and represents the average percentage of cells counted.

c Banded neutrophils represent a subpopulation of neutrophils with bands. These cells are included in the neutrophil cell count.

$* \mathrm{p} \leq 0.05$ vs. vehicle control. 
Table 11. Chapter 3. Differential percentages 14 days after herbicide treatment

\begin{tabular}{|l|c|c|cc|}
\hline Population & Lymphocytes $^{\text {a }}$ & Monocytes & Neutrophils & Banded \\
& & & & Neutrophils \\
& & & \\
& $97 \pm 3^{\mathrm{b}}$ & $0.2 \pm 0.4$ & $3 \pm 3$ & 0 \\
\cline { 1 - 1 } Vehicle & $93 \pm 2$ & $0.6 \pm 0.5$ & $6 \pm 1$ & 0 \\
\cline { 1 - 1 } P200 & $97 \pm 2$ & $0.2 \pm 0.4$ & $2 \pm 1$ & 0 \\
\cline { 1 - 1 } D200 & $80 \pm 7$ & $1.6 \pm 1.5$ & $18 \pm 7 *$ & $8 \pm 4$ \\
\cline { 1 - 1 } & & & & 0 \\
\hline
\end{tabular}

${ }^{\mathrm{a}}$ Mice were treated with vehicle, $200 \mathrm{mg}$ propanil/kg body weight (P200), $200 \mathrm{mg}$ 2,4-

$\mathrm{D} / \mathrm{kg}$ body weight (D200) or a mixture containing $200 \mathrm{mg}$ propanil $+200 \mathrm{mg}$ 2,4-D/kg body weight (200/200). Spleens were extracted at 14 days after treatment as detailed in Materials and Methods. 100 cells were counted/spleen.

${ }^{\mathrm{b}}$ Data represent the average of 12 animals/group and represents the average percentage of cells counted.

c Banded neutrophils represent a subpopulation of neutrophils with bands. These cells are included in the neutrophil cell count. $* \mathrm{p} \leq 0.05$ vs. vehicle control. 
Chapter 4. Evaluation of the Antibody Response to Streptococcus pneumoniae after Exposure to a Mixture of Herbicides 


\section{INTRODUCTION}

Pesticides represent an important group of chemicals that are often applied as mixtures and that are found as common contaminates in air and groundwater samples (US Geological Survey, 1997; USGS National Water Quality Assessment Program, 1998). The present study examines the changes that occur in the immune response to Streptococcus pneumoniae after exposure to a chemical mixture containing the herbicides 3,4-dichloropropionanaline (propanil) and 2,4-dichlorophenoxyacetic acid (2,4-D). Propanil and 2,4-D are heavily used by the agricultural industry and are commonly applied as a mixture under the product names of NOX-D ${ }^{\circledR}$ and Herbanil $368^{\circledR}$ (Farm Chemicals Handbook, 1998).

This study examines the changes in the antibody response to vaccination with heat-killed Streptococcus pneumoniae (HKSP) after exposure to the mixture of propanil and 2,4-D. S. pneumoniae is recommended in the National Toxicology Program's Tier II guidelines as a host-resistance model for the assessment of changes to the humoral immune system (Luster et al., 1988). The antibody response after immunization with the heat-killed, nonencapsulated, type II variant of $S$. pneumoniae elicits a T-independent type II (TI-2) antibody response and a T-dependent (TD) antibody response (Snapper and Mond, 1996). In the absence of the polysaccharide capsule, the main antigen in the TI-2 response is phosphorylcholine (PC) (Snapper and Mond, 1996). Our results demonstrate that exposure to propanil, or to the mixture containing propanil and 2,4-D, increases the frequency of B cells in the spleen specific for PC and whole HKSP antigens. 


\section{MATERIALS AND METHODS}

Animals. C57BL/6 female mice, 6-8 weeks of age, were purchased from Charles River Farms (Wilmington, DE). Mice were allowed to acclimate for one week after shipment and received food and water ad libitum.

Source of xenobiotics. Propanil was purchased from Chem Service (West Chester, PA) and has a purity of 99\%. Commercial-grade 2,4-D amine (dimethylamine salt of 2,4-dichlorophenoxyacetic acid, Universal Cooperatives, Inc., Minneapolis, MN) with a purity of $39.2 \%$ was purchased from Southern States Cooperative (Morgantown, WV). The concentration of 2,4-D used for all experiments was calculated based on the amount of active 2,4-D.

Exposure of mice to herbicide mixtures and immunization with HKSP. Mice were treated with vehicle, $200 \mathrm{mg}$ propanil/kg body weight (P200), $200 \mathrm{mg}$ 2,4-D/kg body weight (D200) or a mixture containing $200 \mathrm{mg}$ propanil/kg body weight $+200 \mathrm{mg}$ 2,4D/kg body weight (200/200). Propanil was dissolved in peanut oil (Planters, Nabisco Inc.) and 2,4-D amine was dissolved in phosphate buffered saline (PBS) to the appropriate concentration. Following the protocol of Barnett et al., 1992, animals were immunized i.p. with $1 \times 10^{8}$ heat-killed HKSP four days after exposure to P200, D200 or 200/200. The phenotype of spleen cells, and number of antibody producing cells in the spleen were assessed at 10 days after immunization (14 days after herbicide exposure).

Cell isolation. Spleens were weighed and the spleen to body weight was calculated as the ratio of the individual spleen weight to the total body weight. Single cell suspensions were prepared by suspending individual spleens in $3 \mathrm{ml}$ of RPMI (BioWittaker, Walkersville, MD) containing 10\% fetal bovine serum (FBS, Hyclone, 
Logan, UT), 50 mM HEPES (Sigma, St. Louis), 2 mM L-glutamine (Gibco, Rockville, MD), 100 units/ml penicillin (Gibco), $100 \mathrm{mg} / \mathrm{ml}$ streptomycin (Gibco) and $0.049 \mathrm{mM} \beta$ mercaptoethanol (Sigma) and pressing them through a $70 \mu \mathrm{M}$ nylon screen bag (Fisher Scientific, Pittsburgh, PA). Cells were then passed through a 26 gauge needle. Red blood cells were lysed with Tris-buffered ammonium chloride.

Culture of Streptococcus pneumoniae and preparation of HKSP. Biosafety level II OSHA safety regulations were followed during culture. Streptococcus pneumoniae R36a (Sp), a rough phase phenotype derived from the type 2 variant D39, was streaked on to a trypticase soy agar plate containing 5\% defibrinated sheep blood (TSA II 5\% SB) (Becton Dickinson Microbiology Systems, Cockeysville, MD). Plates were sealed with parafilm and incubated at $37^{\circ} \mathrm{C}$ for $12-24 \mathrm{hrs}$. New plates were streaked every $24 \mathrm{hrs}$ or removed from the incubator at $12 \mathrm{hrs}$ and left at $27^{\circ} \mathrm{C}$. At room temperature, cells were found to be viable for one week. For vaccine culture, 1-2 colonies were selected and passed into $4 \mathrm{ml}$ Todd Hewitt Broth (THB) (DIFCO Laboratories, Detroit, MI) containing $0.02 \%$ defibrinated sheep blood (Rockland, Gilbertsville, PA). The culture was incubated in a candle jar at $37^{\circ} \mathrm{C}$ for $12 \mathrm{hrs}$ until log phase OD (absorbance at $650 \mathrm{~nm}$ ) of 0.6 was achieved. Four $\mathrm{ml}$ of culture was transferred into $20 \mathrm{ml}$ of THB containing $0.02 \%$ sheep blood and incubated for $1 \frac{1}{2}-2 \mathrm{hrs}$ in a candle jar at $37^{0} \mathrm{C}$. Two$3 \mathrm{ml}$ aliquots of live culture were separated out and plated in serial dilutions (starting at 1:1000) on TSAII 5\%SB plates to determine bacterial density. Bacterial cultures to be heat-killed were placed in a $60^{\circ}$ water bath for $10 \mathrm{hrs}(1 \mathrm{hr} / 20 \mathrm{ml})$. Heat killed bacteria were centrifuged at $6000 \mathrm{rpm}$ for $15 \mathrm{~min}$. and washed 4 times with $20 \mathrm{ml}$ of $0.85 \%$ saline solution. The sterility of the culture was checked by plating on TSAII $5 \%$ SB plates. The 
pellet was then diluted to $10^{9}$ bacteria / $\mathrm{ml}$ in $1 \mathrm{X}$ PBS and frozen at $-20^{\circ} \mathrm{C}$. For immunization, $0.1 \mathrm{ml} /$ mouse $\left(1 \times 10^{8}\right.$ bacteria/immunization $)$ was administered by intraperitoneal injection (i.p.).

ELISPOT assays. Antibody producing cells were determined in an ELISPOT assay by counting the number of spot forming cells (SFC) specific for the PC polysaccharide antigen or the whole bacteria, HKSP. Using sterile culture technique, ninety six well nitrocellulose plates (Millipore, Bedford, MA) were coated overnight at $4^{0}$ $\mathrm{C}$ with $50 \mu \mathrm{l} /$ well of PC-BSA (Biosearch Technologies, Novato CA) at a final concentration of $10 \mu \mathrm{g} / \mathrm{ml}$ or HKSP $(50 \mu \mathrm{l} /$ well $)$ using $1 \times 10^{8}$ bacteria/ml diluted in sterile PBS. The following day, plates were washed 3 times with sterile PBS and blocked with $200 \mu 1 /$ well of sterile RPMI containing $20 \%$ fetal bovine serum (FBS) and incubated at $37^{0} \mathrm{C}$ in $5 \% \mathrm{CO}_{2}$ for at least $2 \mathrm{hr}$. After blocking, plates were washed twice with sterile PBS using $200 \mu 1 /$ well. Single cell suspensions of spleen cells were diluted to $1 \times$ $10^{7}, 5 \times 10^{6}, 1 \times 10^{6}$ and $5 \times 10^{5} / \mathrm{ml}$ and $100 \mu \mathrm{l}$ of cells plated/well. Plates were incubated at $37^{\circ} \mathrm{C}$ and $5 \% \mathrm{CO}_{2}$ for exactly $4 \mathrm{hrs}$. Plates were washed 6 times with PBS containing $0.05 \%$ Tween 20 (PBS-T, Fischer Scientific) and incubated overnight at $4^{0} \mathrm{C}$ with $100 \mu 1$ of akaline phosphatase (AP) conjugated goat anti-mouse $\operatorname{IgM}(\mu$ heavy chain specific) and IgG (heavy and light chain specific) (Southern Biotechnology Associates, Inc., Birmingham, AL). Secondary antibody was diluted 1:250 in PBS-T containing 1\% BSA and $100 \mu \mathrm{l} /$ well was added to each well. Plates were incubated with secondary antibody for $1 \mathrm{hr}$ at $27^{0} \mathrm{C}$ and subsequently washed 6 times with washing buffer. SIGMAFAST $0.15 \mathrm{mg} / \mathrm{ml}$ 5-bromo-4-cholor-3-indoyl phosphate, $0.30 \mathrm{mg} / \mathrm{ml}$ nitro blue tetrazolium and $5 \mathrm{mM} \mathrm{MgCl}_{2}$ (BCIP/NBT) tablets were dissolved in deionized water (1 
tablet $/ 10 \mathrm{ml}) .100 \mu \mathrm{l}$ of substrate was added to each well and plates were allowed to develop until spots were visible. Plates were then washed 8 times with deionized water and allowed to dry overnight. Dilutions were selected that allowed for counting of 30-50 spots/well using a dissection microscope. Counts were normalized to $10^{6} \mathrm{~B}$ cells by dividing the number of spots in $10^{6}$ cells by the ratio of $\mathrm{B} 220^{+}$cells in the spleen. The total number of spot forming cells (SFC) in the spleen was calculated as the number of $\mathrm{SFC} / 10^{6}$ spleen cells multiplied by the total spleen cell count.

Immunofluorescence. For flow cytometric analysis, spleen cells were washed and re-suspended in media containing PBS supplemented with $2 \%$ FBS and $0.02 \%$ sodium azide (Sigma) (staining media). Fc $\gamma$ III/II receptors were blocked with purified antiCD16/CD32. Cells were stained with anti-CD4-FITC (GK1.5), anti-CD8 $\alpha-P E ~(53-6.7)$, anti-CD45R/B220-PE (RA3-6B2), anti-Ly-6G(Gr-1) and anti-Ly6C-Fitc (RB6-8C5), anti-CD11b-PE (M1-70) and anti-I-A ${ }^{\mathrm{b}}\left(\mathrm{A}_{\beta}^{\mathrm{b}}\right)$ (AF6-120.1) (Pharmingen, San Diego, CA). Staining media was used for all washes. Individual spleens were stained. Fc $\gamma$ III/II receptors were blocked prior to staining using $1 \mu \mathrm{g}$ antibody/million cells. Cells were then washed twice and $1 \times 10^{6}$ cells were stained in a total volume of $25 \mu l$ of antibody at the appropriate concentration for $25 \mathrm{~min}$. on ice in the dark. Cells were washed twice and fixed in $0.04 \%$ paraformaldehyde (Fisher Scientific, Pittsburgh, PA). For analysis, 10,000 cells were analyzed on a Becton-Dickinson FACScan (Becton Dickinson Immunocytometry Systems, Mansfield, MA). Analysis was performed using WinMDI software (Joseph Trotter, Scripps Institute, San Diego, CA) on ungated splenocytes. The following population percentages were determined: $\mathrm{CD}^{+} \mathrm{T}$ cells, $\mathrm{CD} 8^{+} \mathrm{T}$ cells, $\mathrm{B} 200^{+} \mathrm{B}$ cells, $\mathrm{CD} 11 \mathrm{~b}^{+} \mathrm{RB}^{+}$(neutrophils), CD11b ${ }^{+} \mathrm{I}-\mathrm{A}^{\mathrm{b}+}$ (monocytes/dendritic cells). Population 
percentages, obtained from flow cytometric analysis, were used to calculate the absolute cell numbers by multiplying the ratio of cells in a population by the total number of cells harvested per organ.

Statistics. Comparison of herbicide treatment groups: One way analysis of variance (ANOVA) with a significance level of $\mathrm{p} \leq 0.05$ was done on all parameters assayed using a Dunnett's t-test to compare the response of treated animals to vehicle control and a Tukey-Kramer test was used to compare all treatment pairs. Mixture interactions were analyzed using a partial factorial analysis.

\section{RESULTS}

\section{The frequency of SFC specific for HKSP antigen}

Ten days after vaccination and 14 days after herbicide exposure, the number of SFC specific for the whole cell HKSP was determined. The P200 and 200/200 HKSPspecific IgM response was elevated 8-fold and 12-fold respectively over the response given by vehicle treated animals (Figure 12A). The average number of HKSP-specific IgM SFC was 366 SFC $/ 10^{6}$ B cells for P200 treatment and 548 SFC $/ 10^{6}$ B cells for 200/200 treatment as compared to $46 \mathrm{SFC} / 10^{6} \mathrm{~B}$ cells produced by vehicle treated animals. The changes associated with 2,4-D exposure were never significant as compared to vehicle, however, there was an apparent 2 fold increase in the D200 HKSP specific IgM response resulting in an average of $116 \mathrm{SFC} / 10^{6} \mathrm{~B}$ cells (Figure 12A). The HKSP specific IgG response was also elevated after P200 and 200/200 treatments (Figure 12B). P200 treatment resulted in a 6-fold increase over vehicle resulting in $405 \mathrm{SFC} / 10^{6}$ B cells vs. $64 \mathrm{SFC} / 10^{6} \mathrm{~B}$ cells after vehicle treatment (Figure 12B). The D200 treatment was not increased as compared to vehicle control but there was an apparent average 2- 
fold increase over vehicle resulting in $132 \mathrm{SFC} / 10^{6} \mathrm{~B}$ cells. The 200/200 treatment was increased 8-fold over vehicle producing $512 \mathrm{SFC} / 10^{6} \mathrm{~B}$ cells (Figure 12B).

\section{The frequency of SFC specific for PC antigen}

The PC specific IgM response after P200 treatment was increased almost 5-fold over the response given by immunized animals treated with vehicle, increasing from an average of $81 \mathrm{SFC} / 10^{6} \mathrm{~B}$ cells for vehicle to $391 \mathrm{SFC} / 10^{6} \mathrm{~B}$ cells in propanil-treated animals (Figure 13A). In a similar manner, the PC specific IgM response from 200/200 mixture-treated animals was increased 7 -fold over vehicle, averaging $570 \mathrm{SFC} / 10^{6} \mathrm{~B}$ cells (Figure 13A). In contrast, the D200 treatment response to the PC antigen was similar to the response given by vehicle-treated spleens averaging $66 \mathrm{SFC} / 10^{6} \mathrm{~B}$ cells (Figure 13A). The PC specific IgG response in animals exposed to P200 and 200/200 was increased 5 fold (P200) and 8 fold (200/200) over vehicle averaging 336 and 530 $\mathrm{SFC} / 10^{6} \mathrm{~B}$ cells respectively as compared to vehicle, $64 \mathrm{SFC} / 10^{6} \mathrm{~B}$ cells (Figure $13 \mathrm{~B}$ ).

Animals exposed to D200 ( $78 \mathrm{SFC} / 10^{6} \mathrm{~B}$ cells) had a PC specific IgG response similar to vehicle treated animals (Figure 13B). Non-immunized animals did not respond to PC or HKSP antigens (data not shown).

\section{Cell populations in the spleen.}

Leukocytes in the spleen were separated into their individual lymphocyte and granulocyte populations by immunofluorescence and flow cytometric analysis. The populations analyzed were $\mathrm{B} 220^{+}$(B cells), $\mathrm{CD} 4^{+}$and $\mathrm{CD} 8^{+}\left(\mathrm{T}\right.$ cells), $\mathrm{CD} 11 \mathrm{~b}^{+} \mathrm{Gr}-1^{+}$ (neutrophils), CD11 b $\mathrm{I}^{+} \mathrm{A}^{\mathrm{b+}}$ (macrophage/dendritic cells) and NK1.1 ${ }^{+}$(NK cells). Treatment with P200 and 200/200 resulted in decreases in the percentage of B cells and T cells and a significant increase in the percentage of neutrophils in the spleen $(10 \% \pm 4 \%$ 
for P200 treatment and $13 \% \pm 6 \%$ for $200 / 200$ treatment vs. $4 \% \pm 3 \%$ in the vehicle group) (Table 12). The spleen phenotype of D200 treated animals was similar to vehicle (Table 12).

\section{Absolute cell numbers in the spleen}

In spite of decreases in the percentage of lymphocytes in the spleens of P200 treated animals (Table 12), the absolute number of lymphocytes was similar to that of immunized control animals (Table 13). The average total cell count $\left(10^{6}\right)$ in vehicle treated spleens was $84 \pm 18$ as compared to $116 \pm 26$, P200, $78 \pm 15$, D200 and $117 \pm 30$ 200/200 treatment. Therefore, after treatment with P200, lymphocyte populations in the spleen are maintained at vehicle control levels by an increase in the total number of cells. In contrast, in spite of an increase in cell number with the 200/200 treatment, the absolute number of B cells in 200/200-treated animals were decreased compared to vehicle. CD4 ${ }^{+}$ T cells in 200/200-treated animals were decreased compared to vehicle treatment (Table 13). The absolute number of $\mathrm{CD} 8^{+} \mathrm{T}$ cells in the $200 / 200$ treatment group was similar to vehicle treated animals (Table 13). The absolute number of neutrophils was increased after both P200 and 200/200 treatment as compared to vehicle (Table 13). The absolute number of macrophage/dendritic cells was also increased to with 200/200 treatment (Table 13). There were also apparent, although not statistically significant, increase in NK cells in all treatment groups (Table 13).

\section{The total number of HKSP SFC after mixture treatment.}

The total number of SFC in an individual spleen were calculated in order to determine the effect of the loss of B cells after 200/200 treatment on the total number of SFC in the spleen. The fold increase in the number of SFC in animals exposed to P200 
and D200 treatment were similar to the increases seen when the number of SFC was normalized to $10^{6} \mathrm{~B}$ cells (Table 14 and Figures 12-13). In contrast, the fold increases in the number of SFC in the 200/200 treatment group were consistently lower, reflecting the decreases in the absolute number of B cells in the spleen after exposure to the 200/200 mixture. Therefore, although the frequency of responding B cells was greater with mixture treatment, there were fewer SFC in the spleens of $200 / 200$ treated animals than P200 treated animals.

\section{DISCUSSION}

This research demonstrates that propanil and a mixture containing propanil and 2,4-D can alter the humoral immune response to HKSP by increasing the frequency of antibody forming B cells in the spleen. Exposure to propanil or to the mixture four days prior to immunization with HKSP increased the frequency of SFC specific for HKSP and PC antigen. Exposure to 2,4-D resulted in apparent increases in the HKSP antibody response but did not change the $\mathrm{PC}$ specific antibody response.

Increases in antibody forming cell frequency after propanil or mixture treatment were not specific to either the HKSP or PC antigen. This suggests that these changes result from changes in a general regulatory mechanism of antibody production that regulates both the TD and TI-2 antibody responses such as increased antigen presentation or increased B cell stimulation.

Propanil and the mixture treatment act to increase the number of neutrophils at 14 days after treatment. The fact that the two treatment groups that had neutrophil increases also had the highest increases in the frequency of antigen specific antibody-forming B cells leads us to hypothesize that neutrophils may act to enhance the antibody response to 
the S. pneumoniae antigens. Mature neutrophils have been shown to process and present antigen on MHC class I molecules (Potter et al., 2001). The immediate precursors of mature neutrophils can be driven in vitro to acquire a dendritic cell phenotype, including the expression of MHC class II and costimulatory molecules (Oehler, et al. 1998). Neutrophils also have been shown to produce numerous cytokines including IL-1 $\beta$, TNF$\alpha$, IL-8 and TGF- $\beta$. TNF- $\alpha$ has been demonstrated to be required for an optimal antibody response to HKSP (Cassatella, 1995). Neutrophils also produce macrophage inflammatory protein (MIP)-3 $\alpha$ and MIP-3 $\beta$, chemokines that have been shown to induce chemotaxis of immature and mature dendritic cells (DC) to the site of inflammation (Scapini et al., 2001). However neutrophil numbers are normal at 7 days after treatment. Cytokine and chemokine help, however, are necessary in the very early response to antigen. TNF- $\alpha$ regulation is required within the first $72 \mathrm{~h}$ after immunization (Khan $e t$ al., 2002). Therefore, more experiments on earlier timepoints (1-4 days after treatment) are necessary in order to determine the role of neutrophils in the antibody response to $S$. pneumoniae.

Although the highest average frequency of $S$. pneumoniae specific plasma cells occurs in the mixture-treated group, the total number of antigen specific B cells in mixture treated spleens was actually decreased below the number of antigen specific B cells in animals exposed to propanil. Even with $35 \%$ fewer B cells and 43\% fewer CD4 ${ }^{+}$ T cells after 200/200 treatment, the number of S. pneumoniae specific plasma cells found in the spleens of mixture treated animals were still increased 2-4 fold over the total number of S. pneumoniae specific plasma cells found in the spleens of immunized animals that were exposed to vehicle (Table 13). Taken together, these results suggest 
that the mechanism(s) responsible for the increase in the frequency of $S$. pneumoniae specific plasma forming B cells in the spleen is independent of the total number of B or T cells in the spleen. A possible mechanism will be discussed in greater detail in the General Discussion.

Animals exposed to 2,4-D had apparent, modest increases in the number of HKSP specific antibody producing cells suggesting that the 2,4-D associated effect may be $\mathrm{T}$ cell dependent. However, 2,4-D also appears to enhance the frequency of PC and HKSP specific plasma cells over the response given by propanil exposure alone when present in the mixture, although these increases are not statistically significant (Figures 12-13). The nonencapsulated form of the HKSP vaccine that we are using excludes the polysaccharide capsule of wild type $S$. pneumoniae, however, the HKSP response is a response to the whole bacteria including both $\mathrm{PC}$ (TI-2) and protein (TD) antigens. Therefore, further research is necessary using purified S. pneumoniae protein antigens in order to determine the exact nature of the response after exposure to 2,4-D.

One of the advantages of assessing the toxicological effects of chemical exposure on the immune system is that it is possible to study both the functional changes and their molecular mechanisms in vitro with the aim of correlating these changes to in vivo immunosuppression in a murine model (Munson et al., 1982; Luster et al., 1993). In this study, however, exposure to the herbicides propanil or 2,4-D, or a mixture containing propanil and 2,4-D, resulted in functional immune changes that could not be predicted by previous in vivo or in vitro studies. Of particular interest is the fact that the antibody response to the SRBC antigen was decreased after exposure to propanil while the antibody response to $S$. pneumoniae is increased in both propanil and mixture-treated 
animals. These results confirm that the nature of the antigen is important in the response to a chemical toxicant. In the immune response to $S$. pneumoniae, the bacterial cell wall and membrane have antigens that are recognized by both the innate and adaptive immune system, allowing for a global immune response. Furthermore, teichoic acid and possibly other components of the cell wall may act as adjuvants as they are known to cause inflammation resulting in increased TNF- $\alpha$ cytokine levels in the blood (Takashima et al., 1997). TNF- $\alpha$ is a cytokine that has been shown to promote B cell development in the spleen (Takashima et al., 1997; Schneider et al., 2001). Therefore, the response to a whole cell bacterial antigen may be significantly different from the response to a hapten or a less complex protein antigen, like SRBC, that is administered without adjuvant.

An increase in the frequency of antibody forming cells may predispose an animal to be susceptible to autoimmune disease. Positive selection of B cells occurs in the spleen and is dependent on B cell activation through the B cell receptor (BCR) and the specificity of antibody for the antigen. In a normal spleen, only $1-3 \%$ of $\operatorname{IgM}^{+} \mathrm{B}$ cells complete development. Increases in the frequency of B cells in the spleen that respond to antigen could result from a decrease in the stringency of positive selection leading to autoantibody production and subsequent autoimmune disease. Although the total number of $B$ cells found in the spleens of mixture-treated mice were equal to the number of $B$ cells in vehicle treated animals, there are important differences between mixture-treated and untreated spleens because the frequency of antibody forming B cells is increased after exposure to the mixture. These increases may result from dis-regulated antibody production. Further research is necessary to determine the mechanism(s) responsible for increases in the number of antibody forming B cells produced in response to HKSP 
immunization after propanil and mixture exposure. Research is also necessary to determine whether these increases will result in actual changes in resistance to immune challenge. 
Figure 12. The frequency of SFC specific for HKSP antigen. Mice were treated with vehicle, P200, D200 or 200/200 and immunized with HKSP as described in Materials and Methods. Spleens were removed 14 days after herbicide treatment. A. Number of IgM SFC $/ 10^{6}$ B cells specific for HKSP. B. Number of IgG SFC $/ 10^{6}$ B cells specific for HKSP. Each circle represents an individual animal. Bars represent the mean number of SFC/10 ${ }^{6} \mathrm{~B}$ cells. $* p \leq 0.05$ vs. vehicle. $\diamond p \leq 0.05$ P200 and 200/200 vs. D200. Fold increase over vehicle is indicated below treatment groups. 
Figure 12. Chapter 4. The number of SFC responding to HKSP

A. HKSP specific IgM

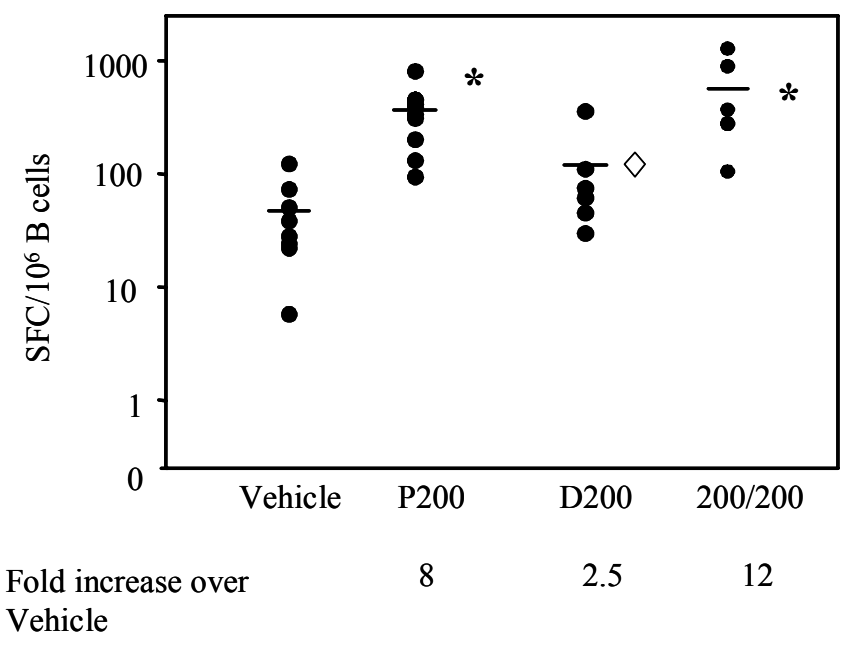

B. HKSP specific IgG

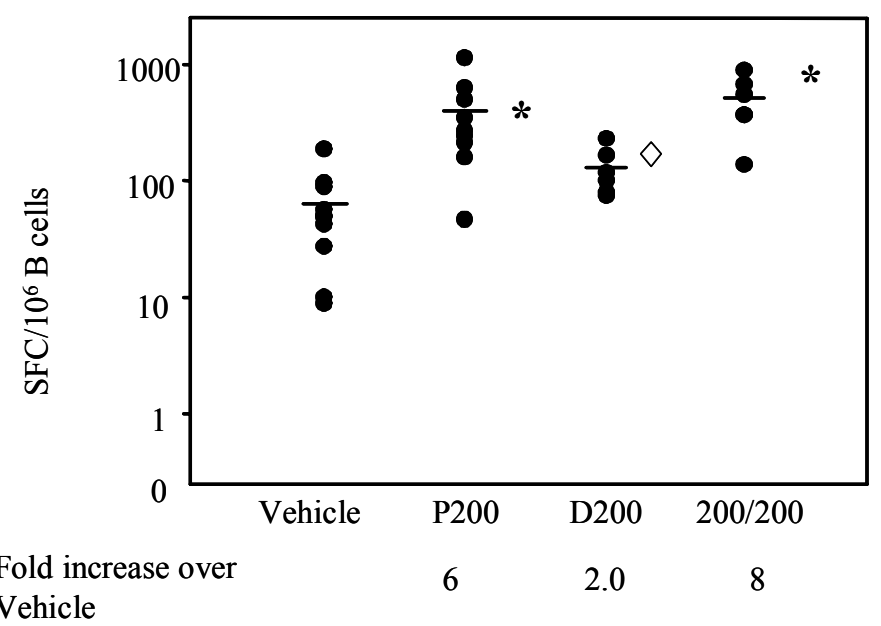


Figure 13. The frequency of SFC specific for PC antigen. Mice were treated with vehicle, P200, D200 or 200/200 and immunized with HKSP as described in Materials and Methods. Spleens were removed 14 days after herbicide treatment. A. Number of IgM SFC $/ 10^{6}$ B cells specific for PC. B. Number of IgG SFC $/ 10^{6}$ B cells specific for PC. Each circle represent individual animal. Bars represent the mean number of SFC $/ 10^{6} \mathrm{~B}$ cells. $* p \leq 0.05 . \diamond p \leq 0.05$ P200 and 200/200 vs. D200. Fold increase over vehicle is indicated below treatment groups. 
Figure 13. Chapter 4. The number of SFC responding to PC antigen

A. PC specific IgM

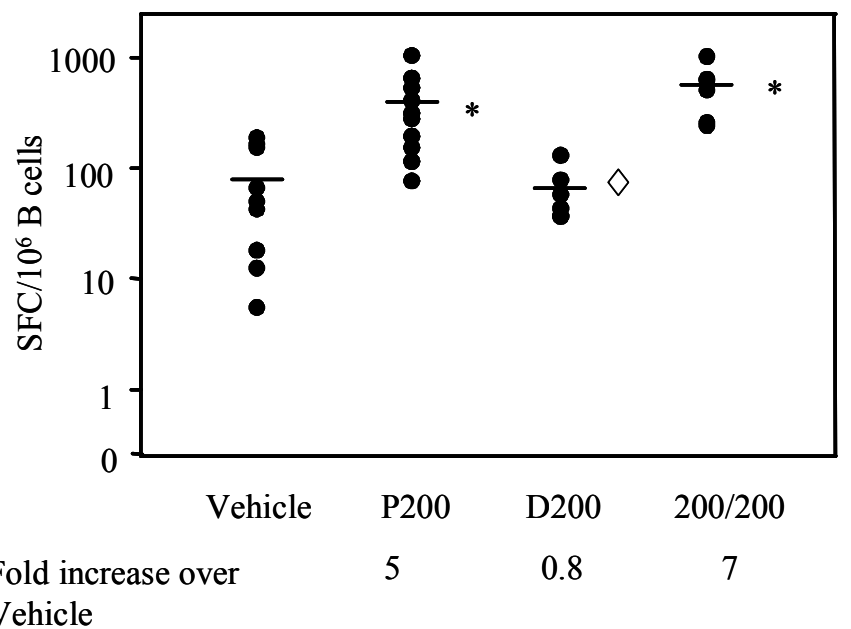

B. PC specific IgG

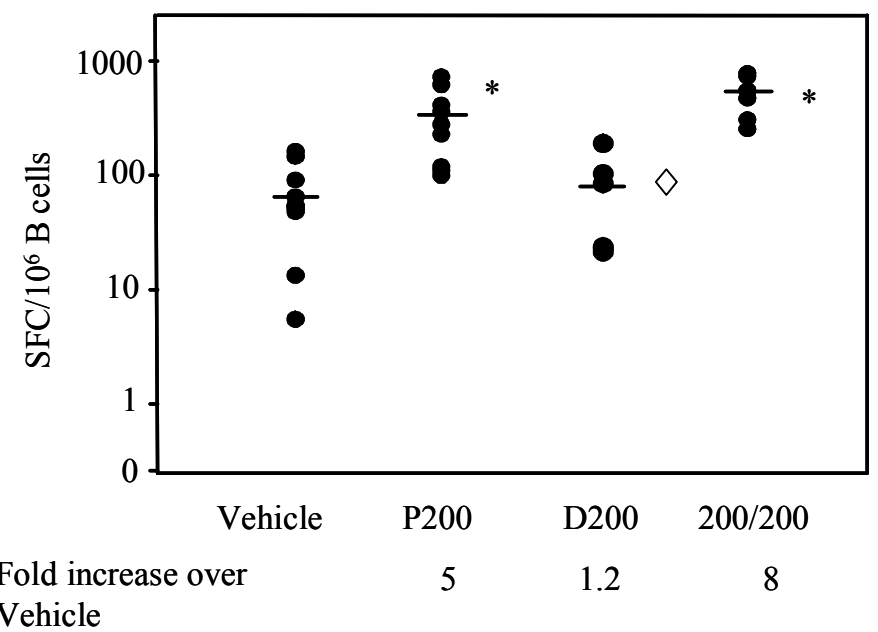


Table 12. Chapter 4. Spleen population percentages

\begin{tabular}{|c|c|c|c|c|}
\hline Population $^{\mathrm{c}}$ & Vehicle $^{\mathrm{a}}$ & P200 & D200 & $200 / 200$ \\
\hline$\overline{\mathrm{B} 220^{+}}$ & $48 \pm 3^{b}$ & $36 \pm 4 *$ & $50 \pm 2$ & $25 \pm 1 *$ \\
\hline $\mathrm{CD}^{+}{ }^{+}$ & $18 \pm 1$ & $10 \pm 1 *$ & $17 \pm 2$ & $6 \pm 3 *$ \\
\hline $\mathrm{CD}^{+}$ & $13 \pm 0.5$ & $8 \pm 0.8 *$ & $11 \pm 1$ & $8 \pm 1 *$ \\
\hline $\mathrm{CD} 11 \mathrm{~b}^{+} / \mathrm{Gr}-1^{+}$ & $4 \pm 3$ & $10 \pm 4^{*}$ & $5 \pm 3$ & $13 \pm 6^{*}$ \\
\hline $\mathrm{CD} 11 \mathrm{~b}^{+} / \mathrm{I}-\mathrm{A}^{\mathrm{b}+}$ & $2 \pm 1$ & $3 \pm 2$ & $3 \pm 2$ & $4 \pm 0.7$ \\
\hline NK cell & $6 \pm 1$ & $7 \pm 1$ & $8 \pm 0.1$ & $7 \pm 2$ \\
\hline
\end{tabular}

${ }^{\mathrm{a}}$ Mice were treated with vehicle, $200 \mathrm{mg}$ propanil/kg body weight (P200), $200 \mathrm{mg}$ 2,4-

D/kg body weight (D200) or a mixture containing $200 \mathrm{mg}$ propanil $+200 \mathrm{mg}$ 2,4-D/kg body weight (200/200). Spleens were extracted at 14 days after herbicide treatment/10 days after vaccination as detailed in Materials and Methods and analyzed by flow cytometric analysis.

${ }^{b}$ Data represent the average percent of positive staining cells per spleen \pm standard deviation. 6 animals were used per group.

${ }^{\mathrm{c}} \mathrm{B} 220^{+} \mathrm{B}$ cells, $\mathrm{CD} 4^{+} \mathrm{T}$ cells, $\mathrm{CD} 8^{+} \mathrm{T}$ cells, $\mathrm{CD} 11 \mathrm{~b}^{+} / \mathrm{Gr}-1^{+}$Neutrophils, $\mathrm{CD} 11 \mathrm{~b}^{+} / \mathrm{I}-\mathrm{A}^{\mathrm{b}+}$ Macrophage/Dendritic cells $* \mathrm{p} \leq 0.05$ vs. vehicle control. 
Table 13.Chapter 4. Absolute cell number in the spleen

\begin{tabular}{|c|c|c|c|c|}
\hline Population $^{\mathrm{c}}$ & Vehicle $^{a}$ & P200 & D200 & $200 / 200$ \\
\hline $\mathrm{B} 220^{+}$ & $40 \pm 8^{b}$ & $48 \pm 18$ & $40 \pm 8$ & $26 \pm 15^{*}$ \\
\hline $\mathrm{CD}^{+}$ & $14 \pm 4$ & $12 \pm 3$ & $13 \pm 2$ & $8 \pm 4^{*}$ \\
\hline $\mathrm{CD}^{+}$ & $10 \pm 2$ & $9 \pm 2$ & $9 \pm 1$ & $9 \pm 1$ \\
\hline $\mathrm{CD} 11 \mathrm{~b}^{+} / \mathrm{Gr}-1^{+}$ & $4 \pm 2$ & $14 \pm 6^{*}$ & $4 \pm 2$ & $16 \pm 8^{*}$ \\
\hline $\mathrm{CD}_{11 \mathrm{~b}} / \mathrm{I}-\mathrm{A}^{\mathrm{b}+}$ & $2 \pm 1$ & $5 \pm 4$ & $3 \pm 1$ & $5 \pm 1^{*}$ \\
\hline NK cell & $4 \pm 0.1$ & $9 \pm 2$ & $6 \pm 0.1$ & $8 \pm 3$ \\
\hline
\end{tabular}

${ }^{\mathrm{a}}$ Mice were treated with vehicle, $200 \mathrm{mg}$ propanil/kg body weight (P200), $200 \mathrm{mg}$ 2,4-

D/kg body weight (D200) or a mixture containing $200 \mathrm{mg}$ propanil $+200 \mathrm{mg} 2,4-\mathrm{D} / \mathrm{kg}$ body weight (200/200). Spleens were extracted at 14 days after treatment/10 days after immunization as detailed in Materials and Methods.

${ }^{b}$ Data represent the mean absolute number of positive staining cells/spleen $\left(10^{6}\right) \pm$ standard deviation $\left(10^{6}\right) .6$ animals were used per group.

${ }^{\mathrm{c}} \mathrm{B} 220^{+} \mathrm{B}$ cells, $\mathrm{CD} 4^{+} \mathrm{T}$ cells, $\mathrm{CD} 8^{+} \mathrm{T}$ cells, $\mathrm{CD} 11 \mathrm{~b}^{+} / \mathrm{Gr}-1^{+}$Neutrophils, $\mathrm{CD}_{11 \mathrm{~b}}{ }^{+} / \mathrm{I}_{-} \mathrm{A}^{\mathrm{b}+}$ Macrophage/Dendritic cells

$* \mathrm{p} \leq 0.05$ vs. vehicle control. 
Table 14. Chapter 4. Average number of SFC/spleen

\begin{tabular}{|c|c|c|c|c|c|}
\hline Antigen & Antibody $^{a}$ & Vehicle & P200 & D200 & $200 / 200$ \\
\hline \multirow[t]{2}{*}{ PC } & IgM & $34 \pm 33^{b}$ & $\begin{array}{c}181 \pm 136^{*} \\
(5)^{\mathrm{c}}\end{array}$ & $\begin{array}{c}24 \pm 10 \\
(0)\end{array}$ & $\begin{array}{c}139 \pm 105 \\
(4)\end{array}$ \\
\hline & IgG & $13 \pm 13$ & $\begin{array}{c}54 \pm 37 * \\
(5)\end{array}$ & $\begin{array}{c}14 \pm 13 \\
\text { (1) }\end{array}$ & $\begin{array}{c}28 \pm 26 \\
(2)\end{array}$ \\
\hline \multirow[t]{2}{*}{ HKSP } & IgM & $9 \pm 10$ & $\begin{array}{c}54 \pm 37 * \\
(6)\end{array}$ & $\begin{array}{c}14 \pm 13 \\
(2)\end{array}$ & $\begin{array}{c}28 \pm 26 \\
\text { (3) }\end{array}$ \\
\hline & IgG & $11 \pm 10$ & $\begin{array}{c}63 \pm 48^{*} \\
(6)\end{array}$ & $\begin{array}{c}24 \pm 8 \\
(2)\end{array}$ & $\begin{array}{c}26 \pm 25 \\
\text { (2) }\end{array}$ \\
\hline
\end{tabular}

a Mice were treated with vehicle, $200 \mathrm{mg}$ propanil/kg body weight (P200), $200 \mathrm{mg}$ 2,4-

D/kg body weight (D200) or a mixture containing $200 \mathrm{mg}$ propanil $+200 \mathrm{mg}$ 2,4-D/kg body weight (200/200) and immunized 4 days later as detailed in Materials and Methods. Spleens were extracted at 14 days after treatment.

${ }^{b}$ Data represent the mean number of SFC $\left(10^{2}\right) \pm$ standard deviation $\left(10^{2}\right) .9$ animals were used per group.

${ }^{\mathrm{c}}$ fold increase over vehicle control.

$* \mathrm{p} \leq 0.05$ vs. vehicle control. 
Chapter 5. Increases in the T-independent and Tdependent Antibody Response to Streptococcus pneumoniae after Exposure to a Mixture of Herbicides 


\section{INTRODUCTION}

It has long been recognized that all exposures to chemicals are to mixtures of chemicals due to the presence of many compounds in our environment (Simmons, 1995). A key question in toxicology is whether exposure to a mixture of chemicals can increase the chances of deleterious health effects to a greater extent than the effects caused by the individual components of the mixture (Yang, 1998). Of special importance, within this area of research, is whether chemicals that are not themselves toxic may act to increase the toxicity of a mixture. The herbicides 3,4-dichloropropionanaline (propanil) and 2,4dichlorophenoxyacetic acid (2,4-D) are heavily used by the agricultural industry and are commonly applied as a mixture under the product names of NOX-D ${ }^{\circledR}$ and Herbanil $368^{\circledR}$ (Farm Chemicals Handbook, 1998). This research examines the effects of exposure to a mixture of propanil and 2,4-D on the antibody response to heat-killed Streptococcus pneumoniae immunization.

This study examines in vivo changes to the antibody response after exposure to propanil, 2,4-D, or a mixture containing propanil and 2,4-D, and immunization with heatkilled Streptococcus pneumoniae (HKSP). The antibody response to immunization with the heat-killed non-encapsulated type II variant of S. pneumoniae has been well characterized in mice (Wu et al.,1999). The main antigens in the response are phosphorylcholine (PC) and pneumococcal surface protein A (PspA). PC is a polysaccharide antigen that elicits a $\mathrm{T}$ independent type II (TI-2) antibody response while PspA is a protein antigen that elicits a $\mathrm{T}$ dependent (TD) antibody response (Snapper and Mond, 1996). 
This study investigates mixture specific changes in the immune response to HKSP.

\section{MATERIALS AND METHODS}

Animals. C57BL/6 female mice, 6-8 weeks of age, were purchased from Charles River Farms (Wilmington, DE). Mice were allowed to acclimate for one week after shipment and received food and water ad libitum.

Source of xenobiotics. Propanil was purchased from Chem Service (West Chester, PA) and has a purity of 99\%. Commercial-grade 2,4-D amine (dimethylamine salt of 2,4-dichlorophenoxyacetic acid, Universal Cooperatives, Inc., Minneapolis, MN) with a purity of $39.2 \%$ was purchased from Southern States Cooperative (Morgantown, WV). The concentration of 2,4-D used for all experiments was calculated based on the amount of active 2,4-D.

Exposure of mice to herbicide mixtures. Mice were treated with either $200 \mathrm{mg}$ propanil/kg body weight (P200), $200 \mathrm{mg}$ 2,4-D/kg body weight (D200) or a mixture containing $200 \mathrm{mg}$ propanil/kg body weight $+200 \mathrm{mg}$ 2,4-D/kg body weight (200/200). Propanil was dissolved in peanut oil (Planters, Nabisco Inc.) and 2,4-D amine was dissolved in phosphate buffered saline (PBS) to the appropriate concentration. Animals were immunized i.p. with $2 \times 10^{8} \mathrm{HKSP}$ on day 0 of herbicide treatment. Assays were performed at 7 and 14 days after immunization and herbicide exposure for the PC or PspA response respectively. It has been previously reported that these are the peak times for the PC and PspA antibody response (Wu et al., 1999). Collection of Blood for Sera ELISA. Mice were anesthetized by injection of $0.1 \mathrm{ml}$ of sodium brevitol (Jones Pharma, Inc., St. Louis, MO) diluted to $10 \mathrm{mg} / \mathrm{ml}$ in sterile water. 
Blood was collected by cardiac puncture using a 26 gauge needle. Collected blood was allowed to coagulate at $4^{0} \mathrm{C}$ overnight. Individual sera were separated by centrifugation at $10,000 \mathrm{RPM}$ for $10 \mathrm{~min}$ and frozen at $-20^{\circ} \mathrm{C}$.

Cell isolation. Spleens were weighed and the spleen to body weight was calculated as the ratio of the individual spleen weight to the total body weight. Single cell suspensions were prepared by suspending individual spleens in $3 \mathrm{ml}$ of RPMI (BioWittaker, Walkersville, MD) containing 10\% fetal bovine serum (FBS, Hyclone, Logan, UT), 50 mM HEPES (Sigma, St. Louis), 2 mM L-glutamine (Gibco, Rockville, MD), 100 units/ml penicillin (Gibco), $100 \mathrm{mg} / \mathrm{ml}$ streptomycin (Gibco) and $0.049 \mathrm{mM} \beta$ mercaptoethanol (Sigma) and pressing them through a $70 \mu \mathrm{M}$ nylon screen bag (Fisher Scientific, Pittsburgh, PA). Cells were then passed through a 26 gauge needle. Red blood cells were lysed with Tris-buffered ammonium chloride.

ELISA for PC and PspA specific Ig isotype titers. Ninety-six well, Immulon 2 plates (Fisher Scientific, Pittsburgh, PA) were coated (50 $\mu \mathrm{l} /$ well) with $5 \mu \mathrm{g} / \mathrm{ml}$ PC-BSA (Biosearch Technologies, Inc. Novato, CA). Immulon 4 plates (Fisher Scientific, Pittsburgh, PA) were coated ( $50 \mu \mathrm{l} /$ well) with $5 \mu \mathrm{g} / \mathrm{ml} \mathrm{rPspA}$ (a gift from Clifford Snapper Ph.D., Uniformed Services University). Plates were incubated overnight at $4^{0} \mathrm{C}$ in a humidified chamber. The next day, plates were washed 4 times in PBS containing 0.05\% Tween-20 (PBS-T). Following washing, plates were blocked with 3\% BSA diluted in PBS ( $200 \mu \mathrm{l} /$ well) and incubated for $2 \mathrm{hrs}$ at $27^{\circ} \mathrm{C}$. Plates were washed 4 times after blocking using PBS-T. Sample dilutions were made in dilution buffer of PBS containing 1\% BSA starting with a 1:10 dilution using 3 fold serial dilutions. Samples were plated in triplicate and plates were incubated overnight at $4^{0} \mathrm{C}$ in a humidified 
chamber. The next day, plates were washed 4 times with PBS-T. Both PC and PspA coated plates were reacted with $100 \mu \mathrm{l} /$ well of akaline phosphatase (AP) conjugated goat anti-mouse $\operatorname{IgM}\left(\mu\right.$ heavy chain specific), $\operatorname{IgG}$ (heavy and light chain specific), $\operatorname{IgG1}\left(\gamma_{1}\right.$ chain specific) and IgG2b ( $\gamma_{2 b}$ chain specific) (Southern Biotechnology Associates, Inc., Birmingham, AL) using $100 \mu \mathrm{l} /$ well using a 1:2000 dilution in dilution buffer. PC coated plates were also reacted with IgG3 (Southern Biotechnology Associates, Inc., Birmingham, AL), $100 \mu 1 /$ well using a 1:2000 dilution in dilution buffer. Plates were incubated with secondary antibody for $1 \mathrm{hr}$ at $27^{\circ} \mathrm{C}$ and subsequently washed 6 times with washing buffer. For AP development P-Nitrophenyl phosphate disoduim (PPNP) (Sigma 104 phosphatase substrate Sigma, St. Louis, MO) was used at a final concentration of $1 \mathrm{mg} / \mathrm{ml}$ or 1 tablet in $5 \mathrm{ml}$ and plated at $100 \mu \mathrm{l} / \mathrm{well}$. Plates were read on an ELISA reader at an optical density (OD) of $405 \mathrm{~nm}$. Standard sera was run on each plate and the lowest point of the linear part of the dilution curve was used to determine sample antibody titers. Serum OD's matching the standard OD were selected their corresponding dilutions were selected for the individual serum antibody titer. Treatment titers were calculated using the geometric mean by multiplying all data points and taking the root of the power. Results were expressed as the $\log _{10}$ of the geometric mean.

ELISPOT assays. Antibody producing cells were measured using an ELISPOT assay specific for the PC polysaccharide antigen or the protein antigen PspA. Using sterile culture technique, ninety six well nitrocellulose plates (Millipore, Bedford, MA) were coated overnight at $4^{0} \mathrm{C}$ with $50 \mu \mathrm{l} /$ well of PC-BSA (Biosearch Technologies, Novato CA) or PspA (a generous gift from Clifford Snapper, M.D., Ph.D, USUHS) at a final concentration of $10 \mu \mathrm{g} / \mathrm{ml}$ diluted in sterile PBS. The following day, plates were 
washed 3 times with sterile PBS and blocked with $200 \mu \mathrm{l} /$ well of sterile RPMI containing $20 \%$ fetal bovine serum (FBS) and incubated at $37^{\circ} \mathrm{C}$ for at least $2 \mathrm{hr}$. After blocking, plates were washed twice with sterile PBS using $200 \mu \mathrm{l} /$ well. Single cell suspensions of spleen cells were diluted to $1 \times 10^{7}, 5 \times 10^{6}, 1 \times 10^{6}$ or $5 \times 10^{5} / \mathrm{ml}$ and $100 \mu 1$ of cells plated/well. Plates were incubated at $37^{\circ} \mathrm{C}$ and $5 \% \mathrm{CO}_{2}$ for exactly 4 hrs. Plates were washed 6 times with PBS containing 0.05\% Tween 20 (PBS-T) and incubated overnight at $4^{0} \mathrm{C}$ with $100 \mu \mathrm{l} /$ well of akaline phosphatase (AP) conjugated goat anti-mouse $\operatorname{IgM}(\mu$ heavy chain specific), IgG (heavy and light chain specific), $\operatorname{IgG1}\left(\gamma_{1}\right.$ chain specific), $\operatorname{IgG} 2 \mathrm{~b}\left(\gamma_{2 \mathrm{~b}}\right.$ chain specific) or IgG3 (Southern Biotechnology Associates, Inc., Birmingham, AL). Secondary antibody diluted 1:250 in PBS-T containing 1\% BSA and $100 \mu 1 /$ well was added to each well. Plates were incubated with secondary antibody for 1 hr at $27^{0} \mathrm{C}$ and subsequently washed 6 times with washing buffer. SIGMAFAST 0.15 $\mathrm{mg} / \mathrm{ml}$ 5-bromo-4-cholor-3-indoyl phosphate, $0.30 \mathrm{mg} / \mathrm{ml}$ nitro blue tetrazolium and $5 \mathrm{mM} \mathrm{MgCl}_{2}(\mathrm{BCIP} / \mathrm{NBT})$ tablets were dissolved in deionized water $(1 \mathrm{tablet} / 10 \mathrm{ml}) .100$ $\mu l$ of substrate was added to each well and plates were allowed to develop until spots were visible. Plates were then washed 8 times with deionized water and allowed to dry overnight. Dilutions were selected that allowed for counting of 30-50 spots/well using a dissection microscope. Counts were normalized to $10^{6} \mathrm{~B}$ cells by dividing the number of spots in $10^{6}$ cells by the ratio of $B 220^{+}$cells in the spleen. The total number of spot forming cells (SFC) in the spleen was calculated as the number of $\mathrm{SFC} / 10^{6}$ spleen cells multiplied by the total spleen cell count.

Immunofluorescence. For flow cytometric analysis, spleen cells were washed and re-suspended in media containing PBS supplemented with $1 \%$ FBS and $0.04 \%$ sodium 
azide (Sigma) (staining media). Fc III/II receptors were blocked with purified antiCD16/CD32. Cells were stained with anti-CD4-FITC (GK1.5), anti-CD8 $\alpha-\mathrm{PE}$ (53-6.7), anti-CD45R/B220-PE (RA3-6B2), anti-Ly-6G(Gr-1)/anti Ly6C-Fitc (RB6-8C5), antiCD11b-PE (M1-70), anti-I-A ${ }^{\mathrm{b}}\left(\mathrm{A}_{\beta}^{\mathrm{b}}\right)(\mathrm{AF} 6-120.1)$, anti-IgM ${ }^{\mathrm{b}}$-Fitc (Igh-6b), anti-IgDBiotin (217-170), anti-CD21/35-Fitc (76G) or anti-CD23-PE (B3B4) (Pharmingen, San Diego, CA). Anti-IgM-Biotin was purchased from Southern Biotechnology Associates, Inc. (Birmingham, AL). Staining media was used for all washes. Individual spleens were analyzed by flow cytometric analysis. Fc $\gamma$ III/II receptors were blocked prior to staining using $1 \mu \mathrm{g}$ antibody/million cells for $25 \mathrm{~min}$. Cells were then washed twice and 1 $\mathrm{x} 10^{6}$ cells were stained in a total volume of $25 \mu 1$ of antibody at the appropriate concentration for $25 \mathrm{~min}$. on ice in the dark. Streptavidin CY-chrome was used as a second-step reagent for biotinylated antibodies (Pharmingen). Cells were fixed in $0.04 \%$ paraformaldehyde (Fisher Scientific, Pittsburgh, PA). For analysis, 10,000 cells were analyzed on a Becton-Dickinson FACScan (Becton Dickinson Immunocytometry Systems, Mansfield, MA). Analysis was performed using WinMDI software (Joseph Trotter, Scripps Institute, San Diego, CA). The following populations were separated: $\mathrm{CD}^{+} \mathrm{T}$ cells, $\mathrm{CD} 8^{+} \mathrm{T}$ cells, $\mathrm{B} 200^{+} \mathrm{B}$ cells, $\mathrm{CD} 11 \mathrm{~b}^{+} \mathrm{RB}^{+}$(neutrophils) CD11b $\mathrm{I}^{+} \mathrm{A}^{\mathrm{b}+}$ (monocytes/dendritic cells, M $\varphi / \mathrm{DC}$ ). Splenic B cell populations were further separated using $\mathrm{B}_{200^{+}} \operatorname{IgM}^{+} \operatorname{IgD}^{\text {low }}$ (new B cells), $\mathrm{B}^{200^{+}} \operatorname{IgM}^{+} \operatorname{IgD}^{+}$(mature B cells), B200 $\operatorname{IgM}^{-}$ IgD $^{-}$(isotype-switched B cells), B200 ${ }^{+} \mathrm{CD} 21 / 35^{\text {high }} \mathrm{CD} 23^{\text {low }}$ (marginal zone B cells (MZB), B200 ${ }^{+} \mathrm{CD} 21 / 35^{\text {int }} \mathrm{CD} 23^{\text {hi }}$ (follicular B cells). Population percentages, obtained from flow cytometric analysis, were used to calculate the absolute cell numbers by 
multiplying the ratio of cells in a population by the total number of cells harvested per organ.

Differential Cell Count. Individual spleens were processed into single cell suspensions. $5 \mu$ l of cells suspended in RPMI, were fixed in a single cell layer on a microscope slide by placing a bead of the spleen cell suspension on a slide and passing over it with another microscope slide. Cells were allowed to air dry and then were stained by dipping the slide in a buffered differential Wright-Giemsa stain (Camco Quik Stain II) (Cambridge Diagnostic Products, Inc., Fort Lauderdale, FL) for 10 seconds. Slides were then washed in deionized water twice for 20 seconds each wash and allowed to air dry. One hundred cells were counted per treatment. Lymphocytes, monocytes, neutrophils, and eosinophils were included in the count.

Statistics. Comparison of herbicide treatment groups: One way analysis of variance (ANOVA) was done on spleen population percentages and total cell numbers using a Dunnett's t-test to compare the dose response of treated animals to vehicle control. A Tukey-Kramer test was used to compare all groups. The mean $\log 10$ antibody titers were used for analysis of sera antibody levels. Mixture interactions were performed using a partial factorial analysis. A synergistic interaction was defined as an increase in the antibody response by the mixture that was greater than the addition of the increase in response given after exposure to the individual components of the mixture. A significance level of $\mathrm{p} \leq 0.05$ was used for all tests. All experiments were performed at least three times with similar results 


\section{RESULTS}

\section{The frequency of PC specific SFC}

Seven days after treatment, the number of PC-specific IgM, total IgG, IgG1, IgG2b and IgG3 SFC were increased in 200/200 mixture-treated animals (Figure 14A-E). PC specific SFC $/ 10^{6}$ B cells were increased over immunized vehicle treated animals 72 fold for $\operatorname{IgM}(12959 \pm 4828$ vs $179 \pm 80), 72$ fold for $\operatorname{IgG}(14093 \pm 6057$ vs $195 \pm 72)$ 151 fold for $\operatorname{IgG} 1(303 \pm 328$ vs $2 \pm 2), 749$ fold for $\operatorname{IgG} 2 b(4491 \pm 4874$ vs. $6 \pm 3)$ and 135 fold for IgG3 ( $1480 \pm 1607$ vs $11 \pm 13$ ) (Figure 14A-E). The anti-PC total IgG, IgG2b and IgG3 responses were found to be synergistically increased over the responses given by P200 and D200 treated animals (Figure 14B, D and E, denoted by $\Psi$ ).

P200 treatment apparently increased the frequency of PC specific SFC for IgM, $\mathrm{IgG}, \mathrm{IgG} 1, \mathrm{IgG} 2 \mathrm{~b}$ and $\mathrm{IgG} 3$. However, none of these increases were statistically significant as compared to immunized vehicle treated animals (Figures 14A-E). The frequency of anti-PC SFC $/ 10^{6}$ B cells in immunized P200 treated animals was IgM, 2193 \pm 2044; IgG, $956 \pm 980 ;$ IgG1, $24 \pm 25 ; \operatorname{IgG} 2 b, 222 \pm 252$ and IgG3, $78 \pm 58$ (Figure 14A-E). D200 treatment apparently increased the PC specific SFC for IgM and IgG2b, however, these increases were not significant as compared to vehicle control. The frequency of anti-PC SFC $/ 10^{6}$ B cells in immunized D200 treated animals was IgM, 705 \pm 683; IgG, $480 \pm 321 ; \mathrm{IgG} 1,1 \pm$ 0.9; IgG2b, $79 \pm 132$ and IgG3, $21 \pm 9$ (Figure 14A-E).

\section{The frequency of PspA specific SFC}

Fourteen days after treatment and immunization, the frequency of PspA-specific IgM, IgG, IgG1 and IgG2b SFC were significantly increased in 200/200 mixture-treated animals (Figure 15A-D). PspA specific SFC $/ 10^{6}$ B cells were increased over immunized 
vehicle treated animals 9 fold for $\operatorname{IgM}(39 \pm 27$ vs $4 \pm 1), 17$ fold for $\operatorname{IgG}(53 \pm 13$ vs $3 \pm$ 1), 34 fold for $\operatorname{IgG} 1$ ( $35 \pm 8$ vs $1 \pm 1$ ) and 11 fold for $\operatorname{IgG} 2 \mathrm{~b}$ ( $37 \pm 11$ vs. $3 \pm 1$ ) (Figure 15A-D).

Although the frequency of anti-PspA SFC apparently increased after P200 treatment, these increases were not statistically significant. The frequency of PspA specific SFC $/ 10^{6}$ B cells after P200 treatment were $18 \pm 8$ for the IgM, $13 \pm 3$ for the $\operatorname{IgG}, 10 \pm 2$ for the $\operatorname{IgG} 1$ and $8 \pm 5$ for the $\operatorname{IgG} 2 \mathrm{~b}$ specific antibody responses (Figure 15A-D). Antibody responses after D200 treatment were similar to immunized vehicle treated animals. The frequency of PspA specific SFC $/ 10^{6}$ B cells after D200 treatment were $3 \pm 3$ for $\operatorname{IgM}, 4 \pm 2$ for $\operatorname{IgG}, 4 \pm 2$ for IgG1, and $6 \pm 5$ for IgG2b (Figure 15A-D).

\section{The total spleen cell count, cell population percentages and absolute numbers at 7 days after treatment}

The total cell count of the spleen was increased after 200/200 mixture treatment. At 7 days post treatment, immunized vehicle treated animals had an average spleen cell count of $76 \pm 16 \times 10^{6}$. Immunized animals treated with P200 and D200 had spleen cell counts similar to vehicle averaging $87 \pm 13 \times 10^{6}$ and $62 \pm 14 \times 10^{6}$ respectively. In contrast, immunized animals treated with the 200/200 mixture had an average of $138 \pm$ $16 \times 10^{6}$ cells/spleen. Leukocyte populations in the spleen were separated into $\mathrm{B} 220^{+}(\mathrm{B}$ cells), $\mathrm{CD}^{+} \mathrm{T}$ cells, $\mathrm{CD} 8^{+} \mathrm{T}$ cells, $\mathrm{CD} 11 \mathrm{~b}^{+} / \mathrm{Gr}-1^{+}$(neutrophils), and $\mathrm{CD} 11 \mathrm{~b}^{+} / \mathrm{I}-\mathrm{A}^{\mathrm{b}+}$ $(\mathrm{M} \varphi / \mathrm{DC})$. At 7 days post treatment, $\mathrm{P} 200$ and D200 treatments were similar to the population percentages found in immunized, vehicle-treated animals (Table 15). The 200/200 treatment, however, decreased the percentage of B cells, CD4 $4^{+} \mathrm{T}$ cells and $\mathrm{CD} 8^{+}$ $\mathrm{T}$ cells in comparison to immunized, vehicle treated animals (Table 15). In contrast, 
200/200 mixture treatment increased the neutrophil population in comparison to immunized, vehicle treated animals (Table 15).

Although the percentage of B cells and T cells were decreased in the 200/200 treated group, the absolute number of $\mathrm{B}$ cell, $\mathrm{T}$ cell and the $\mathrm{M} \varphi / \mathrm{DC}$ populations remained similar to vehicle treated absolute cell numbers for all treatment groups (Table 16). This is due to an increase in the absolute number of cells in the spleen at 7 days after 200/200 treatment. In contrast, the absolute number of neutrophils was increased 7 days after 200/200 treatment (Table 16).

\section{The total spleen cell count, cell population percentages and absolute numbers at 14 days after treatment}

The average total cell count of the spleens of immunized P200 and 200/200 treated animals remained increased 14 days after treatment. Fourteen days after treatment, immunized vehicle and D200 treated animals had an average spleen cell count

of $81 \pm 30 \times 10^{6}$ and $85 \pm 24 \times 10^{6}$ spleen cells, respectively. Immunized animals treated with P200 and the 200/200 mixture had increased spleen cell counts averaging $106 \pm 34$ $\times 10^{6}$ spleen cells and $127 \pm 39 \times 10^{6}$ spleen cells, respectively.

The percent of B cells in all treatment groups were similar to vehicle control at 14 days after treatment (Table 17). The percentage of $\mathrm{CD}^{+}$and $\mathrm{CD} 8^{+} \mathrm{T}$ cells was decreased after P200 treatment or 200/200 treatment (Table 17). The percent decreases in the $\mathrm{T}$ cell populations were offset by increases in the neutrophil populations. Neutrophil percentages were increased after P200 treatment and after 200/200 treatment as compared to vehicle and D200 treated animals (Table 17). 
The absolute number of B cells were increased after P200 and 200/200 treatment Table 18). The spleens of vehicle treated and D200 treated animals had similar numbers of B cells (Table 18). In contrast to the percent decreases, the absolute cell number of $\mathrm{T}$ cells in P200 and 200/200 treated spleens were equal to the absolute number of T cells in vehicle-treated animals (Table 18). This was due to the increase in total cell numbers in the spleens of P200 and 200/200 treated animals. Striking increases occurred in the absolute number of neutrophils in P200 and 200/200 treated spleens (Table 18). Significant increases also occurred in the absolute number of M $\varphi / D C$ in P200 and 200/200 treated spleens (Table 18). In summary, the major population changes after P200 and 200/200 treatment were increases in the B cell and granulocyte populations.

\section{The total number of SFC in the spleen}

The total number of PC and PspA specific SFC in the spleen was calculated in order to account for the increases in leukocyte numbers in the spleens of P200 and 200/200 treated animals. The fold increase in the total number of SFC in the spleens of P200 and 200/200 treated animals were equivalent to the fold increases in the number of $\mathrm{SFC} / 10^{6} \mathrm{~B}$ cells (Table 19 and 20 vs. Figure 14 and 15). Therefore, there is an increase in the total number of PC and PspA specific plasma forming cells in the animal. In the total spleen analysis, the number of PC and PspA SFC in the animal were significantly increased after mixture treatment, from vehicle control with the exception of the more variable PC specific IgG1 response (Table 19 and 20).

\section{Differential cell counts at 7 and 14 days after treatment}

Differential cell counts were done to determine the percentage of lymphocytes, monocytes, neutrophils and eosinophils in the spleen after herbicide treatment. 
Eosinophil percentages were not changed by herbicide treatment (data not shown). The number of banded, immature neutrophils was also enumerated. The percentage of neutrophils in the differential cell count at 7 days after treatment with vehicle, P200 and D200 were $1 \pm 1,2 \pm 2$, and $3 \pm 2$ respectively, as compared to $6 \pm 2$ percent in the 200/200 treated spleens (Table 21). At 7 days, a small portion of the increases in the 200/200 neutrophil population could be attributed to the presence of banded, precursor neutrophils $(1 \pm 0.1$ percent) while no banded neutrophils were counted in the vehicle, P200 and D200 smears (Table 21).

At 14 days after treatment, the percentage of neutrophils was increased with both P200 (5 \pm 3$)$ and 200/200 (5 \pm 2$)$ treatments over vehicle $(2 \pm 2)$ and D200 (2 \pm 2$)$

treatments (Table 22). At this time point, a small percentage of banded neutrophils were found in the differential cell count of P200 and 200/200 treated spleens, however, their presence was highly variable $(1 \pm 2$ and $1 \pm 3)$ respectively (Table 22$)$. Banded, precursor neutrophils were not found in spleen cell smears of vehicle and D200 treated animals (Table 22). The percentage of lymphocytes and monocytes in the differential cell counts were unchanged by herbicide treatment at both 7 and 14 days after exposure (Table 21 and 22).

\section{Sera antibody titers at 7 and 14 days after treatment}

Sera antibody titers for the TI-2 response to PC antigen were measured at 7 and 14 days (Figure 16 and 17) and the TD response to PspA antigen was measured at 14 days after treatment (Figure 18). All groups had similar antibody titers for IgM, and all IgG specific isotypes tested (Figure 16A-D, Figure 17A-E and Figure 18A-C). 


\section{DISCUSSION}

To our knowledge, this is the first time that it has been demonstrated that exposure to a mixture of herbicides can act to enhance the humoral immune response. Increases in the total number of SFC in the spleen correlate to an increase in the frequency and number of plasma forming cells in the spleen specific for $S$. pneumoniae antigen. Although significant increases in the antibody response were only seen after mixture treatment, propanil treatment resulted in consistently greater mean SFC responses to both PC and PspA antigen. Although these increases were not significant, thye suggest that propanil exposure alone can act to increase the antibody response to HKSP immunization. (Figures 14A-E and 15A-D).

One explanation for the increased antibody response could be that the number of $\mathrm{B}$ cells in the spleen is increased, thereby increasing the repertoire of BCR available for selection into the plasma forming cell pool. We have found that the absolute number of B cells is significantly increased at 14 days after propanil and mixture treatment (Table 18). However, increases in the antibody response to the HKSP vaccine occurred at 7 days in response to the $\mathrm{PC}$ antigen (Figure 14A-E). At 7 days after treatment, increases in the frequency and number of S. pneumoniae specific antibody forming cells occurred at a time when the absolute number of B cells in all treatment groups were similar (Table 16). These results suggest that the increases in frequency of $S$. pneumoniae specific antibody forming cells are not due to general increases in B cell numbers. In previous research, we have found that when mice were immunized 4 days after 200/200 exposure, the frequency of S. pneumoniae antibody forming B cells was increased even when the percentage and absolute number of B cells in the spleen were decreased (Figure 12A-B 
and 13A-B and Table 12 and 13). These results support the idea that the increases in the frequency of antibody forming cells after mixture exposure are independent of the total number of splenic B cells. The possibility still remains, however, that B cells are being depleted in the spleen as a direct result of the herbicide treatment and that this population is being constantly replenished either by influx from other organs or hematopoiesis in the spleen. This scenario would allow for a larger number of B cells to be exposed to antigen while the absolute number of B cells remained constant. Further research on the maintenance and recovery of the B cell population in the spleen after propanil and mixture exposure is necessary in order to answer this question.

The $\mathrm{CD}^{+}$and $\mathrm{CD} 8^{+} \mathrm{T}$ cell population numbers were unchanged by single herbicide and mixture treatment in spite of the fact that precursor cell populations were depleted in the thymus (Table 16 and 18 and Figure 2 - 6). One mechanism for the increase in the antibody response could be changes in $\mathrm{T}$ cell function. Although the PC antibody response is not dependent on $\mathrm{T}$ cell recognition of antigen presented on $\mathrm{MHC}$ class II, both PC (TI-2) and PspA (TD) antibody response are dependent on $\mathrm{CD}^{+}{ }^{+}$cell interactions including direct B cell stimulation by CD40 ligand (CD40L) (Wu et al., 1999). B7 costimulation is also necessary for an optimal antibody response to both PC and PspA antigen (Wu et al., 2000). The B7 ligands, B7-1 and B7-2 are found on antigen presenting cells such as DC, M $\varphi$ s and B cells. B7 costimulation mediated through CD28 is necessary for activation of $\mathrm{T}$ cells that have recognized antigen in the context of MHC. CD28 signaling is required for both TI-2 and TD antibody production after $S$. pneumoniae immunization, however, the signaling time necessary for the anti-PC response is shorter than for the anti-PspA response (Wu et al., 2000). Sera antibodies 
levels were unchanged after herbicide treatment and immunization. Therefore, these aspects of $\mathrm{CD}^{+} \mathrm{T}$ cell and $\mathrm{M} \varphi$ functions, necessary for the optimal production of sera antibodies during the immune response to the $S$. pneumoniae vaccine, remain intact in the spleens of herbicide treated animals.

Although this research did not look at specific cytokines produced immediately after herbicide exposure and immunization, cytokines are involved in immunoglobulin class switching, and the IgG isotype responses may be used as general indicators of cytokine changes. In mice, IL-4, a TH2 cytokine, is a switch factor for IgG1 (Snapper and Finkelman 1999). TGF- $\beta$, an anti-inflammatory cytokine, is a switch factor for $\operatorname{IgG} 2 b$, and IFN- $\gamma$, a TH1 cytokine, is a switch factor for IgG3 (Snapper and Finkelman 1999). Changes in the type or quantity of $\mathrm{T}$ cell and $\mathrm{M} \varphi$ derived cytokines may be one mechanism by which the antibody response is increased after herbicide treatment. Kahn et al. (2002), recently demonstrated that increases in sera levels of TNF- $\alpha$ that occur within the first $72 \mathrm{hrs}$ after immunization enhance the PspA and, to a lesser extent, the PC specific IgG isotype response (Khan et al., 2002). IL-6 and IFN- $\gamma$ enhanced all PspA specific IgG primary responses (IgG2a, IgG2b and IgG1) (Khan et al., 2002). The PC response to changes in IL-6 and IFN- $\gamma$ was isotype specific. The anti-PC response to IgG2b was enhanced by IL- 6 while the IgG2a response was enhanced by IFN- $\gamma$ (Khan et al., 2002). In contrast, IL-10, an anti-inflammatory cytokine, was found to globally suppress the primary anti-PspA and anti-PC responses (Khan et al., 2002). Therefore, the cytokines produced within the first few hours of immunization can act to regulate antibody production in an antigen-specific, isotype-specific manner. 
Propanil exposure in vitro and in vivo has been demonstrated to reduce con Astimulated T cell production of IL-2, IL-6, IFN- $\gamma$ and GM-CSF, and LPS-stimulated M $\varphi$ cytokine production of IL-6 and TNF- $\alpha$ (Zhao et al.,1998; Xie et al.,1997). In contrast, following challenge with Listeria monocytogenes, propanil treatment in vivo did not change cytokine responses in the spleen, liver and blood, and did not reduce resistance to infection (Watson, et al., 2000). Although we did not measure cytokine changes after $S$. pneumoniae immunization, it is possible that the immune response to S. pneumoniae differs from L. monocytogenes infection in a manner that promotes $\mathrm{T}$ cell and $\mathrm{M} \varphi$ activation. If so, increases in the quantity and type of antibody produced in response to HKSP immunization would be possible.

Although Kahn et al., 2002, did not study the effects of cytokines on the number of SFC in the spleen, it is possible that increases in cytokine levels could increase B cell switching, thereby increasing the number of SFC in a particular subclass. The kinetics of the herbicide-induced antibody increases suggest that cytokines may play a key role in the increased antibody response after herbicide exposure. The greatest increases in the antibody response after herbicide treatment occurred when mice were immunized simultaneous with herbicide exposure. In a previous set of experiments, we exposed animals to identical herbicide treatments but waited 4 days to inoculated them with the HKSP vaccine (day 4 immunization) (Figure 12A-B and 13A-B). In these experiments, ELISPOT analysis of PC-specific SFC were assessed at 14 days after herbicide treatment and 10 days after immunization. The number of SFC responding to both PC specific IgM or IgG antigen were increased 5-12 fold over vehicle in both propanil and mixture treated animals in that treatment regimen (Figure 13A and B). This response, however, was 
decreased $>10$ fold from the PC specific IgM and IgG SFC counts in the current assay (day 0 immunization) (Figure 14A-E). These results strongly suggest that the regulatory mechanism(s) involved in propanil and mixture-induced antibody changes function within the first four days after herbicide exposure.

Both propanil and mixture treatment have been demonstrated to increase sera glucocorticoid levels in response to chemical stress. Glucocorticoid hormones have been demonstrated to regulate cytokine production (Miyaura and Iwata, 2002; Ramierz et al.,1996). Several studies have suggested that glucocorticoid hormones act to inhibit the development of the Thelper cell type 1 (Th1) response and promote $\mathrm{T}$ helper cell type 2 (Th2) production of IL-4, IL-10 and IL-13 (Miyaura and Iwata, 2002; Ramierz et al.,1996). At 14 days after treatment, the isotype subclasses in the sera were similar to the responses given after S. pneumoniae vaccination without herbicide treatment (anti-PC $\operatorname{IgM}>\operatorname{IgG} 3=\operatorname{IgG} 2 b>\operatorname{IgG1}$ and anti-PspA $\operatorname{IgG} 2 \mathrm{~b}=\operatorname{IgG1})(\mathrm{Wu}$ et al., 1999). These results suggest that the early glucocorticoid increases after herbicide treatment did not change the cytokine response to $S$. pneumoniae.

Taken together, these results suggest that herbicide treatment may act to increase cytokine production in response to S. pneumoniae immunization, resulting in an increase in the number of SFC, but that the overall cytokine response, determined indirectly using the antibody isotype responses, is not skewed by herbicide treatment.

The absolute number of neutrophils were increased after propanil exposure at 7 days and after mixture exposure at 7 and 14 days. Possible correlations between increases in the neutrophil population and increases in the antibody response were discussed in Chapter 4 Discussion. 
In this study we have found that exposure to a mixture of the herbicide propanil and 2,4-D resulted in significant increases in the frequency of SFC in the spleens of animals. Single herbicide treatment with 2,4-D did not significantly increase the frequency of SFC in the spleen, however, the presence of 2,4-D in the mixture increased both TI-2 and TD antibody responses. Mixture exposure synergistically increased the frequency of PC specific IgG2b and IgG3 SFC. We do not as yet know the mechanism for these increases, however, increases in cytokine production after herbicide treatment is one possible mechanism. These results indicate that a mixture of herbicides can enhance the changes in the antibody response over the changes caused by exposure to the individual components of the mixture and highlight the necessity of studying the effects of mixtures on the immune system. 
Figure 14. The frequency of SFC specific for PC. Mice were treated with vehicle, $200 \mathrm{mg}$ propanil/kg body weight (P200), $200 \mathrm{mg}$ 2,4-D/kg body weight (D200) or a mixture containing $200 \mathrm{mg}$ propanil $+200 \mathrm{mg}$ 2,4-D/kg body weight (200/200) and immunized with $2 \times 10^{8}$ heatkilled S. pneumoniae or PBS on day 0. Spleens were removed 7 days after immunization and herbicide treatment. A. Number of IgM SFC $/ 10^{6}$ B cells specific for PC. B. Number of IgG $\mathrm{SFC} / 10^{6}$ B cells specific for PC. C. Number of $\operatorname{IgG} 1 \mathrm{SFC} / 10^{6} \mathrm{~B}$ cells specific for PC. D. Number of $\operatorname{IgG} 2 \mathrm{~b} \mathrm{SFC} / 10^{6}$ B cells specific for PC. E. Number of $\operatorname{IgG} 3 \mathrm{SFC} / 10^{6}$ B cells specific for PC. Each circle represents an individual animal. Bars represent the mean number of $\mathrm{SFC} / 10^{6} \mathrm{~B}$ cells. ${ }^{*} \mathrm{p} \leq 0.05$ as compared to vehicle. $\Psi$ indicates a mixture interaction. 
Figure 14. Chapter 5. The number of SFC specific for $\mathrm{PC}$ antigen 7 days after herbicide exposure and immunization

A. PC specific IgM

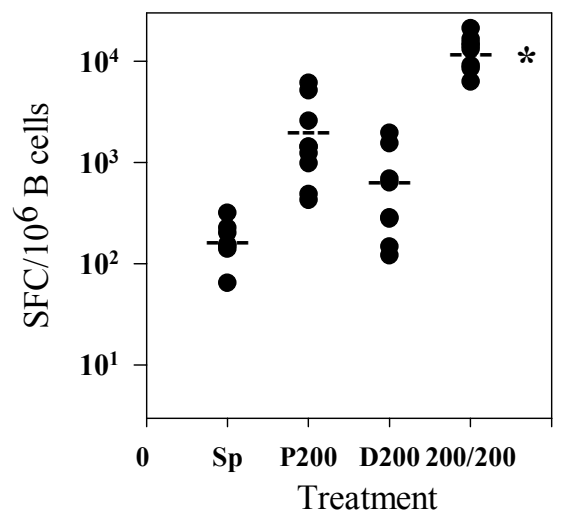

C. PC specific IgG1

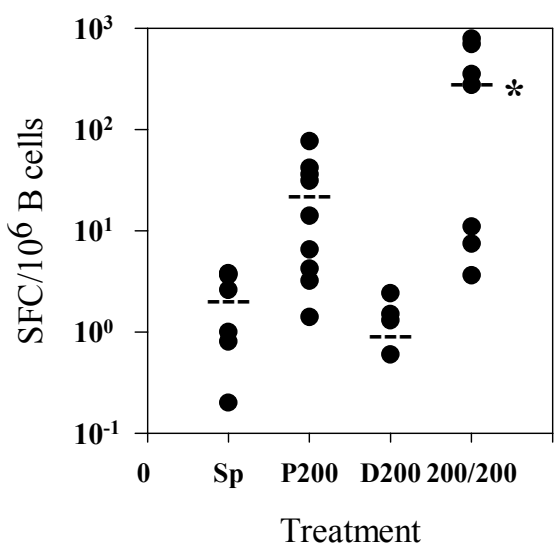

E. PC specific IgG3

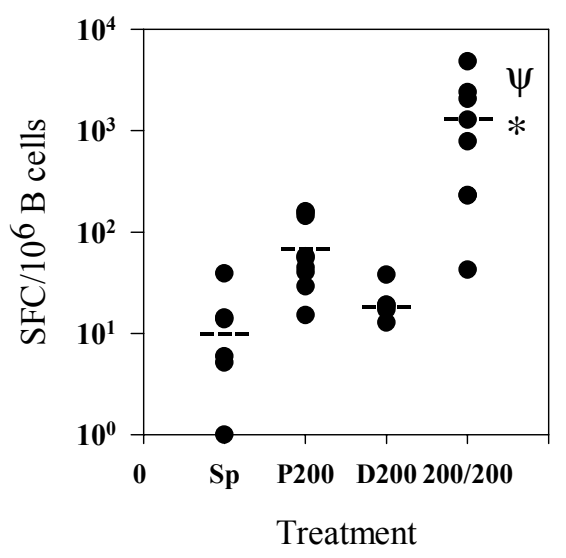

B. PC specific IgG

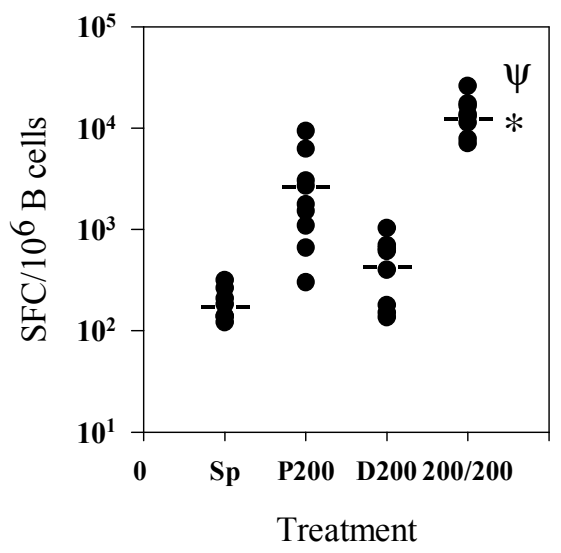

D. PC specific $\operatorname{IgG} 2 b$

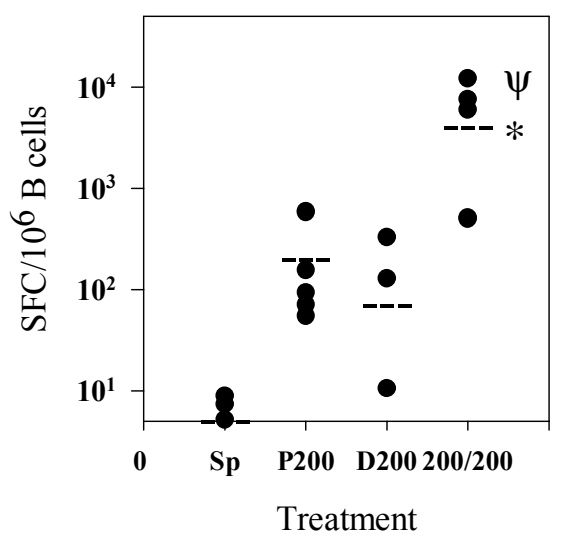


Figure 15. The frequency of SFC responding to PspA antigen. Mice were treated with vehicle, $200 \mathrm{mg}$ propanil/kg body weight (P200), $200 \mathrm{mg}$ 2,4-D/kg body weight (D200) or a mixture containing $200 \mathrm{mg}$ propanil $+200 \mathrm{mg} 2,4-\mathrm{D} / \mathrm{kg}$ body weight $(200 / 200)$ and immunized with $2 \times 10^{8}$ heat-killed S. pneumoniae or PBS on day 0 . Spleens were removed 14 days after immunization and herbicide treatment. A. Number of IgM $\mathrm{SFC} / 10^{6}$ B cells specific for PspA. B. Number of $\operatorname{IgG} \mathrm{SFC} / 10^{6}$ B cells specific for PspA. C. Number of IgG1 SFC $/ 10^{6}$ B cells specific for PspA. D. Number of IgG2b SFC/10 ${ }^{6}$ B cells specific for PspA. Each circle represents an individual animal. Bars represent the mean number of SFC $/ 10^{6}$ B cells. ${ }^{*} \mathrm{p} \leq 0.05$. 
Figure 15. Chapter 5. The number of SFC responding to PspA antigen 14 days after herbicide exposure and immunization

A. PspA specific IgM

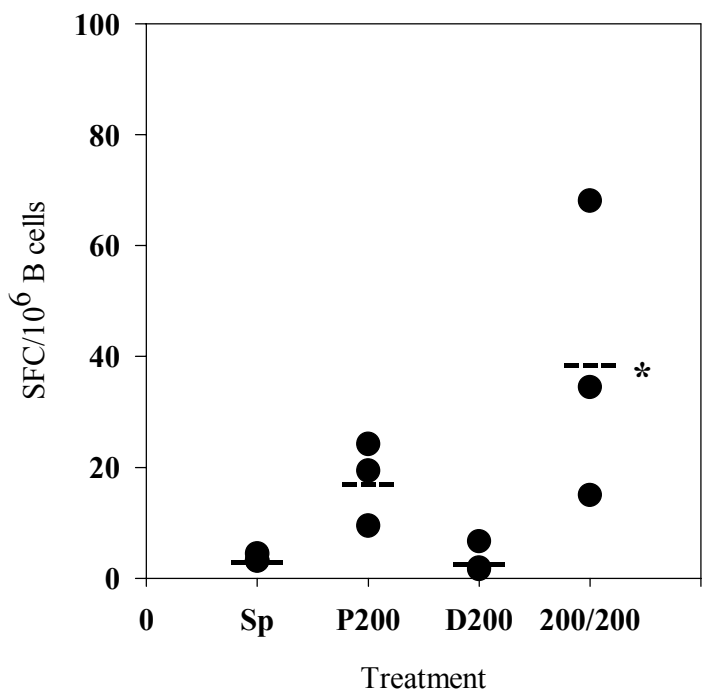

C. PspA specific IgG1

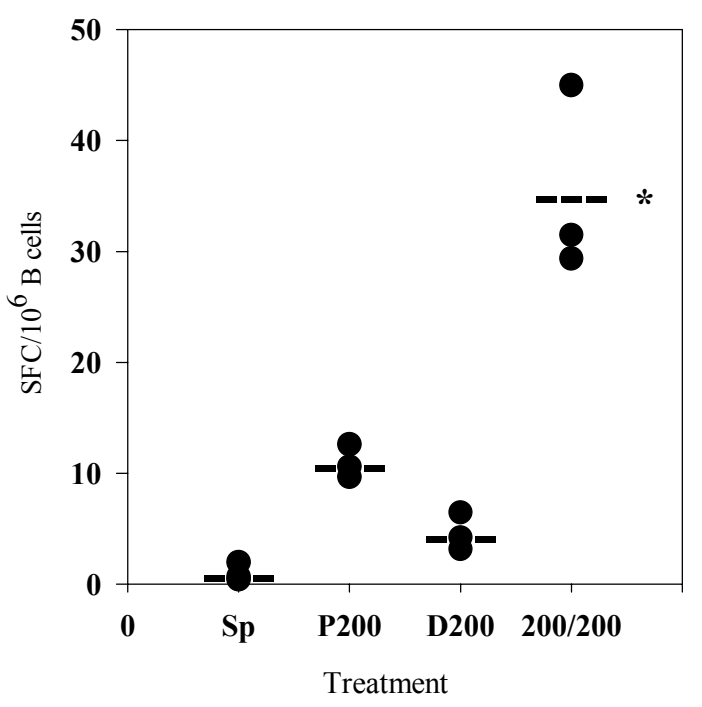

B. PspA specific IgG

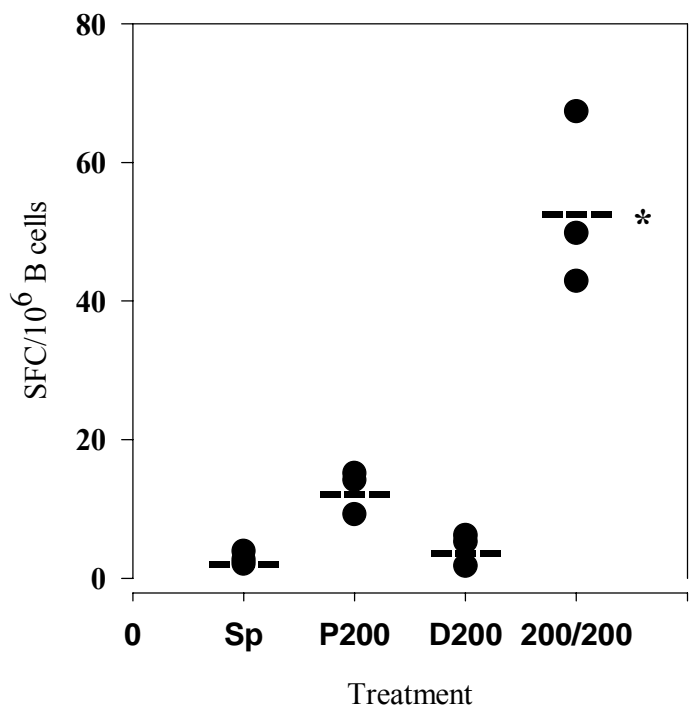

D. PspA specific IgG2b

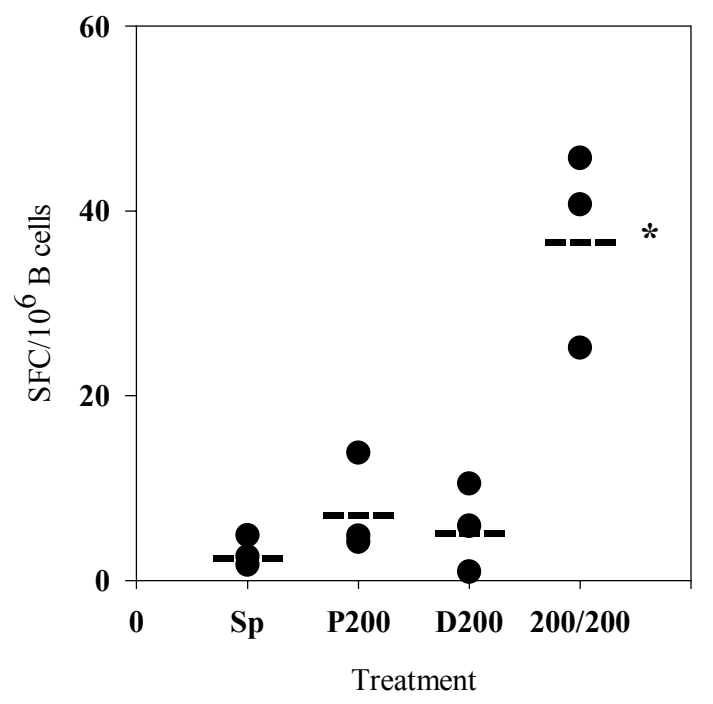


Table 15. Chapter 5. Spleen population percentages 7 days after herbicide treatment and immunization

\begin{tabular}{|c|c|c|c|c|}
\hline Population $^{\mathrm{c}}$ & Vehicle $^{\mathrm{a}}$ & P200 & D200 & $200 / 200$ \\
\hline$\overline{\mathrm{B} 220^{+}}$ & $48 \pm 6^{b}$ & $43 \pm 6$ & $44 \pm 2$ & $26 \pm 3 *$ \\
\hline $\mathrm{CD}^{+}$ & $21 \pm 4$ & $17 \pm 2$ & $19 \pm 5$ & $11 \pm 3 *$ \\
\hline$\overline{\mathrm{CD} 8^{+}}$ & $15 \pm 2$ & $13 \pm 3$ & $15 \pm 4$ & $10 \pm 6 *$ \\
\hline $\mathrm{CD} 11 \mathrm{~b}^{+} / \mathrm{Gr}-1^{+}$ & $2 \pm 0.1$ & $4 \pm 1$ & $2 \pm 0.1$ & $6 \pm 3 *$ \\
\hline $\mathrm{CD} 11 \mathrm{~b}^{+} / \mathrm{I}-\mathrm{A}^{\mathrm{b}+}$ & $3 \pm 0.05$ & $3 \pm 0.05$ & $4 \pm 0.05$ & $4 \pm 1$ \\
\hline
\end{tabular}

${ }^{\mathrm{a}}$ Mice were treated with vehicle, $200 \mathrm{mg}$ propanil/kg body weight (P200), $200 \mathrm{mg}$ 2,4-

D/kg body weight (D200) or a mixture containing $200 \mathrm{mg}$ propanil $+200 \mathrm{mg}$ 2,4-D/kg body weight (200/200). Spleens were extracted at 7 days after treatment as detailed in Materials and Methods.

${ }^{b}$ Data represent the average percent of positive staining cells per spleen \pm standard deviation. 8 animals were used per group.

${ }^{\mathrm{c}} \mathrm{B} 220^{+} \mathrm{B}$ cells, $\mathrm{CD} 4^{+} \mathrm{T}$ cells, $\mathrm{CD}^{+} \mathrm{T}$ cells, $\mathrm{CD} 11 \mathrm{~b}^{+} / \mathrm{Gr}-1^{+}$Neutrophils, $\mathrm{CD}_{11 \mathrm{~b}}{ }^{+} / \mathrm{I}-\mathrm{A}^{\mathrm{b}+}$ Macrophage/Dendritic cells.

$* \mathrm{p} \leq 0.05$ vs. vehicle control. 
Table 16. Chapter 5. Absolute cell numbers in the spleen 7 days after herbicide treatment and immunization

\begin{tabular}{|c|c|c|c|c|}
\hline Population $^{\mathrm{c}}$ & Vehicle $^{a}$ & P200 & D200 & $200 / 200$ \\
\hline $\mathrm{B} 220^{+}$ & $36 \pm 8^{b}$ & $34 \pm 7$ & $28 \pm 6$ & $27 \pm 10$ \\
\hline $\mathrm{CD}^{+}$ & $16 \pm 2$ & $13 \pm 2$ & $12 \pm 3$ & $12 \pm 5$ \\
\hline $\mathrm{CD}^{+}$ & $10 \pm 2$ & $10 \pm 2$ & $9 \pm 3$ & $12 \pm 7$ \\
\hline $\mathrm{CD} 11 \mathrm{~b}^{+} / \mathrm{Gr}-1^{+}$ & $2 \pm 1$ & $3 \pm 1$ & $2 \pm 1$ & $7 \pm 5^{*}$ \\
\hline $\mathrm{CD}_{11 \mathrm{~b}^{+} / \mathrm{I}-\mathrm{A}^{\mathrm{b}+}}$ & $2 \pm 0.05$ & $2 \pm 0.05$ & $2 \pm 0.1$ & $2 \pm 0.1$ \\
\hline
\end{tabular}

a Mice were treated with $200 \mathrm{mg}$ propanil/kg body weight (P200), $200 \mathrm{mg}$ 2,4-D/kg body weight (D200) or a mixture containing $200 \mathrm{mg}$ propanil + $200 \mathrm{mg}$ 2,4-D/kg body weight (200/200). Spleens were extracted at 7 days after treatment as detailed in Materials and Methods.

${ }^{b}$ Data represent the mean absolute number of positive staining cells per spleen $\times 10^{6} \pm$ standard deviation. 8 animals were used per group.

${ }^{\mathrm{c}} \mathrm{B} 220^{+} \mathrm{B}$ cells, $\mathrm{CD} 4^{+} \mathrm{T}$ cells, $\mathrm{CD} 8^{+} \mathrm{T}$ cells, $\mathrm{CD} 11 \mathrm{~b}^{+} / \mathrm{Gr}-1^{+}$Neutrophils, $\mathrm{CD}_{11 \mathrm{~b}}{ }^{+} / \mathrm{I}-\mathrm{A}^{\mathrm{b}+}$ Macrophage/Dendritic cells

$* \mathrm{p} \leq 0.05$ vs. vehicle control. 
Table 17. Chapter 5. Spleen population percentages 14 days after herbicide treatment and immunization

\begin{tabular}{|c|c|c|c|c|}
\hline Population $^{\mathrm{c}}$ & Vehicle $^{a}$ & P200 & D200 & $200 / 200$ \\
\hline $\mathrm{B} 220^{+}$ & $52 \pm 5^{b}$ & $47 \pm 7$ & $55 \pm 4$ & $45 \pm 8$ \\
\hline $\mathrm{CD}^{+}$ & $18 \pm 4$ & $12 \pm 2 *$ & $16 \pm 2$ & $9 \pm 1 *$ \\
\hline $\mathrm{CD}^{+}$ & $14 \pm 2$ & $10 \pm 2 *$ & $13 \pm 1$ & $9 \pm 1 *$ \\
\hline $\mathrm{CD} 11 \mathrm{~b}^{+} / \mathrm{Gr}-1^{+}$ & $2 \pm 0.1$ & $6 \pm 0.01 *$ & $2 \pm 0.1$ & $12 \pm 0.01 *$ \\
\hline $\mathrm{CD} 11 \mathrm{~b}^{+} / \mathrm{I}-\mathrm{A}^{\mathrm{b}+}$ & $2 \pm 1$ & $3 \pm 1$ & $1 \pm 1$ & $4 \pm 1$ \\
\hline$\%$ Total Spleen & 82 & 67 & 84 & 47 \\
\hline
\end{tabular}

a Mice were treated with vehicle, $200 \mathrm{mg}$ propanil/kg body weight (P200), $200 \mathrm{mg}$ 2,4-

$\mathrm{D} / \mathrm{kg}$ body weight (D200) or a mixture containing $200 \mathrm{mg}$ propanil $+200 \mathrm{mg}$ 2,4-D/kg body weight (200/200). Spleens were extracted at 14 days after treatment as detailed in Materials and Methods.

${ }^{b}$ Data represent the average percent of positive staining cells per spleen \pm standard deviation. 12 animals were used per group.

${ }^{\mathrm{c}} \mathrm{B} 220^{+} \mathrm{B}$ cells, $\mathrm{CD} 4^{+} \mathrm{T}$ cells, $\mathrm{CD} 8^{+} \mathrm{T}$ cells, $\mathrm{CD} 11 \mathrm{~b}^{+} / \mathrm{Gr}-1^{+}$Neutrophils, $\mathrm{CD}_{11 \mathrm{~b}}{ }^{+} / \mathrm{I}-\mathrm{A}^{\mathrm{b}+}$ Macrophage/Dendritic cells $* \mathrm{p} \leq 0.05$ vs. vehicle control. 
Table 18. Chapter 5. Absolute cell number in the spleen 14 days after herbicide treatment and immunization

\begin{tabular}{|c|c|c|c|c|}
\hline Population $^{c}$ & Vehicle $^{a}$ & P200 & D200 & $200 / 200$ \\
\hline $\mathrm{B} 220^{+}$ & $39 \pm 13^{b}$ & $56 \pm 14 *$ & $41 \pm 12$ & $58 \pm 18 *$ \\
\hline $\mathrm{CD}^{+}$ & $15 \pm 6$ & $15 \pm 4$ & $12 \pm 4$ & $12 \pm 4$ \\
\hline $\mathrm{CD}^{+}$ & $10 \pm 4$ & $12 \pm 2$ & $10 \pm 3$ & $11 \pm 3$ \\
\hline $\mathrm{CD} 11 \mathrm{~b}^{+} / \mathrm{Gr}-1^{+}$ & $2 \pm 1$ & $8 \pm 4 *$ & $2 \pm 1$ & $15 \pm 5 *$ \\
\hline $\mathrm{CD} 11 \mathrm{~b}^{+} / \mathrm{I}-\mathrm{A}^{\mathrm{b}+}$ & $2 \pm 1$ & $3 \pm 0.1^{*}$ & $1 \pm 1$ & $4 \pm 0.1 *$ \\
\hline
\end{tabular}

a Mice were treated with $200 \mathrm{mg}$ propanil/kg body weight (P200), $200 \mathrm{mg}$ 2,4-D/kg body weight (D200) or a mixture containing $200 \mathrm{mg}$ propanil + $200 \mathrm{mg}$ 2,4-D/kg body weight (200/200). Spleens were extracted at 14 days after treatment as detailed in Materials and Methods.

${ }^{\mathrm{b}}$ Data represent the mean absolute number of positive staining cells per spleen $\left(10^{6}\right) \pm$ standard deviation $\left(10^{6}\right) .12$ animals were used per group.

${ }^{\mathrm{c}} \mathrm{B} 220^{+} \mathrm{B}$ cells, $\mathrm{CD} 4^{+} \mathrm{T}$ cells, $\mathrm{CD} 8^{+} \mathrm{T}$ cells, $\mathrm{CD} 11 \mathrm{~b}^{+} / \mathrm{Gr}-1^{+}$Neutrophils, $\mathrm{CD}_{11 \mathrm{~b}}{ }^{+} / \mathrm{I}-\mathrm{A}^{\mathrm{b}+}$ Macrophage/Dendritic cells

$* \mathrm{p} \leq 0.05$ vs. vehicle control. 
Table 19. Chapter 5. Average number of SFC/spleen 7 days after herbicide treatment and immunization

\begin{tabular}{|c|c|c|c|c|c|}
\hline Antigen & Antibody & Vehicle $^{\mathrm{a}}$ & P200 & D200 & $200 / 200$ \\
\hline \multirow[t]{5}{*}{$\mathbf{P C}$} & IgM & $68 \pm 33^{b}$ & $\begin{array}{c}817 \pm 786 \\
(12)\end{array}$ & $\begin{array}{c}211 \pm 239 \\
(3)\end{array}$ & $\begin{array}{c}4247 \pm 1601^{*} \\
(65)^{\mathrm{c}}\end{array}$ \\
\hline & $\overline{I g G}$ & $72 \pm 29$ & $\begin{array}{c}1074 \pm 1074 \\
(15)\end{array}$ & $\begin{array}{c}134 \pm 99 \\
(2)\end{array}$ & $\begin{array}{c}4668 \pm 2061 * \\
(65)\end{array}$ \\
\hline & IgG1 & $0.90 \pm 0.68$ & $\begin{array}{c}1058 \pm 1188 \\
(1175)\end{array}$ & $\begin{array}{c}0.26 \pm 0.24 \\
(0.28)\end{array}$ & $\begin{array}{c}130 \pm 201 \\
(145)\end{array}$ \\
\hline & IgG2b & $158 \pm 108$ & $\begin{array}{c}84 \pm 72 \\
(0.53)\end{array}$ & $\begin{array}{c}1 \pm 1.5 \\
(0.0063)\end{array}$ & $\begin{array}{c}1552 \pm 1892 * \\
(981)\end{array}$ \\
\hline & IgG3 & $4.2 \pm 5.1$ & $\begin{array}{c}34 \pm 22 \\
(8.0)\end{array}$ & $\begin{array}{c}5.3 \pm 1.8 \\
(1.3)\end{array}$ & $\begin{array}{c}568 \pm 607 * \\
(134)\end{array}$ \\
\hline
\end{tabular}

${ }^{\mathrm{a}}$ Mice were treated with vehicle, $200 \mathrm{mg}$ propanil/kg body weight (P200), $200 \mathrm{mg}$ 2,4-

$\mathrm{D} / \mathrm{kg}$ body weight (D200) or a mixture containing $200 \mathrm{mg}$ propanil $+200 \mathrm{mg}$ 2,4-D/kg body weight (200/200) and immunized 4 days later as detailed in Materials and Methods. Spleens were extracted at 14 days after treatment.

${ }^{\mathrm{b}}$ Data represent the mean number of SFC $\left(10^{2}\right) \pm$ standard deviation $\left(10^{2}\right) .9$ animals were used per group.

c fold increase over vehicle control.

$* \mathrm{p} \leq 0.05$ vs. vehicle control. 
Table 20. Chapter 5. Average number of SFC/spleen 14 days after herbicide treatment and immunization

\begin{tabular}{|c|c|c|c|c|c|}
\hline Antigen & Antibody & Vehicle $^{a}$ & P200 & D200 & $200 / 200$ \\
\hline \multirow[t]{4}{*}{ PspA } & IgM & $154 \pm 96^{b}$ & $\begin{array}{c}922 \pm 302 \\
\text { (6) }\end{array}$ & $\begin{array}{c}152 \pm 190 \\
(0.98)\end{array}$ & $\begin{array}{c}1613 \pm 568 * \\
(10)^{\mathrm{c}}\end{array}$ \\
\hline & IgG & $128 \pm 94$ & $\begin{array}{c}735 \pm 365 \\
(5.7)\end{array}$ & $\begin{array}{c}175 \pm 156 \\
(1.3)\end{array}$ & $\begin{array}{c}2528 \pm 723 * \\
(20)\end{array}$ \\
\hline & IgG1 & $50 \pm 59$ & $\begin{array}{c}605 \pm 163 \\
(12.1)\end{array}$ & $\begin{array}{c}180 \pm 158 \\
(3.6)\end{array}$ & $\begin{array}{c}1664 \pm 431 * \\
\text { (33) }\end{array}$ \\
\hline & IgG2b & $143 \pm 132$ & $\begin{array}{c}416 \pm 280 \\
(2.9)\end{array}$ & $\begin{array}{c}155 \pm 123 \\
(1.1)\end{array}$ & $\begin{array}{c}1816 \pm 842 * \\
\text { (13) }\end{array}$ \\
\hline
\end{tabular}

${ }^{\mathrm{a}}$ Mice were treated with vehicle, $200 \mathrm{mg}$ propanil/kg body weight (P200), $200 \mathrm{mg}$ 2,4-

D/kg body weight (D200) or a mixture containing $200 \mathrm{mg}$ propanil $+200 \mathrm{mg} 2,4-\mathrm{D} / \mathrm{kg}$ body weight (200/200) and immunized on day 0 as detailed in Materials and Methods. Spleens were extracted at 14 days after treatment.

${ }^{\mathrm{b}}$ Data represent the mean number of SFC $\times 10^{2} \pm$ standard deviation. 9 animals were used per group.

${ }^{\mathrm{c}}$ fold increase over vehicle control.

$* \mathrm{p} \leq 0.05$ vs. vehicle control. 
Table 21. Chapter 5. Differential percentages of lymphocytes, monocytes and neutrophils 7 days after herbicide treatment and immunization

\begin{tabular}{|l|c|c|cc|}
\hline \multicolumn{1}{|c|}{ Population } & Lymphocytes $^{\mathrm{a}}$ & Monocytes & Neutrophils & $\begin{array}{c}\text { Banded } \\
\text { Neutrophils }\end{array}$ \\
\cline { 1 - 1 } Vehicle & $99 \pm 0.4^{\mathrm{b}}$ & $0.4 \pm 0.5$ & $1 \pm 1$ & $0^{\mathrm{c}}$ \\
\cline { 1 - 1 } P200 & $98 \pm 2$ & $0.1 \pm 0.4$ & $2 \pm 2$ & 0 \\
\cline { 1 - 1 } D200 & $96 \pm 3$ & $1 \pm 1$ & $3 \pm 2$ & 0 \\
\cline { 1 - 1 } $200 / 200$ & $94 \pm 2$ & $0.5 \pm 0.8$ & $6 \pm 2 *$ & $1 \pm 0.1$ \\
\hline
\end{tabular}

a Mice were treated with $200 \mathrm{mg}$ propanil/kg body weight (P200), $200 \mathrm{mg}$ 2,4-D/kg body weight (D200) or a mixture containing $200 \mathrm{mg}$ propanil $+200 \mathrm{mg}$ 2,4-D/kg body weight (200/200). Spleens were extracted at 7 days after treatment as detailed in Materials and Methods. 100 cells were counted/spleen.

${ }^{b}$ Data represent the average of 12 animals/group and is represented as a percentage.

${ }^{\mathrm{c}}$ Banded neutrophils. This population is a subset of the neutrophil population.

$* \mathrm{p} \leq 0.05$ vs. vehicle control. 
Table 22. Chapter 5. Differential percentages of lymphocytes, monocytes and neutrophils 14 days after herbicide treatment and immunization

\begin{tabular}{|l|c|c|cc|}
\hline \multicolumn{1}{|c|}{ Population } & Lymphocytes $^{\mathrm{a}}$ & Monocytes & Neutrophils & $\begin{array}{c}\text { Banded } \\
\text { Neutrophils }\end{array}$ \\
\cline { 1 - 1 } Vehicle & $96 \pm 3^{\mathrm{b}}$ & $3 \pm 3$ & $2 \pm 2$ & $0^{\mathrm{c}}$ \\
\cline { 1 - 1 } P200 & $94 \pm 3$ & $2 \pm 1$ & $5 \pm 3$ & $1 \pm 2$ \\
\cline { 1 - 1 } D200 & $96 \pm 2$ & $2 \pm 2$ & $2 \pm 2$ & 0 \\
\cline { 1 - 1 } $200 / 200$ & $92 \pm 3$ & $4 \pm 2$ & $5 \pm 2 *$ & $1 \pm 3$ \\
\hline
\end{tabular}

${ }^{\mathrm{a}}$ Mice were treated with vehicle, $200 \mathrm{mg}$ propanil/kg body weight (P200), $200 \mathrm{mg}$ 2,4-D/kg

body weight (D200) or a mixture containing $200 \mathrm{mg}$ propanil $+200 \mathrm{mg}$ 2,4-D/kg body weight

(200/200). Spleens were extracted at 14 days after treatment as detailed in Materials and

Methods. 100 cells were counted/spleen.

${ }^{\mathrm{b}}$ Data represent the average of 12 animals/group and is represented as a percentage.

${ }^{\mathrm{c}}$ Banded neutrophils. This population is a subset of the neutrophil population.

$* \mathrm{p} \leq 0.05$ vs. vehicle control. 
Figure 16. PC specific sera antibody titers at 7 days after treatment. Mice were treated with vehicle, $200 \mathrm{mg}$ propanil/kg body weight (P200), $200 \mathrm{mg}$ 2,4-D/kg body weight (D200) or a mixture containing $200 \mathrm{mg}$ propanil $+200 \mathrm{mg}$ 2,4-D/kg body weight (200/200) and immunized with $2 \times 10^{8}$ heat-killed S. pneumoniae or PBS on day 0. Mice were bled 7 days after immunization and herbicide treatment. A. PC specific IgM. B. PC specific IgG. C. PC specific IgG1. D. PC specific IgG3. Bars represent standard deviation. $\mathrm{n}=3$ mice per group. Groups without bars had similar titers in all three mice. 
Figure 16. Chapter 5. PC specific sera antibody titers 7 days after herbicide treatment and immunization

A. PC specific IgM

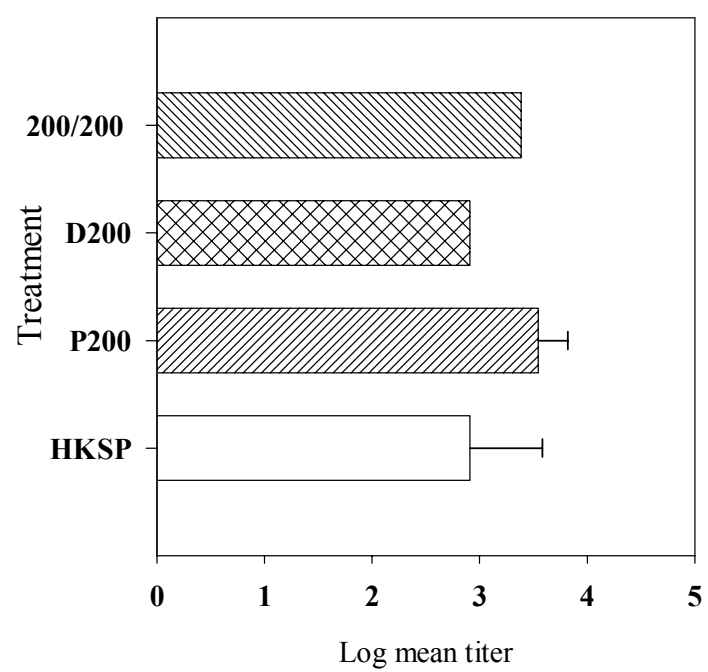

C. PC specific IgG2b

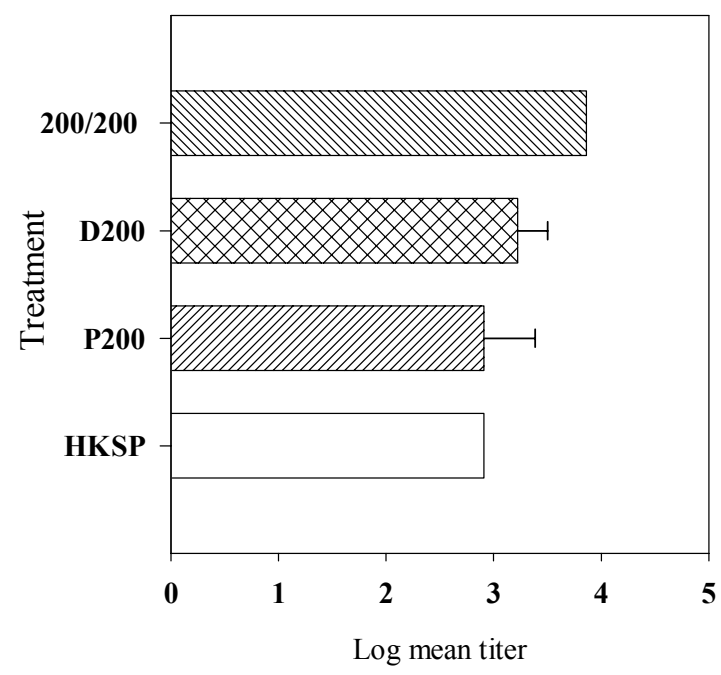

B. PC specific IgG1

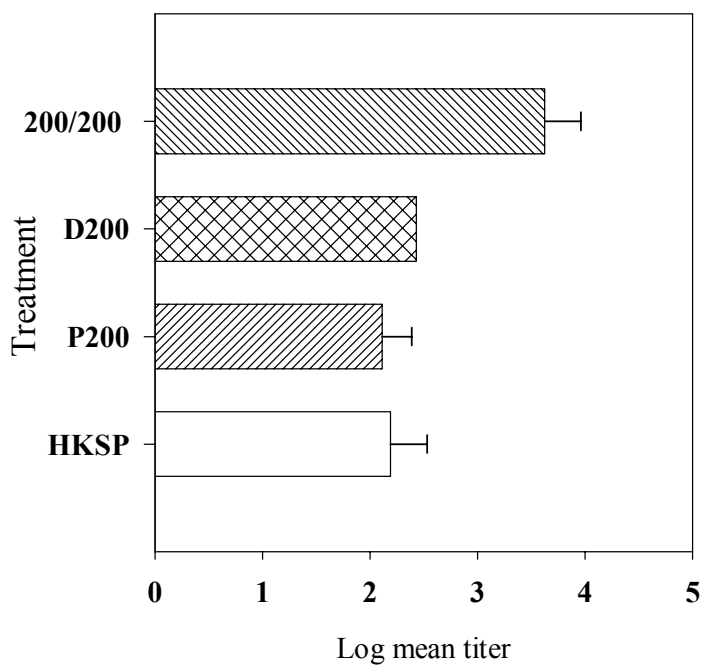

D. PC specific IgG3

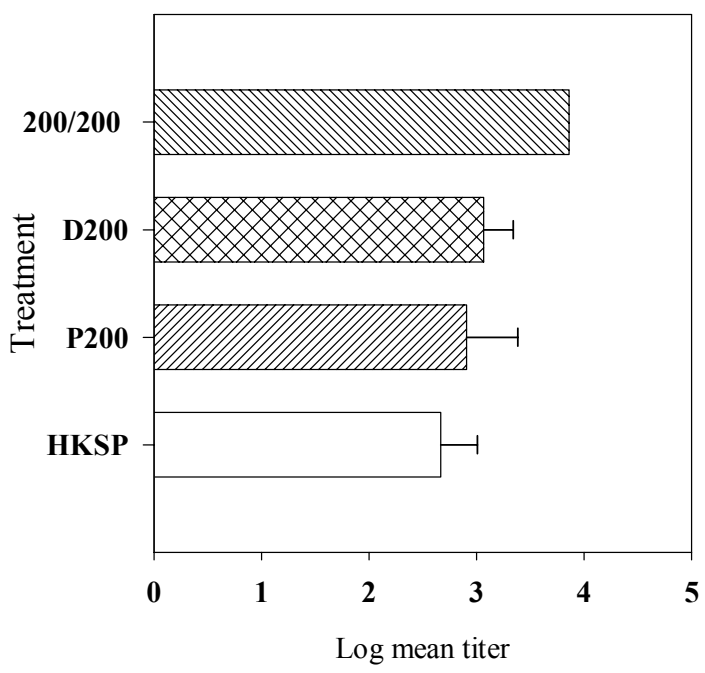


Figure 17. PC specific sera antibody titers at 14 days after treatment. Mice were treated with vehicle, $200 \mathrm{mg}$ propanil/kg body weight (P200), $200 \mathrm{mg}$ 2,4-D/kg body weight (D200) or a mixture containing $200 \mathrm{mg}$ propanil $+200 \mathrm{mg}$ 2,4-D/kg body weight (200/200) and immunized with $2 \times 10^{8}$ heat-killed S. pneumoniae or PBS on day 0 . Mice were bled 14 days after immunization and herbicide treatment. A. PC specific IgM. B. PC specific IgG. C. PC specific IgG1. D. PC specific IgG2b. E. PC specific IgG3. Bars represent standard deviation. $\mathrm{n}=3$ mice per group. Groups without bars had similar titers in all three mice. 
Figure 17. Chapter 5. PC specific sera antibody titers 14 days after treatment and immunization
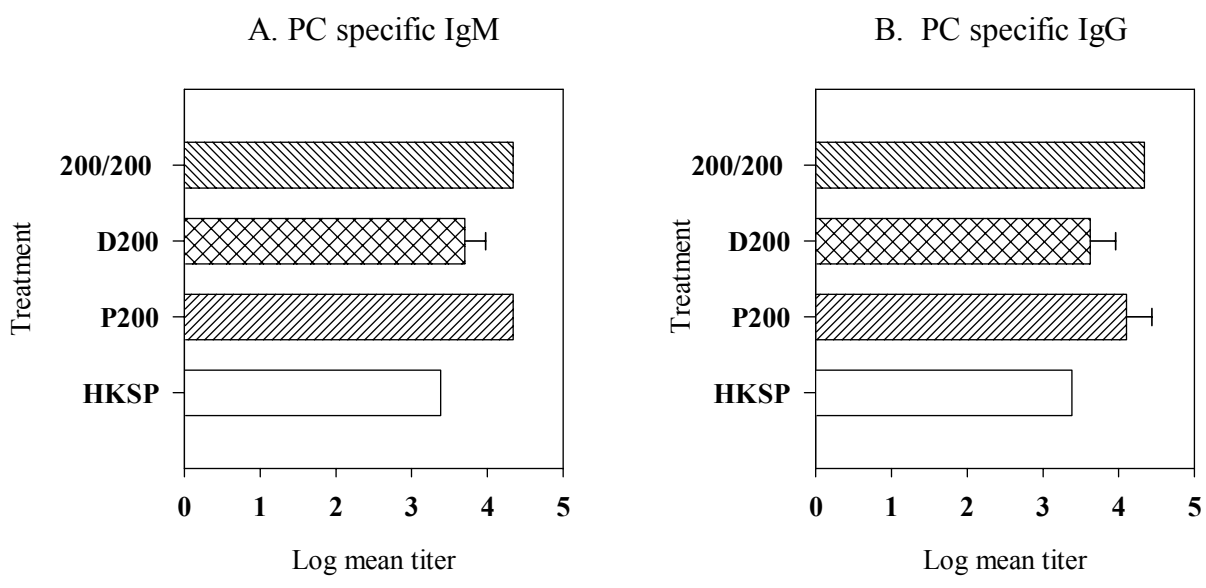

C. PC specific IgG1
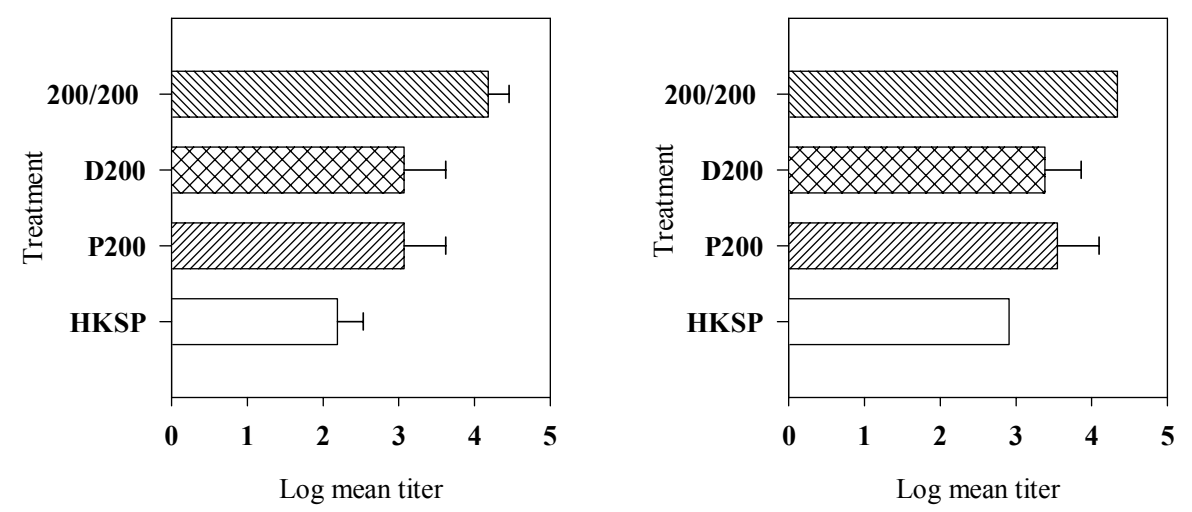

E. PC specific IgG3

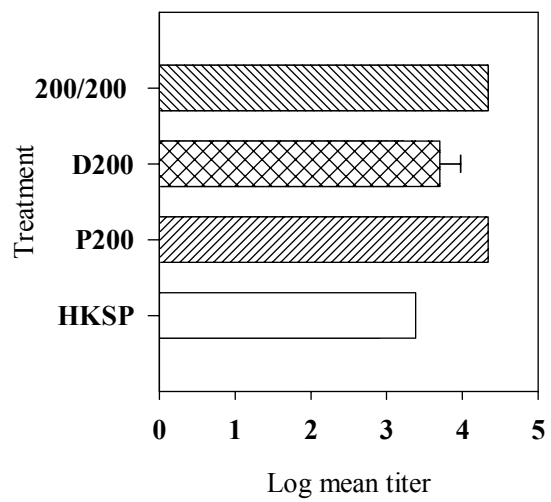


Figure 18. PspA specific sera antibody titers at 14 days after treatment. Mice were treated with vehicle, $200 \mathrm{mg}$ propanil/kg body weight (P200), $200 \mathrm{mg}$ 2,4-D/kg body weight (D200) or a mixture containing $200 \mathrm{mg}$ propanil $+200 \mathrm{mg}$ 2,4-D/kg body weight (200/200) and immunized with $2 \times 10^{8}$ heat-killed $S$. pneumoniae or PBS on day 0 . Mice were bled 14 days after immunization and herbicide treatment. A. PspA specific IgM. B. PspA specific IgG1. C. PspA specific IgG2b. Bars represent standard deviation. $\mathrm{n}=$ 3 mice per group. Groups without bars had similar titers in all three mice. 
Figure 18. Chapter 5. PspA specific sera antibody titers 14 days after herbicide treatment and immunization

A. PspA specific IgM

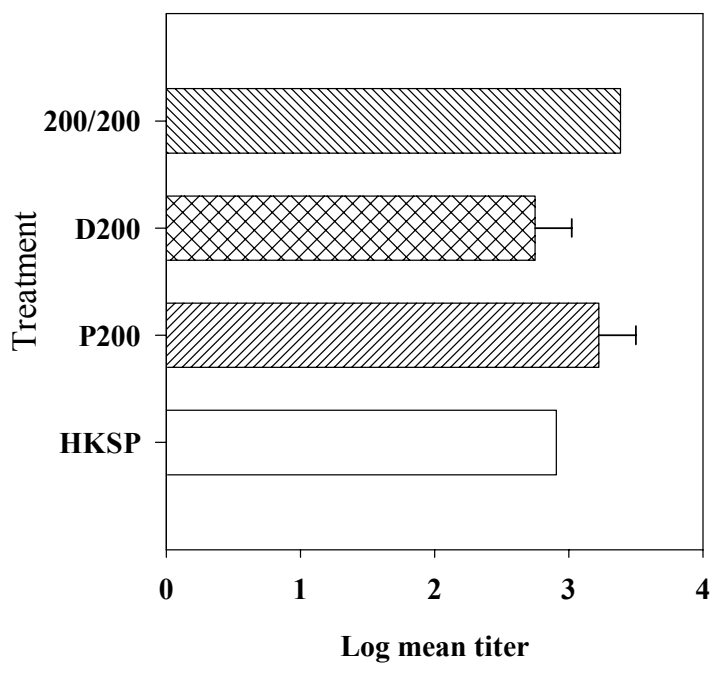

C. PspA specific IgG2b

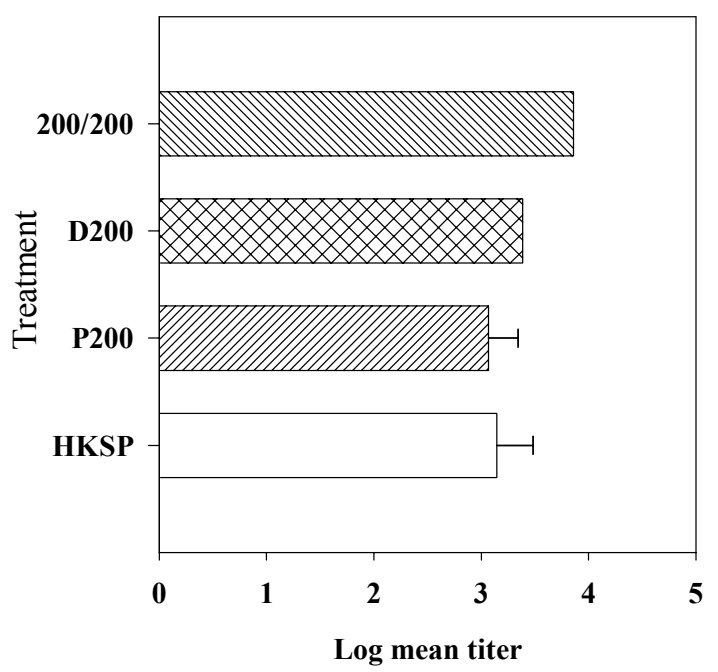

B. PspA specific IgG1

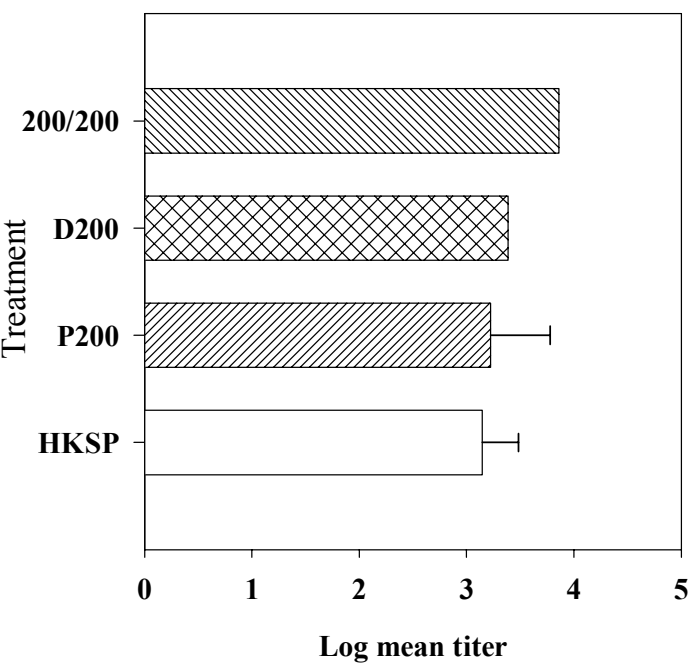




\section{GENERAL DISCUSSION}

\section{Hypothesis}

The overall objective of this thesis was to analyze the effects of in vivo exposure to a mixture of chemicals on the immune system. We hypothesized that since propanil decreases specific immune cell populations and function, and 2,4-D exposure can decrease thymocyte and bone marrow B cell numbers, a mixture, containing propanil and 2,4-D, would increase cellular and functional immune changes in an additive fashion. The effects of this mixture were studied in three ways: (i) the cell populations in the spleen, thymus and bone marrow were studied using flow cytometric analysis, cell numbers, and organ weight of the thymus and spleen; (ii) changes in sera levels of the stress hormone, corticosterone were correlated to changes in cell populations; and (iii) the antibody response, after immunization with HKSP, was used to evaluate functional changes to the immune system after mixture exposure.

\section{Overall results}

With the exception of the increases in the level of sera corticosterone hormone, the response to the mixture of propanil and 2,4-D could not be modeled simply as the sum of the responses given by the individual components of the mixture. Noteably, at some treatment doses where 2,4-D was not found to cause changes in immune cell number or function, 2,4-D acted to increase the changes caused by propanil. Furthermore, the increases in the antibody response to HKSP that occur after herbicide exposure were not predicted by cell changes in the thymus, spleen and bone marrow and, importantly, were not predicted by previous research on the functional changes that occur to immune cells after in vivo and in vitro exposure to propanil. 


\section{Sera corticosterone changes after propanil, 2,4-D or mixture treatment.}

Increases in serum corticosterone levels that occur in a biological response to chemical stress were examined as a possible mechanism for the depletion of immune cell populations after exposure to propanil, 2,4-D or a mixture containing propanil and 2,4-D. Mice that had thymic atrophy, a classical response to glucocorticoid hormones, also had increased sera corticosterone levels (P150, P200, D200, 150/150 and 200/200) (Figure 7A-C). However, significant increases in sera corticosterone levels were also measured after exposure to concentrations of propanil that did not cause thymic atrophy or measurable changes in any immune cell population or functions (P10, P25, P50, 50/50, 100/100). In contrast, D200 was the only 2,4-D dose that increased sera corticosterone levels. These data suggest that corticosterone increases are not sufficient, to effect immunological changes after herbicide exposure.

Double positive $\left(\mathrm{CD}^{+} \mathrm{CD}^{+}\right)$thymocyte decreases after 150/150 mixture treatment were partially caused by increases in sera corticosterone levels and were prevented, in part, by pre-treatment of mice with RU 486, a glucocorticoid receptor block. Mixture treatment extended the time needed for the $\mathrm{CD} 4^{+} \mathrm{CD} 8^{+}$thymocyte population to recover. With exposure to $150 / 150$ mixture treatment the $\mathrm{CD} 4^{+} \mathrm{CD} 8^{+}$ thymocyte population was decreased at two days and remained decreased as compared to vehicle treated animals at 7 days after treatment (Figure 2 and 6A). In contrast, single herbicide treatment of $\mathrm{P} 150$ caused decreases in the $\mathrm{CD} 4^{+} \mathrm{CD} 8^{+}$thymocyte population at 2 days after treatment but this population was recovered by 7 days after treatment (Figure 2 and $6 \mathrm{~A})$.

The $\mathrm{CD} 4^{+} \mathrm{CD} 8^{-}$thymocyte population was unaffected by mixture exposure. In contrast, the $\mathrm{CD} 4^{-} \mathrm{CD} 8^{+}$thymocyte population was specifically decreased by exposure to 
the mixture at 2 days after treatment (Figure 4), CD4 CD8 ${ }^{-}$thymocytes, although not decreased as compared to vehicle, were also decreased in the factorial analysis after 100/100, 150/150 and 200/200 mixture treatment (Figure 5). Mixture-specific changes in the $\mathrm{CD} 4^{-} \mathrm{CD} 8^{+}$and $\mathrm{CD} 4^{-} \mathrm{CD} 8^{-}$thymocyte populations indicate that either the mixture increases cell loss to a degree where statistically significant decreases occur in populations that are normally not affected by propanil treatment alone, or mixture specific effects can occur in the thymus.

Bone marrow $\mathrm{B}$ cell numbers are also decreased by exposure to all three herbicide treatments. Initial non-significant decreases occur in the pre B cell population in the bone marrow at 1 day (data not shown) and this loss is followed by cell losses in the pre B cell population and the developmentally downstream $\operatorname{IgM}^{+} \mathrm{B}$ cell population at 2 days after treatment (Figure 9A-D and 10A-D). In contrast to the $\mathrm{CD} 4^{+} \mathrm{CD} 8^{+} \mathrm{T}$ cells in the thymus, the pre $\mathrm{B}$ and $\operatorname{IgM}^{+} \mathrm{B}$ cell decreases in the bone marrow were not associated with increases in sera corticosterone levels (Figure 11B-C). C57B1/6 mice treated i.p. with 75-100 mg corticosterone/kg bw demonstrated similar absolute numbers of pro and pre B cells as compared to vehicle-treated control animals (Figure 11A-B and data not shown). $\operatorname{IgM}^{+} \mathrm{B}$ cells were actually increased with $75-100 \mathrm{mg}$ corticosterone $/ \mathrm{kg}$ bw (Figure 11C). Pretreatment of animals with RU 486 prior to mixture exposure did not abrogate the decreases in the pre $\mathrm{B}$ or $\operatorname{IgM}^{+} \mathrm{B}$ cell populations (Figure 11B-C). Treatment with the 150/150 herbicide mixture resulted in significant decreases in the pre $\mathrm{B}$ and $\operatorname{IgM}^{+} \mathrm{B}$ cell population. Therefore, in contrast to in vitro studies that found bone marrow B cell populations were decreased by exposure to synthetic glucocorticoids 
(Sabbele, et al., 1987), the effects of the herbicide mixture on bone marrow B cell populations is glucocorticoid independent .

It is interesting that the $\mathrm{CD} 4^{+} \mathrm{CD} 8^{+}$thymocyte and pre $\mathrm{B}$ cell populations that are most affected by herbicide treatments are the cell populations that undergo proliferation during development. Cell cycle analysis of the thymus at 4 days after treatment has determined that recovery of the thymus is initiated in the more mature $\mathrm{CD} 4^{+} \mathrm{CD} 8^{+}$and $\mathrm{CD}^{-} \mathrm{CD}^{+}$populations (Cuff et al., 1996). It is possible that exposure to propanil, 2,4-D and the mixture affect the ability of the late $\mathrm{CD} 4^{-} \mathrm{CD} 8^{-} /$early $\mathrm{CD} 4^{+} \mathrm{CD} 8^{+}$to proliferate. In the flow cytometric analysis, we did not separate the immature $\mathrm{CD} 3^{-} \mathrm{CD} 4^{-} \mathrm{CD} 8^{+}$from the $\mathrm{CD}^{+} \mathrm{CD} 4^{-} \mathrm{CD} 8^{+}$thymocyte population. It would be interesting to determine if the earlier $\mathrm{CD} 3^{-\mathrm{CD}} 4^{-\mathrm{CD}} 8^{+}$precursor cells, and not mature $\mathrm{CD} 3^{+} \mathrm{CD} 4^{-} \mathrm{CD} 8^{+}$thymocytes, are the population that is sensitive to mixture treatment as this would support the idea that herbicide treatment affects the late $\mathrm{CD} 4{ }^{-} \mathrm{CD} 8^{-} /$early $\mathrm{CD} 4^{+} \mathrm{CD} 8^{+}$transitional cell population. In a similar manner, inhibition of proliferation may also occur in the large pre B population. Future studies involving analysis of cell cycling profiles in thymocyte and bone marrow B cell subpopulations at 2 days after treatment would determine if herbicide treatment acts to block development in the bone marrow and thymus.

The effects of exposure to P200, D200, 150/150 and 200/200 treatment results in a greater than $50 \%$ loss in $\mathrm{CD} 4^{+} \mathrm{CD} 8^{+}$thymocytes and bone marrow pre $\mathrm{B}$ cells as compared to vehicle (Figure 2 and Figure 9A-D). At this point, we do not know the complete effect that significant cell loss in the developing organs will have on the peripheral immune system. It is possible that cell loss after herbicide exposure could result in a skewing of the $\mathrm{T}$ cell and $\mathrm{B}$ cell repertoires. It has been demonstrated that $\mathrm{T}$ 
cell depletion in the thymus, resulting from decreases in thymus-derived glucocorticoid hormones, can result in the deletion of specific $\mathrm{V}_{\beta}$ expressing thymocyte populations ( $\mathrm{Lu}$ et al., 2000). This skewing of the $\mathrm{T}$ cell repertoire can lead to antigen-specific unresponsiveness and inhibition of autoimmunity (Lu et al., 2000; Tolosa et al., 1998). Therefore, it is possible that herbicide treatment could result in similar changes in the $\mathrm{T}$ cell response to antigen. Analysis of in vivo $\mathrm{V}_{\beta} \mathrm{T}$ cell populations after herbicidetreatment and immunization, or in an autoimmune mouse model would address this question.

The antibody response may also be changed by exposure to stress hormones and the nature of the change may be antigen dependent (Pruett and Fan, 2001; Han and Pruett, 1995). Pruett and Fan, (2001), found that exposure to $2500-10,000 \mathrm{ng} / \mathrm{ml} \cdot \mathrm{hr}$ of corticosterone (corresponding to $9-18 \mathrm{mg} / \mathrm{kg}$ treatment with exogenous corticosterone) resulted in dose-dependent decreases in the amount of IgG1 and IgG2a produced in response to KLH antigen. In contrast, the antibody response to SRBC immunization was increased after low-dose corticosterone treatment (between 0-3000 ng/ml hr) (Pruett and Fan, 2001). In vivo exposure to the neurotransmitter, norepinephrine, has also been demonstrated to increase the antibody response to SRBC (Sanders and Munson, 1984a). These experiments suggest that neuroendocrine mediators, including glucocorticoid hormones, could contribute to the increase in antibody response after immunization with S. pneumoniae that occurs after herbicide exposure. There are two experiments that could help to elucidate the role of neuroendocrine mediators in the antibody response. Using the experimental protocol designed by Pruett et al., (1999 and 2000), the corticosterone AUC can be used to compare the antibody response after mixture 
treatment as compared to the response given after treatment with an equivalent amount of exogenous corticosterone. This response would suggest the degree to which corticosterone is involved in the increased antibody response. In conjunction, RU 486 pre-treatment could be used before herbicide treatment and immunization to determine the effects of corticosterone on the antibody response.

\section{Phenotypic changes in the spleen after propanil, 2,4-D or mixture treatment.}

Exposure to propanil, 2,4-D and a mixture containing propanil and 2,4-D, resulted in changes in the phenotype of the spleen (Table 4, 5, 7 and 8). In contrast to the thymus and the bone marrow, where mixture decreases were more profound and of longer duration than the effects caused by single herbicide treatment, mixture treatment in the spleen resulted in a combined response that was not significantly greater than the changes caused by exposure to propanil or 2,4-D alone (Table 5 and 8). Mixture treatment resulted in decreases in the number of $\mathrm{B}$ cells and $\mathrm{CD}^{+} \mathrm{T}$ cells in the spleen that were similar to the decreases caused by exposure to 2,4-D (Table 5 and 8). In a similar manner, propanil treatment resulted in increases in neutrophil absolute cell numbers in the spleen, similar to the increases caused by mixture treatment (Table 5 and 8 ). Therefore, lymphocyte populations in the spleen appear to be more resistant than $\mathrm{T}$ cells in the thymus and B cells in the bone marrow to the effects of mixture exposure.

Significant differences were found in the manner in which homeostasis is maintained in the lymphocyte populations in the spleen. Preliminary data using flow cytometric analysis and differential cell counts indicate that maintenance of the B cell population in the spleen and expansion of the neutrophil population after herbicide exposure may be initiated by splenic hematopoiesis (Table 6 and 9). In mice, the liver 
and spleen are known to participate in the development of the hematopoietic system and these organs act to maintain homeostasis shortly after birth (Wolber, et al. 2002). Exposure to propanil resulted in increases in the number of myeloid and erythroid multipotent precursor cells in the spleen at a time when these cells are depleted in the bone marrow (Blyler, et al. 1994; Barnett, et al. 1992). These results suggest that the spleen and bone marrow may continue to cooperate in the maintenance of homeostasis throughout life. Additional research using CFU assays on the pluripotent and multipotent stem cell populations in the bone marrow, liver and spleen may help to determine the phenotype and origin of the precursor cells in the spleen after herbicide exposure.

\section{Changes in the antibody response to HKSP immunization after herbicide exposure}

Exposure to the mixture of herbicides resulted in an enhanced TI-2 (PC polysaccharide) and TD (PspA protein) antibody response after immunization with HKSP. In these experiments, two different exposure regimens were used including simultaneous herbicide exposure and immunization (day 0 immunization) and immunization 4 days after herbicide exposure. The day 0 immunization protocol resulted in increases that ranged between 72-749 fold for the anti-PC response and 9-34 fold for the anti-PspA response after mixture treatment (Figure 14A-E and Figure 15A-D). In these experiments, although significant increases in the antibody response were only seen with mixture treatment, propanil treatment resulted in consistently greater mean SFC frequencies to both PC and PspA antigen (Figures 14A-E and 15A-D). Therefore, propanil exposure alone can act to increase the antibody response to HKSP immunization. 
In other experiments, when animals were exposed to herbicide on day 0 and immunized with HKSP on day 4 (day 4 immunization) the number of SFC responding to both PC specific IgM or IgG antigen were increased 5-12 fold over vehicle in both propanil and mixture-treated animals (Figure 13A-B). This increase, although significant, were less than the antibody increases that occur when herbicide treatment and immunization occurred on day 0 (Figure 13A-B vs. Figure 14A-B).

These two sets of experiments demonstrate that the timing of the immunization and herbicide exposure determines the extent of increase that occurs in the antibody response. Immediate immunization after herbicide exposure resulted in a greater than 10 fold increase in the number of anti-PC SFC as compared to immunization 4 days after propanil and mixture exposure, suggesting that exposure to either propanil or the mixture results in immediate effects on the initiation of the immune response that promote an increased antibody response. These effects appear to decrease with time resulting in an antibody response more similar to the response given by vehicle-treated immunized animals when the herbicides are given at four days after treatment. Further studies, including an immunization time-line before and after herbicide treatment would help to clarify critical timepoints where exposure to the herbicides can cause significant change in the antibody response.

\section{A possible cellular mechanism for the increase in antibody production after herbicide exposure}

Regardless of the timing of immunization (day 0 or day 4 immunization), there were herbicide-related increases in the number of SFC in the spleen (Figure 12A-B, Figure 13A-B and Figure 14A-E and 15A-D). Some probable mechanisms for the increases that occur in plasma cell frequency could include: (i) an increase in B cells 
with BCR specific for S. pneumoniae antigen; (ii) an increase in B cell activation through CD40L or cytokine stimulation; (iii) an increase in presentation of antigen; or (iv) an increase in the ability of the spleen to sustain plasma cells.

Mixture treatment results in increases in the number of B cells in the spleen at 14 days after treatment (Table 18). Although these increases in B cell number occur after the development of the antibody response, they suggest that the B cell population may be affected at earlier timepoints by mixture exposure. It is possible that rapid B cell turnover occurs in the spleen after mixture treatment and that these cells are being continuously replaced by new B cells. Rapid B cell turnover may allow for a larger number of $\mathrm{B}$ cells to be exposed to antigen, thereby increasing the chance that a greater number of BCR will recognize antigen. This possibility was reviewed in greater detail in Chapter 5 Discussion. Alternatively, changes in B cell development could allow for the preferential survival of a Ig heavy chain (IgH) B cell phenotype capable of responding to S. pneumoniae. This possibility could be studied by following the changes in $\operatorname{IgH}$ expression after herbicide exposure using flow cytometric analysis.

T cell stimulation of $\mathrm{B}$ cells with cytokines or through $\mathrm{CD} 40 / \mathrm{B} 7$ ligation is necessary for optimal TI-2 and TD antibody response to S. pneumoniae (Wu et al., 1999). Although this research did not look at specific cytokines produced immediately after herbicide exposure and immunization, cytokines are involved in immunoglobulin class switching, and the IgG isotype responses may be used as general indicators of cytokine changes. The possible correlation between increased cytokine stimulation by $\mathrm{T}$ cells and the increase in antibody response to S. pneumoniae was discussed in detail in the Chapter 5 Discussion. Neutrophils can also produce cytokines and chemokines that are important 
in the antibody response (Cassatella,1995; Scapini et al., 2001). The increases in the neutrophil population at 14 days after treatment (Table 16), and the relationship of these increases to the increased antibody response were discussed in the Chapter 4 Discussion.

An increase in antigen presentation could also result in increased antibody production. Neutrophils have been shown to process and present antigen (Potter et al., 2001; Oehler, et al. 1998). The implications that the increase in the neutrophil population after herbicide treatment in relation to increased antigen presentation is discussed in greater detail in the Chapter 4 Discussion.

Increased antigen presentation and increased B cell survival could also occur as a result of an increase in the DC population. Initial studies on colony forming progenitor cells $(\mathrm{CFU})$ in the spleen indicate that there is an increase in the number of multipotent myeloid progenitor cells (Zhao, et al. 1995; Barnett et al., 1992). It is possible that an APC population is maturing from these progenitor cells, allowing for increased presentation of antigen and/or increased plasma cell survival. Immature DC are capable of capturing whole bacteria (Svensson et al., 1997). After antigen encounter, DC decrease phagocytosis and begin antigen presentation, surface expression of costimulatory molecules and differentiation into APC (Sallusto et al., 1995). It is possible that propanil and mixture exposure initiate an expansion of myeloid precursor cells in the spleen that, in the presence of heat-killed S. pneumoniae, differentiate into myeloid DC. In our study, we stained for the $\mathrm{CD} 11 \mathrm{~b}^{+} / \mathrm{I}-\mathrm{A}^{\mathrm{b}+}$ population of cells that includes the $\mathrm{M} \varphi$ population along with some mature DC. At 14 days after herbicide exposure, there was only a slight increase in $\mathrm{CD} 11 \mathrm{~b}^{+} / \mathrm{I}-\mathrm{A}^{\mathrm{b}+}$ cells in the spleens of 200/200 treated animals (Table 18). This increase would be too late to assist in the antibody 
response to the vaccine, however changes may occur in this or other dendritic cell populations at earlier timepoints.

Recently it has been determined that initial T-independent B cell selection and plasma cell formation occurs on myeloid DC that are CD11 $\mathrm{c}^{\text {high }}$ (Garcia de Vinuesa, C. et al., 1999a). CD11 $\mathrm{c}^{\text {high }}$ DC are capable of transporting and presenting native peptide to B cells (Berney et al., 1999). One subset of myeloid, CD11 $\mathrm{c}^{\text {high }}$ dendritic cells, called plasmablast-associated dendritic cells (PDC), have been found to be required for differentiation of follicular B cells into plasma cell (Garcia de Vinuesa, C. et al., 1999a). Sze, et al. (2000) found that the number of CD11 $\mathrm{c}^{\text {high }}$ DC determine the number of plasma cells produced in response to immunization with the hapten antigen NP-Ficoll. Treatment of mice with anti-CD40 results in splenomegaly associated with an increase in the number of CD11 $\mathrm{c}^{\text {high }} \mathrm{DC}$ in the spleen. Augmentation of the CD11c $\mathrm{c}^{\text {high }} \mathrm{DC}$ population in vivo using anti-CD40 results in a 20 fold increase in the number of NPspecific plasma forming cells (Garcia de Vinuesa, C. et al., 1999a). Conversely, in QM mice with BCR specific for NP hapten, if the number of antigen specific B cells is expanded beyond the capacity of the CD11 $\mathrm{c}^{\text {high }} \mathrm{DC}$, surviving cells are found to be physically associated with the CD11 $\mathrm{c}^{\text {high }} \mathrm{DC}$, suggesting that physical contract with the CD11 $\mathrm{c}^{\text {high }}$ DC population promotes plasma cell survival (Sze, et al., 2000).

Colino et al., (2002) have demonstrated that adoptive transfer of bone marrow derived myeloid dendritic cells (BMDC) pulsed in vitro with S. pneumoniae antigen and subsequently transferred into naïve mice can elicit an antibody response similar in kinetics and Ig isotype to the response after immunization with HKSP. BMDC viability was necessary for both the anti-PC and the anti-PspA antibody response, suggesting an 
active role in vivo for the BMDC in the response to $S$. pneumoniae. BMDC's that had internalized $S$. pneumoniae bacteria were also stimulated to produce and secrete TNF- $\alpha$, IL-6, IL-12, and IL-10, suggesting that they not only present antigen, but also participate in control of the immune response (Colino et al., 2002). In other studies, myeloid DC have been found to control Th-2 development (Moser, et al., 2000) and myeloid CD11 $\mathrm{c}^{\text {high }}$ DC have been shown to express BAFF (B cell activating factor of the TNF family), a protein required for B cell homeostasis, plasma cell differentiation and class switching (MacLennan et al., 2002; Litinskiy et al., 2002). Therefore DC, and in particular myeloid DC, may play a central role in the regulation of the immune response to the S. pneumoniae vaccine. Further analysis of the PDC population may be possible using immunohistochemistry or flow cytometric analysis. If this population is increased in herbicide-treated spleens, treatment of mice with anti-CD40 prior to immunization with S. pneumoniae would help indicate the extent to which the PDC cells are involved in the increased antibody response after herbicide treatment. If this population is increased, resulting increases in the expression of BAFF protein, or signaling through the PDC CD40 molecule, are two possible mechanisms that could lead to increased antibody production.

Increases in the number of PDC may also increase the survival time of plasma cells in the spleen. The average plasma cell survives 1-3 days in the spleen (Sze, et al., 2000). In a TI-2 response to NP antigen, the number of plasma B cells peaks by 5 days and foci begin to involute by 6 days after immunization (Garcia de Vinuesa, C. et al., 1999b). Although sera antibody levels were not significantly increased after propanil or mixture exposure at 7 and 14 days after treatment, it is possible that these levels are 
increased at later timepoints. There is a possibility that the number of SFC are not only increased but their survival is also prolonged by propanil and mixture treatment. In a normal response, the maximum anti-PC sera antibody levels are reached at 7 days after treatment and remain constant for 28 days after vaccination (Wu et al., 1999). In contrast, the anti-PC sera antibody response after propanil and mixture treatment is normal at 7 and 14 days in spite of increases in plasma cell frequencies in the spleen (Figure 16A-D, Figure 17A-E and Figure 18A-C). ELISPOT analysis of the PC response at 14 or 21 days and collection of sera antibody at time intervals between $0-30$ days will be necessary to determine if plasma cell survival is increased.

In previous research, Barnett and Gandy (1989) demonstrated that propanil decreases the antibody response to SRBC. Furthermore, in mice infected with Listeria monocytogenes, propanil exposure did not change IL-6, IFN- $\gamma$, TNF- $\alpha$ or IL-1 $\beta$ cytokine levels in the spleen or liver (Watson et al., 2000). These results suggest that increases in immune cell function after herbicide treatment and S. pneumoniae immunization may be antigen specific. C-reactive protein, an acute phase protein produced by the liver is critical to the resolution of S. pneumoniae infection (Mold et al., 2002). Increases in Creactive protein would allow for increased opsonization of the bacteria. These increases could result in increased DC maturation, activation and presentation of antigen. Therefore, increases in C-reactive protein may be one way in which the antibody response to S. pneumoniae differs from the response to SRBC.

Exposure to propanil or the mixture and subsequent immunization with $S$. pneumoniae may result in increased resistance to challenge with live S. pneumoniae bacteria. However, an increased primary immune response does not guarantee an 
increase in the response to subsequent immunizations or to infectious challenge. After propanil or mixture exposure, the memory response may be increased, due to an increased B cell response to antigen. It may be decreased, due to the fact that B cells are being recruited into the plasma cell pool at the expense of the memory pool. Or, it may be unchanged because the large portion of plasma cells produced are from the TI-2 B cell response and are not recruited into the long-lived plasma cell pool. Analysis of the memory response is possible using herbicide treated animals that are boosted at one month after the first immunization and enumerating the number of antigen specific SFC in an ELISPOT analysis.

The increased antibody response may also promote long term, detrimental effects by the immune system. In animals that are genetically predisposed to autoimmunity, increases in the antibody response may decrease the time of onset or increase the severity of disease. This may be particularly true if splenic myelopoiesis is shown to be the mechanism of antibody increase. The mouse models for lupus autoimmune disease, lpr/lpr and gld/gld mice exhibit extramedullary myelopoiesis, including increases in CFU-S in the spleen (Schneider et al., 1999). In other research, mice transgenic for BAFF, a TNF family protein normally expressed on myeloid dendritic cells, have enlarged spleens, Peyers patches and lymph nodes. These mice have high levels of circulating antibody and are susceptible to autoimmune disease (Mackay et al., 1999). Therefore, it is possible that splenic myelopoiesis and/or increased antibody production resulting from propanil or mixture exposure may promote autoimmune disease. Further analysis of the affects of the herbicide mixture on autoimmune disease is possible using our current protocol in an autoimmune mouse model. 
Further research, focusing on the development of the antibody response during the first four days after immunization is necessary in order to elucidate a mechanism(s) for the increase in antibody production after herbicide exposure and to determine the difference between the day 0 and day 4 immunization responses. Several key experiments would include: (i) in vitro culture of spleen cells using S. pneumoniae antigen as a stimulant to evaluate cytokine changes that occur in the spleen during the first few days after herbicide treatment; (ii) evaluation of changes in the DC populations after herbicide and S. pneumoniae treatment by flow cytometric analysis or immunohistochemistry; (iii) evaluation of the effects of the neutrophil population by blocking with Gr-1/RB6 a monoclonal antibody specific for neutrophils; and (iv) evaluation of the effects of glucocorticoid hormones in the spleen after herbicide treatment using the glucocorticoid receptor blocker RU 486.

\section{Toxicological Relevance}

This research is preliminary and has been designed to determine whether exposure to a mixture of chemicals can be more toxic than exposure to the individual components of the mixture. These experiments did not address several issues of relevant human exposure routes, including dermal or oral exposure routes, or the effects of exposure to environmentally relevant doses. In particular, i.p. exposure promotes the concentration of propanil and the mixture in the liver where they could overwhelm existing stores of acylamidase, resulting in greater toxicity than other exposure routes where delivery to the liver is more gradual. The preferential concentration of the herbicides in a few tissues may also explain the increased sensitivity of particular immune populations to the mixture effects. The use of an agricultural preparation of 2,4- 
D presents a problem in that it is impossible to be certain that the effects attributed to single herbicide exposures to 2,4-D are due to the herbicide or to other ingredients present in the herbicide preparation. These are a few of the questions that need to be answered before the relevance of this data can be extrapolated to human environmental mixture exposures. Future research is planned to address these problems.

\section{Summary}

We are continually exposed to mixtures of chemicals in our environment. The biological response to a mixture of chemicals may be uniquely different from those of the individual components of the mixture, reflecting the complexity of the immune system. In this study, propanil was consistently found to be the main immunotoxicant in the mixture. In many cases, 2,4-D alone did not change the immune response, but 2,4-D in the mixture potentiated the immunotoxic effects of propanil. Mixture effects on immune cell population numbers and antibody production were similar, but often more severe, than the effects caused by propanil alone. Interestingly, herbicide-induced changes in the antibody response after immunization appear to be antigen specific. After exposure to propanil and the mixture, the response to $S$. pneumoniae resulted in increases in antibody production that could not be predicted by previous in vivo or in vitro studies. This research highlights the necessity of studying the effects of chemical mixtures and provides insight into possible links between environmental contamination and disease. 


\section{APPENDIX}


Table 23. Appendix Changes in absolute cell number in the thymus at 2 and 7 days post treatment and changes in corticosterone hormones at $1 \mathrm{hr}$ post treatment

\begin{tabular}{|c|c|c|c|c|c|c|c|c|c|c|c|}
\hline & \multicolumn{5}{|c|}{2 days post treatment } & \multicolumn{5}{|c|}{7 days post treatment } & \multirow{2}{*}{$\begin{array}{l}1 \mathrm{hr} \\
\begin{array}{l}\text { Cort } \\
(\mathrm{ng} / \mathrm{ml})\end{array}\end{array}$} \\
\hline & TW:BW & $\begin{array}{l}\text { CD4- } \\
\text { CD8 }\end{array}$ & $\begin{array}{l}\mathrm{CD}^{+} \\
\mathrm{CD}^{+}\end{array}$ & $\begin{array}{l}\mathrm{CD}^{+} \\
\mathrm{CD} 8^{-}\end{array}$ & $\begin{array}{l}\mathrm{CD}^{-} \\
\mathrm{CD}^{+}\end{array}$ & TW:BW & $\begin{array}{l}\text { CD4 } \\
\text { CD8 }\end{array}$ & $\begin{array}{l}\mathrm{CD} 4^{+} \\
\mathrm{CD}^{+}\end{array}$ & $\begin{array}{l}\mathrm{CD}^{+} \\
\mathrm{CD}^{-}\end{array}$ & $\begin{array}{l}\mathrm{CD}^{-} \\
\mathrm{CD} 8^{+}\end{array}$ & \\
\hline D50 & & & & & & & & & & & \\
\hline D100 & & & & & & & & & & & \\
\hline D150 & & I & & $\mathrm{I}$ & & & & & & & \\
\hline D200 & $\mathrm{D}$ & & & & & & & & & & \\
\hline D200 & & & D & $\mathrm{D}$ & $\mathrm{D}$ & $\mathrm{D}$ & $\mathrm{D}$ & $\mathrm{D}$ & $\mathrm{D}$ & $\mathrm{D}$ & $>500$ \\
\hline $\mathrm{P} 5$ & & & & & & & & & & & \\
\hline P10 & & & & & & & & & & & 218 \\
\hline P25 & & & & & & & & & & & 399 \\
\hline P50 & & & & & & & & & & & $>500$ \\
\hline $\begin{array}{l}\text { P100 } \\
\end{array}$ & & & $\mathrm{D}$ & & & & & & & & $>500$ \\
\hline $\begin{array}{l}\text { P150 } \\
\end{array}$ & & & $\mathrm{D}$ & & & $\mathrm{D}$ & & & & & $>500$ \\
\hline P200 & $\bar{D}$ & & $\mathrm{D}$ & & $\mathrm{D}$ & & & & & $\mathrm{D}$ & $>500$ \\
\hline $50 / 50$ & & & & & & & & & & & $>500$ \\
\hline $100 / 100$ & & MI & $\mathrm{D}$ & & $\mathrm{D}$ & & & & & & $>500$ \\
\hline $150 / 150$ & D & MI & $\begin{array}{l}\mathrm{D} \\
\mathrm{MI}\end{array}$ & MI & $\begin{array}{l}\mathrm{D} \\
\mathrm{MI}\end{array}$ & D & $\mathrm{D}$ & $\bar{D}$ & $\mathrm{D}$ & $\mathrm{D}$ & $>500$ \\
\hline $200 / 200$ & $\mathrm{D}$ & MI & $\begin{array}{l}\mathrm{D} \\
\mathrm{MI}\end{array}$ & MI & $\begin{array}{l}\mathrm{D} \\
\mathrm{MI}\end{array}$ & $\mathrm{D}$ & $\mathrm{D}$ & $\mathrm{D}$ & $\mathrm{D}$ & $\mathrm{D}$ & $>500$ \\
\hline
\end{tabular}

$\mathrm{D}=\mathrm{p} \leq 0.05$ vs. vehicle

$\mathrm{I}=\mathrm{p} \geq 0.05$ vs. vehicle

$\mathrm{MI}=$ Mixture Interaction

Empty cells are unchanged as compared to vehicle. 
Table 24. Appendix. Changes in bone marrow $B$ cells at 2, 7 and 14 days after treatment.

\begin{tabular}{|l|l|l|l|l|l|l|l|l|l|}
\hline & \multicolumn{9}{|c|}{ Bone Marrow B Cells } \\
\hline $\begin{array}{c}\text { Days } \\
\text { post } \\
\text { treatment }\end{array}$ & \multicolumn{3}{|c|}{2} & \multicolumn{3}{|c|}{7} & \multicolumn{3}{|c|}{14} \\
\hline & Pro B & Pre B & $\begin{array}{l}\text { IgM } \\
\text { B }\end{array}$ & Pro B & Pre B & $\begin{array}{l}\text { IgM } \\
\text { B }\end{array}$ & Pro B & Pre B & $\begin{array}{l}\text { IgM }^{+} \\
\text {B }\end{array}$ \\
\hline D50 & & & & & & & & & \\
\hline D100 & & & & & & & & & \\
\hline D150 & & & & & & & & & \\
\hline D200 & & & D & & D & D & & & \\
\hline P50 & & & & & D & & & & \\
\hline P100 & & & & & & & & & \\
\hline P150 & & & D & & D & D & & & \\
\hline P200 & & & D & & D & & & & \\
\hline $50 / 50$ & & D & D & & D & D & & & \\
\hline $100 / 100$ & & D & D & & D & D & & & \\
\hline $150 / 150$ & & D & D & & $\begin{array}{l}\text { D } \\
\text { MI }\end{array}$ & $\begin{array}{l}\text { D } \\
\text { MI }\end{array}$ & & & \\
\hline $200 / 200$ & & D & D & & D & $\begin{array}{l}\text { D } \\
\text { MI }\end{array}$ & & & \\
\hline
\end{tabular}

$\mathrm{D}=\mathrm{p} \leq 0.05$ vs. vehicle

$\mathrm{I}=\mathrm{p} \geq 0.05$ vs. vehicle

$\mathrm{MI}=$ Mixture Interaction

Empty cells are unchanged as compared to vehicle. 
Table 25. Appendix. Changes in the absolute cell number with RU 486 pretreatment 2 hrs prior to herbicide exposure.

\begin{tabular}{|l|l|l|l|l|}
\hline \multicolumn{1}{|c|}{ Treatment } & \multicolumn{5}{|c|}{ 2 days post treatment } \\
\hline & $\begin{array}{l}\text { CD4 } \\
\text { CD8 }\end{array}$ & Pro B & Pre B & $\begin{array}{l}\text { IgM }^{+} \\
\text {B }\end{array}$ \\
\hline RU 486 & U & U & U & U \\
\hline $\begin{array}{l}\text { Corticosterone } \\
75 \mathrm{mg} / \mathrm{kg}\end{array}$ & $\mathrm{D}$ & $\mathrm{U}$ & $\mathrm{U}$ & $\mathrm{U}$ \\
\hline $\begin{array}{l}\text { Corticosterone } \\
100 \mathrm{mg} / \mathrm{kg}\end{array}$ & $\mathrm{ND}$ & $\mathrm{U}$ & $\mathrm{U}$ & $\mathrm{U}$ \\
\hline P150 & $\mathrm{D}$ & $\mathrm{ND}$ & $\mathrm{ND}$ & $\mathrm{ND}$ \\
\hline RU $486+\mathrm{P} 150$ & $\mathrm{U}$ & $\mathrm{ND}$ & $\mathrm{ND}$ & $\mathrm{ND}$ \\
\hline $150 / 150$ & $\mathrm{D}$ & $\mathrm{U}$ & $\mathrm{D}$ & $\mathrm{D}$ \\
\hline RU $486+150 / 150$ & $\mathrm{U}$ & $\mathrm{U}$ & $\mathrm{U}$ & $\mathrm{U}$ \\
\hline
\end{tabular}

$\mathrm{D}=\mathrm{p} \leq 0.05$ vs. vehicle

$\mathrm{U}=$ Unchanged vs. vehicle

$\mathrm{ND}=$ Experiment not done 
Table 26. Appendix. Changes in absolute cell number in non-immunized spleens at 7 and 14 days post treatment

\begin{tabular}{|l|l|l|l|l|l|l|l|l|l|l|l|l|l|l|l|l|}
\hline \multicolumn{9}{|c|}{7 days post treatment } & \multicolumn{7}{c|}{ 14 days post treatment } \\
\hline & $\begin{array}{l}\text { SW: } \\
\text { BW }\end{array}$ & $\begin{array}{l}\text { Total } \\
\text { cells }\end{array}$ & B & CD4 & CD8 & PMN & $\begin{array}{l}\text { M } \varphi \\
\text { DC }\end{array}$ & $\begin{array}{l}\text { Band } \\
\text { PMN }\end{array}$ & $\begin{array}{l}\text { SW: } \\
\text { BW }\end{array}$ & $\begin{array}{l}\text { Total } \\
\text { cells }\end{array}$ & B & CD4 & CD8 & PMN & $\begin{array}{l}\text { M } \varphi \\
\text { DC }\end{array}$ & $\begin{array}{l}\text { Band } \\
\text { PMN }\end{array}$ \\
\hline D200 & & & & & & & & & & & D & D & & & & \\
\hline P100 & I & & & & & & & & ND & ND & & & & & & \\
\hline P150 & I & & & & & & & & ND & ND & & & & & & \\
\hline P200 & I & I & & & & & & P & I & I & & & & I & & A \\
\hline $50 / 50$ & & & & & & & & & & & & & & & & \\
\hline $\begin{array}{l}100 / \\
100\end{array}$ & I & & & & & & & & ND & ND & & & & & & \\
\hline $\begin{array}{l}150 / \\
150\end{array}$ & I & I & & & & & & & ND & ND & & & & & & \\
\hline $\begin{array}{l}200 / \\
200\end{array}$ & I & I & D & D & & & & P & I & I & I & D & & I & & P \\
\hline
\end{tabular}

$\mathrm{D}=\mathrm{p} \leq 0.05$ vs. vehicle

$I=p \geq 0.05$ vs. vehicle

$\mathrm{ND}=$ Experiment not done

$\mathrm{P}=$ Present

$\mathrm{A}=$ Absent

Empty cells are unchanged as compared to vehicle. Treatment with 50,100 and 150

$\mathrm{mg} / \mathrm{kg}$ 2,4-D and $50 \mathrm{mg} / \mathrm{kg}$ Propanil did not change spleen size, cell count or leukocyte populations. 
Table 27. Appendix. Changes in absolute cell number in the spleens of D4 immunized animals.

\begin{tabular}{|l|l|l|l|l|l|l|l|l|}
\hline \multicolumn{7}{|c|}{ 14 days post herbicide treatment and 10 days post vaccination } \\
\hline & $\begin{array}{l}\text { SW: } \\
\text { BW }\end{array}$ & $\begin{array}{l}\text { Total } \\
\text { cells }\end{array}$ & B & CD4 & CD8 & PMN & $\begin{array}{l}\text { M } \\
\text { DC }\end{array}$ & $\begin{array}{l}\text { Band } \\
\text { PMN }\end{array}$ \\
\hline D200 & & & & & & & & \\
\hline P200 & I & I & & & & I & & ND \\
\hline $\begin{array}{l}200 / \\
200\end{array}$ & I & I & D & D & & I & & ND \\
\hline
\end{tabular}

Table 28. Appendix. Changes in absolute cell number in spleens of D0 immunized animals at 7 and 14 days post treatment.

\begin{tabular}{|c|c|c|c|c|c|c|c|c|c|c|c|c|c|c|c|c|}
\hline \multicolumn{9}{|c|}{7 days post treatment } & \multicolumn{8}{|c|}{14 days post treatment } \\
\hline & $\begin{array}{l}\text { SW: } \\
\text { BW }\end{array}$ & $\begin{array}{l}\text { Total } \\
\text { cells }\end{array}$ & $\bar{B}$ & $\mathrm{CD} 4$ & CD8 & $\overline{\mathrm{PMN}}$ & $\begin{array}{l}\mathrm{M} \varphi \\
\mathrm{DC}\end{array}$ & $\begin{array}{l}\text { Band } \\
\text { PMN }\end{array}$ & $\begin{array}{l}\text { SW: } \\
\text { BW }\end{array}$ & $\begin{array}{l}\text { Total } \\
\text { cells }\end{array}$ & $\mathrm{B}$ & $\overline{\mathrm{CD} 4}$ & CD8 & $\begin{array}{l}\text { PMN } \\
\end{array}$ & $\begin{array}{l}\mathrm{M} \varphi \\
\mathrm{DC}\end{array}$ & $\begin{array}{l}\text { Band } \\
\text { PMN }\end{array}$ \\
\hline $\mathrm{D} 200$ & & & & & & & & & & & & & & & & \\
\hline$\overline{\mathrm{P} 200}$ & $\bar{I}$ & I & & & & & & & $\bar{I}$ & $\bar{I}$ & I & & & $\bar{I}$ & & $P$ \\
\hline $\begin{array}{l}200 / \\
200\end{array}$ & I & I & & & & I & & $P$ & I & I & $\mathrm{I}$ & & & I & & $\mathrm{P}$ \\
\hline
\end{tabular}

$\mathrm{D}=\mathrm{p} \leq 0.05$ vs. vehicle

$\mathrm{I}=\mathrm{p} \geq 0.05$ vs. vehicle

$\mathrm{ND}=$ Experiment not done

$\mathrm{P}=$ Present in sample

Empty cells are unchanged as compared to vehicle. 
Table 29. Appendix. Changes in the number of SFC in the spleen after D4 immunization.

\begin{tabular}{|c|c|c|c|c|c|c|c|c|}
\hline & \multicolumn{6}{|c|}{ D4 Immunization } \\
\hline Antigen & \multicolumn{3}{|c|}{ PC } & \multicolumn{3}{c|}{ HKSP } \\
\hline Organ & SFC & SFC & Sera & Sera & SFC & SFC & Sera & Sera \\
\hline Isotype & IgM & IgG & IgM & IgG & IgM & IgG & IgM & IgG \\
\hline D200 & $1^{\text {a }}$ & 1 & NC & NC & 3 & 2 & NC & NC \\
\hline P200 & 5 & 5 & NC & NC & 8 & 6 & NC & NC \\
\hline $200 / 200$ & 7 & 8 & NC & NC & 12 & 8 & NC & NC \\
\hline
\end{tabular}

${ }^{a}=$ fold increase over vehicle

$\mathrm{NC}=$ No change compared to vehicle

$\mathrm{ND}=$ Experiment not done 
Table 30. Appendix. Changes in the number of SFC and sera antibody levels after D0 immunization.

\begin{tabular}{|c|c|c|c|c|c|c|c|c|}
\hline & \multicolumn{8}{|c|}{ D0 Immunization } \\
\hline Antigen & \multicolumn{8}{|c|}{ PC } \\
\hline Organ & SFC & SFC & SFC & SFC & Sera & Sera & Sera & Sera \\
\hline Isotype & IgM & $\operatorname{IgG}$ & $\mathrm{IgG} 3$ & $\operatorname{IgG} 2 b$ & $\mathrm{IgM}$ & $\operatorname{IgG}$ & $\mathrm{IgG} 3$ & $\operatorname{IgG} 2 b$ \\
\hline D200 & $4^{a}$ & 3 & 2 & 13 & $\mathrm{NC}$ & $\mathrm{NC}$ & $\mathrm{NC}$ & $\mathrm{NC}$ \\
\hline P200 & 12 & 15 & 7 & 37 & $\mathrm{NC}$ & $\mathrm{NC}$ & $\mathrm{NC}$ & $\mathrm{NC}$ \\
\hline $200 / 200$ & 72 & 76 & 135 & 749 & $\mathrm{NC}$ & $\mathrm{NC}$ & $\mathrm{NC}$ & $\mathrm{NC}$ \\
\hline Antigen & \multicolumn{8}{|c|}{ PspA } \\
\hline $\begin{array}{l}\text { Isotype } \\
\end{array}$ & IgM & $\operatorname{IgG}$ & $\mathrm{IgG3}$ & $\operatorname{IgG} 2 \mathrm{~b}$ & IgM & IgG & $\mathrm{IgG3}$ & $\operatorname{IgG} 2 b$ \\
\hline$\overline{\mathrm{D} 200}$ & 1 & 1 & ND & 2 & $\mathrm{NC}$ & $\mathrm{NC}$ & $\mathrm{NC}$ & $\mathrm{NC}$ \\
\hline P200 & 5 & 4 & ND & 3 & $\mathrm{NC}$ & $\mathrm{NC}$ & $\mathrm{NC}$ & $\mathrm{NC}$ \\
\hline $200 / 200$ & 10 & 18 & ND & 12 & $\mathrm{NC}$ & $\mathrm{NC}$ & $\mathrm{NC}$ & $\mathrm{NC}$ \\
\hline
\end{tabular}

$\mathrm{a}=$ fold increase over vehicle

$\mathrm{NC}=$ No change compared to vehicle

$\mathrm{ND}=$ Experiment not done 


\section{REFERENCES}

Adams, S. L., Horvat, S. T., Irwin, A. E., Junkin, R. W., Koreman, N. M., and Blakley, B. R. (1991). The effects of Tordon 202c exposure on urethan-induced lung adenoma formation in female CD-1 mice. Vet. Hum. Toxicol. 33, 209-211.

Ader, R., Felten, D., and Cohen, N. (1990). Interactions between the brain and the immune system. Annu. Rev. Pharmacol. Toxicol. 30, 561-602.

Anderson, G., Moore, N. C., Owen, J. J., and Jenkinson, E. J. (1996). Cellular interactions in thymocyte development. Annu. Rev. Immunol. 14, 73-99.

Andréau, K., Lemaire, C., Souvannavong, V., and Adam, A. (1998). Induction of apoptosis by dexamethasone in the B cell lineage. Immunopharmacology. 40, 6776.

Barnes, C. J., Lavy, T. L., and Mattice, J. D. (1987). Exposure of non-applicator personnel and adjacent areas to aerially applied propanil. Bull. Environ. Contam. Toxicol. 39, 126-133.

Barnett, J. B. and Gandy, J. (1989). Effect of acute propanil exposure on the immune response of C57B1/6 mice. Fundam. Appl. Toxicol. 12, 757-764.

Barnett, J. B., Gandy, J., Wilbourn, D., and Theus, S. A. (1992). Comparison of the immunotoxicity of propanil and its metabolite, 3,4- dichloroaniline, in $\mathrm{C} 57 \mathrm{Bl} / 6$ mice. Fundam Appl Toxicol 18, 628-631.

Benoist, C. and Mathis, D. (1998). T-lymphocyte differentiation and biology. In Fundamental Immunology (W.E. Paul, Ed.), pp. 367-410. Lippincott - Raven, Philadelphia - New York. 
Berney, C., Herren, S., Power, C. A., Gordon, S., Martinez-Pomares, L., and KoscoVilbois, M. H. (1999). A member of the dendritic cell family that enters B cell follicles and stimulates primary antibody responses identified by a mannose receptor fusion protein. J.Exp.Med. 190, 851-860.

Blakley, B. R. (1986). The effect of oral exposure to the n-butylester of 2,4dichlorophenoxyacetic acid on the immune response in mice. Int. J. Immunopharmacol. 8, 93-99.

Blakley, B. R. and Schiefer, B. H. (1986). The effect of topically applied n-butylester of 2,4- dichlorophenoxyacetic acid on the immune response in mice. J. Appl. Toxicol. 6, 291-295.

Blakley, B. R., Gagnon, J. M., and Rousseaux, C. G. (1992). The effect of a commercial 2,4-D formulation on chemical- and viral- induced tumor production in mice. J. Appl. Toxicol. 12, 245-249.

Blakley, B. R. (1997). Effect of roundup and tordon 202C herbicides on antibody production in mice. Vet. Hum. Toxicol. 39, 204-206.

Blakley, B. R., Yole, M. J., Brousseau, P., Boermans, H., and Fournier, M. (1998). Effect of 2,4-dicholorophenoxyacetic acid, trifluralin and triallate herbicides on immune function. Vet. Hum. Toxicol. 40, 5-10.

Blakley, P. M., Kim, J. S., and Firneisz, G. D. (1989a). Effects of preconceptional and gestational exposure to Tordon 202c on fetal growth and development in CD-1 mice. Teratology 39, 547-553. 
Blakley, P. M., Kim, J. S., and Firneisz, G. D. (1989b). Effects of paternal subacute exposure to Tordon 202c on fetal growth and development in CD-1 mice. Teratology 39, 237-241.

Blalock, J. E. (1994). The syntax of immune-neuroendocrine communication. Immunol. Today 15, 504-511.

Blyler, G., Landreth, K. S., Lillis, T., Schafer, R., Theus, S. A., Gandy, J., and Barnett, J. B. (1994). Selective myelotoxicity of propanil. Fundam. Appl. Toxicol. 22, 505510.

Bodanski, O. (1951). Methemoblobinemia and methmoglobin-producing compounds. Pharmacology Reviews 3, 144-196.

Borghesi, L. A., Smithson, G., and Kincade, P. W. (1997). Stromal cell modulation of negative regulatory signals that influence apoptosis and proliferation of B lineage lymphocytes. J. Immunol. 159, 4171-4179.

Boyd, C. A., Weiler, M. H., and Porter, W. P. (1990). Behavioral and neurochemical changes associated with chronic exposure to low-level concentration of pesticide mixtures. J. Toxicol. Environ. Health 30, 209-221.

Bruyn, G. A. (1992). Mechanisms of host defense against infection with Streptococcus pneumoniae. Clin. Infect. Dis. 14, 251-262.

Burns, L. A. (1994). Gallium arsenide-induced increase in serum corticosterone is not responsible for suppression of the IgM antibody response. J. Pharmacol. Exp. Ther. 268, 740-746. 
Carsetti, R. (2000). The development of B cells in the bone marrow is controlled by the balance between cell-autonomous mechanisms and signals from the microenvironment. J. Exp. Med. 191, 5-8.

Casale, G. P., Cohen, S. D., and DiCapua, R. A. (1983). The effects of organophosphateinduced cholinergic stimulation on the antibody response to sheep erythrocytes in inbred mice. Toxicol. Appl. Pharmacol. 68, 198-205.

Cassatella, M. A. (1995). The production of cytokines by polymorphonuclear neutrophils. Immunol. Today 16, 21-26.

Cavieres, M. F., Jaeger, J., and Porter, W. (2002). Developmental toxicity of a commercial herbicide mixture in mice: I. Effects on embryo implantation and litter size. Environ. Health. Perspect. 110, 1081-1085.

Chagraoui, H., Komura, E., Tulliez, M., Giraudier, S., Vainchenker, W., and Wendling, F. (2002). Prominent role of TGF-beta 1 in thrombopoietin-induced myelofibrosis in mice. Blood 100, 3495-3503.

Charles, J. M., Bond, D. M., Jeffries, T. K., Yano, B. L., Stott, W. T., Johnson, K. A., Cunny, H. C., Wilson, R. D., and Bus, J. S. (1996a). Chronic dietary toxicity/oncogenicity studies on 2,4- dichlorophenoxyacetic acid in rodents. Fundam. Appl. Toxicol. 33, 166-172.

Charles, J. M., Cunny, H. C., Wilson, R. D., and Bus, J. S. (1996b). Comparative subchronic studies on 2,4-dichlorophenoxyacetic acid, amine, and ester in rats. Fundam. Appl. Toxicol. 33, 161-165. 
Charles, J. M., Dalgard, D. W., Cunny, H. C., Wilson, R. D., and Bus, J. S. (1996c). Comparative subchronic and chronic dietary toxicity studies on 2,4dichlorophenoxyacetic acid, amine, and ester in the dog. Fundam. Appl. Toxicol. 29, 78-85.

Chaturvedi, A. K., Kuntz, D. J., and Rao, N. G. S. (1991). Metabolic aspects of the toxicology of mixtures of parathion, toxaphene and/or 2,4-D in mice. J. Appl. Toxicol. 11, 245-251.

Cohen, J. J. (1992). Glucocorticoid-induced apoptosis in the thymus. Semin. Immunol. 4, 363-369.

Colino, J., Shen, Y., and Snapper, C. M. (2002). Dendritic cells pulsed with intact Streptococcus pneumoniae elicit both protein- and polysaccharide-specific immunoglobulin isotype responses in vivo through distinct mechanisms. J. Exp. Med. 195, 1-13.

Cuff, C. F., Zhao, W., Nukui, T., Schafer, R., and Barnett, J. B. (1996). 3,4Dichloropropionanilide-induced atrophy of the thymus: mechanisms of toxicity and recovery. Fundam. Appl. Toxicol. 33, 83-90.

Cushman, J. R. and Street, J. C. (1982). Allergic hypersensitivity to the herbicide 2,4-D in BALB/c mice. J. Toxicol. Environ. Health 10, 729-741.

DeFranco, A.L. (2002). B-lymphocyte activation. In Fundamental Immunology (W. E. Paul, Ed.), pp. 225-261. Lippincott-Raven, Philadelphil, PA.

Dhabhar, F. S. (1998). Stress-induced enhancement of cell-mediated immunity. Ann. N Y Acad. Sci. 840, 359-372. 
Dhabhar, F. S., Miller, A. H., McEwen, B. S., and Spencer, R. L. (1995). Effects of stress on immune cell distribution. Dynamics and hormonal mechanisms. J. Immunol. 154, 5511-5527.

Di Santo, J. P. (1999). The common cytokine receptor gamma chain and the pre-T cell receptor provide independent but critically overlapping signals in early alpha/beta T cell development. J. Exp. Med. 189, 563-574.

Egerton, M. (1990). Kinetics of mature T-cell development in the thymus. Proc. Natl. Acad. Sci. U.S.A. 87, 2579-2582.

Environmental Health Criteria 29. Dichlorophenoxyacetic acid, 2,4-D. (1984). Inchem. http://www.inchem.org/documents/ehc/ehc/ehc29.htm, World Health Organization.

Environmental Health Criteria 84. 2,4-Dichlorophenoxyacetic acid (2,4-D) Environmental Aspects. (1989). Finland, United Nations Environment Programme, International Labour Organisation and the World Health Organization.

Erne, K. and Sperber, I. (1974). Renal tubular transfer of phenoxyacetic acids in the chicken. Acta Pharmacol. Toxicol. (Copenhagen) 35, 233-241.

Farm Chemicals Handbook. 1998. 37733 Euclid Ave., Willoughby, Ohio, 44094-5992, Meister Publishing Company.

Faustini, A., Settimi, L., Pacifici, R., Fano, V., Zuccaro, P., and Forastiere, F. (1996). Immunological changes among farmers exposed to phenoxy herbicides: preliminary observations. Occup. Environ. Med. 53, 583-585. 
Fiegl, M., Greil, R., Pechlaner, C., Krugmann, J., and Dirnhofer, S. (2002). Intravascular large B-cell lymphoma with a fulminant clinical course: a case report with definite diagnosis post mortem. Ann. Oncol. 13, 1503-1506.

Finette, B. A., Homans, A. C., and Albertini, R. J. (2000). Emergence of genetic instability in children treated for leukemia. Science 288, 514-517.

Fleshner, M., Brennan, F. X., Nguyen, K., Watkins, L. R., and Maier, S. F. (1996). RU486 blocks differentially suppressive effect of stress on in vivo anti-KLH immunoglobulin response. Am. J. Physiol. 271, R1344-R1352.

Fleshner, M., Deak, T., Nguyen, K. T., Watkins, L. R., and Maier, S. F. (2001). Endogenous glucocorticoids play a positive regulatory role in the anti- keyhole limpet hemocyanin in vivo antibody response. J. Immunol. 166, 3813-3819.

Flint, M. S., Miller, D. B., and Tinkle, S. S. (2000). Restraint-induced modulation of allergic and irritant contact dermatitis in male and female B6.129 mice. Brain Behav. Immun. 14, 256-269.

Flint, M. S., Valosen, J. M., Johnson, E. A., Miller, D. B., and Tinkle, S. S. (2001). Restraint stress applied prior to chemical sensitization modulates the development of allergic contact dermatitis differently than restraint prior to challenge. J. Neuroimmunol. 113, 72-80.

Freier, D. O. and Fuchs, B. A. (1994). A mechanism of action for morphine-induced immunosuppression: corticosterone mediates morphine-induced suppression of natural killer cell activity. J. Pharmacol. Exp. Ther. 270, 1127-1133. 
Frost, L. L., Neeley, Y. X., Schafer, R., Gibson, L. F., and Barnett, J. B. (2001). Propanil inhibits tumor necrosis factor-alpha production by reducing nuclear levels of the transcription factor nuclear factor-kappa $\beta$ in the macrophage cell line IC-21. Toxicol. Appl. Pharmacol. 172, 186-193.

Fulop, G. M. and Osmond, D. G. (1983). Regulation of bone marrow lymphocyte production. IV. Cells mediating the stimulation of marrow lymphocyte production by sheep red blood cells: studies in anti-IgM-suppressed mice, athymic mice, and silica- treated mice. Cell Immunol. 75, 91-102.

Garabrant, D. H. and Philbert, M. A. (2002). Review of 2,4-dichlorophenoxyacetic acid (2,4-D) epidemiology and toxicology. Crit. Rev. Toxicol. 32, 233-257.

Garcia de Vinuesa, C., Gulbranson-Judge, A., Khan, M., O'Leary, P., Cascalho, M., Wabl, M., Klaus, G. G., Owen, M. J., and MacLennan, I. C. (1999a). Dendritic cells associated with plasmablast survival. Eur. J. Immunol. 29, 3712-3721.

Garcia de Vinuesa, C., O'Leary, P., Sze, D. M., Toellner, K. M., and MacLennan, I. C. (1999b). T-independent type 2 antigens induce B cell proliferation in multiple splenic sites, but exponential growth is confined to extrafollicular foci. Eur. J. Immunol. 29, 1314-1323.

Garry, V. F., Schreinemachers, D., Harkins, M. E., and Griffith, J. (1996). Pesticide appliers, biocides, and birth defects in rural Minnesota. Environ. Health Perspect. 104, 394-399.

Garry, V. F., Burroughs, B., Tarone, R., and Kesner, J. S. (1999). Herbicides and adjuvants: an evolving view. Toxicol. Ind. Health 15, 159-167. 
Garry, V. F., Tarone, R. E., Kirsch, I. R., Abdallah, J. M., Lombardi, D. P., Long, L. K., Burroughs, B. L., Barr, D. B., and Kesner, J. S. (2001). Biomarker correlations of urinary 2,4-D levels in foresters: genomic instability and endocrine disruption. Environ. Health Perspect. 109, 495-500.

Geenen, V., Kecha, O., Brilot, F., Charlet-Renard, C., and Martens, H. (1999). The thymic repertoire of neuroendocrine-related self antigens: biological role in T-cell selection and pharmacological implications. Neuroimmunomodulation. 6, 115125.

Germolec, D. R., Yang, R. S., Ackermann, M. F., Rosenthal, G. J., Boorman, G. A., Blair, P., and Luster, M. I. (1989). Toxicology studies of a chemical mixture of 25 groundwater contaminants. II. Immunosuppression in B6C3F1 mice. Fundam. Appl. Toxicol. 13, 377-387.

Godfrey, D. I. (1992). Phenotypic and functional characterization of c-kit expression during intrathymic T cell development. J. Immunol. 149, 2281-2285.

Gorzinski, S. J., Kociba, R. J., Campbell, R. A., Smith, F. A., Nolan, R. J., and Eisenbrandt, D. L. (1987). Acute, pharmacokinetic, and subchronic toxicological studies of 2,4-dichlorophenoxyacetic acid. Fundam. Appl. Toxicol. 9, 423-435.

Grover, R. and C.A.Franklin, N. I. M. A. J. C. a. D. R. (1986a). Dermal exposure and urinary metabolite excretion in farmers repeatedly exposed to 2,4-D amine. Toxicology Letters 33, 73-83.

Grover, R., Cessna, A. J., Muir, N. I., Riedel, D., Franklin, C. A., and Yoshida, K. (1986b). Factors affecting the exposure of ground-rig applicators to 2,4-D dimethylamine salt. Arch. Environ. Contam. Toxicol. 15, 677-686. 
Haks, M. C., Oosterwegel, M. A., Blom, B., Spits, H. M., and Kruisbeek, A. M. (1999). Cell-fate decisions in early $\mathrm{T}$ cell development: regulation by cytokine receptors and the pre-TCR. Semin. Immunol. 11, 23-37.

Han, Y. C., Lin, T. L., and Pruett, S. B. (1993). Thymic atrophy caused by ethanol in a mouse model for binge drinking: involvement of endogenous glucocorticoids. Toxicol. Appl. Pharmacol. 123, 16-25.

Hardell, L. and Sandstrom, A. (1979). Case-control study: soft-tissue sarcomas and exposure to phenoxyacetic acids or chlorophenols. Br. J. Cancer 39, 711-717.

Hardy, R. R., Carmack, C. E., Shinton, S. A., Kemp, J. D., and Hayakawa, K. (1991). Resolution and characterization of pro-B and pre-pro-B cell stages in normal mouse bone marrow. J. Exp. Med. 173, 1213-1225.

Harris, D. T., Sakiestewa, D., Robledo, R. F., and Witten, M. (1997a). Short-term exposure to JP-8 jet fuel results in long-term immunotoxicity. Toxicol. Ind. Health 13, 559-570.

Harris, D. T., Sakiestewa, D., Robledo, R. F., and Witten, M. (1997b). Protection from JP-8 jet fuel induced immunotoxicity by administration of aerosolized substance P. Toxicol. Ind. Health 13, 571-588.

Harris, D. T., Sakiestewa, D., Robledo, R. F., Young, R. S., and Witten, M. (2000). Effects of short-term JP-8 jet fuel exposure on cell-mediated immunity. Toxicol. Ind. Health 16, 78-84.

Hestdal, K., Ruscetti, F. W., Ihle, J. N., Jacobsen, S. E. W., Dubois, C. M., Kopp, W. C., Longo, D. L., Keller, J. R. (1991). Characterization and regulation of RB6-8C5 antigen expression on murine bone marrow cells. J. Immunol. 147, 22-28 
Hill, R. H., Jr., To, T., Holler, J. S., Fast, D. M., Smith, S. J., Needham, L. L., and Binder, S. (1989). Residues of chlorinated phenols and phenoxy acid herbicides in the urine of Arkansas children. Arch. Environ. Contam. Toxicol. 18, 469-474.

Hill, R. H., Jr., Head, S. L., Baker, S., Gregg, M., Shealy, D. B., Bailey, S. L., Williams, C. C., Sampson, E. J., and Needham, L. L. (1995). Pesticide residues in urine of adults living in the United States: reference range concentrations. Environ. Res. 71, 99-108.

Hoar, S. K., Blair, A., Holmes, F. F., Boysen, C. D., Robel, R. J., Hoover, R., and Fraumeni, J. F. J. (1986). Agricultural herbicide use and risk of lymphoma and soft-tissue sarcoma [published erratum appears in JAMA (1986).

Dec;256(24):3351]. JAMA. 256, 1141-1147.

Hofstra, G. and Switzer, C. M. (1963). The phytotoxicity of propanil. Weed Science 16, 23-28.

Hong, H. L., Yang, R. S., and Boorman, G. A. (1991). Residual damage to hematopoietic system in mice exposed to a mixture of groundwater contaminants. Toxicol. Lett. 57, 101-111.

Hong, H. L., Yang, R. S., and Boorman, G. A. (1992). Alterations in hematopoietic responses in $\mathrm{B} 6 \mathrm{C} 3 \mathrm{~F} 1$ mice caused by drinking a mixture of 25 groundwater contaminants. J. Environ. Pathol. Toxicol. Oncol. 11, 1-10.

Hong, H. L., Yang, R. S., and Boorman, G. A. (1993). Enhancement of myelotoxicity induced by repeated irradiation in mice exposed to a mixture of groundwater contaminants. Arch. Toxicol. 67, 358-364. 
Hoppin, J. A., Umbach, D. M., London, S. J., Alavanja, M. C., and Sandler, D. P. (2002). Chemical predictors of wheeze among farmer pesticide applicators in the Agricultural Health Study. Am. J. Respir. Crit. Care Med. 165, 683-689. http://www.24d.org. Industry Task Force II on 2,4-D Research Data Web Site. BASF (Germany), Dow AgroSciences (U.S.) Nufarm Ltd. (Australia and Agro-Gor Corp., a U.S. corporation jointly owned by Attanor, S.A. (Argentina) and PBIGordon Corp. (U.S). B-26 Cedar Point Villas. Swansboro, NC 28584

Izmerov, N. F. (1984). Propanide. Scientific Review of Soviet Literature on Toxicity and Hazards of Chemicals 76, 1-24.

Jackson, J. B. (1966). Toxicologic studies on a new herbicide in sheep and cattle. Am. J. Vet. Res. 27, 821-824.

Jacob, J., Kassir, R., and Kelsoe, G. (1991). In situ studies of the primary immune response to (4-hydroxy-3- nitrophenyl)acetyl. I. The architecture and dynamics of responding cell populations. J. Exp. Med. 173, 1165-1175.

Kale, P. G., Petty, B. T., Jr., Walker, S., Ford, J. B., Dehkordi, N., Tarasia, S., Tasie, B. O., Kale, R., and Sohni, Y. R. (1995). Mutagenicity testing of nine herbicides and pesticides currently used in agriculture. Environ. Mol. Mutagen. 25, 148-153.

Keller, S. E., Schleifer, S. J., Liotta, A. S., Bond, R. N., Farhoody, N., and Stein, M. (1988). Stress-induced alterations of immunity in hypophysectomized rats. Proc. Natl. Acad. Sci. U.S.A 85, 9297-9301.

Kello, D. (1989). WHO drinking water quality guidelines for selected herbicides. Food Addit. Contam. 6 Suppl 1, S79-S85. 
Khan, A. Q., Shen, Y., Wu, Z. Q., Wynn, T. A., and Snapper, C. M. (2002). Endogenous pro- and anti-inflammatory cytokines differentially regulate an in vivo humoral response to Streptococcus pneumoniae. Infect. Immun. 70, 749-761.

Killeen, N., Irving, B. A., Pippig, S., and Zingler, K. (1998). Signaling checkpoints during the development of T lymphocytes. Curr. Opin. Immunol. 10, 360-367.

Kim, C. S. and O'Tuama, L. A. (1981). Choroid plexus transport of 2,4dichlorophenoxyacetic acid: interaction with the organic acid carrier. Brain Res. 224, 209-212.

King, L. B., Vacchio, M. S., Dixon, K., Hunziker, R., Margulies, D. H., and Ashwell, J. D. (1995). A targeted glucocorticoid receptor antisense transgene increases thymocyte apoptosis and alters thymocyte development. Immunity 3, 647-656.

Knopp, D. (1994). Assessment of exposure to 2,4-dichlorophenoxyacetic acid in the chemical industry: results of a five year biological monitoring study. Occup. Environ. Med. 51, 152-159.

Laakko, T. and Fraker, P. (2002). Rapid changes in the lymphopoietic and granulopoietic compartments of the marrow caused by stress levels of corticosterone. Immunol. 105, 111-119.

Laufer, T. M., Glimcher, L. H., and Lo, D. (1999). Using thymus anatomy to dissect T cell repertoire selection. Semin. Immunol. 11, 65-70.

Lee, W. R., Abrahamson, S., Valencia, R., von Halle, E. S., Wurgler, F. E., and Zimmering, S. (1983). The sex-linked recessive lethal test for mutagenesis in Drosophila melanogaster. A report of the U.S. Environmental Protection Agency Gene- Tox Program. Mutat. Res. 123, 183-279. 
Litinskiy, M. B., Nardelli, B., Hilbert, D. M., He, B., Schaffer, A., Casali, P., and Cerutti, A. (2002). DCs induce CD40-independent immunoglobulin class switching through BLyS and APRIL. Nat. Immunol. 3, 822-829.

Lu, L. and Osmond, D. G. (1997). Apoptosis during B lymphopoiesis in mouse bone marrow. J. Immunol. 158, 5136-5145.

Lu, F. W., Yasutomo, K., Goodman, G.B., McHeyzer-Williams, L. J., McHeyzer Williams, M. G., Germain, R. N., Ashwell, J. D. (2000). Thymocyte resistance to glucocorticoids leads to antigen-specific unresponsiveness due to "holes" in the T cell repertoire. Immunity. 12, 183-192

Luster, M. I., Munson, A. E., Thomas, P. T., Holsapple, M. P., Fenters, J. D., White, K. L. J., Lauer, L. D., Germolec, D. R., Rosenthal, G. J., and Dean, J. H. (1988). Methods Evaluation. Development of a testing battery to assess chemicalinduced immunotoxicity: National Toxicology Program's guidelines for immunotoxicity evaluation in mice. Fundam. Appl. Toxicol. 10, 2-19.

Luster, M. I., Portier, C., Pait, D. G., White, K. L. J., Gennings, C., Munson, A. E., and Rosenthal, G. J. (1992). Risk assessment in immunotoxicology. I. Sensitivity and predictability of immune tests. Fundam. Appl. Toxicol. 18, 200-210.

Luster, M. I., Portier, C., Pait, D. G., Rosenthal, G. J., Germolec, D. R., Corsini, E., Blaylock, B. L., Pollock, P., Kouchi, Y., and Craig, W. (1993). Risk assessment in immunotoxicology. II. Relationships between immune and host resistance tests. Fundam. Appl. Toxicol. 21, 71-82. 
Lyons, C. D., Katz, S. E., and Bartha, R. (1985). Persistence and mutagenic potential of herbicide-derived aniline residues in pond water. Bull. Environ. Contam. Toxicol. 35, 696-703.

Mackay, F., Woodcock, S. A., Lawton, P., Ambrose, C., Baetscher, M., Schneider, P., Tschopp, J., and Browning, J. L. (1999). Mice transgenic for BAFF develop lymphocytic disorders along with autoimmune manifestations. J. Exp. Med. 190, $1697-1710$.

MacLennan, I. and Vinuesa, C. (2002). Dendritic cells, BAFF, and APRIL: innate players in adaptive antibody responses. Immunity 17, 235-238.

Malerba, I., Castoldi, A. F., Parent-Massin, D., and Gribaldo, L. (2002). In vitro myelotoxicity of propanil and 3,4-dichloroaniline on murine and human CFUE/BFU-E progenitors. Toxicol. Sci. 69, 433-438.

Maruyama, S., Minagawa, M., Shimizu, T., Oya, H., Yamamoto, S., Musha, N., Abo, W., Weerasinghe, A., Hatakeyama, K., and Abo, T. (1999). Administration of glucocorticoids markedly increases the numbers of granulocytes and extrathymic T cells in the bone marrow. Cell Immunol. 194, 28-35.

Matsunaka, S. (1968). Propanil hydrolysis: Inihibition in rice plants by insecticides. Science 160, 1360-1361.

Maugh, T. H. (1982). Just how hazardous are dumps. Science 215, 490-493.

McClure, G. Y., Helm, R. M., Stine, K., Burks, A. W., Jones, S. M., and Gandy, J. (2001). Evaluation of immune parameters in propanil-exposed farm families. Arch. Environ. Contam. Toxicol. 41, 104-111. 
McHeyzer-Williams, M. G., McLean, M. J., Lalor, P. A., and Nossal, G. J. (1993).

Antigen-driven B cell differentiation in vivo. J. Exp. Med. 178, 295-307.

McMillan, D. C., Freeman, J. P., and Hinson, J. A. (1990). Metabolism of the arylamide herbicide propanil. I. Microsomal metabolism and in vitro methemoglobinemia. Toxicol. Appl. Pharmacol. 103, 90-101.

Meisner, L. F., Belluck, D. A., and Roloff, B. D. (1992). Cytogenetic effects of alachlor and/or atrazine in vivo and in vitro. Environ. Mol. Mutagen. 19, 77-82.

Miller, A. H., Spencer, R. L., Pearce, B. D., Pisell, T. L., Azrieli, Y., Tanapat, P., Moday, H., Rhee, R., and McEwen, B. S. (1998). Glucocorticoid receptors are differentially expressed in the cells and tissues of the immune system. Cell Immunol. 186, 45-54.

Miyaura, H. and Iwata, M. (2002). Direct and indirect inhibition of Th1 development by progesterone and glucocorticoids. J. Immunol. 168, 1087-1094.

Mold, C., Rodic-Polic, B., Du Clos, T. W. (2002). Protection from Streptococcus pneumoniae infection by C-reactive protein and natural antibody requires complement but not Fc gamma receptors. J. Immunol. 12, 6375-6381.

Mond, J. J., Lees, A., and Snapper, C. M. (1995). T cell-independent antigens type 2. Annu. Rev. Immunol. 13, 655-692.

Morse, D. L., Baker, E. L., Jr., Kimbrough, R. D., and Wisseman, C. L., III (1979). Propanil-chloracne and methomyl toxicity in workers of a pesticide manufacturing plant. Clin. Toxicol. 15, 13-21.

Moser, M. and Murphy, K. M. (2000). Dendritic cell regulation of TH1-TH2 development. Nat. Immunol. 1, 199-205. 
Munro, I., Carlo, G., Orr, J., Sund, K., Wilson, R., Kennepohl, E., Lynch, B., Jablinske M, and Lee, N. (1992). A Comprehensive, integrated review and evaluation of the scientific evidence relating to the safety of the herbicide 2,4-D. Journal of the American College of Toxicology 11, 559-663.

Munson, A. E., Sanders, V. M., Douglas, K. A., Sain, L. E., Kauffmann, B. M., and White, K. L., Jr. (1982). In vivo assessment of immunotoxicity. Environ. Health Perspect. 43, 41-52.

Mustonen, R., Kangas, J., Vuojolahti, P., and Linnainmaa, K. (1986). Effects of phenoxyacetic acids on the induction of chromosome aberrations in vitro and in vivo. Mutagenesis 1, 241-245

Nielsen, K., Kaempe, B., and Jensen-Holm, J. (1965). Fatal poisoning in man by 2,4dichlorophenoxyacetic acid (2,4-D): Determination of the agent in forensic materials. Acta Pharmacol. et Toxicol. 22, 224-234.

Oakes, D. J. and Pollack, J. K. (1999). Effects of a herbicide formulation, Tordon 75D, and its individual components on the oxidative functions of mitochondria. Toxicology 136, 41-52.

Oehler, L., Majdic, O., Pickl, W. F., Stockl, J., Riedl, E., Drach, J., Rappersberger, K., Geissler, K., and Knapp, W. (1998). Neutrophil granulocyte-committed cells can be driven to acquire dendritic cell characteristics. J. Exp. Med. 187, 1019-1028.

Osmond, D. G. and Nossal, G. J. (1974). Differentiation of lymphocytes in mouse bone marrow. II. Kinetics of maturation and renewal of antiglobulin-binding cells studied by double labeling. Cell Immunol. 13, 132-145. 
Padgett, E. L., Sibley, D. A., and Jerrells, T. R. (2000). Effect of adrenalectomy on ethanol-associated changes in lymphocyte cell numbers and subpopulations in thymus, spleen, and gut-associated lymphoid tissues. Int. J. Immunopharmacol. 22, 285-298.

Pazirandeh, A., Xue, Y., Rafter, I., Sjovall, J., Jondal, M., and Okret, S. (1999). Paracrine glucocorticoid activity produced by mouse thymic epithelial cells. FASEB J. 13, 893-901.

Pelletier, O., Ritter, L., Caron, J., and Somers, D. (1989). Disposition of 2,4dichlorophenoxyacetic acid dimethylamine by Fischer 344 rats dosed orally and dermally. J. Toxicol. Environ. Health 28, 221-234.

Picker, L. J. and Siegelman, M. H. (1998). Lymphoid tissues and organs. In Fundamental Immunology (W. E. Paul, Ed.), pp. 479-532. Lippincott - Raven, Philadelphia New York.

Plaut, M. (1987). Lymphocyte hormone receptors. Annu. Rev. Immunol. 5, 621-669.

Porter, W. P., Hinsdill, R., Fairbrother, A., Olson, L. J., Jaeger, J., Yuill, T., Bisgaard, S., Hunter, W. G., and Nolan, K. (1984). Toxicant-disease-environment interactions associated with suppression of immune system, growth, and reproduction. Science 224, 1014-1017.

Porter, W. P., Green, S. M., Debbink, N. L., and Carlson, I. (1993). Groundwater pesticides: interactive effects of low concentrations of carbamates aldicarb and methomyl and the triazine metribuzin on thyroxine and somatotropin levels in white rats. J. Toxicol. Environ. Health 40, 15-34. 
Porter, W. P., Jaeger, J. W., and Carlson, I. H. (1999). Endocrine, immune, and behavioral effects of aldicarb (carbamate), atrazine (triazine) and nitrate (fertilizer) mixtures at groundwater concentrations. Toxicol. Ind. Health 15, 133150.

Potter, N. S. and Harding, C. V. (2001). Neutrophils Process Exogenous Bacteria Via an Alternate Class I MHC Processing Pathway for Presentation of Peptides to T Lymphocytes. J. Immunol. 167, 2538-2546.

Pruett, S. B., Ensley, D. K., and Crittenden, P. L. (1993). The role of chemical-induced stress responses in immunosuppression: a review of quantitative associations and cause-effect relationships between chemical-induced stress responses and immunosuppression. J. Toxicol. Environ. Health 39, 163-192.

Pruett, S. B., Collier, S., Wu, W. J., and Fan, R. (1999). Quantitative relationships between the suppression of selected immunological parameters and the area under the corticosterone concentration vs. time curve in $\mathrm{B} 6 \mathrm{C} 3 \mathrm{~F} 1$ mice subjected to exogenous corticosterone or to restraint stress. Toxicol. Sci. 49, 272-280.

Pruett, S. B., Fan, R., Zheng, Q., Myers, L. P., and Hebert, P. (2000). Modeling and predicting selected immunological effects of a chemical stressor (3,4dichloropropionanilide) using the area under the corticosterone concentration versus time curve. Toxicol. Sci. 58, 77-87.

Pruett, S. B. and Fan, R. (2001). Quantitative modeling of suppression of IgG1, IgG2a, IL-2, and IL-4 responses to antigen in mice treated with exogenous corticosterone or restraint stress. J. Toxicol. Environ. Health A 62, 175-189. 
Purton, J. F., Boyd, R. L., Cole, T. J., and Godfrey, D. I. (2000). Intrathymic T cell development and selection proceeds normally in the absence of glucocorticoid receptor signaling. Immunity. 13, 179-186.

Ramierz, F., Fowell, D. J., Puklavec, M., Simmonds, S., and Mason, D. (1996). Glucocorticoids promote a TH2 cytokine response by $\mathrm{CD} 4^{+} \mathrm{T}$ cells in vitro. $\mathrm{J}$. Immunol. 156, 2406-2412.

Richards, S. M., McClure, G. Y., Lavy, T. L., Mattice, J. D., Keller, R. J., and Gandy, J. (2001). Propanil (3,4-dichloropropionanilide) particulate concentrations within and near the residences of families living adjacent to aerially sprayed rice fields. Arch. Environ Contam. Toxicol. 41, 112-116.

Roloff, B. D., Belluck, D. A., and Meisner, L. F. (1992). Cytogenetic studies of herbicide interactions in vitro and in vivo using atrazine and linuron. Arch. Environ. Contam. Toxicol. 22, 267-271.

Rosso, S. B., Gonzalez, M., Bagatolli, L. A., Duffard, R. O., and Fidelio, G. D. (1998). Evidence of a strong interaction of 2,4-dichlorophenoxyacetic acid herbicide with human serum albumin. Life Sci. 63 , 2343-2351.

Sabbele, N. R., Van Oudenaren, A., Hooijkaas, H., and Benner, R. (1987). The effect of corticosteroids upon murine B cells in vivo and in vitro as determined in the LPSculture system. Immunology 62, 285-290.

Sallusto, F., Cella, M., Danieli, C., and Lanzavecchia, A. (1995). Dendritic cells use macropinocytosis and the mannose receptor to concentrate macromolecules in the major histocompatibility complex class II compartment: downregulation by cytokines and bacterial products. J. Exp. Med. 182, 389-400. 
Samal, B., Sun, Y., Stearns, G., Xie, C., Suggs, S., and McNiece, I. 1994. Cloning and characterization of the cDNA encoding a novel human pre-B-cell colonyenhancing factor. Mol. Cell. Biol. 14,1431-1437.

Sanders, V. M. and Munson, A. E. (1984a). Kinetics of the enhancing effect produced by norepinephrine and terbutaline on the murine primary antibody response in vitro. J. Pharmacol. Exp. Ther. 231, 527-531.

Sanders, V. M. and Munson, A. E. (1984b). Beta adrenoceptor mediation of the enhancing effect of norepinephrine on the murine primary antibody response in vitro. J. Pharmacol. Exp. Ther. 230, 183-192.

Sauerhoff, M. W., Braun, W. H., Blau, G. E., and Gehring, P. J. (1977). The fate of 2,4dichlorophenoxyacetic acid (2,4-D) following oral administration to man. Toxicology 8, 3-11.

Scapini, P., Laudanna, C., Pinardi, C., Allavena, P., Mantovani, A., Sozzani, S., and Cassatella, M. A. (2001). Neutrophils produce biologically active macrophage inflammatory protein- 3alpha (MIP-3alpha)/CCL20 and MIP-3beta/CCL19. Eur. J. Immunol. 31, 1981-1988.

Schneider, E., Moreau, G., Arnould, A., Vasseur, F., Khodabaccus, N., Dy, M., Ezine, S. (1999). Increased fetal and extramedullary hematopoiesis in Fas-deficient C57BL/6-lpr/lpr mice. Blood. 94(8), 2613-2621. 
Schneider, P., Takatsuka, H., Wilson, A., Mackay, F., Tardivel, A., Lens, S., Cachero, T. G., Finke, D., Beermann, F., and Tschopp, J. (2001). Maturation of marginal zone and follicular B cells requires B cell activating factor of the tumor necrosis factor family and is independent of B cell maturation antigen. J. Exp. Med. 194, 16911697.

Schreinemachers, D. M. (2000). Cancer mortality in four northern wheat-producing states. Environ. Health Perspect. 108, 873-881.

Schoen, E. D. (1996). Statistical designs in combination toxicology: a matter of choice. Food Chem. Toxicol. 34:1059-1065.

Short, P. and Colborn, T. (1999). Pesticide use in the U.S. and policy implications: a focus on herbicides. Toxicol. Ind. Health 15, 240-275.

Simmons, J. E. (1995). Chemical mixtures: challenge for toxicology and risk assessment. Toxicology 105, 111-119.

Singh, U., Millson, D. S., Smith, P. A., and Owen, J. J. (1979). Identification of beta adrenoreceptors during thymocyte ontogeny in mice. Eur. J. Immunol. 9, 31-35.

Singh, U. (1984). Sympathetic innervation of fetal mouse thymus. Eur. J. Immunol. 14, $757-759$.

Singleton, S. D. and Murphy, S. D. (1973). Propanil (3,4-dichloropropionanilide)induced methemoglobin formation in mice in relation to acylamidase activity. Toxicol. Appl. Pharmacol. 25, 20-29.

Smith, K. G., Hewitson, T. D., Nossal, G. J., and Tarlinton, D. M. (1996). The phenotype and fate of the antibody-forming cells of the splenic foci. Eur. J. Immunol. 26, $444-448$. 
Snapper, C. M. and Mond, J. (1996). A model for induction of T cell-independent humoral immunity in response to polysaccharide antigens. J. Immunol. 157, 2229-2233.

Snapper, C. M. and Finkelman, F. D. (1999). Immunoglobulin class switching. In Fundamental Immunology (W. E. Paul, Ed.), pp. 831-862. Lippincott-Raven, Philadelphia, New York.

Squibb, R. E., Tilson, H. A., and Mitchell, C. L. (1983). Neurobehavioral assessment of 2,4-dichlorophenoxyacetic acid (2,4-D) in rats. Neurobehav. Toxicol. Teratol. 5, $331-335$

Suwalsky, M., Benites, M., Villena, F., Aguilar, F., and Sotomayor, C. P. (1996). Interaction of 2,4-dichlorophenoxyacetic acid (2,4-D) with cell and model membranes. Biochim. Biophys. Acta 1285, 267-276.

Svensson, M., Stockinger, B., and Wick, M. J. (1997). Bone marrow-derived dendritic cells can process bacteria for MHC-I and MHC-II presentation to T cells. J. Immunol. 158, 4229-4236.

Sze, D. M., Toellner, K. M., Garcia, D., V, Taylor, D. R., and MacLennan, I. C. (2000). Intrinsic constraint on plasmablast growth and extrinsic limits of plasma cell survival. J. Exp. Med. 192, 813-821.

Takashima, K., Tateda, K., Matsumoto, T., lizawa, Y., Nakao, M., and Yamaguchi, K. (1997). Role of tumor necrosis factor alpha in pathogenesis of pneumococcal pneumonia in mice. Infect. Immun. 65, 257-260. 
Tani, K., Ogushi, F., Shimizu, T., and Sone, S. (2001). Protease-induced leukocyte chemotaxis and activation: roles in host defense and inflammation. J. Med. Invest. 48, 133-141.

Tarlinton, D. M. and Smith, K. G. (2000). Dissecting affinity maturation: a model explaining selection of antibody-forming cells and memory B cells in the germinal center. Immunol.Today 21, 436-441.

Thurmond, T. S., and Gasiewicz, T. A., (2000). A single dose of 2,3,7,8tetrachlorodibenzo-p-dioxin produces a time-and dose-dependent alteration in the murine bone marrow B-lymphocyte maturation profile. Toxicol. Sci. 58, 88-95.

Tolosa, E., King, L. B., Ashwell, J. D. (1998). Thymocyte glucocorticoid resistance alters $\mathrm{T}$ cell selection and inhibits autoimmunity and lymphoproliferative disease in MRL - lpr/lpr mice. Immunity 8, 67-76.

Tolosa, E. and Ashwell, J. D. (1999). Thymus-derived glucocorticoids and the regulation of antigen-specific T-cell development. Neuroimmunomodulation. 6, 90-96.

Ullrich, S. E. (1999). Dermal application of JP-8 jet fuel induces immune suppression. Toxicol. Sci. 52, 61-67.

Ullrich, S. E. and Lyons, H. J. (2000). Mechanisms involved in the immunotoxicity induced by dermal application of JP-8 jet fuel. Toxicol. Sci. 58, 290-298.

US Environmental Protection Agency Office of Pesticide Programs. US EPA pesticides and food: Search results for chemicals with tolerances on rice. (2002a). http://www.epa.gov/cgi-bin/oppsrch. 
US Environmental Protection Agency Office of Pesticide Programs. US EPA pesticides and food: Search results for commodities with tolerances for 2,4dichlorophenoxyacetic acid. (2002b). http://www.epa.gov/cgi-bin/oppsrch.

US Environmental Protection Agency Office of Pesticide Programs. Pesticide regulation (PR) Notice 97-6. (2002c). http://www.epa.gov/PR_Notices/pr97-6.html.

US Geological Survey. Pesticides in the atmosphere. Current understanding of distribution and major influences. Fact Sheet FS-152-95. (1997).

USGS National Water Quality Assessment Program, NAWQA. Herbicides in groundwater. US Geological Survey. Pesticide National Synthesis Project. (1998).

Vacchio, M. S., Papadopoulos, V., and Ashwell, J. D. (1994). Steroid production in the thymus: implications for thymocyte selection. J. Exp. Med. 179, 1835-1846.

Vacchio, M. S., Lee, J. Y., and Ashwell, J. D. (1999). Thymus-derived glucocorticoids set the thresholds for thymocyte selection by inhibiting TCR-mediated thymocyte activation. J. Immunol. 163, 1327-1333.

Villalobos, A. R., Dunnick, C. A., and Pritchard, J. B. (1996). Mechanism mediating basolateral transport of 2,4-dichlorophenoxyacetic acid in rat kidney. J. Pharmacol. Exp. Ther. 278, 582-589.

Vinson, R. B., Carroll, J. L., and Pruett, S. B. (1998). Mechanism of suppressed neutrophil mobilization in a mouse model for binge drinking: role of glucocorticoids. Am. J. Physiol 275, R1049-R1057. 
Watson, V. A., Barnett, J. B., and Schafer, R. (2000). In vivo cytokine production and resistance to infection after acute exposure to 3,4-dichloropropionaniline. J. Toxicol. Environ. Health A 60, 391-406.

Wiegers, G. J. and Reul, J. M. (1998). Induction of cytokine receptors by glucocorticoids: functional and pathological significance. Trends Pharmacol. Sci. 19, 317-321.

Weisglas-Kuperus, N., Sas, T. C., Koopman-Esseboom, C., van der Zwan, C. W., De Ridder, M. A., Beishuizen, A., Hooijkaas, H., and Sauer, P. J. (1995). Immunologic effects of background prenatal and postnatal exposure to dioxins and polychlorinated biphenyls in Dutch infants. Pediatr. Res. 38, 404-410.

Weiss, P. A., Collier, S. D., and Pruett, S. B. (1996). Role of gulcocorticoids in ethanolinduced decreases in expression of MHC class II molecules on B cells and selective decreases in spleen cell number. Toxicol. Appl. Pharmacol. 139,153162.

Wekerle, H. and Ketelsen, U. P. (1980). Thymic nurse cells--Ia-bearing epithelium involved in T-lymphocyte differentiation? Nature 283, 402-404.

Williams, C. H. and Jacobson, K. H. (1966). An acylamidase in mammalian liver hydrolyzing the herbicide 3,4-dichloropropionanilide. Toxicol. Appl. Pharmacol. 9, 495-500.

Wolber, F. M., Leonard, E., Michael, S., Orschell-Traycoff, C. M., Yoder, M. C., and Srour, E. F. (2002). Roles of spleen and liver in development of the murine hematopoietic system. Exp. Hematol. 30, 1010-1019. 
Wu, W. J. and Pruett, S. B. (1996). Suppression of splenic natural killer cell activity in a mouse model for binge drinking. II. Role of the neuroendocrine system. J. Pharmacol. Exp. Ther. 278, 1331-1339.

Wu, Z. Q., Vos, Q., Shen, Y., Lees, A., Wilson, S., Briles, D. E., Gause, W. C., Mond, J. J., and Snapper, C. M. (1999). In vivo polysaccharide-specific IgG isotype responses to intact Streptococcus pneumoniae are $\mathrm{T}$ cell dependent and require CD40- and B7-ligand interactions. J. Immunol. 163, 659-667.

Wu, Z. Q., Khan, A. Q., Shen, Y., Schartman, J., Peach, R., Lees, A., Mond, J. J., Gause, W. C., and Snapper, C. M. (2000). B7 requirements for primary and secondary protein- and polysaccharide-specific Ig isotype responses to Streptococcus pneumoniae. J. Immunol. 165, 6840-6848.

Wu, Z. Q., Shen, Y., Khan, A. Q., Chu, C. L., Riese, R., Chapman, H. A., Kanagawa, O., and Snapper, C. M. (2002). The mechanism underlying T cell help for induction of an antigen-specific in vivo humoral immune response to intact Streptococcus pneumoniae is dependent on the type of antigen. J. Immunol. 168, 5551-5557.

Wyllie, A. H. (1980). Glucocorticoid-induced thymocyte apoptosis is associated with endogenous endonuclease activation. Nature 284, 555-556.

Xie, Y. C., Schafer, R., and Barnett, J. B. (1997). Inhibitory effect of 3,4dichloropropionaniline on cytokine production by macrophages is associated with LPS-mediated signal transduction. J. Leukoc. Biol. 61, 745-752.

Xie, Y. C., Schafer, R., and Barnett, J. B. (1997b). The immunomodulatory effects of the herbicide propanil on murine macrophage interleukin- 6 and tumor necrosis factor-alpha production. Toxicol. Appl. Pharmacol. 145, 184-191. 
Xue, Y., Murdjeva, M., Okret, S., McConkey, D., Kiuossis, D., and Jondal, M. (1996). Inhibition of I-Ad-, but not Db-restricted peptide-induced thymic apoptosis by glucocorticoid receptor antagonist RU486 in T cell receptor transgenic mice. Eur. J. Immunol. 26, 428-434.

Yang, R. S. (1998). Some critical issues and concerns related to research advances on toxicology of chemical mixtures. Environ. Health Perspect. 106 Suppl 4, 10591063.

Zacharchuk, C. M., Mercep, M., Chakraborti, P. K., Simons, S. S. J., and Ashwell, J. D. (1990). Programmed T lymphocyte death. Cell activation- and steroid-induced pathways are mutually antagonistic. J. Immunol. 145, 4037-4045.

Zaldumbide, A., Carlotti, F., Pognonec, P., Boulukos, K. E. (2002), The role of the Ets2 transcription factor in the proliferation, maturation and survival of mouse thymocytes. J. Immunol. 169, 4873-4881.

Zhao, W., Schafer, R., Cuff, C. F., Gandy, J., and Barnett, J. B. (1995). Changes in primary and secondary lymphoid organ T-cell subpopulations resulting from acute in vivo exposure to propanil. J. Toxicol. Environ. Health. 46, 171-181.

Zhao, W., Schafer, R., and Barnett, J. B. (1998). Cytokine production by C57BL/6 mouse spleen cells is selectively reduced by exposure to propanil. J. Toxicol. Environ. Health. A. 55, 107-120.

Zhao, W., Schafer, R., and Barnett, J. B. (1999). Propanil affects transcriptional and posttranscriptional regulation of IL-2 expression in activated EL-4 cells. Toxicol. Appl. Pharmacol. 154, 153-159. 


\title{
CURRICULUM VITAE
}

\author{
PATRICIA de la ROSA
}

\section{ACADEMIC TRAINING}

September 1997 - present 2003.

September 1980 -

School August 1981

September 1978 May 1980
Ph.D. candidate. Expected date of graduation, March

Dept. of Microbiology, Immunology and Cell Biology

West Virginia University

Thesis Subject: "The effects of exposure to a mixture of herbicides on the immune system".

Advisor: Rosana Schafer, Ph.D.

Graduate Research Assistant. University of Pittsburgh, of Public Health, Dept. of Environmental Microbiology Pittsburgh, PA.

Advisor: Jan Sikora Ph.D.

B.S., Magna cum laude, University of Pittsburgh,

\section{PROFESSIONAL EXPERIENCE}

1992 - April 1996

October 1988-

University November 1989

Kennett

May 1986

August 1986

May 1985

Management, August 1985

Pymatuning

Richard
Director of Environmental Education. FIREMA

Foundation. San José, Costa Rica

Research assistant. School of Veterinary Sciences, of Pennsylvania, Poultry Microbiology Laboratory. Square, PA.

Research assistant. Pymatuning Laboratory of Ecology, Pennsylvania Department of Environmental Resources, Division of Forestry. P.I.: Richard T. Hartman, Ph.D.

Research assistant. Bureau of Water Quality Pennsylvania Department of Water Resources and Laboratory of Ecology, University of Pittsburgh. P.I.: T. Hartman, Ph.D.

\section{PROFESSIONAL SOCIETIES (Student Member)}

Society of Toxicology

American Association for the Advancement of Science American Society for Microbiology 
TEACHING

September 1997-

November 1997

1992-1996

1995-1996

BUSINESS
Teaching Assistant. Parasitology

Development and publication of environmental education materials for Costa Rican teachers, the Monteverde Cloud Forest Reserve and the Monteverde Conservation League

Marketing and sales manager for Ecopapier, a paper recycling business funded by FIREMA Foundation and US AID.

\section{Journal Articles}

de la Rosa, P., J. B. Barnett, and R. Schafer. 2002. Immunotoxicity to the thymus after in vivo exposure to a mixture of herbicides. Toxicol. Sci. In preparation.

de la Rosa, P., J. B. Barnett, and R. Schafer. 2002. Immunotoxicity to the bone marrow after in vivo exposure to a mixture of herbicides. Toxicol. Sci. In preparation.

\section{$\underline{\text { Abstracts }}$}

de la Rosa, P., J. B. Barnett, and R. Schafer. 2002. Enhanced Antibody Production In The Spleen After Exposure To A Mixture Of Herbicides. Poster Session. $41^{\text {st }}$ Annual Meeting, Society of Toxicology

de la Rosa, P., J. B. Barnett, and R. Schafer. 2001. Cellular and Functional Immunotoxicity After Exposure to a Mixture of Herbicides. Poster Session. $9^{\text {th }}$ International Congress of Immunology Meeting. Stockholm, Sweden.

de la Rosa, P., G. R. Hobbs, J. B. Barnett, and R. Schafer. 2001. Factorial analysis of thymus cell populations after in vivo exposure to a mixture of herbicides: correlating mixture interactions to biological mechanisms of toxicity. Presented by P. de la Rosa at $40^{\text {th }}$ Annual Meeting, Society of Toxicology, Platform Session, Immunotoxicology.

de la Rosa, P., G. R. Hobbs, J. B. Barnett, and R. Schafer. 2001. Factorial analysis of bone marrow B cell populations after in vivo exposure to a mixture of herbicides. Poster 
Session. Application of Technology to Chemical Mixture Research Meeting. Colorado State University, Fort Collins, Co.

de la Rosa, P., J. B. Barnett, and R. Schafer. 2000. Alterations in the pre B cell population of the bone marrow after in vivo exposure to a mixture of herbicides. Presented by P. de la Rosa at $39^{\text {th }}$ Annual Meeting, Society of Toxicology, Platform Session, Immunotoxicology.

de la Rosa, P., and R. Schafer. 1999. Changes in thymus and spleen cell populations after acute in vivo exposure to an herbicide mixture. Poster Session 27th Mid-Atlantic Imunobiology Meeting. Harpers Ferry, WV. 